\title{
Crisis of Praxis: Depoliticization and Leftist Fragmentation in Brazil
}

$$
\text { by }
$$

\section{Sabrina Fernandes}

A thesis submitted to the Faculty of Graduate and Postdoctoral Affairs in partial fulfilment of the requirements for the degree of

Doctor of Philosophy

In

Sociology

Carleton University,

Ottawa, Ontario

(C) 2017

Sabrina Fernandes 


\begin{abstract}
This dissertation focuses on two problems in Brazilian left politics: fragmentation and depoliticization. There is consensus inside the Brazilian left regarding its fragmentation, but the scenario requires a careful analysis of fragmentation since the conjunctural change of June 2013. The same can be said about depoliticization, explained here through the phenomena of post-politics and ultra-politics, and which is arguably the marker of the difficulties the left has found to mobilize the working class even as this class is under attack. This dissertation fills the gap in the literature by addressing these two problems from the Gramscian-influenced perspective of a crisis of praxis. The concept of a crisis of praxis is proposed to attend to the misalignment between theory and practice at the leftist organizational level that has led to melancholia and distance from the consciousness of the class, despite the potential held by new mobilizations - both spontaneous and organized. It is argued that without properly addressing fragmentation and depoliticization, the left will have trouble appealing to the working class, especially given the conclusions of a crisis of representation that was exposed in Brazil in June 2013 and capitalized on by right-wing conservative forces in order to foster political instability in their favour.
\end{abstract}


This dissertation is dedicated to the loving memory of Simone Peres, who will continue to inspire those fighting for social justice in Brazil for years to come. 


\section{Acknowledgements}

The path I began trailing in 2012 to write this dissertation is not the one where I ended up in 2016, and I am thankful for that. The idea for this dissertation was born from political and personal struggle, so change was a constant theme throughout. I could not have withstood this challenging course without the help of some incredible people.

My first thank you goes to my doctoral supervisor Justin Paulson, who truly embodies the meaning of mentorship. Justin helped me craft the foundation of my research project at a turbulent political time, encouraging me to take on the challenge of studying revolution and counter-revolution as they happened. A careful listener, he guided me through fieldwork and all of my conflicts as a militant-researcher, including during moments of health-related distress, while, of course, helping me sail through programme requirements and those endless funding applications.

Justin is one element of an amazing PhD committee, which I consider myself lucky to have been able to put together. I offer my sincere gratitude to Rebecca Schein for her disposition to help, even when it meant just having me brainstorm with her in her office when I showed up with a clueless look in my face. Thank you also to Marie-Eve Carrier-Moisan, who I consider a true friend in my years at Carleton. Marie-Eve mentored me as a teacher and a peer, and helped to boost my interests through amazing opportunities in teaching and research assistantships. I hope to one day be as much help to you as you have been to me! I'm also grateful for the thoughtful guidance and collaboration offered by Stefan Klein as a fieldwork supervisor at the University of Brasília. 
There are many other people in the Carleton community who have impacted me during my tenure at the university and I may not be able to mention everyone. I would like to highlight my thank you to the staff at the Department of Sociology and Anthropology as well as the encouragement and recognition given by many faculty members such as Aaron Doyle, Neil Gerlach, Peter Gose and Janet Siltanen over the past four and a half years. My PhD cohort is also worthy of a special mention, especially Sarah, Melissa, Kyle, Konstantin and Adam, who learned to give and receive support in a very special way in academia. Thank you also to Donna Coghill for being the amazing person you are and the true glue of my dear Institute of Political Economy. Thank you to my friends Brynne, Nikki, Steven, Mikhail, Lucas, Daniel, Ananda, Késsia, Patty and many others for the emotional support throughout this journey and the interesting and stimulating conversations.

Very few people would be able to finish a project like this without loving support from their family, and I am not one of them. My father and my mother have been true believers in my academic potential and have showed patience at every step on the way. My sister Sinara could not have been more loving and encouraging, and I hope I can always be there for her too. My brother Samuel has been - himself an academic in the making - a cheerleader and propeller to my efforts, pushing me to be better each time. Thanks for the debates, the intellectual struggles, and the emotional support and guidance no one else could have given when I needed it. I love you all endlessly!

Thanks finally to those not mentioned but who know the implicit value of their contributions. Personal circumstances change, but the material impact we make on each others' lives, especially throughout intensive journeys such as the researching and writing of a doctoral dissertation, is certain and lasting. 
"The crisis consists precisely in the fact that the old is dying and the new cannot be born; in this interregnum a great variety of morbid symptoms appear." Antonio Gramsci 


\section{Table of contents}

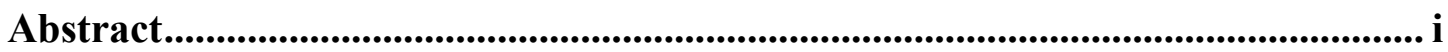

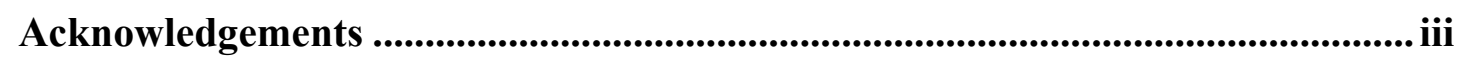

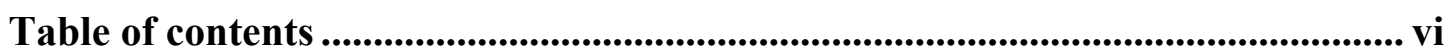

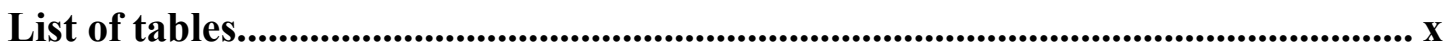

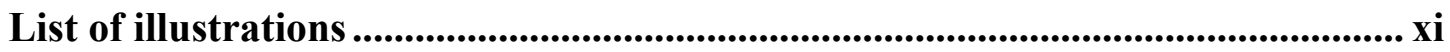

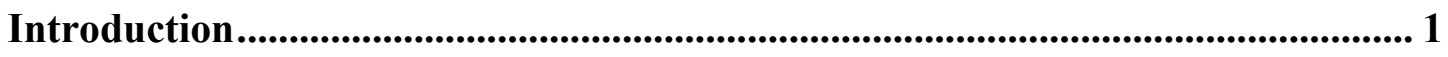

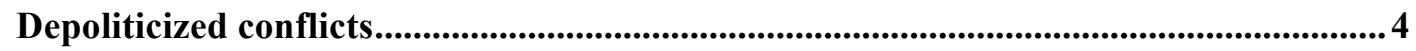

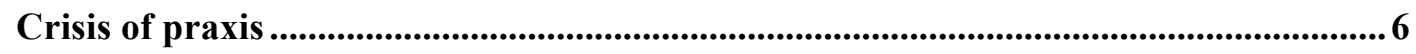

Fragmented actors.......................................................................................................................

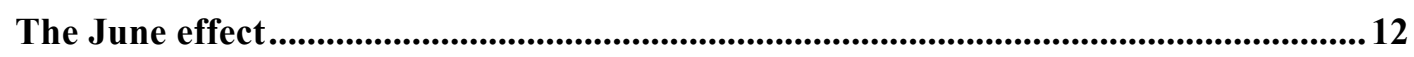

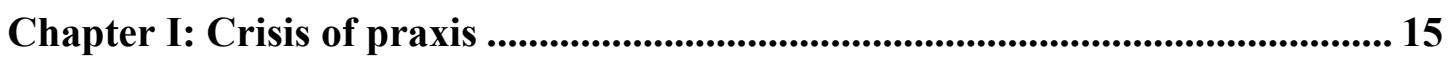

Foundations of the concept of praxis ...................................................................................... 15

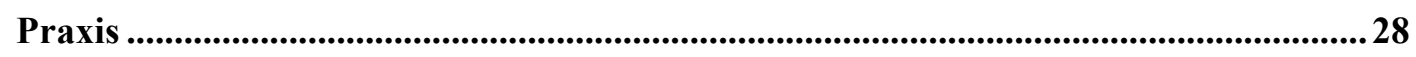

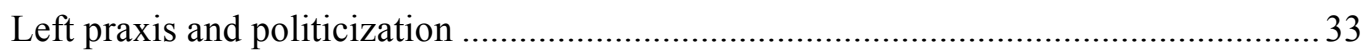

Where is the radical in revolutionary praxis? ...............................................................36

Between radical ideas and counter-revolutionary distractions ........................................ 39

June during a crisis of praxis ....................................................................................................49

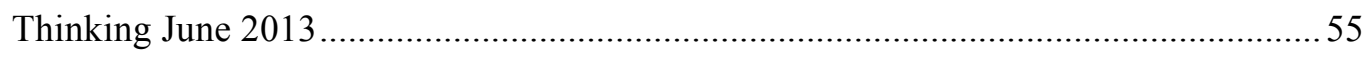

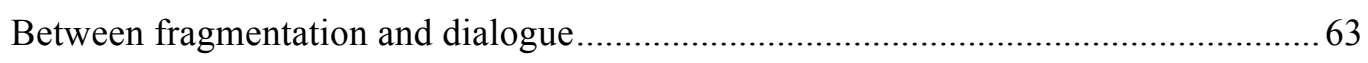

Chapter II: The moderate left .............................................................................6 68

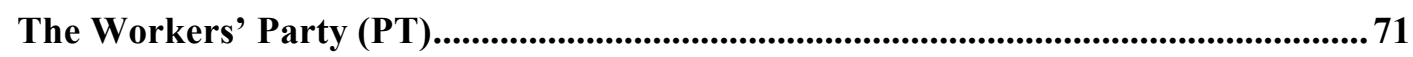


Trasformismo: the establishment of the moderate left 76

Party crisis and political reform as maintenance of power 82

The Communist Party of Brazil ....................................................................................................8 87

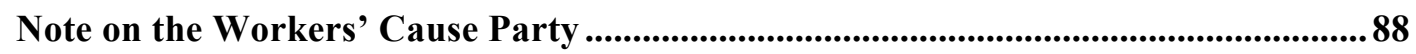

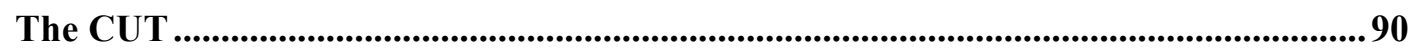

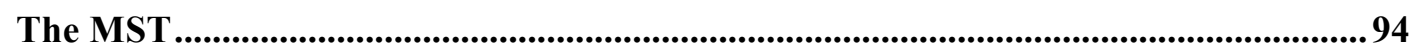

Chapter III: The radical left .......................................................................................... 101

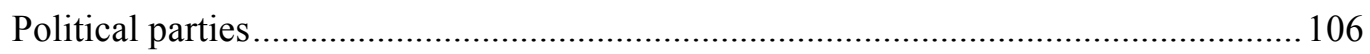

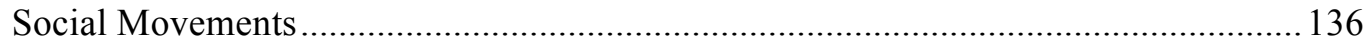

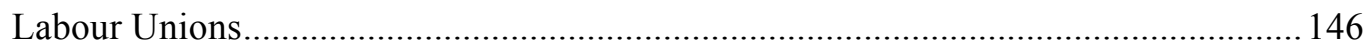

The radical left in the fragmented context .............................................................................149

Chapter IV: Depoliticization: post-politics....................................................... 151

What is post-politics? ................................................................................................................. 154

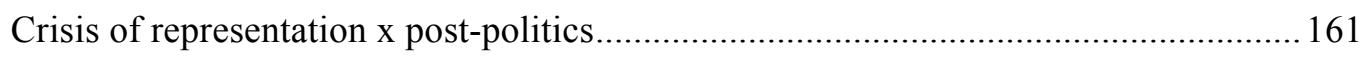

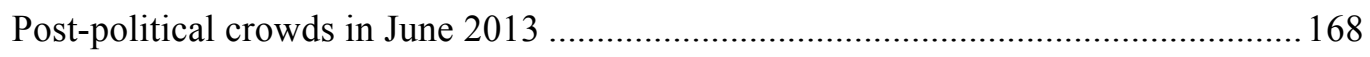

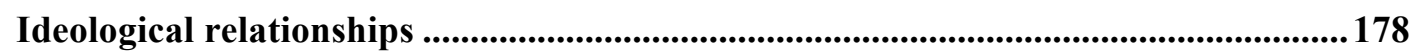

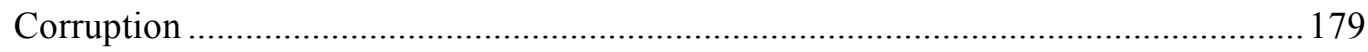

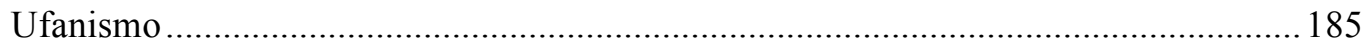

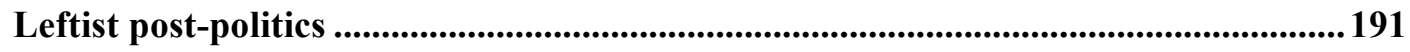

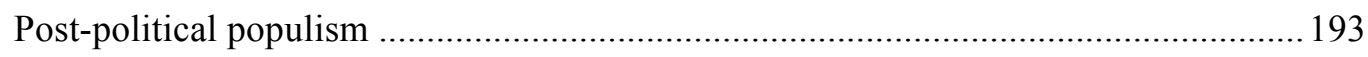

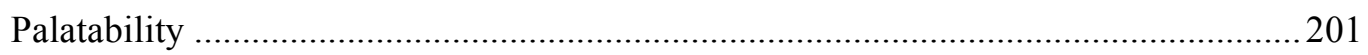

Chapter V: Depoliticization: ultra-politics ........................................................ 206

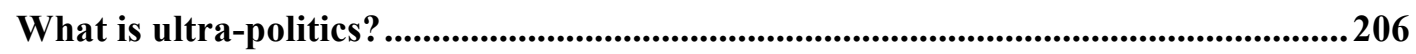

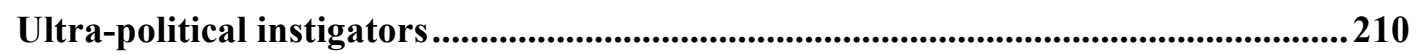

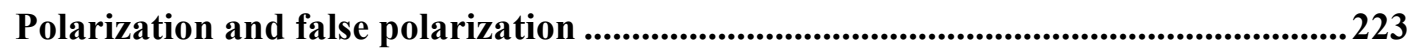


Chapter VI: Fragmentation: melancholia ............................................................. 241

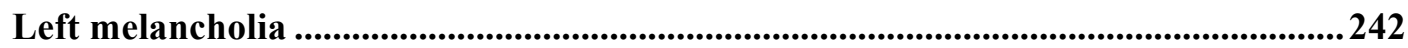

The melancholia of the moderate left in Brazil.....................................................................249

The melancholia of the radical left in Brazil..........................................................253

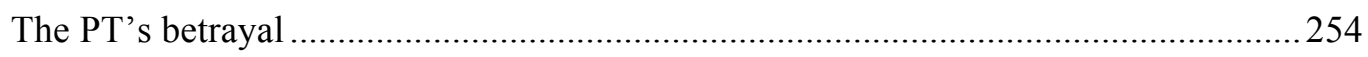

Misplaced desire: united left gone wrong …………............................................25

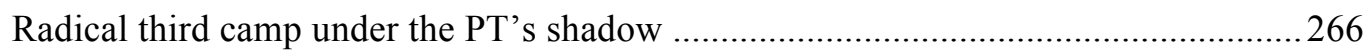

Unresolvedness and the need for a conclusive synthesis .........................................22

Agitation and anxiety over defeats and small victories....................................................285

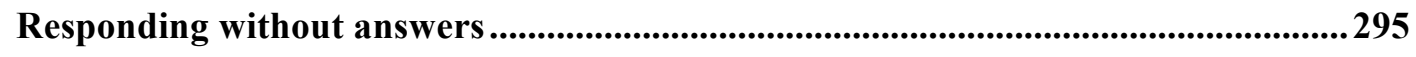

Chapter VII: Fragmentation: schisms .......................................................................... 297

The logic of schism .........................................................................................................................299

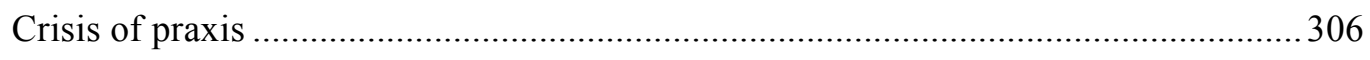

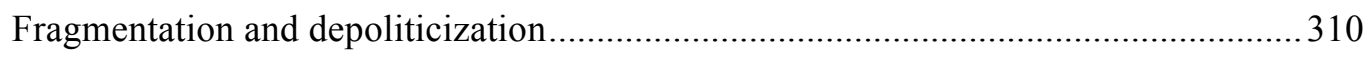

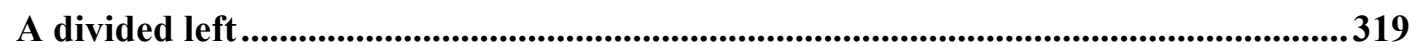

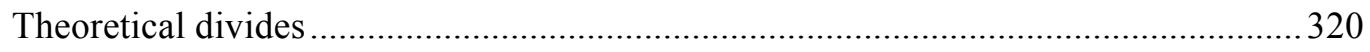

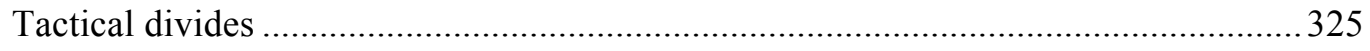

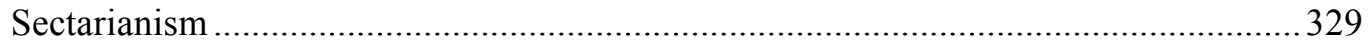

Fronts and alliances...............................................................................................................338

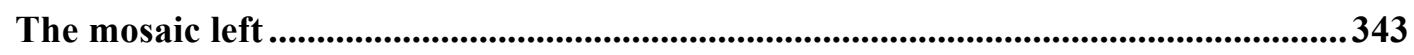

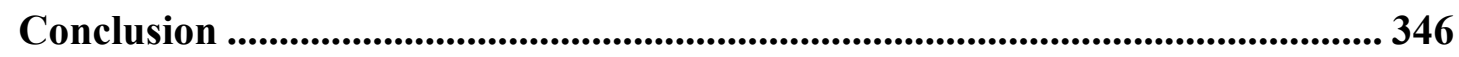

Crisis of praxis .......................................................................................................................347

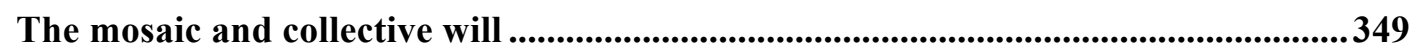




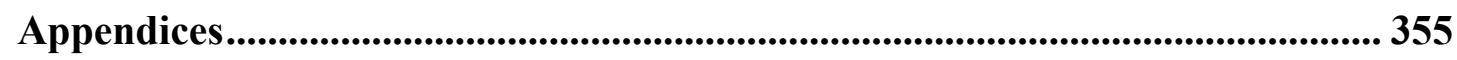

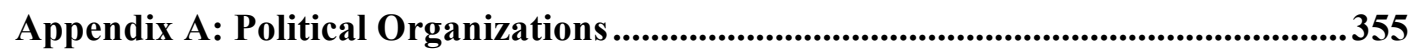

Appendix B: Other acronyms ............................................................................................357

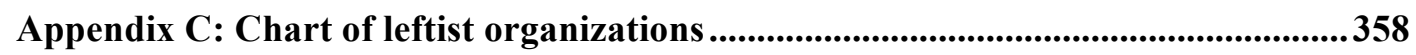

Appendix D: Methodological considerations .........................................................................360

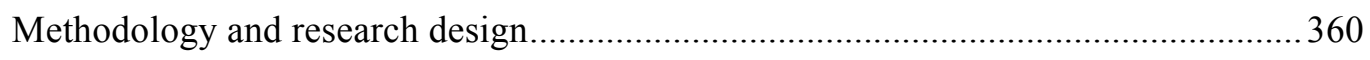

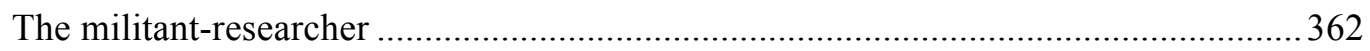

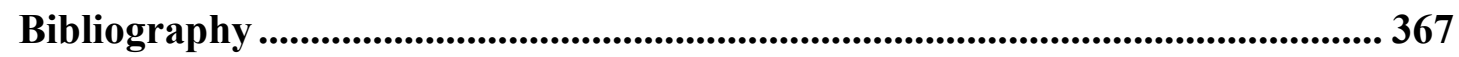




\section{List of tables}

Table 1. June 2013 crowd moments 


\section{List of illustrations}

Figura 1. Strategic left praxis of parties and social movements 63

Figura 2 Porto Alegre inspiration by Juntos in São Paulo 110

Figura 3 Key PSOL tendencies 117

Figure 4 "Fora Todos" (left-wing) and (right-wing). 230

Figura 5 Natália Szemerta (MTST) speaks to the crowds on top of sound truck (April 2015) 266

Figura 6 MTST-DF and Government of the Federal District sign non-binding agreement ahead of the movement voluntarily leaving occupied lands (February 2015) 290

Figura 7 Debate promoted by the PSOL with Luciana Genro at University of Brasília (March 2015) 291

Figura 8 Plenary for federal congress candidate Rafael Madeira (PSOL - Insurgência) to set the terms of a "collective candidacy" with PSOL militants (July 2014) 295 


\section{Introduction}

Many doctoral dissertations in Sociology are researched and written at times of constant change regarding the subject of study, but I reckon that not as many are written during such political turmoil as I have encountered when immersed in the reality of the Brazilian left. While I knew that June 2013 would mark the Brazilian conjuncture in ways that we are yet to see, it was only after I arrived in Brazil in June 2014 to begin my ethnographic fieldwork that I realized that there was much more in store than the hypotheses I had set and that this realization was still hidden from the sight of quite a number of organizations I considered important for the left.

In my dissertation proposal, I put forward the thesis that the Brazilian left is fragmented, which is common knowledge to the organizations and movements studied. I was concerned, however, that these organizations underestimated to which degree this fragmentation was affecting more than each other, but also the political consciousness of the people in Brazil that found themselves in a widely recognized crisis of representation. This crisis of representation, I gathered, was perceived by a portion of the radical left at the time as a mere problem of a Workers' Party (PT) that failed their base, and a right-wing sector that could never represent those calling for social justice in some way. In fact, some organizations saw the crisis of representation as a progressive result of the failures of the system and the people's reaction of rejecting this system, refusing the possibility that it was also symptomatic of a larger and long-lasting disconnect between the people and leftist and radical organizing as well. I found their openness to the idea that the "Não me representa" cries of June 2013 was inherently progressive, rather than indicative of a cry for change of any kind, to be troublesome, 
as it downplayed how the anti-petismo (Anti-Workers' Party) sentiment of the crowd could give way to a rejection of the left as a whole and an open embrace of conservative politics by popular sectors. ${ }^{1}$ This is why I started working on a complementary thesis: the crisis of representation was a symptom of a bigger problem, a crisis of praxis. The crisis of praxis appeals to the structure of politicization that permeates the whole of society, and in the current situation, shows that the entire left-wing camp, not just the PT, had to be held responsible for the wide scenario of depoliticization that, as the 2014 elections showed, was now benefitting the right directly. The left had been unable to reconcile the theoretical and practical consciousness of the masses, the oppressed, and now this collective fragmented consciousness gave way to depoliticization of two kinds: post-political and ultra-political (examined in Chapters 4 and 5), both of which favoured hegemonic renewal through the perceived lost relevance of leftist actors beyond special clusters of politicization (e.g.: organized labour, student movements, etc.). Praxis itself was fragmented. This fragmentation extended itself to consciousness, common sense, the ability to politicize, base-building and the state of the organizations themselves, still trapped in schisms, poor dialogue, difficulties to establish a common synthesis and fight contradictions, all the while trying to figure out what the left was in the face of the shards of the PT's rise and fall in power and in political consciousness.

Since the notion of praxis I employ is dialectical and dialogical, my initial idea was that fieldwork could become an opportunity to create bridges of dialogue between organizations, and perhaps even help them focus on their convergences rather than their divergences. This dialogue could lead to alliances that could affect political consciousness at least in a counter-

\footnotetext{
${ }^{1}$ The election of evangelical leaders from the fundamentalist or populist sectors of the church is an example of a conservative consciousness nurtured in the popular sector in face of low leftist representation.
} 
hegemonic way (the conjuncture was too grim to ask for revolutionary consciousness at once). Even with such nuances, it was naïve of me to think this way. I found that these organizations often sat together, often talked. Their militants went to work together, drank beer together, held up their own flags at rallies together. Their lack of dialogue was not a matter of insufficient bridges. There were many deeper problems underneath the surface; problems that kept the left fragmented and probably will continue to do so for a much longer horizon than I expected. $O$ buraco era mais embaixo, as we say it in Portuguese.

The year I finished researching and writing this dissertation, 2016, marked an explosion in Brazilian politics. Not only did it reach the apex of an ultra-political conjuncture that had been unfolding directly since 2014 , but with foundations of hatred and false-polarization that trace back to the beginnings of the PT administration, it also revealed how disorganized the radical left remained. It is true that some efforts at dialogue and forming a cohesive alliance against the right (and even the PT when necessary) came to fruition in 2016. One example is the Frente Povo Sem Medo, led by the MTST and which took a while to acquire its current shape. This front, however, was only able to gather one part of the radical left, and another continued to stand aside through continuous displays of vanguardism. Not that the Povo Sem Medo was better; it had many problems and inconsistencies. In fact, the fragmentation in fronts revealed one of the main contradictions the radical left did not seem to shake: the presence of a moderate left, governista, holding on to the last traces of its hegemony with support from a popular base still captured by lulo-petismo and the promises of the PT from the 1980s. ${ }^{2}$ Melancholia was common to both the radical and the moderate left, and the crowds that

${ }^{2}$ This base of the PT is fading (more rapidly since June 2013) in different directions: part of it to the radical left, part of it to the right, part of it to traditional parties associated with the centreright and part of it to new parties promising new, post-ideological, politics. 
gathered during protests since 2013 would express it differently from the resentment growing in the mass population that felt abandoned by the PT and betrayed by the political system that allowed for Dilma Rousseff's impeachment.

\section{Depoliticized conflicts}

Depoliticization occurs through conscious and unconscious efforts and may depend directly on the political conjuncture (i.e.: who is in power and what is the state of the economy and social welfare) or not. The current state of depoliticization in Brazil follows a previous period of mass politicization and mobilization that marked the beginning of the democratization post-dictatorship, the struggles for rights and direct democracy as well as resistance to representatives governing against the people (e.g.: the Fora Collor movement). This prior period of politicization was marked by strong action and leadership by the Brazilian left, primarily the Workers' Party, which was consolidated as an aggregator not only of leftist organizations but also of mass consciousness through class elements.

Politicization, of course, is not a monolithic concept. To politicize means, in the broadest sense, to create awareness of the political arena and its concepts (e.g. class, oppression, exploitation, antagonism, social conflict, etc.), which is the technical capability of all ideological camps. However, for the purposes of this dissertation, founded in Marxist and Gramscian thought, awareness of the political cannot be detached from the reasons for promoting politicization and the intent of political action. Is it about a politics of progressive, even radical, change or about a politics of the order? Is this intent connected to maintaining the status quo and clouding knowledge about one's own reality or about presenting an alternative political project to society? Whereas there are intellectuals and politicized people 
in the left and in the right, the right-wing intellectuals and organizations 'politicize' the crowds as depoliticization. This is done in order to reassert hegemony, the status quo, and the common sense that keeps the order of things in favour of capitalism and its complementary ideological models such as conservatism and neoliberalism. It masks social phenomena, manipulates information, and produces consent through the promotion of an artificial, one-dimensional (as Herbert Marcuse addresses it), view of reality. Even when the liberal right may politicize around gender issues, for example, its lack of commitment to liberation from all oppression, especially the capitalist system that benefits from and enhances patriarchy, requires it to depoliticize other aspects of it. Therefore, politicization as explored here is a duty of the left, and depoliticization is a fundamental deterrent to leftist organizing and mobilizing. Depoliticization and demobilization happen together, independently of which process is being consciously and primarily driven by political actors in a given place and time.

This perspective shows why post-politics is a form of depoliticization, at the same time as it promotes itself as an apparent solution to a more "ideological" depoliticization, namely ultra-politics. Post-politics is a symptom and cause of further depoliticization precisely because it supresses the political, whereas ultra-politics depoliticizes through fallacies and essentialist polarizations that favour the conservative order. Both create new myths, distort or deny history, and attempt to detach one's consciousness from their practical reading of reality. Despite their different modus operandi, both offer false solutions to the problems caused by depoliticization and instead serve to restore the basic elements of the status quo. Depoliticization creates passive permission for ultra-politics, agreement with post-politics and a/political indifference that allows both to grow through low mobilization and the imperative renewal of common sense. Common sense is perceived by Gramsci as: 
[...] not something rigid and immobile, but is continually transforming itself, enriching itself with scientific ideas and with philosophical opinions which have entered ordinary life. 'Common sense' is the folklore of philosophy, and is always half-way between folklore properly speaking and the philosophy, science, and economics of the specialists. Common sense creates the folklore of the future, that is as a relatively rigid phase of popular knowledge at a given place and time (Gramsci, 1999, p. 630)

A terrain of depoliticization, post and ultra-political, is a fertile one for the right, while it presents a myriad of challenges for the left, as is the case in Brazil despite new sparks of politicization and political interest (which are not the same) after June 2013. After all, these same sparks can be captured by the right through the manipulation of consent to common sense. To re-politicize or to politicize anew, however, is a much more complicated matter and relates to the dialectical processes between consciousness and practice of the collective subject in relation to the structures and superstructures that rely on and rule the status quo. Answers simply based on promoting or restoring democracy, for example, as prevalent in the impeachment period in Brazil (2015-2016) fall into this trap by asking for more of the same (Dean, 2009a, p. 24), in a context where democratic artifacts were manipulated to take away democratic rights and demonstrate that the left is vulnerable to depoliticization even when it means to do the opposite. All of these elements, as well as detailed theoretical explanations of depoliticization in the shape of post and ultra-politics make up Chapters 4 and 5 of this dissertation.

\section{Crisis of praxis}

I work with the concept of a "crisis of praxis" to escape from the dichotomous views of the crisis of representation exposed in June 2013 as either good or bad. Rather, my intent is to look at the roots of this crisis of representation and its consequences for left organizing and revolutionary potential. Praxis entails dialectical action and thought, and as such, political 
formulations, tactics, and strategies that resonate with and reach out to the working class to organize and mobilize effectively towards revolutionary goals. While a crisis of representation deals with formal institutional and non-institutional abilities to represent the classes, the crisis of praxis occurs in many layers, only one of which is representation. This study explains the crisis of praxis from two axes: fragmentation and depoliticization.

These two elements work together and reproduce each other in a crisis of praxis. Although they are not exclusive to the left, they trap the left as they grow in self-reproductive processes that eventually justify the use of the term "crisis". The left, whose praxis ought to be revolutionary in coherence with its goals, ends up stuck in a loop of mismatched practice and thought - just the same as the process incurring in the contradictory consciousness of the working class. This contradictory consciousness affects the prospects for the class to become an effective political subject. From the perspective of politicization and depoliticization proposed in this dissertation, entrenched in the Gramscian view that politicization entails the unification of theoretical and practical consciousness (Gramsci, 2000, p. 333), the right's way of politicization is in fact a depoliticization of issues: it turns big politics into small politics and reverts it back to common sense. Right-wing politicization is in fact a depoliticization project, inasmuch as it diverts people from becoming subjects and creating political reality through their own collective hands.

The current process of fragmentation and depoliticization began with the first signs of decline of the PT as an aggregator and representative of revolutionary aspirations in the left, and into a party of governability and class conciliation. The fragmentation between a moderate and a radical left (examined in Chapters 2 and 3) has heightened as the PT, which once represented the hopes of a more unified left, began engaging in depoliticization in ways that 
also prevented subjectivization, as a form of deterring mobilization that could disrupt the party and the government's political project. The party also demobilized through co-optation, gave in to bureaucratization, mined efforts to bring forth critique from inside their own ranks and allied camps and swapped values important for class consciousness with neoliberal ideals that were masked and legitimized, when needed, through important social policies (whose benefits cannot be denied, despite all flaws). This process led to leftist fragmentation, through schisms, diversions, new formulations, efforts to counter both the right and the governista petista sector, as well as a general fragmented consciousness. This is because every process of depoliticization necessarily imposes barriers on formulating and accessing good sense and on solving the contradiction between the theoretical and practical consciousness of the class. As class consciousness became more fragmented, depoliticization grew and allowed a further entrenchment of the dispute between governismo and the right in the Brazilian context. This depoliticization does not equal demobilization, as protests and other actions led by the moderate left demonstrate, and, in particular, June 2013, which was an event of high mobilization with crowds distributed along various lines of politicization and depoliticization (see Chapters 2 and 3). Instead, it affects the content and prospects of mobilizing activities, especially in terms of the capacity to interpellate mobilized crowds into an organized political subject.

This dissertation approaches the political subject as the working class, but it does not mean that the class is already given as a subject. It must be politicized and interpellated, especially when given as a crowd (Chapter 1). The base refers to the portion of the targeted political subject interpellated by the left, although this interpellation may occur through depoliticization and demobilization, as the PT has done in the past. More generally, one may 
speak of the masses, and they are interesting to this problematic insofar as the masses stand in for the oppressed and exploited.

The current fragmentation in the Brazilian left creates tensions between traditional and new experiments in politics at odds with a society that is mostly depoliticized, but also open to politicization since June 2013 - though the right has been more successful, especially through ultra-politics (Chapter 5). It is also affected by two different states: first and foremost, a melancholia that ties it to the PT debacle and is reflected in the need to hold on to the few victories in a sea of defeats (nationally and internationally), and, to a smaller extent, an anxiety that may prioritize agitation and propaganda during crisis (political, social and economic) over the slow painful process of politicization that may not yield lasting returns for decades. Here we find a radical left that is ready to take on June, but limited by June's own incompleteness and contradictions while the right reasserts its part in the dispute (as the moderate left weakens). The odds between theory and practice in a crisis of praxis are not simply ideological, but refer to the new subjectivizations in the post-June 2013 political period, the difficulties of creating a politics with which to politicize and channel indignation of varied content and sources, the contradiction between organization survival under fragmentation and the creation of syntheses in defragmentation/re-composition that require some level of self-abdication.

\section{Fragmented actors}

To understand fragmentation in Brazil I had to seek out the various fragmented pieces of the Brazilian left, which consisted of many organizations and even fragments inside of them. Since most of the work on the Brazilian left already focuses on the Workers' Party and its allied base, which helps to explain the issues at hand but is not central to the question of 
fragmentation in the radical left, I geared my interviews and ethnographic work towards the radical left entirely. Even during ethnographic fieldwork as a militant, when I expected to be more in contact with the moderate left, most of the organizations present and engaged in building the political processes beyond appearances belonged to the radical left, especially when it came to politicizing efforts. In addition to two years of ethnographic collection (20142016), I interviewed people from all the main radical left organizations over the course of six months in 2015. They represented the organizations below, as well as other smaller organizations that will not be explored as deeply in this dissertation:

- Political parties

- PSOL

- And internal tendencies:

- PSTU $^{3}$

O APS

- MES

Insurgência

- $\mathrm{PCB}$

- Social movements

- MTST

- Terra Livre

- Brigadas Populares

- MPL

○ Labour unions

- CSP-Conlutas

- Intersindical-Central

- Youth and student organizations

- RUA

- Juntos

- UJC

- ANEL

O Other organizations and collectives

- UNEAFRO

- Coletivo Retomadas

- Esquerda Marxista

${ }^{3}$ A few members from the PSTU interviewed in 2015 left the party in 2016 to form another organization known as MAIS. 
Although ethnography was the method chosen for collecting evidence, this dissertation is not an ethnography of the radical left. Rather, evidence is presented alongside interview material to produce theoretical analyses of the issues of fragmentation and depoliticization (See Appendix D for methodological considerations). The collective of organizations listed above indicate not only the level of fragmentation and separation in the Brazilian left, but also how it is not a matter of a dualist fragmentation between the moderate and the radical left, since it is composed of many layers. In fact, one could argue that although the moderate left is composed of multiple organizations, their level of cohesion and coordination is high and corresponds to a small number of organizations with a large number of militants, members, and the majority of the base of the Brazilian left. For instance, while the Workers' Party (PT) is a party of tendencies like the PSOL, the hegemonic power of the direction of the PT leads to more cohesion among its tendencies. While this example demonstrates that the level of fragmentation is lower in the moderate left, this lower incidence is not necessarily a good thing, since the weaker the internal dispute inside the PT, the stronger its capability to intervene single-handedly in the political conjuncture in ways that have caused major depoliticization to the detriment of the entire left in Brazil. This scenario causes fragmentation from the inside of the PT to move into the core of the radical left researched here. The fragments are seen not simply as a large number of organizations, but in differences in programme and strategy, in tactics and approaches, in numbers of schisms and fusions (in their many expressions), in predatory tactics, in vanguardism and sectarian practices, and the challenge of being an alternative to the PT that could rescue its base but also reach out to the base that left the PT towards the right or passivity. As much as new mobilizations since June 2013 (and some from before) indicate progress for the radical left and for work towards social change in Brazil, 
efforts are still contained to the most politicized spaces where the left had been present from before. As one interviewee put it, the little "bracket" where the left lies continues to grow very little, being instead a place of internal dispute among organizations (Teixeira, 2015). The most one hopes that June is a marker for a new period of mass ascension (ascensão de massas), the best to be witnessed so far is stronger resistance and new adhesion in the vanguard and a growth in capillarity in key places where resistance is mandatory in the face of right-wing counterattacks, such as education, workers' rights, and the right to the city. The complexity of left fragmentation in Brazil is explored carefully in Chapters 6 and 7 of this project.

\section{The June effect}

June 2013 is fundamental to all hypotheses and analyses put forward in this dissertation. Although there is no single analysis devoted to explaining June here, given the plethora of academic and political works already dedicated to deciphering the period of mass mobilizations (Gajanigo, 2016; Mattos, 2016; Ricci \& Arley, 2014; Saad-Filho, 2013; Singer, 2014; Vianna, 2013), it permeates this study at every corner. I consider June 2013 to be controversial. Its impact, importance, and mark in Brazilian society and recent history is undeniable, but the different meanings given to these aspects vary according to the reading of the years before, the years to come, and the state of the Brazilian left as a whole. Given this, we find organizations that are open "cheerleaders" of June and value its impact as highly positive, while others focus on the more depoliticized, fragmented, and right-wing co-opted elements of the mobilizations in order to promote a more traditionally leftist organized politics that is seen as clearly connected to the working class. The view of this study is that none of these perspectives are wrong or right in their entirety, but refer to the most important characteristic of June: its complexity in the face of a complex conjuncture, a conjuncture born 
out of and born into a crisis of praxis. June is not the answer to the crisis of praxis, but opens a political era that exposes the organizing problems long faced by the left in hopes of promoting the search for answers even as the negative, conservative, depoliticized and fragmented elements of the conjuncture are heightened.

There are a few points that are worth making already about June and how it influences the overall analysis of the following chapters: it was massive; it opened up more and new ways of thinking and making politics; it alerted the Brazilian moderate and radical left of depoliticization and fragmentation; leftist organizations reacted differently to it; the left took responsibility and assigned fault differently too; there has been more open expressions of mobilization since then; these expressions still depend on topical issues and resistance; most of their potential is still quite spontaneous; larger mobilizing efforts are still slow; protests and demonstrations carry new aesthetics that clash with traditional left events; more people are engaging in regular activism, but most of these additions still make up a vanguard; the majority of the population still connects to June primarily through indignation; the right has managed to capture some (not all) of the June sentiment in its favour; and although politics is again at the tip of everyone's tongue, post-politics and ultra-politics have sequestered much of the language and the content of the debate. Finally, the left is still collectively puzzled by June despite any claims by single organizations to have defined it.

Part of this puzzle relates to how the left struggled to produce immediate responses to June. How to encourage mobilization and further politicize a process whose crisis of representation unjustly ricocheted on the radical left, but justly pointed out the massive gap between it and the majority of the population still trapped in the polarization of the PT and the right? How to demonstrate that the left had been in the streets all along when the moderate left 
had co-opted the streets for the purposes of governability for so long? How to further mobilize with a left identity when the PT had spent the past decade demobilizing? How to reaffirm and give meaning to this left identity if anti-petismo also fostered anti-leftism? How to respond to post-politics in June without creating more rejection to left politicization or falling prey to ultra-politics? And how to show that the major demands made by the crowds in all their cacophony would be best answered by the left if representation itself was shunned at all sides? The trap of simultaneous post and ultra-politics was already in June: to recognize the rejection of representation could give way to post-politics, while to delineate the left stances could favour ultra-politics and help the right close more doors to politicization. The voices were fragmented and so was the consciousness of the people, with only dissatisfaction at its core, which was easily sequestered by hegemony through moralism and around banners (e.g. corruption and fanismo $^{4}$ ) that created false unity, despite some favourable outcomes for the left connected to feminist struggles, for example. Being also fragmented, the left kept struggling and it still does. The last portions of this study took place during delicate political conflicts, and I identify that given the need for mass-based resistance against attacks from all sides, there is a general sentiment that left re-composition is overdue. This sentiment is positive and can be carried through by recognizing the bluntest characteristic of June: the doors are open for leftist politics and the left cannot go down without a fight.

${ }^{4}$ Ufanismo refers to the nationalist and patriotic sentiment promoted by the exaggeration of the riches and qualities of Brazil as a nation. 


\section{Chapter I: Crisis of praxis}

The key concept that underlines the perspective of fragmentation, as well as politicization, that will be presented here is that of praxis. Although the term is commonly employed in Marxist circles, especially in reference to Marx's third thesis on Feuerbach, it tends to be too broadly defined to frame a set of political practices. Therefore, this chapter begins by tracing the meaning of the concept from within the Marxist boundaries in order to arrive at what I call a "crisis of praxis," which will be presented as indeed the basis for left fragmentation in Brazil today.

\section{Foundations of the concept of praxis}

The concept of praxis is the foundation for understanding the crisis of praxis of the left in Brazilian politics. As a term, praxis has been employed in a variety of contexts and offers somewhat different meanings according to the epistemological perspective at hand. In an Aristotelian view, for example, praxis means practice (as distinct from the productive and the theoretical) that is guided by something, as action informed by both reflection and commitment. The discussion on this distinction by Joseph Dunnes sheds light on an understanding of praxis in relation to phronesis, a form of practical wisdom that is also a "reasoned state of the capacity to act" (Dunne, 1993, p. 244). Some authors, even those from the field of critical pedagogy, tend to intermingle the Aristotelian praxis with the praxis discussed by Paulo Freire, favoured in this dissertation. Inasmuch as the Aristotelian praxis refers to a form of committed action without which the theoretical would have no horizon, this connection can indeed be drawn. Dunnes writes that praxis has an end that "is realized in the very doing of the activity itself", and end in itself (Balaban, 1990, p. 191; Dunne, 1993, p. 
244). While such a notion is also present in Freirean praxis, the dialectical component of Freirean praxis also makes of it a means to an end, especially in the context of political imaginaries and the influence of cognition in the process (detailed later). The result is a praxis that is related to Aristotle's praxis as well as his poesis.

Another important distinction relates to how Aristotelian praxis is a form of conduct, whose content is informed not simply theoretically but also morally, whereas the revolutionary praxis with which we are concerned when examining left praxis and a crisis of praxis also has to do with uprooting conduct. Hence, this is a praxis that deals both with foreknowledge and after-knowledge and surpasses a formal view of praxis as practice based on knowledge. In fact, much of this perspective is influenced by the general etymological connections made between practice and praxis, which could also be the fault of the long string of translations and interpretations throughout the history of this discussion. The core difference, however, is that the Freirean praxis does not treat theory as separate yet complementary to practice, but rather unites them dialogically and, most importantly, dialectically.

The particular view of praxis employed in this study, which I believe to be the most accurate reflection of what a revolutionary leftist praxis ought to be, traces back to Karl Marx's Economic and Philosophic Manuscripts of 1844 (EPM). The EPM provides an analysis of the nature of human society, alienated labour, and the historical dialectical development of human potentialities. Kevin Anderson points out that these themes are seen throughout Marx's lifework, such as in the Grundrisse and the volume III of Capital (Marx, 1973, p. 488 [1939], 1981, pp. 117, 182, 959 [1894]), although they were first developed in the EPM (K. Anderson, 1986, p. 15). The Manuscripts are also where one can evidently see Marx's motivation for providing a thorough analysis of capitalism: pointing out its historical contradictions that make 
a theory of human liberation possible in communism, even if at that point Marx's analysis if capital (and of overcoming its domination) was still in development.

Marx considers the worker, through the working class, to be the protagonist of history. His argument is based on humanity's relationship to nature and productive capacity, as well as the historical conclusion of the central role of class struggles. This argument is also made from the perspective of the positive abolition of private property and its appropriation of human existence as the abolition of all alienation. Since the liberation of the worker from alienation affects both consciousness and practice, it leads to all other kinds of alienation that occur through one aspect or the other (Marx, 2007). In fact, it is the possibility of a unity of thought and action in humanity that sets humans apart from other beings in nature. Marx speaks of human species-consciousness that is confirmed in social life, making humans both unique individuals and communal beings in an inseparable connection between free existence and social activity. The result is "the subjective existence of society as thought and experienced" (Marx, 2011, p. 131, my emphasis). The problem of alienation and the question of revolution have to be considered through both thought and practice, whose unity (undertaken by myself as praxis) is paramount to overcoming Hegel's idealism: "The resolution of the theoretical contradictions is possible only through practical means, only through the practical energy of man. Their resolution is not by any means, therefore, only a problem of knowledge, but is a real problem of life which philosophy was unable to solve precisely because it saw there a purely theoretical problem" (Marx, 2011, p. 135, emphasis in the original). Marx would return to the matter of revolutionary praxis and the materialist core of his method shortly after in his Theses on Feuerbach (1845), by echoing the foundation of revolution as a practical-critical 
activity and urging humanity not to simply interpret the world but to do so in order to change it (Marx, 1994).

Marx closes the EPM with his critique of the Hegelian dialectic, establishing not only his concept of man as a natural species-being that "authenticate[s] himself in being as well as in thought" (Marx, 2007), but also to what extent the liberation of man's self-consciousness is tied to a supersession of private property as an entity of thought (Marx, 2007). For Marx, this necessitates the overcoming of Hegel's idealism so that humanity can be liberated both in thought and in real life, as a being (Marx, 2007).

Herbert Marcuse looks into the contributions of the EPM in "The Foundation of Historical Materialism” (Marcuse, 1973a [1932]). Marx is concerned with human essence and its consequential loss due to the estrangement of labour in private property, which, though still economic categories, are employed by Marx in a "philosophical framework"; for Marcuse, it is only through this foundation that a true transformation of human nature and society can occur (Marcuse, 1973a, p. 8). His argument is that historical materialism, grounded in a philosophical critique of economic activity and the development of capital, is a practical theory: "a theory whose immanent meaning (required by the nature of its object) is particular praxis; only particular praxis can solve the problems peculiar to this theory" (Marcuse, 1973a, p. 40).

In this regard, Raya Dunayevskaya states that Marx's method consists of a movement from theory to practice as well as a movement from practice to theory (Dunayevskaya, 2000, pp. 31, 37), though the latter would become a point of contention between her and Marcuse given his thoughts on the one-dimensionality of the proletariat whose relation to capitalism had become more affirmative and less revolutionary (K. B. Anderson \& Rockwell, 2012, p. 
59; Dunayevskaya, 2000, p. xvi; Marcuse, 1991, p. 8). This is connected to Marcuse's concern that technological control has weakened the negative capacity of the proletariat, thus making the working-class position in relation to capital less contradictory and even more amenable to exploitation as a necessary side effect to a relative improvement in the living standards (Marcuse, 1966, p. 110, 1991, p. 31). This position is partly shared by Erich Fromm, who stresses that even Marx had not foreseen the extent to which an affluent alienation could be as dehumanizing as the impoverished kind (Fromm, 1966a, p. ix). Nonetheless, Dunayevskaya's approach to the EPM is similar to Marcuse's in the way it emphasizes Marx's critique and appropriation of the Hegelian dialectic method, "the dialectic of negativity", in order to establish labour as an essential category to human nature, an activity where humans realize themselves as species-being. In fact, both authors assert that Marx's choice of terminology in the EPM, particularly "alienation", was not a matter of a confinement to specific (Hegelian) philosophical terms, but really is the consequence of his work as a dialectician: he grounds his analysis on "alienation" and "man's essential being" exactly because his method focuses on the contradictions between such categories (Dunayevskaya, 2000, p. 57; Marcuse, 1973a, p. 8).

Marcuse argues that the category of labour in the EPM also arises from Marx's critique of Hegel, since Hegel's work is the "last radical reflection on the essence of labour and its unfolding into the concrete spheres of historical existence" found within philosophy until Marx (Marcuse, 1973b, p. 12). In Hegel, labour is the praxis of human existence, which Marx takes to be a condition of human existence through the mediation between man and nature (Marcuse, 1973b, p. 13). Thus, labour is an economic, philosophical, and anthropological category that 
contains a value judgement in the differentiation between free self-expressing labour and alienated self-negating labour (Fromm, 2011; Marx, 2007).

Antonio Gramsci is the Marxist thinker that most influences the foundations of the concept of praxis as a key factor in human society and activity employed here. Gramsci's view on hegemony, pedagogy, and the dialectical formation of good sense (versus common sense) are elemental to seeing praxis as a political force, especially as these same themes are repeated and expanded by Paulo Freire in critical pedagogical thinking that many scholars identify as a Gramscian-Freiran framework (Gross, 2011; Ledwith, 2001; Mayo, 1996, 2010; Semeraro, 2007). Emancipation, in a Gramscian view, is not only economic in character but also contains the emancipation of man's whole existence. Even Gramsci's clear focus on the proletariat, which may give rise to an economistic interpretation, does not deny that the totalizing power of capitalism is connected to oppression in a wider sense. This tension is negotiated by Gramsci's suggestion that by emancipating themselves the proletariat will also collaborate in the emancipation of all other dominated groups through its revolutionary historical role (Gramsci, 2000, p. 120). Paulo Freire makes a similar point when arguing that "the great humanistic and historical task of the oppressed [is] to liberate themselves and their oppressors" (Freire, 1970, p. 28). In Gramsci's words in the L'Ordine Nuovo: “The proletariat, having conquered social power, will have to take on the work of reconquest, to restore in full for itself and all humanity the devastated realm of spirit" (Gramsci, 2007a, p. 20 my emphasis).

Unlike some of his Communist Party comrades, Gramsci was not afraid of Marx's philosophical roots. On multiple occasions throughout his works, Gramsci insists that Marxism is indeed a philosophy, a philosophy of praxis, and that this aspect cannot be discarded in order to favour a more 'scientific' approach. This line of thought by Gramsci was developed even 
though the Manuscripts were not circulated widely during his time, which indicates that he based his understanding of Marx's philosophical grounds on the other texts available. He argues forward that the philosophical understanding of revolution is a requirement for its realization, as it eliminates the contradiction between one's intellectual (theoretical) consciousness and one's practical activity (Gramsci, 2000, p. 328; 333); hence, the need for an integrated approach between the organic intellectuals and the proletariat. This approach establishes that the intellectual class, in particular the organic intellectuals of the party, has a responsibility to the working class to aid in the elimination of this contradiction in such a way that more intellectuals may arise from the base and expand the process hegemonically. The pedagogical aspect comes to light in the dialectical nature of this interaction between intellectuals and masses, ensuring that this is not a process of indoctrination but of free exchange and dialogue that contributes to the growth of the intellectual group in number and in quality (Gramsci, 2000, p. 335).

Raya Dunayevskaya perceives this movement of elimination of contradictory consciousness as a movement from practice to theory, which shows some optimism regarding the spontaneous activities of the proletariat, although she is wary of the potential of counterrevolution within the revolution that can take the shape of totalitarian crude communism. Herbert Marcuse also argues that the proletariat consciousness seeks to develop out of oppression, in an urgent need to do away with its source (Marcuse, 1966, pp. 116-117). Technical progress, he argues, has changed the relationship between classes and the capitalist structure by suppressing alternatives in the form of an autonomous affirmation of the mode of existence in the capitalist mode of production; the result is a rising standard of living that masks exploitation while improving its reach (Marcuse, 1966, p. 116). Instead of using class 
antagonism to revitalize the struggle, the proletariat finds itself in a cultural and materialist fatalist position due to the illusion of progress in the growth of productive capacity (and, henceforth, consumption potential). This point is extremely important when considering how the potential for social change is inevitably connected to the level and kind of politicization in the people. Even moments of mass uprisings can eventually dilute into weak claims and various expressions of self-indulgence if the hegemonic perspective of change is intertwined with an affirmative view of capitalism. Marcuse's worry that the working class has become fatalistic and accommodated in their unfreedom actually makes freedom inseparable from consciousness and practice in a dialectical process (Marcuse, 1991, p. 222).

Similarly to Marcuse, Fromm believes that a more affluent society (hence, one with higher standards of living) would only deepen "man's spiritual problem," but they part ways where Fromm suggests this would generate urgency in class struggle (Fromm, 1966b, p. x). Marcuse is critical of this view by arguing that it provides a diluted critique of alienation in society that hid conformism behind an optimistic approach to liberal concepts such as love and meaningful activity.

Karel Kosik is one of the authors to most explicitly deal with the perspective of praxis, alongside Paulo Freire, whose theoretical influences ultimately connect Kosik's and Freire's praxis to Gramsci. Although a key concept in Marxism, praxis is often taken for granted and dealt with as a given notion embedded in Marx's argument for revolutionary praxis (often translated as practice). Kosik acknowledges this as praxis and not simply practice because he sees cognition as a major human capacity in the overcoming of naive consciousness ${ }^{5}$ when

\footnotetext{
${ }^{5}$ Paulo Freire, whose work is foundational for Marxist critical pedagogy and will be explored
} in the last section, also uses this term (consciência ingênua - naïve consciousness) to indicate 
materially confronting historical reality (Kosik, 1976, p. 26). This means that both labour and man's ability to decode and critically engage with the reality where labour takes place are activities that indicate human potentiality. Cognition, as a dialectical element in the subjectobject theoretical-practical nexus, aids both in the formation of objective reality and mankind's self-formation as historical subjects - what Kosik calls the process of "humanizing man" (Kosik, 1976, p. 30).

A revolutionary praxis builds on an authentic cognition of reality that allows the subject to critically engage with a totality in both the theoretical and practical realms. Kosik establishes that concrete totality is a theory of dialectically structured reality where man is both subject and object. This picture is different from the one presented by classical economics in the shape of the "economic man", for humanity is only depicted as object in this context (Kosik, 1976, p. 53), and is, therefore, located outside of praxis, which is subjectivizing and moves subjects out of the realm of contradictory consciousness wherein the "economic man" finds himself. Marx's concept of labour, on the other hand, is fundamentally connected to a threedimensionality of human activity in the transformation of dialectical opposites (Kosik, 1976, p. 121). This three-dimensionality is not simply a state of non-alienation, but a dynamic state that demands a dialectical relationship between practice and thought.

Cognition becomes one of the important elements that bridge this relationship, especially the cognition of utopia. For Leszek Kolakowski, utopia is a necessary element in the process of creating a revolutionary movement and thinking up the tools for a revolution. It influences theory and the conscious imaginary of the movement in order to establish a

a form of common sense (in Gramscian fashion) that establishes causality as fact and reproduces unverified 'truths' (Freire, 2010, p. 113) 
purposeful direction of action. Cognition is historical and therefore affected by the conditions imposed by history on humanity in the pursuit of the truth of a reality that is accessible to man (human nature) (Kolakowski, 1968, p. 56; 58-59). In The Spirit of Utopia (first published in 1918), Ernst Bloch explores how cognition of the revolutionary process of an awaking consciousness is only possible through a utopia that forms the association between the first dream (an innermost insight into our will) and the restoration of this will (Bloch, 2000, p. 145). Utopia is not a dream that recollects the past. Rather, it is "only that yearning which brings with it what was unfulfilled, what could have absolutely no earthly fulfilment, the waking desire of what alone is right for us" (Bloch, 2000, p. 156). For Bloch, even a state of deep alienation cannot preclude a presentiment of a hidden human potentiality, which is precisely what fuels the capacity for utopia (Bloch, 2000, p. 168). Thus, utopia is not the same as a dream or disengaged hope, but stands as the fruit of a dialectical standing between hope and darkness (Bloch, 2000, p. 201). It is hope that springs out of darkness, and as such, out of oppression and alienation, for there is little cause to continue to hope when the optimistic potentiality carried in it has already been realized. If the negative is contained in the positive, so it is the other way around as a spark against the perceived inevitability of an oppressive totality. Historical cognition prepares for revolution insofar as it determines the first total negation of the system that stands in opposition to utopia. The second negation (aufheben) takes place when utopia is abolished in its act of fruition.

Theory contributes to the process of cognition, but if it is fetishized and promoted instrumentally, its revolutionary potential will be nullified. If perceived as part of a dialectical movement that is committed to a historical materialist perspective, rather than the individual interests of organizations, theory can reenergize the political party intellectually and also build 
a bridge between thought and the actuality of the decisions made (Kolakowski, 1968, p. 163; 166; 171). The left must avoid the tendency towards self-preservation in their political organization form and replace it with the moral responsibility to recognize and act against alienation and oppression. This requires the view of utopia as objectivity, even when possibility appears to be at a minimum; that is, "the excess of hopes and demands over possibilities is necessary in order to force reality to yield all the potentials it contains, and to tap all the resources hidden in it" (Kolakowski, 1968, p. 151). This perspective will be explored further when looking at definitions of the left, between the radical and the revolutionary, in a following section of this chapter.

It is also important to see the working class, or the proletariat, in a way that is both inclusive and non-economistic. Because class consists of human relationships, as well as mediated class locations (Wright, 2015, p. 155), one can speak of the 'working class' without denying the heterogeneous experiences of working people in different sectors. The contingencies created in the relation of one worker to another and to their experiences of exploitation are revealed in unity through class-consciousness, since it expresses "an identity of interests as between all these diverse groups of working people and as against the interests of other classes" (Thompson, 1991, p. 212). Class consciousness ensures that people retain their agency in their own making of history, rather than following a deterministic recipe given out by previous structural conditions. Inasmuch as class consciousness arises from the unified experience of intense exploitation, it also arms the working class against the process of instrumentalization that takes place as capitalist exploitation develops and adapts. Exploitation too is a relationship that varies in intensity according to context, yet as capitalism develops it tends to progress in a direction where humans are fully reduced "to the status of an 
'instrument'” (Thompson, 1991, p. 222). It turns the proletariat into a 'thing' devoid of human potentiality and as nothing more than the precious commodity they sell to the capitalist class for the sole purpose of sustaining accumulation. This same point is a matter of concern for Marcuse, who argues that technology as a form of control leads to the subjugation of theoretical reason to the instrumentality of practice in the mode of production, therefore also reducing humanity to a technical aspect (Marcuse, 1991, p. 158). This process, as it pertains to dehumanization, objectification, the growth in exploitation of one group over another, as well as the impediments in subjectification under hegemony and common sense, is true in any interaction among the oppressive structure of society, be it capitalism, patriarchy, colonialism, white supremacy, and so on. Therefore, I do not find it to be a problem the recognition of a diverse set of terminologies and categories to refer to those who are oppressed and exploited. This dissertation employs the working class as a category, but the people, the masses, the proletarianized, and even the multitude can be applied in different ways to refer to different yet fundamentally similar experiences under oppression. ${ }^{6}$ It is often the insistence in placing one particular type of oppression as more relevant than another one that distracts us from the importance of recognizing oppression as the core concept in dehumanization, loss, and suffering that unites all systems of dispossession.

It is not sufficient to think of revolution and counter-revolution simply from the point of view of a change in the ownership of the means of production, since a wide array of processes that Marx connects to a superstructure come into materiality through the actuation of the realm of consciousness, subjectivity, and knowledge. A purely structural or structuralist

\footnotetext{
${ }^{6}$ Some terms explored later, such as base, crowds, and mass, are used in particular contexts to refer to fractions of the working class and/or subjects-in-the-making larger/smaller than the working class.
} 
perspective would fail to account for these processes and would, therefore, suggest a more mechanistic analysis of leftist fragmentation in Brazil that would reduce the current problems to the political damage effected by the Workers' Party or the different ideological party lines across the left (Stalinist, Marxist-Leninist, Trostskyist, etc). If one was to attempt to provide a purely structuralist explanation for the fragmentation of the Brazilian left and the many challenges for rallying the working class behind a revolutionary project, important elements that will be highlighted throughout this dissertation would be missed, such as politicization and depoliticization, the make-up of crowds and social movements, the challenges of basebuilding, the variety of political party interests in institutional and non-institutional settings, political melancholia, difficulty to produce synthesis, post-politics and ultra-politics, and collective will - all of which amount to the real praxis of the left and what ought to be a revolutionary praxis of the people.

The achievement of liberation is contingent on a revolution because it does not simply consist of the negation of the current system but of the negation of negation - an abolition in the Hegelian sense (aufheben) that requires the restoration of human labour, human relationships, and human interaction with nature to its intended free essence. This is evidently contrary to left populist claims of changing the world without taking power, or nonrevolutionary democratic transitions (Holloway, 2002; Laclau \& Mouffe, 2001). Although aspects that lead to a revolution may come about spontaneously in the daily fight against alienation, the revolutionary process requires organization and theoretical insight of the second negation. For Kolakowski, this is utopian knowledge (Kolakowski, 1968, p. 70-71; 80). For Marcuse, it is the guiding of practical consciousness by theoretical consciousness because the former is often in contradiction with the objective of a free human existence (Marcuse, 1991, 
p. 48; 100). And for Gramsci, it is about the unification of double consciousness and the harnessing of collective will. Thus, whether the revolutionary process requires the work of a political party, organic intellectuals, or the follow up of proletarian impulses by the oppressed, there is no disagreement about the dialectical nature of the relationship between theory and practice in the development of a revolutionary praxis. The negation of the negation that spawns the realm of freedom from commodified labour, alienation, and reification is inherently dialectical and presupposes a 'practical-critical' activity (Marcuse, 1941, p. 401; Marx, 1994, p. 99).

\section{$\underline{\text { Praxis }}$}

Praxis, understood here not simply as practice within the dialectic but as the dialectical unity of theory and practice in the movement of negation, is a precondition for restoring the historical world to the domain of humanity and the free exercise of human potentialities. It is within the dialectic that we find the negation of negation, which are two different stages of the same historical process headed by humanity towards freedom and the restoration of human essence (Marcuse, 1941; Marx, 2007). The principle of two negations is key to a lefist praxis because this praxis must be revolutionary, and to be so it has to ultimately strive towards a new hegemony, which is seen as a socialist or a communist society depending on the revolutionary left spectrum. The dialectical process shows us that it is insufficient to be contained by radical politics, since permanent politicization (practical and theoretical) necessitates more than "anti" or "counter" politics. Since dialectical reason ought to guide this process, Kosik warns of the dangers of trying to abolish philosophy from Marxism, because they would promote a static praxis that is no longer dialectical and hence no longer humanizing (Kosik, 1976, p. 106), stifling the ability of humanity to form a transformative relationship to reality as subjects. Even 
the possibility of a revolution is dependent on the dialectical conception, for it "alone can provide an adequate orientation for revolutionary practice" by preventing this practice from being controlled by an opportunistic philosophy (Marcuse, 1941, p. 401).

Kosik's argument that transformative praxis is dialectical relies on the perspective of theory and practice as an unity rather than just loosely connected in humanity's attempts to explain and change reality (Kosik, 1976, p. 136). In fact, any effort to separate theory from practice in Marxism neglects Marx's own arguments in his critique of Feuerbach, for he provides uncompromising statements on the nature of revolutionary activity as "practicalcritical" historical activity that unites interpretation and self-change (Marx, 1994). This is why Kosik is compelled to refute a notion of praxis that is heavily based on human practice and a primacy of practice over theory (often instrumentalizing theory in the process) in materialist scholarship (Kosik, 1976, p. 135). He establishes that praxis is a mode of being that "permeates the whole of man" (Kosik, 1976, p. 137, emphasis in the original). Because praxis is not an isolated activity but an activity of being, practice and theory must form a dialectical unity in order not to force humanity into choosing one over the other. While practice that dominates theory may stagnate due to the inability to recognize reification, theory that dominates practice prevents the realization of the subjectivity of humanity; both sources of imbalance would halt the positive transformation of reality. Revolutionary breakthroughs are only possible as long as theory and practice inform each other, because "man knows reality only insofar as he forms a human reality and acts primordially as a practical being" (Kosik, 1976, p. 9, emphasis in the original). Therefore, it is of primary importance that theory be understood as constructed on cognition and not on contemplation. 
The rejection of contemplative activity in the formation of theory is why this unity between theory and practice does not mean that one should not follow the other, since a movement of this kind is necessary within a dialectical relationship. Revolutionary praxis must be tied to the truth of reality in a fundamental quality, which entails that practice would follow theory because the latter "will preserve the truth even if revolutionary practice deviates from it proper path" (Marcuse, 1941, p. 322). It is this reasoning that made Marcuse sceptical over Dunayevskaya's aforementioned enthusiasm about a movement from practice to theory in her Marxism and Freedom and in their joint correspondence. While Dunayevskaya argues that a movement from practice to theory can lead to "new impulses" in the path to a revolution, Marcuse is concerned that proletarian impulses can be adorned with an affirmative attitude towards capitalism that essentially negates their revolutionary character (K. B. Anderson \& Rockwell, 2012, p. 49; 59). For this reason, thought must be the vehicle of practice in the process of abolition of labour (Marcuse, 1941, p. 241), which, in its dialectical form (referring to Hegel's Aufheben), consists of restoring labour to its intended form: an expression of human freedom (Marcuse, 1973a, p. 25).

This is where the notion of praxis becomes even more significant, because it explains not only how humanity's dialectical position in history is continuously threatened by the alienating power of common sense in the absence of praxis itself, but also how the restoration of theoretical-practical activity gives a certain permanence to our inquisitive capacity as both reflection on the world and on our experience in the world (Marx, 1994, p. 99). This reflective state is not mere contemplation, as it is driven by the necessity to align our theoretical awareness with our practical consciousness in the midst of their contradictory relation (Gramsci, 2007b, p. 330<169>). In fact, this is the relation that sustains hegemonic control, for 
its renewal capabilities are fed by the blinding disconnect between consciousness and everyday material activity. The establishment of praxis as a fundamental element in transformative activity and inquiry pervades the whole of Freirean critical pedagogy in the belief that education and any other pedagogical practice must be grounded on the historical materialist view of humanity, inasmuch as men and women can only truly live as real men and women when they acquire consciousness of what prevents them from being so and immediately proceed against oppression in the positive expression of the process of liberation.

Capitalism's power is derived from the ability to preclude access to a historical view of existence and, by consequence, the agency of creation and the subjectivity that set humans apart. Cognition of one's own humanity, and the historical potentialities that follow, is a step toward becoming conscious of how one is oppressed. While utopia springs out of our desire to reassert ourselves as human beings, its development takes place in the struggle against oppression, for the more people suffer the more eager they become to escape it, even if the realization on how to do so could be affected by one-dimensionality and problems of politicization. This realization will not come about if utopia retains the static quality of a hopeful dream and as long as its knowledge is separated from our practical activity and reality. For utopia to evolve in the way Kolakowski argues, carrying through the labour of social progress in between moments of illusion and disillusion (Kolakowski, 1968, p. 151), it must be the motivational force behind a praxis, whose continuous dialectical movement between what is envisioned, experienced, and thought will bring utopia to the status of an objectivity. This is different from the kind of utopian thinking Kolakowski would criticize years later, one whose view of socialist society in terms of brotherhood and equality denies the processes of differentiation and disagreement that transpire in human relationships in favour of agreeable 
conformism (Epstein, 2013, p. 36). Rather, utopia must be conceived as a conscious desire for freedom that includes taking steps towards its realization (Lukács, 1971, p. 315), even if the end result is continuously challenged by changes in human interaction. Accordingly, the dialectic cannot be separated from authentic praxis because its recognition acts as a tool for revealing the complex dynamics of a process together with any internal conflicts and contradictions that ought to be expected from human society (Kolakowski, 1968, p. 163).

It is important to point out that action towards realization is also a matter of consciousness because of the dialectical logic of liberation, where "slaves must be free for their liberation before they can become free, and that the end must be operative in the means to attain it" (Marcuse, 1991 [1964], p. 41). ${ }^{7}$ This struggle cannot be done by imputing a certain kind of pseudo-revolutionary knowledge to the masses, by attempts to simply direct these masses, or by consistently reaffirming that revolution will happen because it is the natural progression of history. For Freire, the confrontation of oppression must take place in a pedagogical context. He states that:

There is not another path but the one of the practice of a humanizing pedagogy, in which the revolutionary leadership, instead of superimposing themselves on the oppressed and continuing to keep them as almost 'things', establishes with them a permanent dialogical relation. Pedagogical practice in which the method ceases to be [...] the educator's instrument (in this case, the revolutionary leadership) with which it manipulates the educated (in this case, the oppressed) because [pedagogical practice] is already consciousness (my translation) (Freire, 2005, p. 63).

This consciousness is the moving principle of a political pedagogy geared towards overcoming depoliticization and fighting the reproduction of the status quo that takes place

7 Marcuse first uses the term "thought" in 1941 (Reason and Revolution) and then "consciousness" in 1964 (One-Dimensional Man) when pairing them with "practice" and "action" in similar contexts. Although they could be taken as different concepts according to the paradigm employed, I find that Marcuse has employed them almost synonymously throughout his contributions. 
through common sense, because it exists as something that it is not, and that is outside of it (Freire, 2005, p. 63). However, consciousness on its own would mean no more than a momentary idealist transcendence that cannot, by its very nature, be revolutionary and transform the concreteness of oppression. Marx explains this necessity by stating that in the case of communist ideas, they may help to supersede the idea of private property, but actuality requires communist activity in order to supersede real private property - even if the latter faces historical challenges, for "the development which we already recognize in thought as selftranscending will in reality involve a severe and protracted process" (Marx, 2011, p. 149, emphasis in the original). At the same time that dialectical thought tackles the ontological tension between reality and what reality should be, this thought follows from concrete practice (Marcuse, 1991, p. 133). While thought/consciousness provides the critical impulses in political/critical pedagogy as conscientização, the transformation of reality follows the role of critical consciousness in praxis.

\section{Left praxis and politicization}

If depoliticization poses a major challenge in a society of one-dimensionality, then it must be understood that to politicize cannot mean to simply bring a new and critical form of politics to the people, but to include the people as the actors of political making. To accomplish such a task, agency must be strengthened by challenging the dichotomy between the political leadership and the base, much like the artificial traditional view of teaching and learning as two separate functions and phenomena. The perspective of praxis as a dialectical relationship between theory and practice in a transformative movement of reality is heavily grounded in Marx himself, since it refutes a vulgar materialist interpretation of praxis that sees thought only as a guiding influence on the material, practical, activity of humanity. On the contrary, Marx 
argues that humanity's affirmation in the objective world is made up of all senses, including thought (Marx, 2007). The critical pedagogical perspective establishes that praxis is humanization and that humanization can only take place in praxis if it is to avoid an overly optimistic mystification of human potential. Humans only self-affirm their progressive capacity when they transform consciousness and reality concomitantly. The liberation of humanity from alienation is authentic only when it is 'humanization in process', rather than something that can be 'deposited' in passive individuals (Freire, 2005, p. 77). Critical consciousness cannot be imputed, only acquired, so that whatever action that follows it becomes the materialization of human thought and will. As an expression of dialectical reason, it guides the action towards change, and in this way it already operates as changed reality. To this effect, Marcuse argues that a socialism based on emancipation will need to be part of the consciousness and action of those engaged in the revolutionary process (Marcuse, 1991, p. 41). Hence, he urges us to see the need for revolutionary praxis, which is dependent on politicization of all kinds, when engaging in revolutionary projects.

By the means of a dialogical pedagogy, individuals learn to question their own alienation not because they are told to but because they become aware of their existence within the circumstances of alienation. They are able to critically step aside to find that their struggle with exploitation exists because of how damning oppression is to the human faculties. When Marx mentions the mortification of the workers, he does so because their position either consists of such death that they are unable to see beyond it or such death that requires the proletariat to look for answers outside of it. Instead of simply focusing on their own death, critical consciousness leads them to an understanding of totality, where they find that alienation is a social phenomenon they experience with each other (Freire, 2005, pp. 116-117). Once this 
awareness is embedded in praxis through the hope of re-establishing their humanity, it becomes a negation of oppression in the way the workers think, act, react, and socialize (which solidifies class consciousness and class solidarity). And so action and reflection interact as a dialectical unity, whose revolutionary movement is guided by the influence of revolutionary theory, one structured around human agency in the complexity of capitalism's totalizing character.

In Theses on Feuerbach, Marx affirms that praxis is the coincidence between human activity and the changing of reality and that this transformation also implies the achievement of true consciousness (Fromm, 2011; Marx, 1994). Because praxis involves this two-fold transformation, it is fundamental in both the preparation and fulfilment of revolutionary activity, and as such it is of special interest to political organizing. As a strong advocate for a deliberate connection between pedagogy and the actions of the revolutionary political party, Gramsci's political thought can be linked to Freire's educational view and vice-versa (Mayo, 1996, pp. 149-150). In Gramscian thought, revolution is not a mechanistic process, but one that involves the organic self-capacitating of the oppressed through recognition and the will to change (expressed in a collective will) done together with the organic intellectual representatives of this group (Gramsci, 2000, p. 310; 312). This work is executed both as direct educational/schooling work, but also in the dialogical relationship between leaders and the group they represent. The objective is to bring the theoretical and practical consciousness of the group into alignment so that the common sense produced and reproduced under hegemony can be confronted for the benefit of also bringing others into a questioning and critical position.

This has much to do with the political strategy of the left. Lukács affirms that the organization for the revolution is already a form of mediation in the dialectical relationship between theory and practice (Lukács, 1971, p. 299). The education of the ought to have a 
purpose, with the aim of becoming a self-education in a liberatory framework. The role of the intellectuals is to take advantage of their freedom of thought to further the development of consciousness, as it is their responsibility to move the theoretical consciousness of the working class towards a critical stance (Kolakowski, 1968, p. 171). It is also important that the intellectuals follow impulses from the workers, for their experience with exploitation makes them the most suitable to inform the direction of social change (Dunayevskaya, 2000, p. 287). This suggests a solidaristic relationship in which the revolutionary leadership thinks with the class, and not around the class, contributing to what makes this relation revolutionary and constitutive of authentic praxis (Freire, 2005, p. 145; 151). This solidarity not only transforms the relationship between the organized left - the leadership and the base - but also blurs these categories so that one is not perceived to be in a separate cadre from the other. Overall, a pedagogical perspective of political organization opposes the doctrinarian relationship of the holders of knowledge to the owners of labour found in vulgar communism by establishing dialogue between intellectual and practical activity, even if it is important to have individuals whose primary function in society is intellectual or organizational. It embodies praxis precisely because it renounces the separation between theory and practice that would always keep the working class in a position of subservience, whether to the capitalist or to the party leader.

\section{Where is the radical in revolutionary praxis?}

My task of advancing the concept of a crisis of praxis compels me to draw out a few differences among three other notions that are commonly referred to in the left, although in a generally confusing way. This pertains to what is radical, what is counter-hegemonic, and what is revolutionary. The three notions belong in the left and in the activity of the left and therefore tend to be used as synonyms or as fairly similar to each other. I would rather speak about them 
as a continuum determined (and interrupted) according to the nature of organizing and their common political direction (as embedded in a horizon or utopia). Revolution is the mark of a particular kind of utopia, so what is revolutionary requires also a particular kind of effort that is guided by the revolutionary necessity. What is counter-hegemonic ${ }^{8}$ contributes to a revolutionary process in the effective struggle and damage made against the status quo; however, when counter-hegemony is placed outside the revolutionary necessity, the risk of reversal faced due to hegemonic renewal is stronger (even counter-revolutionary). What is counter-hegemonic is radical, because what is radical is embodied in a politics that is necessarily placed against capitalism (and its neoliberal current); however, not everything that is radical is counter-hegemonic. Radical left politics can oppose capital (and right politics, and moderate left politics in so far as it overlaps with right politics) without actually pursuing a praxis of rupture with capital that is counter-hegemonic in its effects and/or revolutionary in its work towards the abolition of capital (e.g.: politics of resistance). In plain terms, what is revolutionary is also counter-hegemonic and radical; what is radical can be but is not necessarily counter-hegemonic, let alone revolutionary. The positioning and activity of the left is radical as long as it points to the counter-hegemonic process, which entails the effective struggle against the historical structures of domination and oppression fulfilled in the status quo, and revolutionary as long as its movement is dictated by the hegemony of the working class. But the sole promotion of counter-hegemony without the long-term construction of an

\footnotetext{
${ }^{8}$ The counter-hegemonic connects the radical and the revolutionary. Although Gramsci was the one to more successfully champion the concept of hegemony, he did not, however, propose the existence of a counter-hegemony in his own writings. I believe this to be due to the temporal constraints on counter-hegemony when hegemony is already under constant renewal. The answer to hegemony, therefore, must be a new hegemony. Counter-hegemony then plays a temporary part by stressing the importance of the first negation and is well-established in contexts of resistance.
} 
alternative can transform the radical into a kind of radicalism that favours a defensive and reformist politics (Holst, 2002, p. 67), whereas a revolutionary movement employs counterhegemonic tactics in order to uproot and abolish the system of oppression. This dissertation focuses on radical politics as part of a revolutionary horizon and especially as this politics pertains to politicization and depoliticization.

Reformist tendencies usually avoid debates that touch on more revolutionary concepts, such as the commons, by arguing in favour of current constraints and social relations. The enclosure of public spaces by the neoliberal stage of capitalism occurs both in the direct privatization of the public and through the reconfiguration of public services to serve private interests. This reconfiguration can be blunt but also subtle when disguised as reformist social benefits, especially when it comes neoliberal advances under leftist governments. The Workers' Party (PT) administrations in Brazil, from Lula's two terms in office to Dilma Rousseff's tenure, have been heavily analysed with respect to their neoliberal content. These analyses vary, especially in the early beginnings of Lula's mandate, although they more or less converge around the many evidences of alliances between the PT and capitalist interests (Antunes, 2013; Lecio Morais \& Saad-Filho, 2005; Petras, 2005; Sánchez, Neto, \& Marques, 2008). Still, the power of social reform makes it possible for Marilena Chauí to argue that the Lula government was not specifically a leftist government, but it was not a neoliberal government either (Chauí, Boff, Stedile, Santos, \& Guimarães, 2006, p. 40). As confusing as this sounds, for it questions what it is that makes a supposedly leftist government truly an expression of the left while discarding the neoliberal contagion in the moderate left, her statement reflects a limitation of the critique of neoliberalism by defensive radicalism and the governista tendencies. Because it focuses on the more open avenues for challenging neoliberal 
advances of privatization, this radicalism disregards how the neoliberal mutation of the public presents a complex challenge to the left in terms of how it conceals the capitalist agenda behind seemingly benevolent actions of the State. The failures by the radical left to conceptualize the public through the revolutionary perspective of the "common" limit the struggles over rights and public spaces in reformist configurations.

\section{Between radical ideas and counter-revolutionary distractions}

"The Left does not fear history. It believes in the flexibility of social relations and of human nature - in the possibility of changing them." (Kolakowski, 1968, p. 76)

Any attempt to completely homogenize the left fails as soon as history and the diversity of attitudes, positions, and ideologies found among those who identify themselves through their 'leftness' are considered. In some ways, it could be said that there are many 'lefts' that exist in relation to a general "left characteristic" or stance. Even an organized political movement cannot wholly claim to be the left, since its own ranks and divisions conduct themselves as more left or less left than one another (Kolakowski, 1968, p. 77). In plain terms, one can speak of the left and of the radical left - perhaps even of the revolutionary left, since understandings of revolution also vary in the radical strain. Thus, it is possible to try to name and define the left by what it is for, but to do so by who it is would be a futile endeavour. Rather, I choose to examine who is in the left and with the left: whose actions and perspectives are informed according to the general left characteristic. While the concept of the left is a characteristic, a tendency, and the channel for a real movement, the mediation of the left as the expression of this movement consists of those in it and with it. This dissertation is concerned with who is in the Brazilian left and how they organize themselves and the people in relation 
to each other. It focuses on the organized left, especially in terms of class orientation (from anti-capitalist to socialist). While the forms of organization (more autonomous expressions included) in the left are not definitive of it, they are capable of mediating theory and practice dialectically in the left and, by doing so, bestowing it with concreteness in the mediational act (Lukács, 1971, p. 299). This conversation is important for highlighting that the actors in and with the left may work cohesively as well as may be at odds with each other. The difference between periods of conflict and dialogue is mediated by patterns of organization in the left that dictate the relationship between theory and practice in relation to the consciousness of the people. Left organization pertains to the political function of the left in its responsibility to represent and exist as the expression of the interests of the working class people. Organization does not comprise solely of hierarchical structures of leadership, though they certainly exist in complex ways and matter in the nexus among political parties, social movements, grassroots social justice groups, and those they claim to represent. Theory, as well, can guide practice dialectically or determine practice dogmatically. This distinction in theoretical application affects dramatically how different leftist organizations relate to each other.

The left acts according to its political expressions or actors, but understands that its subject is not these expressions. Rather, the subject is the working class (categorized with those oppressed) whose political functions are exercised through the actors mentioned above. I am working with the premise that capitalist relations of exploitation, in the appropriation of the basic human function of labour into states of alienation and reification, inform forms of oppression embedded in gender, racial, and colonial relations, among others. This process is dehumanization in the specific expression of capitalist phenomena. 
Although the left has existed in both capitalist and non-capitalist contexts, I am concerned with the left as the antithesis to the capitalist totality and all forms of oppression that thrive in and through this exploitative environment. In other words, with the left characteristic that is given according to "the real movement which abolishes the present state of things" (Marx \& Engels, 1998, p. 57). Earlier I argued about the distinctions between the radical, counter-hegemonic, and revolutionary politics of the left, even though a particular spectrum within the left may be sometimes referred to as communist, socialist, radical, or revolutionary without much additional thought. The arguments I will put forward in the next paragraphs about the complications that follow from a Left radical politics ingrained with 'post-isms' pertain to the possible stagnation and setbacks that haunt the radical left when it neglects or refuses the revolutionary motion induced by the movement towards the abolition of the present state. Thus, they refer to the conflicts of praxis that arise according to the configuration of the revolutionary side of radical politics in the left in relation to the mode and path of opposition by the radical left.

Tendencies towards post-modernism, post-Marxism, and post-capitalism (not to mention post-structuralism and post-industrialism) have become a subculture in both academic and political ways. David Harvey speaks of this subculture as the prevalence of 'the post' despite its debate's inability to even define 'the pre', which is connected to the emerging resistance to talk about Marx and Marxism in certain radical (intellectual) circles (Harvey, 2000). Barbara Epstein argues that the power of post-modernism, for instance, has had such tremendous reach that it often insists that it is the "intellectual left" and has succeed somewhat in promoting post-modernism as the left and progressive politics in general (Epstein, 1997). Post-isms of this kind have risen in status in the intellectual left (with its natural connection to 
how politics are practiced) partly due to their reinvigorating appearance at times of left melancholia and/or stagnation. French postmodernism, in particular, came out of a time of strong disillusion with mainstream sites of resistance by marginalized actors involved in radical politics (Epstein, 1997).

In their early periods, post-isms seem to fuel radical debate, seemingly pointing out where the problems are and what created them (often pointing the finger at the radical actors themselves). Arguments that resonate with post-capitalism and post-structuralism have been widely circulated in Brazil after the consensus that the current structures of representation are failing to incorporate popular struggles into paths of action - a problem of special concern to political parties, as I will explore later. Before a crisis of representation is finally taken through the elements of post-politics and ultra-politics in a conjuncture, it is common for it to be used as evidence for the need for post-Marxist and post-modern views in the left (which may contribute to and empower post-politics and ultra-politics anyhow). Rather than to radicalize political organization, the groups that reject politics and capitalism at the same time opt to promote resistance and struggle through reconceptualization rather than transformation. This was the case with one of the campaigns against the FIFA World Cup in 2014, which loudly claimed that "there won't be a World Cup" (Não vai ter Copa!) to resist it instead of employing the World Cup as an enhanced site of struggle for politicization and organized action by the people. Although such arguments do not offer an alternative that can be actualized by the left, after long stretches of debate post-isms tend to remain exciting (and retain support) because they come across as the perfect way of addressing a left melancholia sustained by guilt and 
defeatism (Dean, 2012, p. 170), which is the central theme of Chapter 6. ${ }^{9}$ Holst agrees, by questioning why the left tends to look at history and blame itself for "trying to go too far," consequently looking for more "realistic" approaches that he says makes left revisionism actually less realistic and more utopian (Holst, 2002, p. 72). It stands to reason that post-isms reflect some of the intellectual pessimism in the radical left that followed the capitalist advances through neoliberalism at the end of the last century (and continue to do so). The focus on processes and multiple truths of "the post" is where the excitement lies; it is a vague yet hopeful appeal to the solution of a problem misrepresented by the intellectual pessimism. For Harvey, this transformation in thinking resembles Gramsci's statement on "the pessimism of the intellect and the optimism of the will" (Harvey, 2000). I would merely add the caveat that the disputes over the possibility of a unified, collective, will among 'post' thinkers reduce this optimism into multiple celebrations of the particular. Since optimistic celebrations lack substance without a proper direction for the will, they do not go very far into providing comprehensive solutions to the problems the left is trying to address, and pessimism gets the upper hand.

Particularly, the increased focus on process has obscured the importance of the connection between radical politics and revolutionary politics in the left. Powered by trends in post-modern, post-Marxist, and post-capitalist politics, the radical left has roused series of fetishes, such as for purist democracy: a superior democratic politics that is the ideal embodiment of radical politics. This seems to be common in a group Bruno Bosteels terms the 'speculative left,' which mistakes liberal democracy and contemporary notions of democratic

${ }^{9}$ Epstein also notes that, at the level of culture, post-structuralist and post-modern tendencies get highlighted because of their appeal to the common cultural themes of "distraction, absence of rootedness in the past, a sense of meaninglessness" coming out of the 1980s (Epstein, 1997). 
society for the "invariant process whereby the people constitute themselves as people or, conversely, people constitute themselves as the people in a movement of immanent selflegitimation" (Bosteels, 2005, p. 752). Such a process may also be the case in struggles against right-wing and/or fascist offensives similar to the ones experienced in the impeachment moves in Brazil after the 2014 elections, when the moderate left mobilizes in the name of democracy, rather than by radical antagonism, and even capture those further left through the conflation between democracy as the horizon and the post-political conjuncture. This confusion actually hinders the revolutionary articulation and will be further explored in Chapter 4.

The "fetishism of democracy" is an aspect of what Žižek terms "democratic fundamentalism" in the sense of a hegemonic framework that binds leftist thinking to its conditions, such that it acquires a degree of immunity to contestation by those groups fighting for social justice and against totalitarian politics (Dean, 2005, p. 157; Žižek, 2002). The fetishism of democracy (and deliberative politics) imbues democracy with agency, acknowledging the people who live in a supposedly democratic society only so far as they should work to ensure the democratic state. Hope, which guides political struggles through a vision that is to be realized, ends up internalized and destroyed through democratic channels by positing that the procedure holds the answer to the question of how to realize our goals (Dean, 2009b, p. 78). Decisions receive importance according to the process that produced them, rather than their content and pedagogical value. The celebration of the radical process of participatory budgeting in various municipalities, a process born in Brazil, nicely illustrates this problem in the context of localism - while opening a window into why the Workers' Party recently lost terrain in some of the 'progressive' cities where it had introduced the process. The easiness with which the outcomes of democratic processes perceived as radical and 
community-empowering are accepted presents a challenge for the radical left. Outcomes that do not speak to the social justice objectives that informed the way participatory budgeting was first implemented move the process away from radical politics (where the people are political and politicized agents in how they choose to employ a radical democratic system) towards radicalism. The ties between radicalism and post-modernism are strong in the value of criticism for the sake of it, wherein politics become "increasingly a matter of gestures or proclamations" (Epstein, 1997). In the case of the celebratory radicalism around a pluralist participatory democracy, radical politics are reduced to process and methodology. The agency of the people is only considered secondarily, in relation to how it is granted by the overall agency of the process.

The strong focus on democracy is usually accompanied by voluntarist and autonomist trends that, while they advance left politics in the materiality of everyday life, command little effort to grasp capitalism by its totality and negate it accordingly. 'Post-capitalist' politics and process-oriented politics tend to focus on rearranging facets of society and our lives without capitalism, as if its hold has been overcome within those circles, while neglecting that every other aspect of human activity is still determined by the logic of capital. The work of J. K. Gibson-Graham looks into promoting a post-capitalist politics because it assumes that it is possible to have ways of thinking (that translate naturally into practice) about the economy without the messy affairs of the anti-capitalist struggle defined by class and revolutionary politics (Gibson-Graham, 2006). While it is important to consider micro-politics, the insight they offer into local resistance is better understood in terms of the spaces of uneven reification (spaces where hope is possible, as Harvey would express it) that spring from the diversity and differences in our experiences in relation to capital (Paulson, 2010, p. 33). Localist readings of 
local struggles suffer from imbuing the local with an extraordinary capacity that either ignores the size of the struggle or undervalues that radical politics at the local level are still subject to counter-reactions and hegemonic renewal at the macro and global scales. Gibson-Graham's promotion of "bringing desire into language" as a form of resistance illustrates the loose foundations of empowering through assertion (Gibson-Graham, 2003, p. 70), as it embodies the set of proclamations detached from the materiality of the struggle that Epstein highlighted connects post-modernism to radicalism.

I am not trying to ignore the benefits of a prefigurative practice that tends to follow these trends, for such ventures can be exercises in radical imagination and experimentation for an envisioned alternative. However, autonomism without the organization of a collective project seeking to positively uproot capitalism through a real movement of the left dangerously borders on the pragmatist belief characteristic of post-modern thinking that we can fight capitalism one day at a time by pretending it is no longer there (Mclaren \& Jaramillo, 2007, p. 45; Paulson \& Schein, 2012, p. 134). Declarations that there is such a thing as changing the world without taking power are limited by a view of social change as the "conscious and confident sociality of the flow of doing" advocated by John Holloway (Holloway, 2002, p. 210). This perspective exudes of the celebration of process that makes it possible to naïvely conceive of "looking for hope in the very nature of capitalism and in its "ubiquitous [or pluriform] power', to which a 'ubiquitous [or pluriform] resistance' is an appropriate response" (Bensaï, 2005,p. 176). Such thinking actually disarms the left by making social justice claims about how each one of us choose to live our lives in defiance of the structures that breed social injustice without giving additional thought to the real value of promoting social justice in fragmented clusters still dominated by a larger powerful system. 
It is possible that the left has become increasingly concerned with the way politics is made, leaving its content in the background to be resolved after the mode of action is resolved. The work of post-Marxists Ernesto Laclau and Chantal Mouffe illustrates some of this confusion in their argument for a democratic hegemonic practice imbued in a pluralist radical democracy. The application of hegemony from within the boundaries of political practice and isolated from class matters assumes that a 'democratic practice of hegemony' fulfils the role of counter-hegemony in challenging oppression, almost as if this political articulation already replaces the oppressive hegemonic power by changing the rules of the game (Laclau \& Mouffe, 2001, p. 57). The problem with this perspective is that, as long as the capitalist totality informs and permeates hegemonic practices, not all rules will have changed and matters of access and participation promoted through pluralism will be limited. This limitation is not an apparent concern to Laclau and Mouffe because their democratic revolution, concentrated on process, aims to challenge subordination and inequality rather than the dynamics of proletarianization of capitalism (Laclau \& Mouffe, 2001, p. 153). Therefore, it is not surprising that Mouffe's later attempts to critique the negative implications of deliberative democracy end up caught up in the notion of agonistic politics, which treats antagonism as an inherent force in democracymaking, rather than a social force oriented towards its own abolition through the revolutionary process (Mouffe, 2013). The political content, again, is subordinated to the desired democratic methodology.

Because Laclau and Mouffe are inclined to deal with a democratic revolution that involves socialism rather than a socialist revolution that transforms democracy in the communist transition (Laclau \& Mouffe, 2001, p. 156), Gramscian notions of hegemony and collective will are deprived of their dialectical relationship to theory and practice, fixing 
articulations solely in the realm of practical constructions. In fact, the point is often to undress Gramsci's contributions of their fundamental concern with a class-based struggle, which John Holst affirms is part of the connection between post-Marxism with the celebration of New Social Movements (NSMs) - the praise itself resulting from a misreading of the emergence of new actors and their sites of struggle as different struggles altogether from that of the working class (Holst, 2002, pp. 40-41). The declining prominence of union politics as a site of resistance in Brazil, for example, does not mean that the class struggle has become any less important. Rather, it speaks to the assault on formal labour by neoliberalism (Spronk, 2013, p. 81) and the fragmentation of interests that accompanies the diversification of proletarian experiences under capital, demonstrated in the process of proletarianization. This fragmentation is heightened by the strength of reification in spaces configured according to the market and suppresses knots of collective class consciousness, especially as it favours economistic and syndicalist relations between unions and workers that sometimes result in unions bargaining against class interests (termed pelego unions in Brazil). It also relates to distortions in class politics by the moderate left and processess of bureaucratization. Therefore, the novelty around NSMs and identity politics does not reflect the decline in class issues, but the particular difficulties encountered in articulating class through them - including how class experiences structure the struggles for rights and recognitions put forward by NSMs.

The influence of post-capitalist and post-Marxist politics within the left is somewhat unified in the rejection of the revolutionary articulation of a collective will, promoting instead a version of radical tendencies ingrained with freedom from party politics (from a valid critical standpoint) and the pluralist celebration of individual choices and multiple voices that comes out in the recent focus on horizontality as the ethos of contemporary social movements of the 
left. June 2013 echoed some of these elements, such as anti-party sentiment and the rejection of political organizing not just by those affected by the depoliticization of struggle and social activity, but also by groups whose work can be advanced and complemented by the left. While the left should embrace criticism, especially from the inside, the moral appeal of the celebration of 'popular politics without politics' affects the possibility for advancing debate within the left, choosing the momentum provided by a novel way of being political over the capacity to work towards a collective goal (Dean, 2012). Even though the majority of these tendencies carry a hint of anti-capitalist politics, the result is "an ocean of more diverse oppositional movements that lack overall political coherence" (Harvey, 2012,p. 119). In of itself this diversity is a good thing: it exposes the creative ways through which capitalism has exploited and dispossessed entire societies. However, as a merit of creative capital, it manipulates social struggles and the pursuit of social justice into spectacles of vague contestation that attempt to talks about rights without dealing with class relations. In an orthodox fashion that can be as present in Marxist circles as in anarchic currents, questions about rights and sovereignty tend to be split from discussions over class exploitation and antagonism (Harvey, 2012, p. 120).

\section{June during a crisis of praxis}

June, as a political marker, suffered from the diluted effect of this form of politics in the juxtaposition between massive mobilization and the confined, sectarian-like, strategies of traditional political parties and social movements. The result was a political subject split between the idea of the people as a rigid version of the nation, which erases complex (and uncomfortable) antagonistic relationships in order to oppose a general Evil embodied in the State and the fiasco of representative politics, and the notion of the dispossessed whose emphasis on their existence at the margins of society would initially reinsert division and 
discomfort back into the struggle but miscarried in face of the overwhelming power of voluntarism, autonomism, and depoliticized unity. This subject split between depoliticization and the presence of radical demands led to a series of "crowd moments" that, although they do not support the thesis of "multiple Junes," do in fact demonstrate that the diversity in crowds was both temporal and spatial, as the table below summarizes:

\section{Table 1. June 2013 crowd moments}

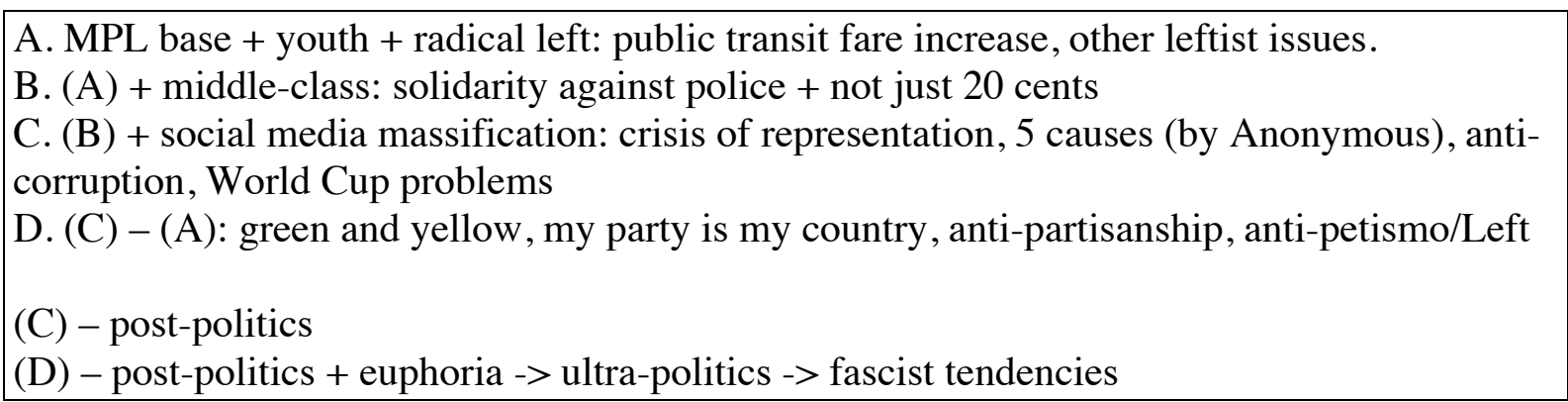

This fragmented and interruptive process of politicization and depoliticization in June requires us to really consider it in terms of "crowds." The concept, employed by Jodi Dean and explained in detail in Chapter 4 with respect to politicization, helps to rescue the heterogeneity of June 2013 without assuming the existence of ready and complete political subjects. For now, it points to the presence of a series of crowd moments. The importance of considering a multiplicity of crowds and crowd moments in June lies in escaping the tendency found in the literature and in the left organizations to try to define June 2013 as one way or another, or to simply label it as all diverse and confusing. These are definite characteristics of June as a political event, or as a "political school for a new generation of workers, with potentially far reaching consequences" (Saad-Filho \& Morais, 2014, p. 242). To focus on labels and defining characteristics, however, is insufficient if we also need to identify the voices of June and how they were instrumentalized or enhanced during and after that period, and by what 
actors. To talk in terms of crowds is to admit that June 2013 was competitive and both the left and the right, in their various expressions, were in dispute to capture and (de)politicize it for their own projects. This diversity in crowd moments, especially the depoliticized aspects, indicate how June brought more than a simple crisis of representation to our attention. The initial view of June as some sort of 'Brazilian spring' energized the radical left, but not only were the organizations unable to deliver, their forms of representation and content (the extension of anti-petismo into anti-leftism) were ultimately rejected and replaced with postpolitics. This is the difference between a rejection of representatives and a rejection of politics as a whole. Since politics, in its larger, Gramscian sense, ought to be the domain of the left, it is no surprise that the right benefitted from the post-political development of June. The moralist focus on corruption is an example of this phenomenon, as it was instrumentalized in a patriotic and anti-left way (Chapter 4). The eventual hegemony of the middle-class in the protests attests to this, since having "no clear understanding of its predicament, [...] it has projected its discontent on to the state and the political system ('corruption', 'inefficiency') and - guess what - the threat posed by inflation to its standard of living" (Saad-Filho \& Morais, 2014, p. 240). The understanding of a crisis of praxis is fundamental for the left to engage in selfcriticism and in finding ways to politicize the crowd again. This crowd is not only (A) or (B), but also (C), which part of the left foolishly rejected due to rigid working class definitions and watched it move further into (D) after the 2014 federal elections.

The June protests revealed the crisis of representation of Brazilian politics, and its particular relevance to the left lies in how this crisis is symptomatic of a larger problem. The fluid and divergent interests that often lead to contradictions between ideological positions, intellectual functions, active and passive representation and the development and evolution of 
leftist actors in relation to the state and the proletarianized people indicates that there is a problem of left praxis related to the dynamics of mobilizing and organizing with a radical (and revolutionary) purpose in Brazil. Also problematic is the way some practices by leftist actors have become largely imbued in neoliberalism and moved these actors and the popular perception of left ideology closer to the right. While this is highlighted by the centrist and compromising tone of the protests, which was manifested "numerically, culturally and ideologically" (Singer, 2014, p. 37), the presence of the right should not be dismissed. A fragmented left is more vulnerable to the effects of hegemonic renewal, which, in Brazil, has been expressed in June and in the post-June period through state violence, depoliticization through appeals to order and patriotic morality, and the active criminalization of political and social movement activity.

The confused state of the left regarding democracy, social change, and revolutionary politics in Brazil opens the discussion for a crisis of praxis. By a crisis of praxis I mean not only a state of misalignment in the activities and projects of political parties, social movements, and the broader social groups but also a disconnect in terms of their goals, organizing, planning, and ideological positions that lead to a plethora of similar but at times antagonistic visions about social justice and alternatives to capitalism (particularly in its neoliberal expression) rather than a collective praxis. As a crisis of praxis, it goes beyond a problem of political representation, since it embodies the breakdown of dialogue within the left as well as its failure to reach out and effectively organize over and above the margins in a truly counter-hegemonic fashion.

In a crisis of praxis, the contradictions in consciousness and practice leave the exploited groups in a state of "moral and political passivity" (Gramsci, 2000, p. 333). My interpretation 
of passivity in this context goes beyond fatalism and inability to act, foreseeable consequences of processes of creation of consent and an uncritical position under hegemonic power. Passivity also consists of a refusal to act in a revolutionary manner by insisting on the primacy and truthful status of one's practical consciousness, dominated by commodified reality and the logic of capital, to the detriment of theoretical orientations (though it is important to heed the warning that the primacy of theory as pure truth also leads to passivity for neglecting the material basis of the struggle.) Not only does this result from a reified state, but its undialectical perception of reality contributes to the perpetuation of the reification of their own consciousness by rejecting the role of theory as an intervener. According to Lukács, "the reified mind necessarily sees [the commodity] as the form in which its own authentic immediacy becomes manifest and - as reified consciousness - does not even attempt to transcend it" (Lukács, 1971, p. 93). This is cause not only for a democratically ingrained process of depoliticization, but also for the great surprise and enthusiasm in the face of what situations will be interpreted as an "Event” (in Badiou's or in Žižek's version of it) and what ruptures in activity patterns arise.

It is important to understand this fragmentation in terms of praxis because a divided left (and a left in conflict with other proletarianized actors) faces obstacles grounded in the separation of theory from practice, of vision from process. Practices within the left that search for guidance solely on the basis of active experience neglect the actuality of reification and alienation by presupposing a pure and autonomous (class) consciousness. While they may produce damage to the status quo in the form of contestation, or even the push for pluralism and more access in a political society grounded in exclusion, they alone do not build the collective will necessary to cause a rupture in the totality. For Gramsci, real democracy (in its 
transitional stage into communism) is equivalent to a real (revolutionary) collective will, which manifests itself as the opposite of passivity (Gramsci, 2000, p. 382). A revolutionary collective will has a two-dimensional dialectical character. First, it is partly already present in society, "has already been recognized and has to some extent asserted itself in action" (Gramsci, 2000, p. 240). Second, it is "directed towards a given political objective" (Coutinho, 2009, p. 35; Gramsci, 2000, p. 239). One element comes into fruition through the practical activity of people, the second follows the theoretical movement inspired by an utopia. Dialectically they interact in a complex process to be made concrete in a praxis which is both "operative awareness of historical necessity, [and] protagonist of a real and effective historical drama" (Gramsci, 2000, p. 241).

The crisis of praxis of the Brazilian left evolves out of the same processes it continues to feed. The next chapters will provide evidence that, primarily, this crisis of praxis consists of the breakdown of dialogue between theory and action and a mismatch of the conceptions of theory and action across diverse groups has resulted in the failure to concretely articulate a collective will to revolution. At times, this appears as the lack of self-criticism characteristic of a concern for electoral results and membership; at times, it resonates of self-proclamatory claims of being the one revolutionary organization despite of practical and affinity distance from the people. Another issue, as introduced by the discussion on democratic fetishism and the focus on process and methodology instead of content and politicization, is the way the need to move beyond vanguardist notions of leadership has been supplied with a fetishistic approach to horizontality and the rejection of leadership. While the political parties, social movements, unions and collectives interviewed for this project do not embrace "horizontalism" as an ideology, fieldwork revealed that horizontality has been a pressing concern, especially since 
2013, which may at times displace conversations and priorities in the organizations (especially whenever the youth is concerned). These differences lead to fragmentation, which is acknowledged by members of the radical left, although the reaction to this fragmentation varies from accepting to efforts of building dialogue or at least facilitating limited collaboration for specific projects and electoral objectives.

\section{Thinking June 2013}

While a continuous report of the events of June 2013 and an overview of the role of leftist organizations (Chapter 3 and Appendix A) can be found later in this study, for now it is important to consider how the view of June 2013 as a paradigm shift played with the imaginary and the praxis of the Brazilian left. Since June 2013 in Brazil, there have been attempts to characterize the period of mass street mobilizations and protests as an "event", whether as this specific category or simply by referring to this meaning as a way to define what happened then. These attempts belong to academia, political organizations, the media, as well as to the imaginary of leftist militants. Most notably employed by Slavoj Žižek and Alain Badiou, the concept of the Event appeals to the idea of a rupture that changes the way something is understood. Despite being a rupture, an Event does not signify the direct change or transformation in the totality of reality, but "the creation of new possibilities [...] not merely at the level of objective possibilities but at the level of the possibility of possibilities" (Badiou, 2010, pp. 242-243). If it were not for the subjectivzing implications Badiou attributes to the Event, it would be clear and appropriate to think of June (and any other moment of political rupture) as an "Event." The main problem of such a category, as Daniel Bensaïd argues, is that truth is second to the Event and its subjects, so that "the truth of the event is that of its participants" and "henceforth pertains to the realm of declarations" (Bensaïd, 2004). As 
Bensaïd continues to explain the issues with the relationship among Event, truth, and subject in the political realm, it is more and more evident how our main concern ought to be not whether June was an Event, despite the agitative value of it, but how the focus on an Event may over-value the elements of June that were subsumed into post-politics, to the detriment of more substantial, politicized, left praxis:

... the subject is primarily its own legislator. Consequently, there is no truth more active than that of a politics which erupts like a pure instance of free decision when the order of things breaks down and when, refusing the apparent necessity of that order, we boldly venture forth into a hitherto unsuspected realm of possibility. Politics as such comes about, then, on the basis of its separation from the state, which is the very opposite and negation of the event, the petrified form of anti-politics; politics proceeds via a 'brutal distancing of the state' (Bensaïd, 2004).

In fact, the diversity of crowd moments in June and the exposure of mass depoliticization that took place demonstrate that although June did open up a set of new possibilities, the Event's collective subject and its "commitment [...] to a new universal emancipatory subject” (Žižek, 2014, p. 180) was fragmented and even subordinated to the postpolitical, non-committed crowd. The reason I bring in the Event as part of the discussion of June 2013, is that even though I am inclined to reject it as a concept, the notion of the Event has had an impact in the way the radical left sees June and how it insists on defining it. While my position is that I see no "Event" as such, simply because I see no analytical, theoretical, and practical sense in subjecting June to the absolute sovereignty of the state of being an Event or a non-Event, the attempts by the radical left to imbue June with its own subjectivity and agency reveal a certain willingness to mould and accept the truth of June (whichever answers to the cries for a new political conjuncture) in a way that is instrumental to adapting to politics post-June and to appealing to the general melancholia felt by the left due to its historical losses and errors, which I shall explore in-depth in Chapter 6. It also reveals a tendency to see the 
fragmented crowds and the depoliticized turn at the most massive expressions through a moralist opposition to corruption, conservative nationalism (as ufanismo), and anti-party sentiment as essentially positive expressions because they were elemental to the rupture of June and contributed to the recognition that there was and these is a crisis of representation. The problem is that somehow, for many, it has been possible to separate these expressions from those that involved anti-leftism, outright reactionary calls all the way to physical threats and aggressions and the calls for impeachment and coups by drawing a line between a crisis of representativity and right-wing co-optation and manipulation. This line is an attempt to characterize June as inherently progressive, with a few exceptions, and to miss the point that the importance of June for the left and its organizations was not whether it was inherently progressive in content, conservative, or too diluted to tell; rather, the progressive element lied in the combination of how mass protests altered the imaginary of the crowds and the left by setting off a fresh era of crowd mobilization (massive or not), and subsequently those from the crowds who became organized in the left, and simultaneously exposed a myriad of problems related not only to representativity but also to political consciousness and leftist organization that until then were blamed on the Workers' Party or specificities of the political conjuncture. Depoliticization, although recognized, was not directly addressed by the radical left as one of the core elements for instigating a revolutionary process for the moment (but certainly later, "when it was time"). The result was this artificial line between the politicized and the depoliticized aspects of June that was built because it was important for the left for June to be a positive political rupture whose desire for change could, then or eventually, gain a leftist meaning and respond to the left's own melancholia. 
I tend to disagree with the view of June 2013 as a rupture that introduced a new politics and propose instead that it was a rupture from the inertia of the politics promoted and accepted as petrified representative democracy until then, but which did not introduce the answer to the crisis and neither broke free from the process of depoliticization that is still on-going. It is known that there were major shifts in the common sense; however, the way the crowds embraced negation and the "anti" without carrying forward into the construction of more representativity and direct participation in politics emphasized more the necessity of the "new" as in new political shapes and formats than the politicization and content necessary for advancing from rupture/revolt to systematic change. June's event effect is therefore related to a shift in mobilization in a movement towards politicization, rather than a political rupture consisting in a movement from street politics towards more mobilization. This difference outlines why the post-June 2013 period has led to spikes in mobilization but its political content has been itself fragmented and is to be disputed among the radical left, the moderate left and the right, whose sequestering of post-political outcry in June translated successfully into their project to oust president Dilma Rousseff and the Workers' Party through a parliamentary coup.

This, of course, was at the level of the crowds, and not at the level of the political organizations of the radical left and the birth of new organizations out of the new militants that, while were not necessarily focused on politicization as an answer, understood it somewhat through the search for political intervention and alternative ways of doing politics. At this level, June 2013 was a tear in the veil that prevented the last radical left organizations from viewing and promoting themselves as more than alternatives to the failed project of the Workers' Party, but as organizations that could no longer operate fragmented among themselves as well as internally fragmented. It also demonstrated to the radical left sector that mass ascension was 
in the horizon again, although a fetish with street mobilizations and crowds would lead some actors to believe that new vanguards in construction since 2013 were indeed excerpts of the masses. While indicative that such vanguards, such as the high school students occupying their schools or the street cleaners that fought their own opportunist union leaders in Rio de Janeiro, may continue growing, ${ }^{10}$ the key factor remains that the majority of the masses remain in a state of depoliticization that requires a much stronger fix than those groups who were already exposed to leftist influence (and organized left actors) during their moments of political struggle.

A crisis of praxis is inevitably connected to the crisis of representation highlighted in June 2013. As horizontality became the answer to this issue at the time (in post-political fashion), both in leftist spaces and in the growth of anarchist currents (between 2013 and 2014), the criticism of the inability to successfully devise a collective will oriented towards a common horizon ends up reduced to the denouncing of leadership and organizational structure in left political organizations - in fact, any diagonal term between the masses and the power that resides in the state (Bosteels, 2005, p. 762). This fragmentation is evident in the organized and in the autonomous actors of the left, though even more clearly in the frictions between the left and the proletarianized around representation, leadership, and dialogue. The investigation into the practice and political positions of these actors in relation to the state of political consciousness in Brazil that takes place in this project helps to elucidate some of the sources of fragmentation and the potential for building a collectivity that recognizes its antagonistic

\footnotetext{
${ }^{10}$ As they have: school and university occupations in Brazil have reinvigorated the left and taught lessons of dialogue and resistance amidst fragmentation since June 2013.
} 
position and forwards social and political change beyond the boundaries of ideal communicative processes of participation.

The crisis of praxis speaks to the conflict created by the left's failure to unify the theoretical and practical consciousness of not only the proletarianized but also the militants and leaders whose organizing functions consist of building political consciousness. In a crisis such as this there is a problem of collectivity: the absence of it. Most of all, there is the absence of left collectivity. Jane Wills argues that the rehabilitation of the left, which I interpret as an issue primarily of praxis, is dependent on more than the ability to represent struggles as left struggles, since new 'multitude' kinds of agency in the networks of anti-capitalism and antiglobalization take place outside the left's version of politicization (Wills, 2006, p. 909).

What is necessary is a challenging process of organization and re-organization. Instead of contributing to the revolutionary process by "establishing and maintaining a continuity of oppositional struggle" (Dean, 2012, p. 234), the protests absorbed antagonistic feelings in a spectacle of voices performed outside of continuous organizing work. Even basic organizing work is impaired by the weak solidaristic relationships and the ability to unify the proletarianized behind their antagonistic position in relation to capitalism (while building their awareness of it through class consciousness) is undermined.

One of the consequences of this crisis of praxis is the progress of anti-party sentiment in various clusters of society. Although this issue crosses ideological camps, it affects the left much more dramatically, since the right is able to capitalize on it through post-politics as well as the sense of urgency in choosing sides in ultra-politics marked by a rejection of the PT and 
anything leftist. ${ }^{11}$ Clearly, passive representation is the norm, as evidenced by a survey of protesters showing that only $4 \%$ of the surveyed were affiliated with a political party, and only $11 \%$ felt represented by a political party $(\mathrm{G} 1,2013)$. Even though leftist parties such as PSOL conducted quite successful membership affiliation campaigns after 2013, the carryover of the crisis of representation into 2015 and 2016 demonstrates that parties are no more than legendas (labels) for most of the population and tend to be perceived as credible organizing structures by militants instead.

The historical process of depoliticization of the masses, where political participation has been reduced to a romantic version of democracy after the military dictatorship, pushed protesters to reject the political space as tainted. For not fulfilling the prophecy of a purist version of democracy, quite utopian given its oblivion to the inequalities reproduced by capital, the political system was criticized and finally rejected. The fear of co-optation of their autonomous and popular mobilizations transformed into the assumption that if an organization does not represent the people it does not need to be re-claimed, but it can be discarded altogether. Anti-party politics mutated into anti-political politics embodied in moralist claims against corruption, and at the same time for order, utopian democracy, and good political morals illustrated by the image of the righteous peaceful protester with no ulterior motives (especially no party militant motives!) The accentuated fear of the Evil of corruption led into anti-party action and even the aggression against party militants, with the PT as a main target following the mensalão corruption scandal that is kept fresh in the minds of the people by the

\footnotetext{
${ }^{11}$ The violence instigated against people dressed in red (in fact, anything red) seen in 2013 and more strongly in 2016 is evidence of it.
} 
mainstream media. ${ }^{12}$ In some circumstances, even the existence of multiple political parties in Brazil's pluriparty system was also questioned, which some conservative groups took further by arguing in favour of re-establishing military power in Brazil to restore "order" (Sakamoto, 2013). While a long shot in 2013, after the 2014 elections and the hold by the right-wing opposition of the anti-Dilma, pro-impeachment protests, calls for military intervention became common, partly as a factor in the Right's anxiety, partly due to bourgeois media influence and the remaining presence of military institutions in daily life such as the military police (PM).

The broad character of the demands put forward in the 2013 protests and the use of ufanismo as a unifying tool removed the revolutionary character from the mobilization by erasing class differences under the mantle of the Brazilian flag (Chapter 4). This process developed into post-politics, wherein ideology and classical left and right position are rejected in favour of a wide-enough umbrella that replaces antagonistic demands with technocratic and moralist ones. ${ }^{13}$ Those identified as too politically radical were either shunned as misguided and immature or as individuals blindly manipulated by the radical left, again bringing to light the cynical rejection of party politics and notion of being a political agent. This crisis threatens not only the stability and continuity of mass popular outcry in Brazil, in particular the construction of poder popular, but also its content as the people's own fear of co-optation, characterized by the view that politicians aim to take advantage of popular effort for their own gain, steers them towards the depoliticization of the mobilizations that, in fact, may facilitate efforts by the hegemonic groups to appropriate the popular discourse and re-shape it to prevent

\footnotetext{
${ }^{12}$ For an overview of the mensalão see Wainwright, H. and Branford, S. (2006) In the Eye of the Storm: left-wing Activists Discuss the Political Crisis in Brazil. Amsterdam: Transnational Institute (TNI).

${ }^{13}$ Post-politics will be explored in-depth in Chapter IV, while also the subject of Fernandes and Paulson (forthcoming).
} 
real damage to the status quo. This is indeed the case for the "green and yellow" protests that ensued after 2014, partly directly enabled by the right, partly a dissatisfied crowd posteriorly appropriated by the right.

\section{Between fragmentation and dialogue}

Axes of representation shift according to one's position and objectives. From a Gramscian perspective, this calls for dialectical alliances between organizations, particularly between the Political Party and the Social Movement. ${ }^{14}$ The perspective adopted in this dissertation is that social movements and political parties in Brazil should ally more than on the basis of topical demonstrations and particular demands, but organically in order for one to feed the other.

Figura 1. Strategic left praxis of parties and social movements

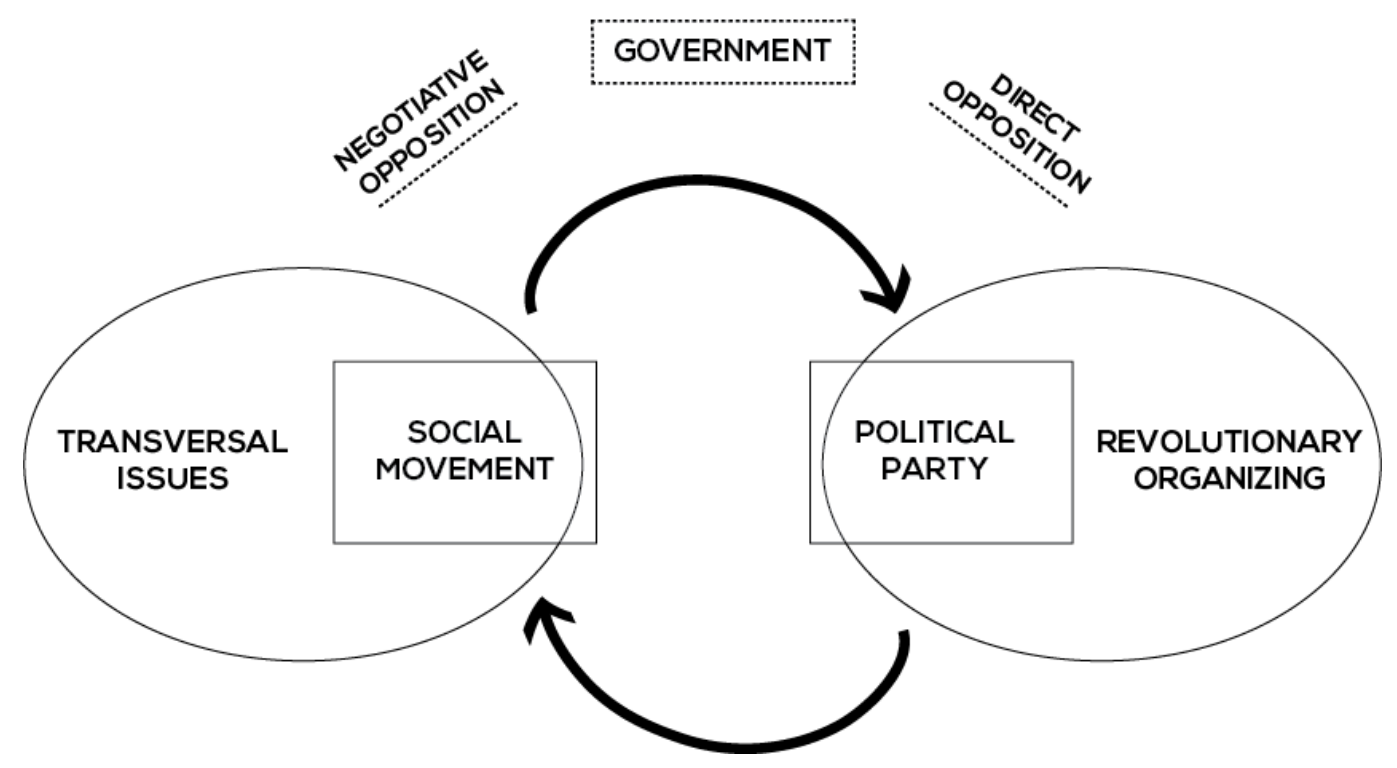

${ }^{14}$ In other countries, it might be useful to also consider the Labour Union. I choose to focus on the Party and the Social Movement because unionism in Brazil, even new unionism, has repeatedly succumbed to syndicalism and the prioritization of the employment apparatus since democratization, to the detriment of the political consciousness of its membership. Rather, I favour a stance of unions as popular movements. 
Parties, unions, and social movements are at a crossroads when it comes to forging alliances, as the substance of these alliances, and their corresponding sustainability, depends on the theoretical foundations for pursuing one course of action or another in reference to the communist question. More so, they depend on the affinity of their popular base, as the continuous attempts to form alliances from the top can amount at most to topical meetings and demonstrations. Furthermore, this question pertains to whether the left has been able to articulate a question at all that goes beyond purist disputes over reform or revolution. Focus on procedure and immediacy suppresses theoretical insights that mediate action and vision; in fact, this focus may suppress the construction of a vision altogether. A minimum level of cooperation, which gives a weak albeit useful appearance of unity in the left, is dependent on keeping questions of self-vision and self-proclamation away from questions of theory and practice. This is most important to the radical left, which tries to define itself and separate itself from the Workers' Party and the governistas (referring to the PT government base) while keeping relevant to the people in a coherent manner. Left melancholia in Brazil relates to what Walter Benjamin argues is the betrayal of revolutionary ideals, as seen in Jodi Dean's exegesis of Benjamin's positions, contrasted with Wendy Brown's contributions (Dean, 2012, pp. 157174), while my own reflection of melancholia in the radical left will add to the analysis of the left's present difficulties in making sense of the impact of the PT's trasformismo and how to respond to it (e.g. opposition to the PT, a third way out, or more extreme/sectarian positioning).

Although the larger protests of 2013 in June and July in Brazil were eventually dominated by a cacophony of demands that reflected little more than surface level criticism a symptom of a strong state of popular depoliticization - the opportunity to re-insert mass struggles into the places of contestation with the State and capital has produced interesting 
opportunities for the left to argue for the need to build politically. The contradictions that arose at the time, even if particularly damaging as in the case of anti-party sentiment, alert the left to the need to organize beyond its regular support base towards the class/masses, while making contestation a major part of the social routine again. The point is to find avenues for reclaiming the political space amidst the blooming of capitalist counterrevolutions facilitated by a crisis of praxis to help to restore a revolutionary praxis. It is often the refusal to recognize these dialectical tensions between the varying visions and practices within the left in relation to political (and even depoliticized) activities of the people that leave the left puzzled, fragmented, and neutralized. Social movements such as the MTST, the Brigadas Populares and youth collectives organizing around saving their public schools have invested in these avenues, while the political parties of the radical left are still struggling somewhat to strike a balance between popular actions, leadership, and electoral/institutional performance - although their support for grassroots actions is coherent and continuous. It is consensus in the radical left that to build poder popular (popular power) ought to be a priority. The challenge lies in eliciting another consensus: what poder popular really entails and how it can be fostered.

The transformation from crisis to revolutionary praxis entails enmeshing the revolutionary into the everyday activities and debates of the radical left, rather than accidentally reaping revolutionary benefits out of sites of struggle focused on reform. David Harvey remarks that an anti-capitalist struggle "ultimately reach[es] deep into the very guts of what a capitalist system is about and wrench[es] out the cancerous tumour of class relations in production" (Harvey, 2012, p. 121). In a crisis of praxis, the struggle may be the consequence of capitalist and other expressions of oppression, but its configuration against hegemony tends to be absorbed into particular struggles focused on the "anti" (anti-capitalist, anti-oppression, 
anti-racism, anti-conservatism, etc). While there is talk of revolution, building a revolutionary process, and even of utopia, these are employed more as rhethorical tools rather than points for deepened discussions across the radical left. In fact, whenever these themes arise in spaces of potential dialogue, the debate tends to be diverted towards the particular and the methodological conflicts between and within organizations. The challenge, therefore, is both practical and theoretical, as methodological conflicts, for instance, can only be resolved if theory is allowed to intervene and if practice is understood beyond particular experiences.

The remainder of this dissertation is dedicated to exploring the challenges of depoliticization and fragmentation in the Brazilian left post-June 2013 in light of the understanding of left praxis presented thus far. The hypoteheses raised in this study are concerned with: the Workers' Party debacle and the left melancholia associated with it and the past century; June 2013 and the variations in the still low level of class consciousness in Brazilian society; the centrality of corruption in people's consciousness, alongside matters of elections and government; the separation between theory and practice, and other issues that plague the left such as predatory and competitive behaviours; and finally, depoliticization, left fragmentation, opportunism and vanguardism. All of these matters are understood according to the theoretical framework of praxis set out in this chapter, as well as analysed through the lenses of post-politics and ultra-politics.

The research questions are:

1. What is the cause of Left fragmentation in Brazil and how does it relate to the phenomenon of a crisis of praxis? 
2. How is the radical left positioned in relation to post-politics and ultra-politics in Brazil?

The hypotheses are:

1. The Brazilian left is fragmented and efforts for unity have failed in principle or in practice so far.

2. Left fragmentation is both a cause and a symptom of a crisis of praxis. Primary causes relate to issues of theory and practice that do not appeal to the people, difficulties in internal organizing such as due to a general left melancholia associated with the difficulty in deciphering the myth and fate of the PT, and lack of development on the construction of the agreed upon poder popular.

3. Post-politics and ultra-politics are both causes and symptoms of depoliticization. The left, however, has had difficulty in dealing with them, especially because of lack of consensus and internal predatory competition.

4. The majority of the working class still do not feel represented by the radical left and an appealing discourse is yet to mobilized to reach the majority. 


\section{Chapter II: The moderate left}

The two years of fieldwork (2014-2016) that preceded this dissertation yielded an indepth look into the various organizations of the Brazilian left. The significant number of publications on what I refer to as the moderate left provided immense insight into the organizations presented here. These publications were complemented through participantobservation and the collection of ethnographic materials during and/or concerning leftist activities. This chapter and the following make up an attempt at providing an overview of what organizations exist in the Brazilian left with the intention of locating their practical and theoretical points of departure in relation to the problems of depoliticization and fragmentation that concern this dissertation. To do so, I work with a framework of a left split in two, which does not prevent the addition of nuances of when one of these lefts behaves too much like the other or the right. The point is to highlight that the challenges of fragmentation faced by the Brazilian left in general are related to a fundamental divide between a dying left - one that has given into compromise and the status quo - and a new left whose own configuration and undefined understanding of what is dying prevents it from being born with the impact and reach that are desirable.

This chapter is concerned with the moderate left, which is dying from reformism and complacency, but manages to remain alive and stands in the way of the new precisely because of methods steeped in reformism and complacency. While the Workers' Party (PT) is the core representative of the moderate left, it does not act alone and its breadth of influence (and base) depends on its relationship to other parties (relatively leftist or not) and its allied social movements and labour unions. There is extensive research published in Brazil and 
internationally on the organizations I place in the moderate left, especially those closely examined in this chapter: the Workers' Party (PT), the Communist Party of Brazil (PCdoB), the Landless Workers' Movement (MST) and the Unified Workers' Central (CUT) (G. R. De Almeida, 2007; Antunes, 2006, 2013; Branford \& Rocha, 2001; Publications, 2010; SaadFilho, 2013; Saad-Filho \& Boito, 2015; Safatle, 2012; Santana, 2012; Singer, 2010; SluyterBeltrão, 2010). Therefore, the accounts of these organizations here are intended to support their placement of the moderate left, whereas more detailed information about their histories and span of influence can be found in the literature in general.

Jeffery R. Webber and Barry Carr argue that recent developments in the Latin American left can be analysed as belonging to a radical left or to an esquerda permitida (authorized left) (Webber \& Carr, 2013, p. 5). As a dichotomy, it oversimplifies the field of contestations where parties, social movements, and civil society groups interact with each other and with the right and the capitalist structure. As a theoretical continuum, though, it provides a useful practical framework for understanding these contestations and how the presence or lack of dialogue in the left, especially regarding those groups that stand in disagreement over theory (utopia, strategy, planning, explaining) and practice (experience, solidarity, antagonism, discontent, class consciousness and identity), can create or resolve a crisis of praxis. I prefer to use this framework rather than other distinctions common to the literature on the complexity of expression on the left, such as socialist versus social democrat, because it better conveys some of the characteristics that help to distinguish the Latin American left from the activities of the left in North America and Europe and because it speaks directly to the ambiguity of the PT as a party that claims socialist roots but practices neoliberal social democracy. The notion of the esquerda permitida is important in this context because it involves the inherited 
influence of colonization and imperialism in the way a moderate left responds to capitalist interests from abroad - since the economic reality in Latin America is often a "foreign bourgeois reality" (Fanon, 2004, p. 122). Therefore, it is also possible to refer to an esquerda permitida as a moderate left, whose moderation is framed through compromise and subordination to the interests of the national and international elite.

The radical left stands in opposition to capitalism and is engaged in the struggle against it through the exploited and the oppressed, while the moderate left operates under the rules of neoliberalism and often divides and co-opts radical groups to neutralize their activities (Webber \& Carr, 2013, p. 5). Both radical and moderate groups exist within the left in a country or region at the same time; however, it is the strength gained through capitalist alliances that normally guarantees that the less radical groups dominate over the more radical ones. In Brazil, the pluriparty system and the pluralism of social movements lead to a wide distribution of organizations among the moderate and radical left spectrums. The administration of the Workers' Party (PT) at the federal level from 2003 up to the impeachment crisis in 2016 is mostly identified in academic circles as centre-left and quite amiable to the neoliberal agenda in spite of its social democratic/socialist roots. The criticism from other non-ally leftist parties and from major social movements is congruent with this perspective and promotes the interpretation of a transformation of the PT towards reform and capitalist interests, which indicates how the PT can be at the same time the most prominent leftist organization in Brazil and an ally of the elites in its character as esquerda permitida (Antunes, 2013; Katz, 2013; Lecio Morais \& Saad-Filho, 2005; Webber \& Carr, 2013, p. 6). In fact, a few years into president Lula's mandate, a schism inside of the PT composed of a political group of socialist militants and intellectuals led to the creation of the Party of Socialism and Freedom (PSOL), 
which would add to the radical side of the leftist political parties and join the likes of the Unified Socialist Workers' Party (PSTU) and the Brazilian Communist Party $(\mathrm{PCB})^{15}$ in opposing the neoliberal advances of the PT from a leftist position of criticism. Other parties normally identified in the radical left are the Workers' Cause Party (PCO) and the Revolutionary Communist Party (PCR), although the former has tended towards a petista/governista position that defends moderate positions for the sake of the social policy gains achieved during the PT governments. The following sections will explore the role of the Workers' Party in changing the perception of the left in Brazil, the negative impacts of this change, and how its breadth of influence, accompanied by other actors from the moderate left, continues to monopolize leftist spaces of struggle in detriment of alternative voices, which are targets for co-optation to secure the moderate left project.

\section{The Workers' Party (PT)}

Looking at the political party scene, the general indignation with the path taken by the PT in the last two decades even leads some to argue for its exclusion as a representative of anything leftist. This is often the case when radical left militants have to "defend themselves" from associations with the PT, and the negative consequences of anti-petismo, by explaining that the "PT isn't really leftist anymore." Whether or not it is authentic and can be categorized as leftist, the PT is still the biggest representative in size and influence of the left in Brazil and continues to be recognized as such by the population for better or for worse. The leftist label is currently negotiated by the PT in its favour or away from it depending on the agenda of the day, but the roots of the party are undoubtedly leftist and of diverse content ranging from those

${ }^{15}$ The PSTU also formed out of a schism within the PT, albeit during the early 1990s. 
interested in a democratic left and those engaged in building a communist revolutionary programme. The PT was born in 1980 out of the necessity of labour unionists and other political organizations for a new political tool that was both national and mass-based, especially after the abolition of the bipartisan system that had prevailed during the military regime (Martinez, 2007, pp. 245-246). With the democratization process lying in the horizon, the left that had operated clandestinely, abroad, or through permitted organizations such as the Catholic church was in search of a way of formally unifying struggles beyond the years of resistance under the dictatorship. Its foundation congregated most of the existing left in Brazil until that point, with the exception of mainly the Brazilian Communist Party (PCB), the Communist Party of Brazil, and the Marxist-Leninist guerrilla group Revolutionary Movement $8^{\text {th }}$ October (MR-8). The Workers' Party was idealized to bring unionists and political actors together and its social base was made up mostly of industrial workers, workers from the transportation and banking sectors, landless workers, teachers and other public sector employees (Martinez, 2007, p. 246). As part of a project of many, including those from organized groups, the PT was established as a political party with internal tendencies, which competed and collaborated with each other to determine the direction and actions of the party as a common political instrument. While the Brazilian left was already fragmented in terms of multiple organizations in the 1980 s, this fragmentation was subordinated to the notion a unifying political tool through the creation of the PT. The right to tendency in the party, which was formalized in 1986 amidst a push by the leadership for limiting the scope and actions of each tendency (Ricci, 2015), attested to the continuous fragmentation of having many organizations and distinct projects inside a general one, but also indicates that this often competing diversity was secondary to a general unifying experience under a political party that 
was to be constructed mutually. This consideration is important to draw out the differences between numeric fragmentation and fragmentation as lack of dialogue, expedient collaboration only, and ever more schisms as is the case of the left today to be examined throughout this dissertation.

During its first decade, the PT operated openly as opposition to the organizations and institutions within the establishment, which Paulo Henrique Martinez argues changed officially after the party's first congress in 1991 (Martinez, 2007, p. 258). Although previous programmes and statements associated with the PT had indicated a project connected to the institutional sectors, the congress marked the point when the dispute for institutional power became directly entrenched in the strategic horizon of the party. Ever since, organizations within and outside of the PT and its support base have put efforts into understanding the process of trasformismo of the PT and what this means for the left. Today, "the PT is a centre-left party that bets on a path of public policies, small concessions - that which André [Singer] calls weak reformism - a very moderate politics trying not to disturb wealth" (Braga, 2015). The perception of the PT and the role it continues to play as a leader of the moderate left and a hegemonic organization of the Brazilian left impacts all other leftist organizations. While this will be explored carefully with respect to the phenomenon of melancholia in the Brazilian left, for now it is sufficient to point out that although a re-radicalization of the PT is not totally impossible, especially as there are both more and less progressive groups within the party, the central dilemmas revolve around how the seizure of state power in Brazil by a self-identified left party has not resulted in a radical break with capital and elite-based class alliances. If anything, it negatively affected political consciousness by openly demonstrating how social 
movements and social rights demands are also ignored by left parties when they do not fit their moderate agenda. ${ }^{16}$

Not even the constant threats and eventual impeachment of Dilma Rousseff and the growth in anti-petismo were enough to move the party a bit more to the left; in fact, Rousseff often opted for more regressive action whenever she felt her mandate was at risk (e.g. signing the anti-terrorism bill that criminalizes social movements). Further, the mensalão corruption scandal that moved through PT ranks in 2005, although not uncommon in Brazilian politics independently of ideological position, as well as more recent scandals, had a demoralizing effect in the left. Even though the PT was targeted selectively by the bourgeois media and the right, the impact of these scandals was ample and it penetrated people's consciousness beyond a moral appeal to corruption by suggesting that leftist political parties do not provide any real alternatives if even they are susceptible to greed and elite backroom deals (Sánchez et al., 2008, p. 62). The Lava Jato investigation and its selective focus on PT members, in particular Lula, is an example. Yet, the PT cannot be dismissed by its critics, nor can any actors of the moderate left, because the moderate left has been the official face of the left in Brazil for decades, despite the moderation of the PT and its alliances with the capitalist class (greatly represented by agribusiness, construction conglomerates, the financial class, and the resource extraction

\footnotetext{
${ }^{16}$ I am not arguing for complete equivalent continuity between the administration of the PT and the previously-inpower centre-right party PSDB (through president Fernando Henrique Cardoso), since the PT has attempted to counter-balance its neoliberal reforms with expanded social policy (even if some of this social policy may as well favour the capitalist class through investments in human capital) and more open access for some groups such as labour unions (though integrated into the state apparatus to a certain extent). What is of relevance here is how the identification of the PT with the radical left changed shortly after president Lula's inauguration, to the surprise of many social movements that counted on the change in electoral politics to advance some of their main demands (e.g.: the Landless Workers' Movement and agrarian reform).
} 
industry) and parties from the right. The moderate left retains a monopoly of leftist symbology in Brazil, to the dismay of politicization and as a contributor to a crisis of praxis. This ambiguity of the PT has contributed to a crisis of representation for the leftist groups and even ordinary citizens who, albeit identified as moderate and/or less politically active, look to the left for social democratic alternatives and improvements related to protections against racism, sexism, and homophobia, as well as access to education and healthcare, security, and affordable public transportation - the culprit of June 2013's explosive show of social discontent through protests, occupations, and civil disobedience brought up in the previous chapter.

Opposition by radical left parties and social movements to the PT government is organized around its bureaucratic hold of the state apparatus, coupled with the party's position in the left spectrum as a hollow shell that had once been filled with class struggle. When first established, the PT had all the relevant traits of a party of the working class as well as strong connections to new unionism. ${ }^{17}$ Marxist and revolutionary ideals were present, even if not at the frontlines. Although it was not a Marxist party in its institution, the focus on class, even on party vanguardism and revolutionary class, and the appeals made to the Marxist scholarship are noted by Marieke Riethof (2004) as constitutive of a radical (sometimes even quasirevolutionary!) basis of the PT in the 1980s and early 1990s. From its inception, the PT was closely connected to labour struggles, social movements, and the opposition to the military dictatorship (Miranda, 2015). It soon constructed itself as the main opposition to the Brazilian right and the context of democratization post-dictatorship in which the PT was created also associated the party with the struggle for democratic rights and a politics connected to the

${ }^{17}$ For a discussion of the history of unionism in Brazil see Antunes, 2013. 
people and their voices. The massive popular opposition to corrupt president Fernando Collor de Mello, who was ultimately impeached, was led and mobilized by the PT in conjunction with other political entities (Duquette, Galdino, Levy, Marques-Pereira, \& Raes, 2005, p. 180). The PT's 1998 national program also called for radical reforms to reconstruct a socialist perspective in Brazil. The question is whether the appeals to socialism actually corresponded to a revolutionary project in the PT's political praxis, or if they were made in a rhetorical fashion to energize the struggle around what was actually closer to moderate social democratic ideals. The ease with which a radical program was dropped after attaining the presidential office suggests the latter, although it does not negate the important work of organizing the left around radical issues undertook by PT and its militants at the local level in the past.

\section{Trasformismo: the establishment of the moderate left}

Trasformismo is a term employed by Antonio Gramsci to refer to a displacement of revolutionary demands during a passive revolution that involves undermining class protagonism through the co-optation of its leaders (Coutinho, 2012, p. 161; Gramsci, 2000, pp. 249-250; Hesketh \& Morton, 2014, p. 150). Ricardo Antunes argues that after taking over the presidential office, the PT went through a trasformismo and became a "party of order" (Antunes, 2013, p. 266). For Antunes, the trasformismo of the PT is related to the expansion of neoliberalism, the defeatist sentiment following "the collapse of the so-called real socialism," and the movement towards social democracy (Ibid.). His last two points are evocative of the reformist tendencies of the left I highlighted earlier in this dissertation, particularly regarding the replacement of revolutionary demands with notions of pluralist democracy in a capitalist system with social policy 'controls.' The process that the PT underwent in its pursuit for institutional power is directly explained by this concept, since the 
party's transition before and, primarily, after Lula's first election was marked by the subjugation of working class interests to the interests of the corporate elite (justified through a developmentalist approach), and the pacification of the working class base through social policy improvements and promises for when a better correlation of forces presented itself. Part of this tactic included the co-optation of social movement and labour union leaders, indicating that the PT's trasformismo is part of a collective transition that led to the grouping of distinct leftist entities under the PT's project in their establishment as a moderate left. Trasformismo is a hegemonic phenomenon, meaning that it consists of undermining revolutionary potential through ways that further entrench the actors in power (such as co-optation) and prevent the class from seeing and seeking alternatives (such as depoliticization and manipulation). Opposition and alternation become difficult or impossible under trasformismo (Forgacs in Gramsci, 2000, p. 430), which is the case of a moderate left that displaces the radical left as opposition by monopolizing the political spaces (through exclusion of the opposition or its absorption - left and right) and making a radical left project less viable in the eyes of the people (and in the norms of the political system, as is the subject of the next section).

Even though the PT is not the only party in Brazil's moderate left (composed of other centre-left political organizations and even the $\mathrm{PCdoB}$, the Communist Party of Brazil ${ }^{18}$, from within the PT government), it is the most well-known protagonist of the Brazilian left. This place of high influence makes its trasformismo possible, since the entrenchment of power through such means necessitates prior "domination" and/or "intellectual and moral leadership" (Gramsci, 2000, p. 249), and alters the balance of possibilities in the left. James Petras argues that the focus on electoral politics is partly to blame for the co-optation of left political parties

${ }^{18}$ Not to be confused with the PCB, the Brazilian Communist Party, in the radical left. 
in Brazil into reformist and moderate organizations that acquiesce to the status quo, especially in the case of the PT (Petras, 2005, p. 123). This tendency reduces political choices to electoral ones that are often expressed in terms of coalitions of convenience, whose quid pro quo basis undermines representation and the original political position of each party. Electoral interests, combined with the process of depoliticization derived from the growing neoliberalization of society, have pushed the PT down a moderate social-democratic path that promotes a "humanization of capitalism" (Chauí in Chauí et al., 2006, p. 53). This process is not particular to the PT's trasformismo, being a common trait of a left willing to compromise principles to maintain itself in power (i.e. Labour in the UK). What makes it interesting in the PT context is how this "humanizing" aspect of capitalism is perceived from the point of view of social reforms and safety nets for the poorest in a way that maintains the co-optations of leaders and the manipulation of consent during the supposed waiting period before more radical improvements. All the while, social rights and labour conditions can continue to be assaulted at large by market interests, including through party-led initiatives as was the Pension Reform headed by Lula in his first year in government. The behaviour of the coordination of the Landless Workers' Movement (MST) and the Unified Workers' Central (CUT) as straightjackets of people's desire to act and protest due to the PT's setbacks and broken promises is justified by the movement and the union based on the already existent social reforms. The fear that an outright conservative government may revoke these benefits is spread as to prevent the people from seeing the many other rights the PT has handed over to the elite.

Of course, the PT's trasformismo cannot be separated from another phenomenon well installed within the Party: lulismo. The concept explored by both André Singer and Rudá Ricci (Ricci, 2013; Singer, 2012), although in different ways, is central to the understanding of how 
the actions and ideology of former president Lula da Silva affected the way the PT does politics, especially at the federal level. While Singer develops the concept by analysing the relationship between leadership and the masses during the Lula eras, and how this enabled Lula to form a conservative pact and consensus, Ricci explores the lulista way of management of the state and, most importantly, securing governability. Ricci traces the origins of lulismo to 1994 and later in its open configuration in the infamous Carta ao Povo Brasileiro (Letter to the Brazilian People) written by Lula in an effort to appease the markets in the event of his election, although one could see some of its elements present in Lula's view of politics from the inception of the PT (Ricci, 2006). Lulismo draws on many characteristics that mark leftwing populism in Latin America, but is more centralized and personal while "seeking its legitimation through technical precision, negotiation, political control and through the seduction by an affective discourse of party leadership" (Ricci, 2006, p. 173- author's translation). The Lula mandates executed every aspect of lulismo by keeping the masses in check or somewhat satisfied through expanded social programmes and increased access to credit and consumption, leading the social movements with strong ties to the PT in a state of control or long wait, and by pleasing the elites through high investment actions (e.g.: the PAC programme) and an economic policy designed to favour the financial market. This perfect balance, which consolidated the PT's take on neoliberalism through populist consensus in Brazil, while possible under Lula, failed under Rousseff. Ricci suggests that this may be due to the uniqueness of Lula's persona and way of management, since none of his possible successors were able to maintain the discursive power and logic of lulismo (Ricci, 2013, p. 114). Another aspect is the favourable economic conditions during the Lula period, which were unsustainable and led to the beginning of an economic crisis during Rousseff's first mandate, 
especially as large economic commitments proved to be unaffordable (e.g. the World Cup) and the government's partner corporations could no longer benefit from the expensive injections of public money into their sectors. The protests of June 2013 gathered not only the people who noticed these big contradictions and wanted change, but were also influenced by the business elite that no longer benefitted from the lulista way of state management and resulted in subsequent displays of anti-petismo. While most of the crowds of June 2013 denounced the crisis of representation that had taken hold of the PT mandate in its reformist actions, the more privileged crowds focused on the PT as a symbol of corruption and improper management of the economy in a way that effectively signalled the end of the smooth pact between the government and the bourgeoisie. Almost 3 years later, while defending the Rousseff government from an impeachment, Lula would still try to appeal to this pact, as he did in his speech during a protest in São Paulo against the impeachment in March 2016, hoping that it could soon be restored in order to pacify the crisis of representation and the anti-petismo that was ever more vocal (Fernandes, 2016).

The PT's trasformismo is not yet complete and current tendencies towards explicitly coercive measures and a right-wing agenda suggest potential for a movement from the authorized left into centre-right shoes. This transition of the PT has strong implications for the radical left and for the left in general, both with respect to the PT's future and to the opportunity to choose between useful self-criticism of the left as a political organization and sidetracking forms of left revisionism. Is it possible that a stronger emphasis on social policy relative to the previous Cardoso-PSDB administrations and the new Temer government may redeem the PT as leftist after all, esquerda permitida nonetheless, despite its alliances with national and international elites rendered in a neoliberal agenda? Can reformist social policy guarantee 
one's place in the left? Or do neoliberal actions make of such policies instruments for legitimization? Furthermore, does the employment of ultra-politics (discussed in Chapter 5) demonstrate the immersion of PT's party work into the state apparatus? Nogueira argues that parties such as the PT, the PSDB, and the PMDB, which were once powerful forces of opposition in the 1970s and 1980s, transitioned into a different kind of political thinking after reaching governmental power that is based on a statist position that submits their party work to the existing State (Chauí \& Nogueira, 2007). The risk of becoming a party of order, and subsequently subordinating oppositional or radical party politics to the hegemonic practice of the State that forces ruling parties to adopt rightist positions to adapt, presents a challenge to the radical left parties if they are to avoid PT's fate of trasformismo.

One cannot detach the trasformismo of the PT from its partnership with the Communist Party of Brazil (PCdoB) and the gradual co-optation of the CUT and the MST by the party and its governments. This is most particular to the Lula mandates, although the two organizations have also remained loyal governistas throughout the Rousseff administrations, even though they have been pushed towards some criticism of Rousseff's smaller efforts at class conciliation, the trademark tactic of lulismo. The pinça (tweezer) strategy of the PT, as it is known, was conceived early in the democratization period and consolidated as the PT achieved more institutional power. The pinça movement is part of a populist perspective on the attainment of power, and despite claims that it could lead to a socialist society without the need for revolutionary struggle, it often results in social democracy or neoliberal leftist experiments - the latter being the most appropriate description for the PT case. The central hypothesis behind this strategy is that change can be attained by "combining the advance over the institutional realm with the creation of poder popular [popular power]" (Guimarães, 1990). 
The pinça strategy was particularly advocated by the Trotskyist tendency of the PT, Democracia Socialista (DS), which conceptualized it as a way of counterbalancing the dangers of the strong institutional growth of the PT in the early 1990s, especially since the "centre of gravity" of a movement should be the combination of popular power and democratization, the latter which would guide the advances in the bourgeois institutions (Karepovs \& Leal, 2007, pp. 215-216). The slow fall of the PT project marks also the failure of the pinça strategy, whose critics argue ended up heavily focused on the institutional side in the detriment of the actual construction of popular power, which was turned into a rhetorical instrument for maintaining base cohesion rather than an active part of the party's horizon (Consolação, 2015; Farias, 2015; Iasi, 2015). The pinça failure also warns the radical left of the risk of trasformismo embedded in the normalization of tactics as strategies.

\section{Party crisis and political reform as maintenance of power}

The crisis of the PT has brought up calls for urgent political reform in Brazil, partly because the system of representation is bent in the direction of the private sector - the same one that funds the electoral campaigns of parties in the Right and in the authorized left. The agenda offers a tactic for the PT to save face under anti-petismo, gain credibility regarding corruption charges and the anti-corruption demands, and to maintain itself in power by strengthening the rules that favour long established political parties such as itself.

The notion of political reform has dominated popular demands for electoral transparency (as a way to make the system 'more democratic') and against the financial and political corruption that has plagued Brazilian politics. Political reform is proposed as a panacea for the problems outlined by the crowds of June 2013 that were concerned with 
corruption as the reason why the political system did not represent the electorate and why public services in Brazil failed in quality and in access. In response to the June protests, president Rousseff proposed a plan for political reform based on a popular plebiscite. The plan did not go farther than her statements, as an ideological debate with leftist and rightist arguments ensued over the choice between a plebiscite and a referendum, although a popular committee connected with the moderate left consulted with the population about how to proceed with the proposal. ${ }^{19}$ Rousseff returned to the proposal after her re-election, especially as a way to address the general discontent with politics (and with the PT) that led to a very close race with Aécio Neves, candidate from the PSDB, and then returned to it again in 2016 during the impeachment crisis. Projects for political reform remain an undercurrent in party politics, legislative debates, and popular thought, although in small increments focused on one small change or another informed by the idea of a "clean" political system with fewer corrupt politicians.

Although a progressive political reform could help to tilt political representation in the favour of the people, especially by reducing the weight of corporate money in political campaigns and by providing more equitable access to debates and television time to small parties, the banner of political reform has been used to eclipse the more important work of politicization and strategic planning in the left, which helps to justify the PT's failures as a problem of imperfections of the liberal democratic political system rather than the party's own choice away from radical politics. Political reform is exactly what it sounds like: a way to address the capitalist influence in government that is reformist and, if pursued to address corruption or a crisis of representation alone, distracts from the deeper ideological and

${ }^{19} \mathrm{http}: / /$ www.plebiscitoconstituinte.org.br (accessed on March 21st, 2014) 
economic practices that tie the right and the authorized left to capitalist interests. PT representatives, including former president Lula, have stated publicly that political reform should outlaw private sector financing of electoral campaigns (Peron, 2013), which is in line with Rousseff's veto to the Congress' attempt to legalize corporate donations. Yet, this position is novel if we considered that the party has become more reliant on corporate donations with time. During the Lula presidential campaigns of 1994 and 1998, the "cohesive national reputation and organization" of the PT managed to garner a considerable percentage of votes despite having less than one-tenth of the campaign funds of the Cardoso campaign (PSDB) (Samuels, 2001, p. 31). However, between 1998 and 2002, the declared contributions to the Lula presidential campaign by the private sector almost tripled (Claessens, Feijen, \& Laeven, 2008, p. 578). In contrast, parties from the radical left such as the PSTU and the PSOL openly refuse to accept corporate campaign donations and rely mostly on fundraisers and membership dues, in addition to actively advocating for political reform..$^{20}$

Rules for campaign financing and political eligibility only go so far, especially since capitalist alliances are also formed after the elections, shaping government spending, policies, and legislative directives. In spite of different patterns and amounts regarding campaigning financing, the nature of the partnerships between the State and the elites during the neoliberal centre-right Cardoso administrations was not radically different from the scenario presented by the PT under both Lula and Dilma Rousseff's tenure.

\footnotetext{
${ }^{20}$ These positions reflect the campaign funding practices of the parties at the national level. Campaign finances are often dictated separately at the state and municipal levels and may result in private partnerships that incur the critique of other parties in the radical left.
} 
It must also be noted that promotion of political reform as the obvious solution to corruption, one of the main motifs of the June 2013 protests (analysed in Chapter 4) and an instrument for fuelling right-wing protests against the PT in 2015, has somewhat backfired due to the different versions of political reform that can be sold to society. The association of the PT with corruption results in support for ambiguous proposals whenever the PT engages with the political reform theme. By failing to address its own trasformismo for its inability to represent the people and promote the radical left politics it once argued for, the PT opts to speak in favour of political reform in order to continue to play the system, which inadvertently adds fire to the right's own version of political reform that would further entrench corporate power in the electoral system and favour candidates from the traditional right-wing party with established paths of influence. The reforms put forward by Eduardo Cunha in 2015 have caused damage so far to small parties of the left, the radical left in particular, since the small parties on the right have managed to attain a certain level of power through expedient coalitions and deals, which has led to their popular identification as "rental parties" (partidos de aluguel). The radical left, on the other hand, must avoid coalitions with even centre parties in order to maintain its own coherence and prospects for base-building. The PT's focus on attaining and securing institutional positions of power has created great flexibility in the party's code for coalitions and alliances through the years, going as far as producing electoral agreements (and synergy) between the PT and the Democrats (DEM), the main right-wing party in Brazil whose policies are based on free-market principles and Christian conservative morals. This is evidence of the lulista practice of looking for allies in the right in order to continue to promote itself in power, even though this tactic has tended towards weaker results for the PT since 2013 and the right-wing mobilization of anti-petismo at all fronts. Whereas before the PT would 
seek support from right-wing candidates to promote their own candidates, a demoralized PT has turned to supporting right-wing candidates in order to reap secondary benefits from electoral alliances. This tactic indicates a desire to hold on to power at all costs, even if it means to support and empower supposed political adversaries, including those that promote antipetismo and led the impeachment process against Rousseff, in order to take their scraps. In reality, the push for a political reform designed to enhance democratic representation gave an opportunity for right-wing actors to push for a reactionary political reform under the excuse that such measures would make the political scenario more efficient and less corrupt. Instead of outlawing corporate campaign donations, for example, the series of bills proposed to legalize and regulate corporate donations. Although president Rousseff vetoed this specific proposal before sanctioning the law package, the practice of reporting donations in bulk, without declaring donors' names, was sanctioned until the Federal Supreme Court ruled it to be unconstitutional. Whereas the prohibition of corporate financing is progress from the standpoint of the demands being made by the people that made political reform part of the Congress' agenda, right-wing parties still managed to produce a reform that secured participation in televised debates and free television campaign insertions to parties based on their number of elected representatives to Congress, with restrictions that affect the parties of the radical left in serious ways, given that only one of them has federal representation and consisting of only six Congress members. This presents a challenge to the radical left, whereas the moderate left will continue to receive exposure and be interpreted as the full composition of the left in Brazil. 


\section{The Communist Party of Brazil}

The Communist Party of Brazil (PCdoB) originated in the early 1960s from a schism of the radical left Brazilian Communist Party (PCB). The schism happened shortly after the original Communist Party of Brazil (also PCB then) adopted the name of Brazilian Communist Party, and those who left decided to adopt the original name in an effort to honour the party roots (Reis, 2007, pp. 450-451). Although both parties claim ownership of the history of the original Communist Party of Brazil (PCB), founded in 1922, it is the gradual turn of the PCdoB from a communist party to social democratic practices, and even dubious bourgeois politics, that currently sets the two parties apart. While documents from the recent era of the PCdoB maintain an allegiance to its Marxist-Leninist roots, I argue, contrary to Daniel Aarão Reis’ overview of the party (Reis, 2007, p. 452), that these documents were designed to please the party base and do not correspond to the practical politics and disregard for Marxist theory that have predominated in the PCdoB since the democratization period in Brazil. Similar claims could be made about the congresses of the PT during this same period, since the establishment of the moderate left depends on maintaining a relationship to leftist roots and discourse as long as there is also a gap between this discourse and the direction of the party to allow to ambiguity, compromise, and negotiations with status quo interests.

The PCdoB has been a long time member of the electoral coalitions that have helped to elect Lula, Rousseff, and other PT representatives at state and local levels. At the time of Lula's first election, the PCdoB was confident that his mandate would produce the social pact necessary to address social change together with economic development, although PCdoB members were wary regarding some of Lula's macroeconomic policies once in power (Pinto \& Sales, 2002, pp. 2-3) (Félix Sánchez, Neto, \& Marques, 2008, p. 49). This concern did not 
prevent the party from maintaining its allegiance through many controversial projects, including by voting in favour of the Pension Reform introduced by the PT government to the detriment of retirees. Renato Rabelo, who was president of the PCdoB at the time, justified the vote based on their commitment to the government and the electoral alliance that supported it (Rabelo, 2003). These moves were often grounded in the idea that the PCdoB was a developmentalist party (Pinto \& Sales, 2002, p. 4), and a neo-developmentalism was already being established as one arm of a two-pronged economic approach by the Lula administration that provided support for continuing neoliberal policies under the guise of "macroeconomic stability" on the other hand (Lécio Morais \& Saad-Filho, 2011, p. 515). The PCdoB maintains a very flexible electoral coalition position and once defended a close relationship with the PMDB, for example, which is the party at the core of conservatism and the impeachment crisis in the Brazilian congress, and has run electoral platforms with openly right-wing parties in the past (Acioli, 2008). The PCdoB has remained aligned with the PT even as other allies left for the opposition (radical left or right-wing) and in the 2015-2016 period, the PCdoB was the only party from the Com a Força do Povo electoral coalition (2014 elections) that remained fully supportive of Rousseff and maintained a position against her impeachment. The party was indeed very engaged in the campaign against the impeachment and helped to mobilize its base on the matter, especially through its youth organization UJS and its influence in the Workers' Central of Brazil (CTB), a central trade union that often sides with the policies and programme defended by the CUT.

\section{Note on the Workers' Cause Party}

The Workers' Cause Party (PCO) is a much smaller party than the PT and the PCdoB and was often characterized by research participants and in the field as an ultra-leftist 
organization that operates in the governista base. The PCO was formed after the PT expelled members from the current Causa Operária in 1991, who directly opposed some alliances made by the PT at the time. Nationally, the PCO prefers to promote its own candidacies, without electoral coalitions, although it participates in coalitions at the local level. It is a Trotskyist party that advocates radical and revolutionary positions, which would ideally place it within the radical left, but practically it has continued to align itself with the general PT programme, even though it can be openly critical of some of the downfalls of the PT's strategy of governability. During interviews and based on observations, the PCO was identified as an auxiliary arm of the PT in many ways, especially at times when the PT comes under attack. This was particularly notable during the impeachment crisis surrounding the mandate of Dilma Rousseff, when the PCO opted for forward defense of Rousseff's actions and policies against the right-wing offense of political maneuvering that resulted in a parliamentary led impeachment process against Rousseff that was full of constitutional irregularities (the impeachment crisis is subject of analysis in Chapters 4 and 5). It is actually the PCO's customary extreme discourse when it comes to the programmatic horizon that leads the general population to believe it should be placed in the radical left, which is more a reflection of the common confused understanding of what the left is (in this case connected to far-left sectarianism) than knowledge of the PCO and its limited political reach. Contending with this, I rather place the PCO as an odd far-left member of the moderate left. It participates together with other actors of the moderate left such as the PT and the PCdoB in the front of parties and movements Frente Brasil Popular, whose main banners revolve around securing basic democratic principles around the Constitution and the fight against the impeachment of president Dilma Rousseff. 


\section{The CUT}

The Unified Workers' Central (CUT) is the largest confederation of trade unions in Brazil and in Latin America and was formed in 1983 during the first CONCLAT (National Congress of the Working Class), just three years after the PT. The term "central" refers to the several confederations of unions in the Brazilian economic scenario, which may be leftist or right-wing. The creation of the CUT was part of the PT project, as the political agents that recognized the need for a mass-based workers' party in Brazil also emphasized the importance of a trade union arm that was not controlled by the state, which was characterized by corporatist practices between government and trade unions since president Getúlio Vargas until the 1980s. Vargas was known for integrating union leaders in governmental ranks in order to run the unions directly. The CUT was conceptualized to escape the norm of this old labour movement by building on community support (Campos, 2015), however, despite still being defined as an autonomous trade union, the continuous bureaucratization of its leadership in relation to the PT federal governments offers a different picture in terms of neo-corporatism (Ladosky, 2014) and the trasformismo of the moderate left. For its first decade, the CUT worked alongside the PT as opposition to the actors in power such as during the fierce attacks by presidents Collor and Cardoso on workers' rights. Once the PT reached the highest level of institutional power, the Lula governments proceeded towards the phagocytosis of the CUT (as a process of ingestion), as labour sociologist Ricardo Antunes puts it (Antunes, 2006, p. 62). It is true that there was always an exchange of militants between the two organizations, and it is not a surprise that many CUT militants were also members of the Workers' Party, especially when considering that the PT was the sole political arm of the masses since the major strikes organized by Lula and his allies in the 1970s. What happened under the Lula governments is 
slightly different because the CUT became entrenched in the PT through more than a shared struggle (Campos, 2015). This entrenchment can be categorized under the lens of the absorption of allies and possible sources of opposition under trasformismo, and helps to characterize the consolidation of the moderate left camp around the PT.

With Lula's election, the CUT became integrated with the federal government for the first time since its creation, having access to debates, decision-making stances, and direct governmental instruments (Carvalho, 2014, p. 42). The intensification of this process began, perhaps, with the trade union reform proposed by Lula, which would establish a hierarchical centralized structure on the unions that undermines the power of local unions and local opposition. The National Labour Forum (FNT) was at the core of this reform, as an institution and place of negotiation between workers and the business class geared towards the formation of a social pact similar to the one proposed by Lula in his infamous Carta ao Povo Brasileiro in 2002. The key change proposed at the FNT and embraced by the directors of the CUT was the power given to the central confederations of trade unions to control labour negotiations over the local unions, including in ways that would allow the central unions to close deals that benefit the employers in disregard of labour laws. This process illustrates not only the phagocytosis of the CUT by the PT governments, but also the phagocytosis of the Lula government by the bourgeois interests right from the start. Gelsom de Almeida argues that this is due to a strong influence of the hegemonic tendencies from inside of the PT and the CUT, Campo Marjoritário and Articulação Sindical, respectively, in the Lula governments (G. R. De Almeida, 2007, p. 57). The 1990s and the early 2000s was a period of transition for the CUT from leftist trade unionism to a more moderate form of unionism rooted in the "European Social democratic model of trade unionism" (Antunes, 2013, p. 263). Instead of being an 
instrument for furthering the interests of the working class and maintaining class consciousness, the CUT was reduced to a bargaining tool designed to mediate the interests of the employer elite and a government in process of neoliberalization. Its leadership was coopted into the PT project as a party of order and absorbed into the government when possible. One might also argue that the CUT underwent its own trasformismo as the most important and largest representative of labour unions on the left in Brazil, which is exemplified in the CUT's willing adhesion to the current model of pension funds that changed a paradigm inside the organization regarding the financial market. In the meantime, the CUT's weak bargaining posture has been criticized by union leaders and members from the base, leading to dissidence and schims. For instance, CUT leadership is known for tentatively accepting deals that are favourable to the employer and lie below the expectations of the workers it represents. This practice led to campaigns for disaffiliation from the CUT - quite notable at the beginning of the second Rousseff administration (Correio do Povo, 2015) - and lower turnouts at protests and demonstrations convened by the central union.

Beyond that, the CUT became concerned with ensuring the self-reproduction of the PT in power, even if it meant depoliticizing certain struggles and utilizing classical instruments of struggle of the working class, such as picketing and strikes, to defend the PT governments against right-wing attacks as well as legitimate critique and dissatisfaction. Together with two of the other largest trade union confederations, Força Sindical (a neoliberal trade union) and the Workers' Central of Brazil (CTB - which also belongs in the moderate left) ${ }^{21}$, the CUT

${ }^{21}$ For an analysis of the different central unions in Brazil, see Antunes, Ricardo. (2013). Trade Unions, Social Conflict, and the Political Left in Present-Day Brazil. In J. R. Webber \& B. Carr (Eds.), The New Latin American Left: cracks in the empire. Lanham: Rowman \& Littlefield Publishers. 
was treated as an ally by the Lula administration given its continuous support for the government despite the number of setbacks to the working class (Boito \& Marcelino, 2011, p. 70). This support continued through Lula's re-election and the two elections of Dilma Rousseff, including during new attacks on the working class put forward by Rousseff and her non-exercise of vetoes of regressive laws passed by the conservative congress elected in 2014 . During the period of unrest before the 2014 World Cup, the CUT tried to steer the working class away from the idea of a general strike and the organization's president, Vagner Freitas, tried to delegitimize the protests against the mega-event by claiming that they were the actions of an opposition and an elitist right-wing who had electoral interests and could not live with the fact that it was Lula who brought the mega-events to Brazil. Governista news outlets such as Brasil 24/7 and Brasil de Fato reinforced the idea of a partnership between the CUT and the Rousseff government with the intent of building support for the World Cup and demobilizing from the protests organized by socialist and anarchist groups (Brasil 24/7, 2014). The PT, the CUT, and the MST were absent from these protests, and according to research participants, went as far as forbidding their members from supporting these protests as individuals (Fernandes, 2014).

Just as the CUT acted to delegimitize popular unrest in order to protect the Rousseff administration from the opposition to the World Cup and its related laws and spending approved by her government, the CUT changed tone when it came to supporting Rousseff throughout her turbulent second mandates. Soon after Rousseff's re-election, the CUT proposed a Program for Job Protection due to the possibility of job losses during the recession to come. The program, which was designed with the government, suggested a reduction of the working week accompanied by a cut of up to $30 \%$ in salaries until the end of 2017 (CUT, 
2015). Even though the CUT officially maintains that it is against austerity measures, the working class was to make 'small' sacrifices during a time of recession. As Rousseff's mandate indicated that a strong austerity agenda was to come, the CUT preferred to focus on the Finance Minister Joaquim Levy as the culprit, which was one of the reasons why the radical left found it difficult to organize alongside the CUT and the governista base. The attempt to split the economic project of Joaquim Levy from Dilma Rousseff, the president who appointed him, was a rhetorical device that allowed the CUT some room for protests, and, simultaneously, limited the impact of any protest or strike, especially the idea of a general strike that had been floating around the radical left. While the PT is deeply entrenched in the politics of its own governments, the CUT more clearly depicts the ambiguity of being a governista organization, since its contradictions prevent it from joining the left opposition camp while it attempts to coopt the radical left towards less efficacious opposition agendas. This was clear not only during the World Cup conflicts but also during the frustrated attempts to form the Front for Popular Reforms (FRP) in early 2015 (mentioned throughout the dissertation but explored in relation to the challenges of building a radical third camp under governista influence in Chapter 6).

\section{The MST}

The Landless Workers' Movement (MST) faces dilemmas similar to the ones presented by the CUT, with the exception that the bureaucratization of the MST has not gone as deep as in the CUT, partly because of the tendency of trade unions to cave into corporatism in Brazil through the management of labour dynamics. This has allowed for relative autonomy at some of the regional bases of the MST despite the often acritical public and official defense of the PT governments by the MST practical and intellectual leadership. The MST was born in 1984, in the sequence of the foundations of the PT and the CUT. The motivation behind the 
movement was to contest one of the highest rates of land concentration in the world and to promote agrarian reform in a way that challenged the prevailing notion of property rights in Brazil (Meszaros, 2000, p. 518). It is by far the most well-known social movement in Latin America and still the largest in Brazil, despite its decline under the PT governments and subsequent loss of ability to mobilize large masses at the national level. Despite growing urbanization, agrarian reform continues to be an important issue for the Brazilian economy and working class. The agribusiness sector dominates both the domestic and export market for agrarian goods and their agents are responsible for environmental damage and violence against indigenous peoples, peasants, and targeted attacks against MST settlements and their militants. Of all the main sectors whose output contributes to Brazil's GDP, agribusiness was the only one to expand between 2014 and 2015, a period of total GDP loss for the country (IBGE, 2016).

Like the CUT, the mobilizations of the MST were fundamental for building support for each of Lula's elections, Rousseff's first election (in the second round), and at least appealing to unity for defeating Aécio Neves when he was virtually tied with Rousseff in 2014. Despite the dismal record of Rousseff's administration when it came to land expropriation and agrarian reform talks, the bureaucratization of the MST and the connections of its highest levels of leadership to the government weaned down the movement's ability to act as opposition to the neoliberal turn of PT governments. Not even when Rousseff appointed Kátia Abreu, a known representative for agribusiness, for the Ministry of Agriculture did the MST protest beyond making a few latifundio occupations. This track record has led social movement scholars to argue that the MST failed to fulfill its role as a social movement connected to popular needs 
and opposed to neoliberalism, since its support for the PT helped to legitimate more than a decade of neoliberal policies under Lula and Rousseff (Prevost, Vanden, \& Campos, 2012).

As argued by Lécio Morais and Alfredo Saad-Filho, MST members and cadres have faced more difficulty in accepting that their own needs "should be contained in the name of political and economic 'stability', precisely when - they think - the PT and its allied organisations are finally in a position to implement their historical programme" (Lecio Morais \& Saad-Filho, 2005, p. 18). I suggest that this is because of the smaller degree of bureaucratization at the local level of the movement and the tradition of critical pedagogy and political formation of all members. The element of political formation is perhaps one of the greatest triumphs of the MST as a social movement in Brazil, and although the PT was successful at depoliticizing certain struggles, including agrarian reform, the inherent practice of politicizing the base at least to a minimum level remains. The Homeless Workers' Movement (MTST), which was born out of the MST, values this same practice but has not been able to implement it cohesively across its base. This is related to at least two differences between the movements. First, the MTST faces the challenges posed by the more fluid nature of urban occupations, especially in terms of a fragmented shared reality and the diversity in labour. Meanwhile, in an MST camp the members occupy the land to both live and work in it and therefore more easily self-identify as a particular class, in a city occupation the primary objective is to live in the occupied terrain, since the members work in different places, are exposed to different contradictions, and share less time together. The second problem the MTST faces to politicize the base is exactly the contradiction that allowed the MST more success in terms of maintaining a unified base. The MST has become dependent on certain structures and funding provided by the government in matters related to health, education, 
agrarian development, and even mobilization instruments, while the MTST continues to be a financially autonomous social movement despite the contradictions that have arisen regarding the movement's focus on the federal government's housing programme Minha Casa Minha Vida (MCMV). This difference outlines the kind of pressure each movement is willing to apply to the government.

The idea that the MST had survived the government's attempts to co-opt it was something of a consensus up until the last years of the Lula's eight year tenure as president (Caldeira, 2008, p. 151). The movement managed to maintain a combative stance (although more protective of the PT and Lula during electoral periods) and faced increased repression as a result. Data released by Comissão Pastoral da Terra, a partner movement of MST through Vía Campesina, reports that although land conflicts declined between 2008 and 2009, the number of peasants murdered and tortured increased (CPT, 2009). Their report also shows that the use of violence by public power also increased during the mandate of President Lula (20032010) when there was an increase in the number of families forcefully removed from occupations (CPT, 2015). The problem is that instead of increasing its opposition to the government in face of so many delays and displays of violence, the MST has gradually moved to a more and more lenient position. It joined the CUT and the PT in the boycott of World Cup protests. João Pedro Stédile, who is one of the key speakers and intellectuals for the movement, went as far as calling the protests a "political mistake" and stating that the World Cup was no different from the Brazilian carnaval and that such events should not be politicized (Nuzzi, 2014). He disregarded the protests as a matter of the disorganized "youth," reinforcing the age gap between the MST and the CUT and the generation fighting against the mega-events from June 2013 onwards. 
After 2013, these organizations changed some of their rhetoric to try to appeal to the youth they had dismissed earlier. They did so by opening up towards a more overt criticism of Dilma Rousseff's administration. Because this criticism did not always extend to the PT as whole, and sometimes detached Rousseff's economic policies from the PT entirely, the MST and the CUT continued to be perceived by other leftist organizations and described by research participants as instrumental arms of the Workers' Party. This made it difficult for the organizations to navigate the crisis of representation. While the radical left was hit by antileftism, the deep connections of the MST and the CUT to the PT and to lulismo, together with their perceived arrogance towards the youth that had just begun their militant journey (individual or organized) denied these organizations their claim to the "June spirit." Even in the rare occasions where lulismo was criticised, there was a conscious effort to detach the governability and pact-forming practices of lulismo from the public figure of former president Lula himself. This is quite evident in the subsequent approach of defending the Rousseff government from impeachment attacks from the right-wing sectors, while defending Rousseff and Lula as important figures for the left as if they were separate from their own policies. This contradiction is a sign of the confusing state of governista organizations when trying to defend an indefensible government from a radical Left standpoint. For Fernando Silva (PSOL Insurgência), this points to the divide caused by the June 2013 protests in the traditional Left, since up to before June, a lulista hegemony prevailed and the myth of class conciliation continued to operate in the minds of the masses (Silva, 2015). This same level of political cognitive dissonance, which is nothing more than the rhetorical devices used to hide and justify their contradictions, has plagued the movement since 2015 in their efforts to protect Dilma Rousseff from an impeachment. Even so, it is notable how the numbers the MST used to be 
able to summon have dropped considerably. In 1997, the MST alone took 100 thousand protesters to Brasília against the Cardoso government, whereas the demonstrations organized jointly by the MST, the CUT, the PT, the Communist Party of Brazil (PCdoB) and the National Union of Students (UNE) have normally gathered up to 50 thousand people only in São Paulo. The exception to this would be the rally of March $18^{\text {th }} 2016$, which was initially scheduled by these organizations in defense of Rousseff and Lula, but grew to over 200 thousand because of the repercussions of illegal actions by judge Sérgio Moro from the Lava-Jato corruption investigation the day before (Piza, Paulo, Araújo, \& Domingos, 2016).

The CUT and the MST remain not only a strong presence but a strong leadership whenever Rousseff and Lula have needed defending or promoting. Other organizations continue to maintain strong ties to the PT, such as the Comissão Pastoral da Terra (CPT), the Workers' Central of Brazil (CTB), the Movimento dos Atingidos por Barragens (MAB) and other social movements that are deeply linked to their own single-issue causes, particularly those related to rural and environmental issues. These organizations, together with the UNE, which is mostly controlled by the PCdoB through its youth organization UJS, and dozens of others have joined together under the leadership of the MST and the CUT to create the political alliance Frente Brasil Popular (FBP - Popular Brazil Front) whose main goals revolve around preserving democracy - interpreted as opposition to the impeachment of Dilma Rousseff - and efforts towards a new economic politics by her government. The front gathers the key organizations of the moderate left whereas the radical left meets around two other fronts of collective action. There are other organizations that maintain a relationship to the PT and operate within the boundaries of the moderate left but do not contribute to the FBP, such as the Conselho Indigenista Missionário (CIMI), linked to indigenous struggles, and the Frente 
Nacional de Luta (FNL), a dissident of the MST that maintains a lulista position but interacts widely with other organizations from the left and the centre-right as it promotes the banner of agrarian reform.

The impeachment crisis made the split between the lefts in Brazil more evident to the eyes of the general population, especially due to the open defense of Rousseff and her policies by the moderate left in contrast to the radical left's negotiation between opposing the impeachment and its right-wing manipulation without defending Rousseff or outright proposing alternatives that included ousting Rousseff too. This dilemma exposes how the radical left, unlike the moderate left, is fragmented not only in numbers but also in terms of tactics and strategies, which leads to competing views on how the radical left must position itself in relation to the moderate left and its longstanding monopoly of leftist spaces and the challenges posed by a strengthened right in this conjuncture. The next chapter analyses the key radical left organizations identified in this research pertaining to what sets them apart from the moderate left and the particular challenges they face in the context of fixing the fragmentation and depoliticization that benefitted and were actively pursuit by the moderate left. 


\section{Chapter III: The radical left}

Whereas the moderate left conducts itself according to the norms of the status quo, tempering the advancement of neoliberalism and the entrenchment of structures of oppression alongside capitalism with the promotion of inclusive social policy (often from the standpoint of developmentalist priorities), the radical left is anti-capitalist in its core and conducts itself according to the needs and struggle of the exploited and oppressed peoples, though it is also susceptible to contradictions. When drawing this distinction, Webber and Carr write:

[The radical left] envisions a transition toward democratic social coordination of the economy and the construction of a development model in which human needs are prioritized above the needs of capital. The radical left fights for communal ownership of economic and natural resources. It pushes for worker and community control of workplaces and neighborhoods. The radical left sees liberal capitalist democracy as a limited expression of popular sovereignty and seeks instead to expand democratic rule through all political, social, economic, and private spheres of life. It is anti-imperialist, seeking the regional liberation of Latin America and the Caribbean and challenging the imperial pretensions of the American empire, as well as those of its emergent rivals active in the region (Webber \& Carr, 2013, pp. 5-6)

In the Brazilian context, the radical left is comprised of a group of actors that is critical of the moderate left project led by the Workers' Party and have stood in opposition to it, to various degrees, since the moderate left established itself as a distinct group with a distinct programme from the general anti-capitalist left. Although this critical position is common to all groups in the radical left, tactics and strategies concerning the PT, moving on from the impacts of its project, and politicizing towards a socialist programme vary, which, in a context of fragmentation, creates tension (even competition) as well as opportunities for collaboration. The Brazilian radical left is made up of parties, social movements, labour unions and collectives and is generally oriented towards socialism and communism. There are autonomist and anarchist groups that may be identified within the radical left, and they do exert a strong 
level of influence in the conjuncture from a leftist perspective, from time to time, such as the Free Pass Movement (MPL) in São Paulo. Because this dissertation is concerned with the organized anti-capitalist left in general, which tends to be structured around parties, movements, unions and other arrangements that follow a non-autonomist route, organizations such as the MPL are not extensively examined in this study.

The political conjuncture in which the actions of the radical left are situated since 2013 also puts it in direct confrontation with the right. Not that this was not the case before, the difference being that the advancement of right-wing discourse as more than simple common sense but as an actual project impacts the terrain of politics in comparison to the liberal centreright/centre-left dichotomy to which the radical left responded from its inception. Before, the radical left had to make general opposition to the moderate left project, steeped in liberalism, and the centre-right project of the PSDB, also liberal, while managing to stand apart as these two versions of a liberal project attacked each other. Now, the ultra-political nature of conflict (Chapter 5) leads the radical left to face attacks from the morally conservative right and its free market project, which goes beyond the liberal dynamic, and to have to respond to the threat of a reactionary project, even if such a project is still tied to centre-right liberalism.

This creates its own particular challenges in terms of securing the existence of the radical left. The PT continues to homogenize leftist space and working with the radical left only when it hopes to instrumentalize it for the upkeep of the moderate left project. Meanwhile, the right is determined to bar both moderate and radical left discourse and spaces of influence from existence and, unlike the liberal centre-right that focuses on the mainstream left as its opponent, the conservative, fundamentalist, and fascist right acknowledges the radical left as its own threat to the status quo for not being co-optable as the moderate left. This dynamic 
helps to locate the radical left in the political scenario in Brazil, because it proposes itself to be an alternative to a wide array of projects, both right-wing and the liberal versions in the left and the right, and is therefore under attack by all sides. It must also be noted that the current problem of confronting a right that goes beyond centre-right liberalism is a result of the unresolved false dichotomy of liberalism itself, represented by the PT x PSDB dualism. This requires the radical left to see the conservative right, in its own distinct capacity and attacks, as intrinsically connected to the centre-right liberal project. This is different from the PT's approach of separating the fascist right from the liberal right in order to continue to flirt with the latter in the name of governability and the maintenance of its project that legitimizes neoliberalism through social policy. Slavoj Žižek elucidates this point the following way:

The difference between liberalism and the radical left is that, although they refer to the same three elements (liberal center, populist Right, radical Left), they locate them in a radically different topology: for the liberal center, the radical left and the Right are two forms of the same "totalitarian" excess; while for the left, the only true alternative is the one between itself and the liberal mainstream, the populist "radical" Right being nothing but the symptom of liberalism's inability to deal with the leftist threat. (Žižek, 2009, p. 75)

In other words, the different versions of liberalism experienced in Brazil in the last 30 years (be it centre-right or centre-left) cannot permanently renew themselves if a radical left is present and may potentially grow as an alternative to the liberal model. This creates fertile ground for the proposal of a right-wing project that could deal with the threat of the radical left, but only as much as the elimination of this threat could save liberalism. The PT has held on to such a hope, so that both the conservative right and the radical left may be perceived as problematic extremes that only its moderate, conciliatory, liberal left project can address. In the meantime, the advancement of conservative right-wing politics in common sense (worsening depoliticization) and institutional politics (worsening social crises and removing 
space from alternative projects) demands immediate attention and resistance from the radical left at a time of continuous fragmentation.

Given this context, this chapter focuses on the radical left, which is also the focus of this dissertation as a whole. This is the case because the dominance of the moderate left in Brazilian politics has led it to be more studied than the radical left organizations, which are often approached as less significant because of their size. However, since this dissertation is concerned with leftist praxis, the radical left must be at the core of the analysis precisely because of the role it still plays (and could play more prominently) in restoring leftist praxis in the face of a moderate left that has abandoned it. The challenges faced by the radical left in terms of fragmentation are profound, especially because the organizations are constantly confronted with their internal conflicts in relation to the existence of the moderate left and the difficulties in approaching the Workers' Party through a collective and cohesive synthesis. These challenges are evident in the chapters on fragmentation, while the advances and setbacks of the radical left in relation to a process of re-politicization of society are examined in relation to its potential, considering that the moderate left is important to the analysis as far as it is significantly responsible for current depoliticization. The purpose of this section is to provide a direct characterization of the key organizations, movements, and collectives I have identified in the Brazilian radical left. This characterization is based on my ethnographic observations during the research period, on the interviews with representatives and members of these groups, and on secondary sources when necessary. This level of intense and hands-on research with the radical left was necessary because not a lot of work has been done on it as a cohesive group of organizations standing in opposition to the moderate left political project, despite the many internal problems, whereas the moderate left has been heavily researched, providing the 
material for the previous chapter. The majority of the information presented and analysed in this dissertation was gathered through participant-observation at leftist activities and general collection of ethnographic material through informal conversations with radical left militants, examination of intellectual production in leftist outlets, organizational material, and a visual ethnography of joint action by these organizations. In addition, I conducted extensive interviews with 34 militants from the radical left in order to confirm, question, or instigate discussion on matters of interest to the research questions and hypotheses proposed in this study. This chapter is a first presentation of the organizations I categorize as belonging to the radical left, which is necessary to understand the various implications between their relationship with the moderate left and their opposition to the right when examining depoliticization and fragmentation in Brazil. Because the radical left is more fragmented and is made up of numerous organizations, it helps to approach them through their categories of social and political incidence, such as political parties, social movements, and labour unions.

In the context of high fragmentation in the Brazilian left, and considering that the radical left also fosters local forms of political organizing that would result in numerous groups and entities, the organizations considered here, and then throughout the dissertation, do not make up the radical left in its entirety. Instead, I chose to present the organizations that represent the radical left as a whole and the nuances, conflicts, and possibilities that characterize this leftist camp. To do so, I present organizations in terms of their main politics, their relationships, and their distinctive characteristics as radical left. This knowledge helps to shed light on the problem of fragmentation and helps to give context to the analyses on both depoliticization and fragmentation that will follow in the next four chapters. I am confident that my choice of organizations, informed by an examination of the influence of the practical 
activity and reach of the programme of each organization, as well as interview material, reflects the most relevant actors in the radical left today.

\section{Political parties}

The PT is the most prominent organization of the moderate left and represented the left as a whole before its trasformismo and associated schisms led us to think of two distinct lefts in the moderate-radical spectrum. With the exception of the Brazilian Communist Party, which existed outside of the PT and before the PT's inception, the two other key parties of the radical left, the Unified Socialist Workers' Party (PSTU) and the Party of Socialism and Freedom (PSOL), spun off the PT through expulsions and deep disagreements. I identify these three parties as key representatives of the Brazilian radical left with national influence ${ }^{22}$ based on my own study of their activities, and on the study of Brazilian party history by Marcelo Ridenti (Ridenti, 2013) and Pablo Moura (Moura, 2011). Although the three parties are united in their opposition to the right and to the PT's ambiguous and moderate political project, their interpretations of political reality differ in many ways and affect their discourse about the PT and the opportunities for these parties to join together in direct action, in strategic alliances, and in the task of politicizing and building a radical left base. In the spirit of this chapter, the following presentations of the parties, and the radical left as a whole, is informed according to sociological interest defined by the matters of depoliticization and fragmentation to be

\footnotetext{
${ }^{22}$ There is a fourth party in the radical left, the Revolutionary Communist Party (PCR) which is in the process of collecting signatures to become a legal party for electoral disputes as Popular Unity for Socialism (UP), but its reach is limited when compared to the PSOL, PSTU, and $\mathrm{PCB}$, especially if considering influence and militant presence at the national level. The PCR is mentioned later in terms of its alliances within the radical left, but it is not perceived by myself nor by the research participants as a powerful player whose programme can impact the directions of the radical left yet.
} 
explored in the remainder of this dissertation, and it is not intended to examine the structure and political programmes of each organization in detail. ${ }^{23}$

In general, the PSTU is self-described as a party made of the labour, student, and popular movements, whose priorities lie in the transformation of society rather than electoral gains (PSTU, n.d.). The PSOL argues for "socialism with democracy" with the strategic goal of overcoming capitalism (PSOL, n.d.). Its program suggests that it gives more focus to elections than the PSTU, although it emphasizes the employment of elections as an avenue for politicization. Pablo Moura suggests that the difference in perspective about elections between the PSOL, the PSTU, and the PCB is related to a more principista (principled focused) view of institutional party tactics by the two latter parties (Moura, 2011, p. 99). The communist focus of the PCB is demonstrated in the more overt revolutionary language it employs, in contrast to the PSOL and the PSTU. In its strategic plan, the party speaks of the formation of a proletarian revolutionary bloc, in the Gramscian sense of historic blocs, a clear rupture of the capitalist system, and the struggle for the hegemony of socialist and communist ideas based on popular movements (PCB, n.d.).

The PSTU and the PCB do not accept corporate donations, while the PSOL has opted to ban donations from banks, multinational corporations, and construction corporations, although some of its internal tendencies may have more restrictions. ${ }^{24}$ The limited financial resources of the parties are split into political party work (organizing, mobilizing and

\footnotetext{
${ }^{23}$ An interesting reference for those looking for a detailed outlook of the programmes and particular histories of the PSOL, PSTU, and the PCB, from a more Political Science perspective, is the Master's Thesis by Pablo Moura (Moura, 2011), which is an occasional source of reference for complementary information in this chapter.

${ }^{24}$ This has changed since the last political reform (2015) outlawing business donations of any kind to political party campaigns.
} 
politicizing) and efforts dedicated to campaigning and pursuing electoral victories. Party work involves building alliances, reaching out to the people around particular issues, and expanding their membership and support base, which also involves politicizing efforts through basebuilding and intellectual production. Their electoral strategies tend to be targeted and consist mostly of pursuing legislative seats and executive positions at the municipal or state levels.

These three parties had both similar and different behaviours in June 2013, which varied according to the particular conjuncture of each city that was host to mass mobilizations. Belo Horizonte was where these parties were more embraced, as the organized left had been involved in its own processes regarding public transit months earlier and was also less fragmented in terms of the organization of protests and assemblies. This was partly due to the already strong influence of Belo Horizonte's own popular committee for the World Cup (COPAC) in both the traditional left and autonomist sectors. Belo Horizonte already had a history of successful mobilizations about right to the city struggles (e.g.: Fora Lacerda), which had facilitated a certain level of dialogue, even though topical, that resulted in more organic calls to organize in 2013, especially with the Horizontal Popular Assembly (APH) that was created together with autonomist and anarchist groups (Ricci \& Arley, 2014, pp. 159-160). The importance of this level of congruence is that it prevented June 2013 from leading into as high of a state of cacophony in Belo Horizonte as was seen in other cities, particularly regarding the transition from Não me representa chants to the rejection, expulsion, and even aggression towards leftist militants of both the moderate and the radical left from the demonstrations. Another radical left party to be present and contribute to the processes at the time was the PCR, which is connected to the struggle for housing in Belo Horizonte and builds 
the housing rights movement Movimento de Luta nos Bairros, Vilas e Favelas (MLB), primarily in Minas Gerais.

São Paulo is perceived as the eye of the storm during June 2013, and the predominance of autonomist, horizontalist, and even some anarchist practices in the beginning of the process may have favoured the gradual takeover by depolicitized, and ultimately, conservative postpolitical voices that focused on mottos such as "My party is my country" or "We are the social network" and, by doing so, delegitimized the organized Left whose demands matched the original demands of the jornadas de junho. Even the Free Pass Movement (MPL), which stated on a continuous basis its non-partisan stance, had its own representativity questioned and rejected later on. In the meantime, militants of many tendencies of the PSOL continued to engage with the crowd through other tactics, such as the members from the tendency MES who found that people were more receptive when they presented themselves as the youth organization built by MES, Juntos. MES was fresh out of the experience of fighting the fare increases in the city of Porto Alegre, and opted to employ the Juntos tactic already in the early phases of the June protests. The PSTU went in a different direction, and opted to built outside of the main crowds after the growth of the rejection of parties and left-wing organizations, by issuing calls for strikes and a demonstration led by the labour unions, which had little attendance beyond the organizing parties and their members. 
Figura 2 Porto Alegre inspiration by Juntos in São Paulo

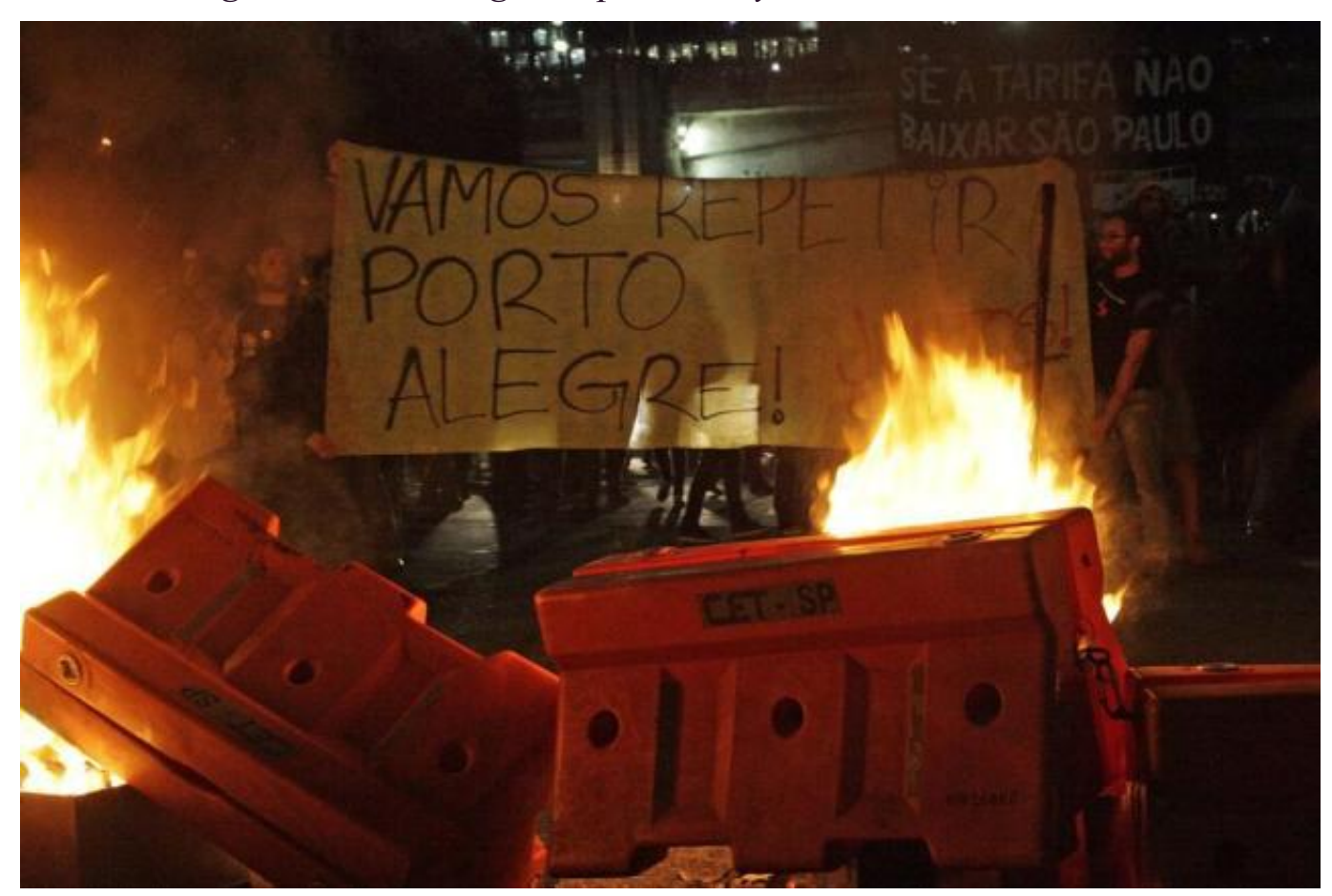

Photo: Gabriela Biló / Futura Press

The Brazilian capital offered a June scenario that was more similar to São Paulo than Belo Horizonte, although there was far less aggressive anti-party and anti-left rejection in Brasília. The process exploded through solidarity against police violence and collective indignation and had one of its brightest moments on June $17^{\text {th }}$, when protesters occupied the roof of the National Congress. Although the majority of protesters were non-partisan, some left organizations managed to reaffirm their presence at the protests, such as some tendencies from the PSOL. The Free Pass Movement did not have a large base in Brasília (as its counterpart did in São Paulo), and the protests had a much more prominent "Not just 20 cents" tone from the beginning. Indignation at the World Cup was also present, which members from Brasília's own World Cup Committee tried to emphasize, even though the committee was not as hegemonic in the capital as in Belo Horizonte. What did happen in Brasília that was quite 
similar to Belo Horizonte was the realization of Popular Assemblies, which set off processes that connected popular indignation to the organized left. The PSOL, through some of its internal tendencies, and the Popular World Cup Committee were major actors in this process.

This summary of the radical left parties in June 2013 introduces some of their current positions, which will be analysed in-depth with reference to the full conjuncture, fragmentation and depoliticization. This analyses can only be understood if a useful picture of their political project in relation to the State, and their relationship to social movements and civil society is provided. The overview of the national parties also helps to shed light on their relationship to each other and addresses questions of unity, solidarity, and fragmentation in the radical left.

\section{Party of Socialism and Freedom (PSOL)}

The PSOL is a broad coalition party (partido amplo) much like Syriza in Greece and the PT (at least on paper) in terms of securing a right to tendencies inside the party. The difference in the PT is that, as it transformed into a party of order, the right to tendencies stopped being the equivalent to a right to critique, to disagree, and to oppose the party bureaucracy. The hegemonic forces within the party were made stronger through physiologism, which favours internal relations and power instead of what would benefit the political project, and through state power. This dynamic effectively drowned out the opposing camps and submitted the base to the decisions of the core with the help of increasing bureaucratic approaches to the party-government relationship. This asphyxiation of the ability of the tendencies to dispute the hegemonic program of the party is one of the reasons for the creation of the PSOL, founded after a schism in the early phases of the first Lula mandate and still being consolidated from later schisms from the PT. 
The PSOL was formed after members from the PT refused to support and vote for Lula's controversial Pension Reform in 2003. While some were expelled from the party, others left of their own volition with the intention to form a new party. Although there were conversations with the PSTU at the time, which was formed out of Convergência Socialista, a Trotskyist tendency that had left the PT almost 10 years earlier, they did not go forward. Israel Dutra (PSOL - MES) points out that one of the difficulties the new dissidents found while studying the possibility of forming a joint party with the PSTU was that the latter wanted to do away with the right to tendency (Dutra, 2015; Genro, 2015). The right of tendency was important to maintain the autonomy of each organization that joined the PSOL in what is known as the first wave (2003), that resulted in the party's foundation, and the second wave in 2005. Some of the key organizations in the party were the MES, the CST, the CSOL (which had left the PSTU in 2003), Enlace (a schism of Democracia Socialista, which remained in the PT) and the APS, which joined originally as part of a democratic affiliation agreement and was later allowed full rights as a tendency (Machado, 2015; Varela, 2015). The APS is currently the tendency that coordinates the PSOL as part of the coalition called Unidade Socialista (US). Although the directions of the PSOL are set according to tendency politics and competition for leadership positions, any person can become a member of the PSOL as an independent and even become a public reference for the party, as is the case of Douglas Belchior, whom I interviewed for this study.

The right to tendency in the PSOL make up one of the core principles of the party and its establishment, from the time of the foundation of the PSOL, is connected to the proposal of a "broad party" that can rally up different political forces in a common project. This is different from the formalization of the right to tendency in the PT, which as mentioned in the previous 
chapter, was established in order to limit the influence and autonomy of the internal organizations and subordinate them to the direction of the party. While the direction of the PSOL is indeed hegemonic and has substantial influence regarding party resources, parliamentary operations, electoral matters and the construction of national proposals, the tendencies have a high degree of autonomy. For instance, both the MES and the CST have promoted anti-impeachment campaigns that differed from the general orientation of the party. The PSOL ended up promoting debate on the matter rather than talks of expulsion as was the case of the PT with Convergência Socialista during the campaign for Collor's impeachment in the 1990s. The Trotskyist currents of the PSOL believe the right to tendency is very important to guarantee debate and stances for dialogue in the party and as an important instrument for a fragmented left. In periods of low mass mobilization and high depoliticization, when fragmentation is rampant, it is important to find forums in the left that allow for a common project rather than simply expedient collaboration (as is the case of coalitions and fronts). This makes of the PSOL an important place of convergence for a variety of organizations whose internal disputes ultimately refer to the desire to influence and guide the direction of the party. This, of course, can be also problematic when the dispute over the party becomes more important than the common construction of a programme beyond the confines of the party form. Symptoms of this are very common in the PSOL during party congress periods, but the chance to meet, work out problems, and build internal alliances is still favourable in a context where most of the radical left operates in isolation on a daily basis; that is, whenever bigger campaigns that result in open fronts are not in the agenda.

A few organizations requested to join the PSOL in 2015. One of them is the Marxist Left (Esquerda Marxista - EM), which voted to leave the PT in April 2015 after a process of 
self-critique in relation to the viability of promoting a revolutionary discourse inside a party of order. It is, as of now, the last PT tendency to leave the party. The decision to join the PSOL, however, was less related to a programmatic affinity with the PSOL, given that just a few years before the EM characterized the PSOL and the PSTU as petit-bourgeois parties (Goulart, 2012), and more related to its ability to remain an organized tendency inside a broad coalition party (Dezorzi, 2015). The PSOL, out of the three main radical left parties, is the only party to be organized in this manner, given that the PCB does not offer a right to tendency and that the PSTU conforms to a strong notion of democratic centralism. The EM and the PCB are relatively close in many points and have collaborated on topical activities, such as a committee around the right to public transportation in São Paulo. However, in conversations with members from the EM, I noted that although the organization wishes to maintain a close dialogue with the PCB, its desire to remain a specific organization with its own formulations (including its particular tie to the International Marxist Tendency) made of the PSOL the most obvious course of action for defending their program while organized through a political party. This unique position of the PSOL in the radical left makes it a desirable home for many organizations that are too small to form a party but would like to organize through a political party instrument. They collectively chose to request to join the PSOL, but their request was denied during the PSOL congress in 2015 - although the Bloco de Esquerda (Insurgência, MES, CST, LSR, TLS, $1^{\circ}$ de Maio) had voted unanimously to accept the Esquerda Marxista as a new tendency. Another organization that showed recent interest in joining the PSOL was the LER-QI, now called the MRT, but its request to join was also denied by the party. PSOL members from several tendencies justified the denied request on the basis of general suspicion of entryism on behalf of the MRT, given previous frictions between PSOL members and MRT 
members in different sectors of organizing (Fernandes, 2015). Despite this rejection, the PSOL made the party available for democratic affiliation for MRT members who wanted to run as candidates in the municipal elections of 2016 (Esquerda Diário, 2015), as it did for the EM.

The PSOL first participated in a federal election in 2006 with the candidacy of Heloísa Helena, who was the main public figure for the party at the time, even though she maintained a more moderate political position than the average of the PSOL. Heloísa Helena has since left to join Marina Silva's REDE ${ }^{25}$, but the party no longer depends on a single public figure. Congress representatives such as Chico Alencar and Jean Wyllys have contributed to the growth of the party as did the performance of Luciana Genro as its presidential candidate in 2014. No PSOL presidential candidate has attained Heloísa Helena's 6\% of the votes again, but Genro's performance is praised by party members for helping to differentiate the PSOL from the PT and reaching a portion of the youth that sought politicization after June 2013. Although Genro's tendency MES has promoted their own particular campaign for general elections during Rousseff's impeachment crisis, contrary to the hegemonic position of the PSOL, there is a general view that her electoral contribution in 2014 conveyed the average

${ }^{25}$ The REDE Sustentabilidade is a party idealized by former Brazilian senator and presidential candidate Marina Silva. Silva spent most of her political career in the PT, and migrated to the Green Party (PV) after disagreements with the party over environmental policy and the repercussion of corruption scandals related to the PT. In 2014, she ran as the presidential candidate for the Brazilian Socialist Party (PSB), while she waited for REDE to become legalized as an electoral platform. While some REDE members identify as leftists, including elected representatives, the general platform of the party revolves around the management of capitalism through sustainability, governability, and general social democratic principles. It should be noted that despite carrying a socialist name, the PSB is also known to promote neoliberal politics and has often sided with the right-wing opposition during the PT governments. 
position of all tendencies (Dutra, 2015; Silva, 2015; Varela, 2015), which is an impressive feat considering the level of internal fragmentation and dispute among the tendencies.

The figure below illustrates the PSOL and its internal tendencies, although it excludes less prominent regional tendencies from its composition. Instead, I portray the tendencies with national reach. I interacted with all of these during ethnographic fieldwork, some more than others. Other smaller tendencies that are less mentioned in this study are the Somos PSOL, the APS-Nova Era (recently going through a schism), and the CRS (in the process of joining a new tendency with other smaller collectives and former PSTU members named Nova Organização Socialista - NOS). In addition, there are prominent figures in the party that are often referred to as "the independents", which consist of parliamentary forces that are not associated with any tendency in particular (even if they may associate with one or the other at a time). Here, the federal congressman Jean Wyllys may be noted, as well as state congressman Marcelo Freixo from Rio de Janeiro. Congressman Ivan Valente organizes himself through the tendency Ação Popular Socialista (APS), while fellow congressman Chico Alencar has been supported by the collective Rosa Zumbi in the past. The tendencies are listed below from top to bottom according to their positioning in the party, where the CST represents a more ultra-leftist position and Fortalecer o PSOL represents a more centrist position in the overall political spectrum, thus being more "right-leaning" inside of the party together with the APS. This classification is drawn from ethnographic observations regarding PSOL congresses and conferences as well as commentary from research participants. It is a flexible classification, since the tendencies tend to organize themselves in different blocs and theses from congress to congress, as well as in relation to conjunctural challenges. For instance, the MES has taken on a more ultra-leftist position regarding the impeachment crisis, which will be approached in 
detail in Chapter 5 in the ultra-political context, but promotes enough flexibility for electoral coalitions to consider alliances with centre-right parties such as REDE.

Figura 3 Key PSOL tendencies

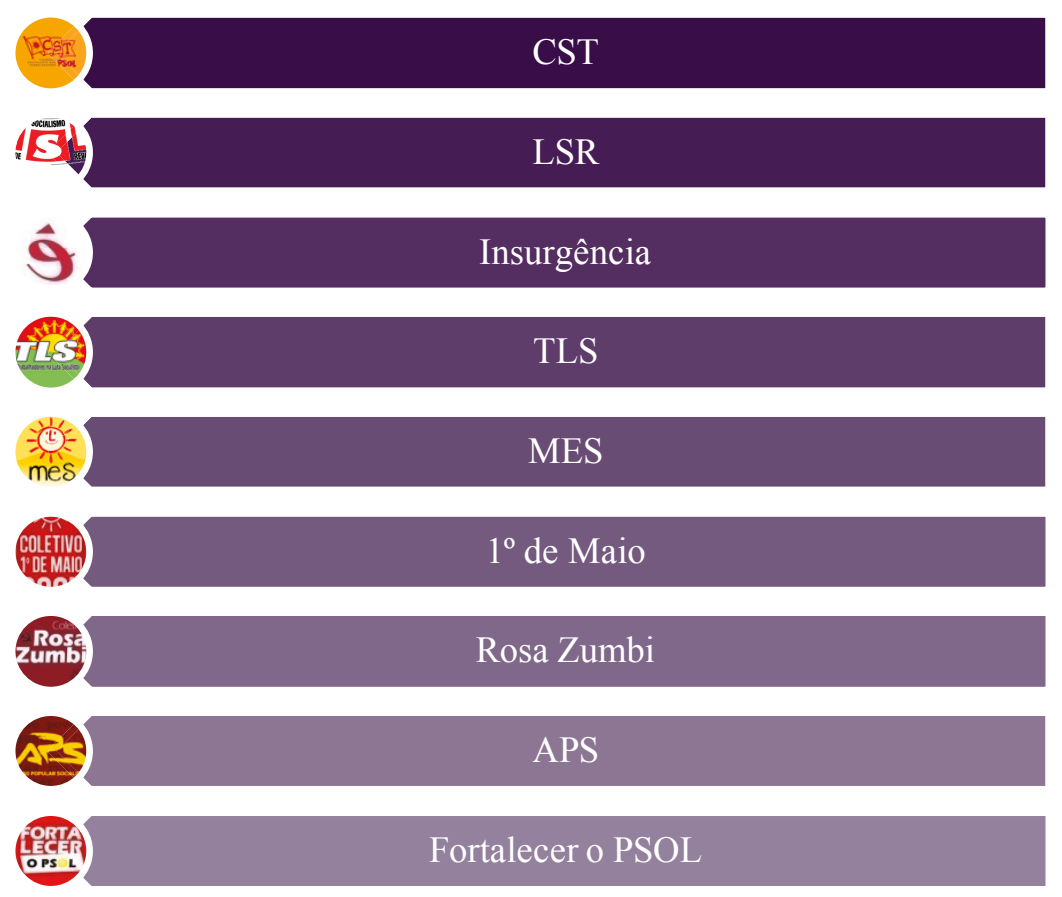

Because of the volatile conjuncture inside of the Brazilian left and in the PSOL, I was unable to get consistent demographic data to assert with precision the size of each tendency. The PSOL congress period of 2015 also indicated that numbers are always in dispute, especially when it comes to the number of delegates. Nonetheless, I have found that the influence of a tendency inside of the PSOL is not necessarily determined by membership numbers alone, and is in fact impacted by whether the tendency holds director seats in the party, the connections between a tendency and social movements and labour unions, the efforts of their youth collectives, their reach into parliamentary structures (either through the representatives or their assistants), the tendency's public figures, and so on. Further, due to the constant controversies around fraudulent numbers during each PSOL congress, a position by a 
tendency in the direction of party may not always correspond to the true number of delegates (a problem one also finds within the PT). From conversations with members from different tendencies inside of the PSOL, I gathered that there is still strong suspicion regarding the numbers that led to the victory of the internal coalition Unidade Socialista (US), of which the APS is the largest tendency, in the PSOL Congress of 2013 and, in a smaller scale, of 2015. The 2013 controversy is mostly related to actions by senator Randolfe Rodrigues and Macapá mayor Clécio Luis, both of whom have left the PSOL and joined Marina Silva's party REDE in 2016.

Although the PSOL and the PSTU compete for some of the same militants - there was a wave of militants from one joining the other and vice-versa post-June 2013 - the parties have different strategies when it comes to base-building and which sectors of the population to target. The PSOL, having had a stronger institutional presence than the other radical left parties, promotes a broader appeal, although not as broad or populist as the PT did in its years of institutional ascension. In contrast to the PT, the PSOL has not dropped the word socialism from its vernacular, overall strategy (or its name), although its internal tendencies diverge on which tactics are more productive and politicizing when talking to the people. Since it is not a party rooted in democratic centralism, the way the PSOL approaches socialism rhetorically and strategically varies according to its leadership from state to state and the reach of each tendency. Its six parliamentary representatives (2016) do not normally speak of socialism either, although their positions in Congress have been mostly consistent with the socialist premise of building poder popular, defending the rights of minorities, promoting anti-capitalist policies, empowering dissent, and rallying the left together. 


\section{$\underline{\text { Key internal tendencies }}$}

Despite the many tendencies inside of the PSOL that I researched for this dissertation, I chose to follow more closely the politics of three key tendencies: the APS, the MES, and Insurgência. My criteria for choosing these currents evolved out of ethnographic research in 2013 and especially in 2014. In my view, these three organizations represent three distinct and influential ideological and programmatic camps within the PSOL. The APS represents the hegemonic view of the PSOL, especially in terms of its parliamentary and institutional approach. The MES has grown in influence since the presidential candidacy of one of its main public personas, Luciana Genro, which led to a political strategy of both internal mediation and tensioning. Insurgência is an organization that I found to position itself as a leftist opposition inside of the party, while being close to youth and social movements. Both the MES and Insurgência are some of the Trotskyist organizations inside of the PSOL, and Insurgência officially makes up a chapter of the Fourth International in Brazil.

\section{APS}

The Ação Popular Socialista (APS) is the main tendency from within the PSOL to make up the national coordination of the party through the coalition it leads, Unidade Socialista (US). The APS originates from another organization named Força Socialista (1989-2004), a former tendency within the PT. The organization left the PT in what is known as the second wave of PT dissidents joining the PSOL and the decision was particularly moved by the involvement of the PT in major corruption scandals (Varela, 2015). While, at first, the presence of the APS inside of the PSOL consisted of democratic affiliation only, the organization's pressure to have full tendency rights was successful and this led to the influence the APS has exerted in the PSOL through leadership and coordination positions in the recent past. The tendency has two 
parliamentary representatives, Edmilson Rodrigues and Ivan Valente, but also work closely with other PSOL representatives through their positions inside the party leadership in Congress.

The APS defends a popular-democratic programme and, from all tendencies within the PSOL, it is one of those with the most focus on institutional power, parliamentary performance, and programmatic defences that fall within the democratic rights and reforms spectrum. This has drawn some criticism from other tendencies, especially during PSOL congresses and conferential periods. Some of it stems from a fear that the PSOL could be geared in the same path as the PT, which Alexandre Varela, a member of the APS and the executive administration of the PSOL in the Federal District, argues is equivocal, for the APS considers the PT project a fiasco for failing to advance the most basic of reforms it had proposed, while the PSOL would be in fact a socialist party (Varela, 2015). Documents from the foundation of the APS in 2004 already stated a disappointment with the PT strategy and its exaggerated focus on electoral politics, even though the APS would remain in the PT for a few more years before joining the PSOL (APS, 2004). Yet, the general perception is that the APS flirts with some elements of the PT project, though repackaged more coherently, and are too open for coordinating with particular actors of the moderate left camp. The latter is not perceived as a problem by Varela, for it would be the others who were in contradiction and not the PSOL (Varela, 2015). My conversations with members from other tendencies in the PSOL revealed that, at times, the concern is less with the possibility that the PSOL may be contaminated by the PT through the APS strategic dealings and more with the fact that the PT will try to use the PSOL to reboot its image, giving it a stronger appearance of credibility, in order to keep the PT's electoral machine well oiled. 
The other main criticism of the APS regards the internal dynamics and conflicts among the various tendencies inside the PSOL, especially concerning the Bloco de Esquerda tendencies and the APS's Unidade Socialista. Complaints over delegate fraud by the US were commonly heard during my ethnographic study with PSOL members from a variety of tendencies. This is particularly the case for the 2013 Congress and the problems related to former PSOL senator and member Randolfe Rodrigues (REDE), and this concern was even echoed by APS members.

In 2012, three different programmatic theses were presented at the APS annual congress and the lack of consensus led to a two-way schism inside the tendency (Varela, 2015). This resulted in another tendency inside of the PSOL called APS-Nova Era. The document issued by the militants that would form the APS-Nova Era expressed concern with the way the directors of the APS had handled prior elections, the Randolfe Rodrigues alliances, in addition to complaints about authoritarian mechanisms and diminished internal democracy (APS, 2012). While the essence of this critique was not much different from the general critique of the APS by other PSOL tendencies and even of the PSOL in its entirety by other leftist organizations (through both predatory and non-predatory means), the core of the APS maintained the majority after the schism, primarily because it wished to priotize the construction of the PSOL, while the dissidence was also related to a desire to prioritize the internal development of the current. The Rosa Zumbi collective was also founded around the same time from members of the third thesis who did not reconcile with the APS nor found common ground with the APS-Nova Era (Varela, 2015). The APS-Nova Era went through its own period of internal dissidence in 2015 , although it maintained its presence as a tendency in the 2015 congress of the PSOL. Both the APS and Rosa Zumbi contribute to the construction 
of the radical left central labour union Intersindical (Central), although part of the members of the APS argue for an intervention in another labour union, CSP-Conlutas. The youth of the APS also constructs a youth collective inside of the PSOL called Juventude Socialismo e Liberdade (JSOL).

\section{MES}

The Movimento Esquerda Socialista (MES) originates from the Convergência Socialista (CS), the same organization whose majority left the PT to ultimately found the PSTU in 1992-1993, and the CST, the organization created by CS members that chose to return to the PT in 1992. The MES retains the same Trotskyist origins of the CS, and although it is no longer connected to Nahuel Moreno's International Workers League - Fourth International (IWLfi), it maintains a general Morenista identity and a central Trotskyist one. Despite the trajectory of the MES inside of the PT, the organization's true protagonism comes to light when it departs the Workers' Party and begins the arduous process of making the PSOL project viable. The parliamentary representatives of the MES inside of the PT were notoriously expelled from the party in the beginning of the first Lula government for refusing to vote for the neoliberal pension reform put forward by the government. According to Israel Dutra, president of the PSOL/Rio Grande do Sul and member of the MES, to leave the party in such circumstances was also a strategy for exposing the contradictions of the majority of the leaders of the party at the time (Dutra, 2015). As a result, the organization proceeded with the efforts for creating a new leftist party that would culminate in the PSOL.

The MES is a tendency that prioritizes the construction of the PSOL as a broad party for the left. In fact, the tendency has suggested parallels between the PSOL and Syriza and promoted the Greek party enthusiastically before the series of setbacks and betrayals post- 
referendum in 2015. Then, Luciana Genro had spoken to me about the Syriza model and how it served as an example of a left that could depart from a process of strengthening alternatives amidst social strife, something she hoped the PSOL could be an instrument for in Brazil (Genro, 2015). Although I had noticed some enthusiasm regarding Syriza by other tendencies of the PSOL, such as Insurgência, the MES was probably the one most focused on tying the experiences of other alternative leftist projects, such as Podemos, and the successes of international broad parties, such as Syriza, to the political experiments of the PSOL.

The historical tradition of the MES and its electoral success, boosted by the strong reach of Genro's presidential campaign in 2014, makes it a valuable actor in the left for connecting with other organizations. The organization's vision is very tied to an idea of the recomposition of the Brazilian left, something they argue is bigger than the MES and should involve an organizational tactic that allows for individual differences and group differences for the time being, given that currently there is no organization in Brazil with sufficient "political authority that is capable of homogenizing from above all this multiplicity of identities, of worldviews," as used to be the case of the PT (Dutra, 2015). This can be observed both in the efforts of the MES directorship in articulating directly with the coordination of other key organizations inside of the PSOL and in the radical left in general, such as the MTST, and its strategic bet on organizing the youth, especially through Juntos, their youth collective founded in 2011. Although Juntos members do not always present themselves publicly as from MES, the tendency normally homogenizes the direction of the collective, albeit with some degree of autonomy, because most of those who construct Juntos also actively construct the MES (Drummond, 2015). Perhaps due to the generally successful intervention of the Juntos in June 2013 in some cities, the MES is known to be "enthusiasts" of the June journeys and promoters 
of a theoretical perspective of that period as an Event. MES opts to intervene in the union conjuncture through the CSP-Conlutas union federation, holding direction power in some states. It also contributes to the housing struggle through the collective Nós da Sul in São Paulo and helps to build the MST in the Northeast of Brazil.

Genro's influential campaign in 2014 also altered some of the internal balance inside of the PSOL. Although the APS, through the US, holds the majority of director seats in the party, the fact that Genro gained a strong audience both inside and outside of the PSOL has given the MES more bargaining power when it comes to party politics and the opportunity to delimitate their own positions publicly. For Dutra, this could go as far as to mean a co-direction of the party by the US and the MES (Dutra, 2015). There is some evidence for this during the 2014-2015 period, but not as much after the PSOL Congress of 2015. One example is the differing positions on Dilma Rousseff's impeachment crisis, when the MES was vocal for an immediate call for general elections, deemed premature by the majority of the PSOL, and ended up aligning itself more closely to the campaigns promoted by the PSTU and the more ultra-left PSOL tendency (the minority schism of their mutual parent tendency) the CST.

\section{Insurgência}

Insurgência is an organization created in 2013 out of the fusion of three previous currents inside of the PSOL: CSOL (national), Enlace (national), and Coletivo Luta Vermelha (CLV - regional Federal District). Each of these currents have their own particular origins and histories. The CSOL, for example, was part of the PSTU before it left to built the PSOL. Enlace had left another large organization inside of the PT called Democracia Socialista (DS), with Trotskyist, Fourth International Roots. The CLV, although limited regionally to the Federal District, was an influential political force in the region due to its direct articulation with social 
movements and popular collectives. Today, Insurgência represents officially the Fourth International (post-reunification), while the MES maintains an observer status in the organization despite its morenista tradition. According to Insurgência coordinator Fernando Silva, the FI vision of leftist organization was a point of convergence between the three organizations and facilitated the progress from a succession of alliances inside and outside of the PSOL into a fusion (Silva, 2015). The vision of internationalism promoted by Trotskyism is well-embedded in the programme and politics of the organization.

Insurgência offers an insight into one of the rare cases of fusions between Trotskyists, since Trotskyism is associated with a long tradition of schisms in both major and smaller scale organizations. This, however, has not come without challenges for the organization and friction has remained among Enlace and CSOL members in some regions, such as in the state of Paraná. After the fusion that created Insurgência in 2013, the youth collectives that corresponded to each of the original currents debated their fusion and creation of a unified youth collective. A national youth camp in early 2014 led to the creation of RUA: Juventude Capitalista, whose format and objectives are similar to those espoused by Juntos, although RUA and Insurgência members affirm that there is a larger degree of autonomy between the youth organization and the PSOL tendency than one finds in the relationship between Juntos and the MES. In fact, Juntos is identified as a "collateral" youth organization due to the direct relationship between the coordination of the tendency and the youth collective, whereas Rua values its autonomy very highly, being also coordinated by independents outside of Insurgência and many members who do not even participate in the PSOL (Drummond, 2015; Nascimento, Constantino, \& Bruner, 2015). Insurgência maintains a close relationship with social movements and youth collectives in the states where it is present. The MTST is one of 
these social movements and I have been able to observe joint work between the MTST and the Insurgência on several occasions in the Federal District and in São Paulo. This articulation happens both at the coordination level as well as through direct support at occupations and joint demonstrations. In 2015, the tendency created a labour union collective, Braços Dados, to increase its union presence, which is relatively small compared to the APS.

Insurgência promotes itself as an ecossocialist organization and this is reflected in many of the campaigns and programmatic choices of the tendency. For instance, in the state of Ceará, Insurgência state congressman Renato Roseno has defended bills related to a ban on aerial agricultural chemical sprays and to the management of water resources (Roseno, 2016). The sum of environmental politics and activism in Insurgência probably makes it the most advanced leftist organization in this theme in Brazil, although the newly formed organization Movimento Raiz Cidadanista ${ }^{26}$ also brings in a strong environmental and anti-capitalist discourse. As for representational presence, the Insurgência is relatively smaller than MES and the APS, although it has promoted some fairly vocal mandates at the state and city levels in Ceará and Rio de Janeiro.

Between the MES and the Insurgência, Insurgência represents the members of the Bloco de Esquerda with most concern over alliances and concessions made by the APS and the direction of the PSOL, especially during electoral periods. While the MES promotes the idea that concessions may be made (and are necessary) as long as they are seen as tactical and not strategic (Dutra, 2015), the Insurgência promotes a more critical vision inside of the PSOL

\footnotetext{
${ }^{26}$ Raiz Cidadanista was born from a schism from REDE and is generally regarded as being to the left of REDE. Its relatively new presence and small size prevent me from placing Raiz Cidadanista in the moderate or radical left, especially since REDE is a centre to centre-right party.
} 
of what kind of alliances can be made and the limits of pragmatism and flexibility. Part of this relates to the challenge faced by the PSOL, more than the PSTU and the PCB, to assert itself in relation to the PT and its electoral project and the fear that flexibility may be interpreted and result in a longer string of concessions and mediations that impair the overall revolutionary programme. Such a concern makes the Insurgência more critical of pragmatic actions put forward by both the APS and the MES, but does not impede the tendency from engaging in dialogue with these tendencies and other leftist organizations. In fact, the Insurgência has been a key actor in many strategic alliances over the last years, both nationally and regionally, which demonstrates how this political apprehension is different from the more vanguardist positions of the PSTU and the PCB, which are less inclined to make any alliances and concessions in order to favour the promotion of their particular programmes.

\section{Unified Socialist Workers' Party (PSTU)}

The PSTU was formed in 1994 by militants from Convergência Socialista (CS) that were expelled from the PT in 1992 (Reis, 2007, p. 453). One of the concrete reasons for their expulsion was the initial campaigns for the impeachment of president Collor at the time that were propelled by members of the CS through CUT posts within their reach or coordination at the time (J. M. de Almeida, 2015). The campaign was not supported by the leadership of the PT at the time and added to other conflicts between the tendency and the party hegemony. It also reflected the general disputes surrounding the PT's right to tendency in a context of growing internal bureaucracy and concentration of power in the hands of the party's leadership. After the expulsion, due to the popular adhesion to the general campaign and the rising opposition against Collor, the Workers' Party ended up joining the campaign as a whole, as did all of the organized left at the time. Despite no longer being in the PT and the formation of 
a new leftist political party, the PSTU continued to build the CUT until the early stages of the Lula government, when it became clear to the party that Lula intended to use the central union as his own political instrument (J. M. de Almeida, 2015). At the time, the PSTU helped to found and build Conlutas, now called CSP-Conlutas, as an alternative to the CUT, which is one of the main instruments for mobilization and politicization employed by the party. The PSTU, as was the CS, consists of a Trotskyist party with a strong tradition connected to the works and leadership of Nahuel Moreno. As such, the party is a member of the International Workers League - Fourth International and connects internationally to other parties that belong to the league.

Despite being older than the PSOL, the PSTU has had smaller parliamentary success in general. Recently, it had two strong mandates with city representatives Cleber Rabelo in Belém-PA and Amanda Gurgel in Natal-RN (who left the PSTU's organic militant core in mid-2016), the latter who received the most votes for a single city representative in Natal's history in 2012. Both of their campaigns were part of an electoral coalition between the PSOL and the PSTU at the local level. At the federal level, it has opted for its own candidacies for president, with party president Zé Maria de Almeida as candidate, with the exception of 1994 and 2006, when the PSTU made up the electoral coalition to support Lula (PT) and Heloísa Helena (PSOL), respectively. The party appeals intensely to a base involved in organized labour, and not only from CSP-Conlutas unions, as well as the student movement and women organized in their workplace and communities. Despite not having a direct collaborative relationship with the MTST, which once belonged to the CSP-Conlutas, the PSTU is involved in housing struggles through the Luta Popular movement, which is more active in São Paulo. 
The youth front of the PSTU engages in politics through ANEL - Free National Assembly of Students, founded in 2009. Differently from collectives such as Juntos or Rua that have a variety of fronts of actions, the ANEL focuses primarily on building an alternative student movement and the strengthening of their organization as an alternative to the National Students' Union (UNE), which is homogenized by the PCdoB and the PT. The central idea behind the ANEL was to respond to a series of educational reforms proposed by the PT government through the University Reform (REUNI) in 2007 and that was supported by the UNE (Tavares, 2015). Arielli Tavares, from the executive board of ANEL and from the PSTU, argues that the perception of the UNE as a bureaucratic arm of the PT government became clear to the student movement when UNE members actively tried to sabotage dean's office occupations against the REUNI (Tavares, 2015). At the Federal University of Rio de Janeiro, UNE members went as far as creating physical barriers (cordões de isolamento) to contain the 600 occupying students (Soto, 2007). From this process, the National Student Congress (CNE) was born, which resulted in the decision to create an alternative space to the UNE. Student and youth militants from the PSTU organize through the ANEL, while Juntos and Rua send representatives to form the leftist opposition block inside of the UNE. Like the CSP-Conlutas, which is not controlled homogeneously by the PSTU, the ANEL also has participants from other organizations, even though the PSTU remains the majority and members from the ANEL executive tend to be also PSTU militants. As an entity, the ANEL is also an affiliated member of the CSP-Conlutas.

As an organization, the PSTU is the protagonist of many labour struggles against employers and the state, especially through the CSP-Conlutas union federation as an instrument. Despite that, the centralized practices of the party often lead to attempts at 
hegemonizing processes that were in theory more diverse in composition and resistant to vanguardist moves and appeals. Probably the biggest example of this in recent history is the actions of the PSTU in face of the protests of June 2013. Due to the crisis of representation, the rise in anti-party sentiment (followed by anti-left positions), and what is arguably a depolicitization of class-based issues by diffuse "anti" tactics such as the black bloc one, the PSTU opted to promote a secondary underlying process in June. They worried the crowds had fallen into a trap by rejecting the bureaucratization of the PT and the CUT through favouring individualized, rather than collectively organized action (E. Almeida, 2014). At the time, the PSTU emphasized the class issues behind popular contempt and pushed for bolder agendas such as a general strike, a call seen as necessary by the whole of the radical left but whose views on timing and methodology varied in organizational strategy. The difference in discourse, while radicalized, was not able to mobilize the numbers necessary for visibility and further action. The National Day of Struggle, scheduled for July $11^{\text {th }}$, brought in much smaller numbers than those presented in the June scale and membership was limited to the organized left, mostly labour union members, instead of clusters of new activists and dissatisfied members of the civil society. In addition, the growing repudiation of black bloc tactics by the PSTU also led to rejection of the party by the youth and those interested in black bloc tactics but also looking for organized left politics. This tension drew a gap between the PSTU and anarchist groups such as the FIP in Rio de Janeiro, sometimes leading to physical altercations and mutual attacks (Carneiro, 2015).

In São Paulo, the divide between the PSTU and the black bloc adopters and anarchists led to divided demonstrations against the World Cup on June $12^{\text {th }}, 2014$. The majority of the PSOL and the PCB have promoted dialogue regarding black bloc adopters in an attempt to 
critique the disadvantages of the tactics for mass mobilizations while recognizing the value of those activists for radicalizing the struggle (and perhaps ultimately adding to the organized Left), the PSTU adopted the practice of "banning" black bloc adopters and sympathizers from protests led or homogenized by the party, which was the case of the World Cup protest in solidarity with the metro workers of São Paulo, whose union was led by CSP-Conlutas and PSTU members. When the police violently drew the more anarchist protest into the site of the metro workers and organized left protest, there was a clash between the PSTU coordination and black bloc youth. I was present at the event and although I had a clear impression that a desirable mediation was reached with the help of other activists and organizations, the tension (and verbal attacks) continued even after the police sent all protesters home. By 2016, the PSTU had reinforced the idea that the crisis of representation that erupted in June 2014 had indeed come from diffuse positions that were not on board of the same programme as the party; yet, they presented a clear sign of a "Fora todos!" (Out with all of them!) movement (Anselmo, 2016), which propelled the party's campaign of the same title during the Dilma Rousseff impeachment process. The campaign was embraced by other morenista organizations, such as the CST, and those building the PSTU conceptualized front Espaço de Unidade e Ação, and at some point part of the MES, which initiated a call for general elections considerably before Rousseff's impeachment was actualized. The remaining organizations found the campaign to do harm to politicization on the matter and disregard basic democratic structures that were in place.

This difficulty in dialogue regarding controversial strategies or organizations with different topical positions (even if their overall horizon is similar to the PSTU's), informs the criticism of the party by other leftist organizations (voiced anonymously in the interviews and 
ethnography). While the PSTU is critical of organizations that are willing to have more flexible tactics depending on the moment, arguing these could jeopardize actual strategic advances, others leftist actors, even those who often adopt the view of the vanguard, perceive the PSTU tactics to be excessively vanguardist both regarding the relationship between the PSTU and the masses and between the PSTU and the radical left. The vanguardist issues as well as the methods for democratic centralism, a common configuration in Trotskyist and MarxistLeninist organizations, have led to some degree of internal conflict in the PSTU for the past three years. A series of departures by once key militants of the PSTU occurred in the 20142016 period, most notably professor Henrique Carneiro, who remained affiliated but no longer a militant (at the time of his interview), and other intellectuals such as Ruy Braga and Alvaro Bianchi. ${ }^{27}$ In mid-2016, the organization split more seriously, with about $40 \%$ of its militants choosing to leave to form the MAIS (Movimento por uma Alternativa Independente Socialista). This included other important intellectuals such as Henrique Canary, Valério Arcary, and city representative Amanda Gurgel. The manifesto issued by MAIS militants explaining their departure from the party indicated problems with the PSTU's vanguardism and its sectarian position regarding the impeachment crisis, in addition to its views on the electoral process (É preciso arrancar alegria ao futuro, 2016). It must be stressed, however, that vanguardism is by no means a problem exclusive to the PSTU and this will be explored in the context of fragmentation and schisms later in this study.

\footnotetext{
${ }^{27}$ Six PSTU militants were interviewed in-depth for this research study. While one of them, Henrique Carneiro, had just announced its departure from the party's militancy (which we discussed), two others left the party (Ruy Braga and Mácia Teixeira) after the interview process had finished. Arielli Tavares left together with the schism that generated the MAIS. Teixeira has also joined the MAIS.
} 


\section{Brazilian Communist Party (PCB)}

The first half of the history of the PCB is disputed, if one considers how both the current PCB and the PCdoB lay claims to the same party origin depending on each of their visions of the schism of the 1960s. Part of the process of changes implemented in the party at the time consisted of the name change to Brazilian Communist Party and the consolidation of the balance made in favour of de-Stalinization. With the Brazilian coup of 1964, the party found itself initially unprepared both to resist the coup and to come up with appropriate syntheses and strategies, especially due to the impacts of etapismo (stagism of two revolutions: bourgeois then socialist) as a strategy defended by the party at the time (Iasi, 2015; Singer, 2010, p. 101). ${ }^{28}$ The resistance against the dictatorship cost the party many of its important members, despite the fact that the PCB did not support armed struggle as a tactic, which led to the dissidence that formed the Aliança Libertadora Nacional (ALN). In the late 1970s and early 1980s, the PCB began to establish its proposal to become a party of masses, built on pluralist and freedom values (PCB, 2014). This process also set off a series of other internal conflicts within the PCB, and the resolutions of the period are permeated with contradictions and attempts to muffle more dissidence. PCB's history ever since has not been without conflict, such as the schism that led to the creation of the PPS in 1992, and their last twenty years are

\footnotetext{
${ }^{28}$ Stagism often implies immediate and temporary compromises with capitalism in order to develop the economy and the market of a country before one proceeds towards more radical change. Webber and Carr argue that stagism is again a topic of policy in Latin America when it comes to the moderate left, which often relies on an ideal of the configuration of class forces before more advanced programme from an anti-capitalist can be implemented. This has contributed to the flexibilization of political strategy to deepen neoliberal policies that are to be reconciled through notions of social citizenship (Webber \& Carr, 2013, pp. 9-10). See also Katz's critique of the notion of stages towards capitalism in the same volume (Katz, 2013).
} 
better characterized as a period of self-critiques and reorganization. This is reflected in the small size of the party in spite of its age.

Unlike the remaining ensemble of leftist organizations operating at the time, the PCB was not a supporter of the creation of the Workers' Party. André Singer points out that the origins of the PT involved some critique by the general Left of the politics of the PCB (Singer, 2010, p. 101). Therefore, the process generally created two separate processes for political intervention in the masses in Brazil, one through the PT and the other through what remained of continuity, after a series of self-critiques and changes, in the PCB. The differences between the PCB and the process of inception of the PT (and in consequence of the CUT and the MST) also applied to the consolidation of the exclusion of the PCB from processes it once coordinated hegemonically. For instance, the PCB once had strong labour union influence and control, but this hegemony was lost when, in the 1980s, the CUT became the strongest labour union arm in Brazil with the emergence of "new unionism" (Santana \& Antunes, 2007, p. 394).

The PCB has no national parliamentary representation, but has had some success at the city level, especially through electoral coalitions, which may involve a variety of parties from the left as well as centre (Sul 21, 2012). In regards to labour unions, the PCB withdrew its support for the CUT completely in 2006 and joined the central union Intersindical, remaining in the Intersindical (Instrumento) (post-schism) until recently. Pressure from a group inside the PCB led the party to leave Instrumento, when it began intervening independently through its instrument Unidade Classista (UC), although still maintains a close relationship to the central union (Ramos, 2015). The PCB's youth front organizes through the União da Juventude Comunista (UJC), which makes up the Oposição de Esquerda at the National Union of Students (UNE) together with the Juntos, Rua, JSOL, Esquerda Marxista, Vamos à luta 
(from PSOL's tendency CST) and others. At the local level, the PCB has contributed to many fronts of struggle, including a public transportation committee in São Paulo and an active participation in some of the Popular Committees of the World Cup, such as in Brasília (Ramos, 2015). Although in 2015, at the time of the interviews conducted for this study, the PCB maintained a watchful distance from direct articulations with the Homeless Workers' Movement (MTST), unless it concerned matters of consensus for the left and direct support for occupations in some areas (Iasi, 2015; Ramos, 2015), the new arrangements in the Brazilian conjuncture have brought the PCB closer to the MTST and the party has since participated openly in events of the Frente Povo Sem Medo, even though the PCB is not a front member.

\section{The PCR or Popular Unity for Socialism (UP)}

Due to its small size and space of influence, this study does not give the Communist Revolutionary Party (PCR) the same attention as the PSOL, the PSTU, and the PCB. Yet, it is important to outline some of the characteristics of this political party because it is present in some political fronts and social movement articulations of interest. The PCR is a MarxistLeninist party, with Stalinist tendencies, that was founded in 1966. It was present during the military dictatorship as part of the underground armed struggle against the regime, and like the PCB, it took some heavy losses. Its youth organization is the Rebellion Youth Union (UJR), created in 1995 after the failed fusion between the PCR and the October $8^{\text {th }}$ Revolutionary Movement (MR-8) (PCR, 2016). The UJR intervenes in the UNE, while the party's labour union arm, Class Struggle Movement (MLC) intervenes in the CUT, contrary to most of the radical left labour instruments that operate in the CSP-Conlutas and the Intersindical (Central and Instrumento). As mentioned before, the party extends itself to the social movement sector 
through the MLB. Internationally, it has been affiliated with the International Conference of Marxist-Leninist Parties and Organizations (ICMLPO) since 2004.

Since 2014, PCR militants have been engaged in collecting signatures to form a new political party, one with electoral aspirations, called Popular Unity for Socialism (UP). This process is still in place and it is still unclear whether the PCR will become the UP once the new party becomes official or if it will remain separate and the UP will operate as a political party instrument of the PCR. Currently, the party and its associated sectors are members of the Frente Povo Sem Medo, which is made up of over 30 organizations but led in part by the MTST. The front, which will be explored in Chapter 7, is an example of coordination between political parties and social movements in the radical left.

\section{$\underline{\text { Social Movements }}$}

The party-movement relationship is part of the regular activities and strategic planning of the Brazilian left in general, as was evident from the role the MST played as leftist opposition in coordination with the Workers' Party for many years. Since the radical left is made up from a more complex and heterogeneous arrangement of organizations, formal coordination is necessary at local and national levels to improve discussion and encourage joint action. This does not guarantee a stream of honest dialogue among the organizations because of all issues involved in the process of fragmentation, but promotes enough coordinated action to present the radical left as a collective that stands in opposition to the political project of the moderate left despite occasional agreement between them against the right. Since June 2013, the coordination between parties and movements in the radical left has become more vivid through occupations, joint demonstrations, and displays of solidarity and the urban question is a definite factor in the development of this relationship. Thus, it is important to consider that 
if the MST was once the most relevant social movement of the left, the MTST is representative of the significance of organizing in the city and how radical left movements are embedded in the urban dynamic.

The MTST's leadership in the radical left is partly due to the centrality of urban issues in Brazilian politics today and the nature of popular demands. The relevance of the Free Pass Movement in São Paulo in 2013 and the way the struggle against public transportation fare hikes evolved into massive demonstrations is not a coincidence, but reflective of growing urbanization without urban planning, democracy, and social provisions in Brazil. The context of right to the city struggles, even when not recognized as such, has mobilized and been mobilized by the radical left. While the MTST is the biggest and most prominent social movement in this context, it is not the only one of its kind. This made room for the creation of the Urban Resistance, which is a somewhat permanent alliance of social movements and collectives connected to the urban struggles, particularly those related to housing and urban reform in Brazil. The largest organization in the front is the MTST, followed by the Brigadas Populares and Terra Livre. It is a national front of movements with the objective of coordinating action among the movements rather than forming political syntheses and in-depth political debates among them. As such, actions by the Urban Resistance tend to be more practical and involve, for example, national days of struggle in all states where the front is present. The power of the front is more connected to rallying up forces rather than deliberation, but it has not lived up to its potential due to difficulties to coordinate it nationally (Boulos, 2015b; Giva, 2015). Member movements are the MTST, the Brigadas Populares, Terra Livre, Luta Popular, and other regional movements. 


\section{Homeless Workers'Movement (MTST)}

The Homeless Workers' Movement (Movimento dos Trabalhadores Sem Teto MTST) is by far the left-wing organization with which I interacted the most during my ethnographic research. This is partly a result of the continuous relevance of right to the city demands given growing urban inequality in Brazil, highlighted in June 2013 and the struggles against international mega-events, and partly related to my own activism around such demands. Since the MTST is the only truly national social movement making urban reform demands in Brazil, and particularly stronger in São Paulo and the Federal District, my main fieldwork cities, my continuous contact with the movement evolved together with the ethnographic research I conducted, especially since this research was guided by the relevant political performance of the organizations in the present conjuncture. The most radical moments of June 2013 were with no doubt connected to urban reform issues, and although the Free Pass Movement (Movimento Passe Livre - MPL) ${ }^{29}$ was the prominent voice at the time, its refusal to connect the demand for free public transportation to the other issues that concerned the people ended up costing the movement much of its relevance and leadership (Silva, 2015). The MTST, which was already undergoing a strong period of occupations in the periphery of São Paulo, was able to gather strength from the opportunity passed by the MPL by tying a plethora of demands made by the streets to the umbrella of urban reform and, at

\footnotetext{
${ }^{29}$ Although the MPL identifies as a leftist movement, and I had the opportunity to interview one of its members in São Paulo, its relevance for the argument of this dissertation in particular is lower than for studies focusing solely on June 2014. In addition, the extent of action and mobilizing power of the organization varies from state to state. Unlike traditionally structured social movements such as the MST and the MTST, which have a coordination and a social base that also contributes to the coordination, the MPL is structured more like a collective that mobilizes a flexible base and wide population periodically according to the struggles regarding public transportation.
} 
times, to the banner of the right to the city as a whole. Part of this power to mobilize is related to the worsening of the housing and urban crisis in Brazil, something which the latest social housing programme, Minha Casa Minha Vida (MCMV), was not even close to solving. As this coincided with the approaching FIFA World Cup in 2014, the movement grew louder and both an occupation in São Paulo and another in Fortaleza were named Copa do Povo (People's Cup). This was in addition to the many protests led by the movement, some which would make international headlines, such as the May $27^{\text {th }}$ protest in Brasília alongside indigenous groups. The MTST coordinated with the national and local Comitês Populares da Copa (Popular World Cup Committees) for most of the tension period ahead of the World Cup, although some real victories and other not-so-promising negotiations with city and state governments at the time led the movement to sit out of the remaining protests until the end of the event.

The MTST was born in 1997 out of the MST and of the acknowledgement that urbanization was creating a need for urban reform that was as big as the need for agrarian reform in Brazil. Primarily based in São Paulo, the movement grew gradually to act in more than a dozen states (2016), sometimes through partnering with other housing social movements such as the Brigadas Populares in Minas Gerais and the Movimento Popular por Moradia (MPM), active in the state of Paraná, which recently became integrated with the MTST as MTST-Paraná. Since this conversation around a national urban movement was born inside the MST, the MTST maintains some communicative and formal ties to the agrarian movement. In fact, the MTST has been an important interlocutor to bring the MST and the CUT together with organizations of the radical left to think about popular reforms and joint demonstrations. The MTST is structured through organizational collectives, or movement sectors, such as political formation, negotiation, and organization, which allows for a degree of hierarchy that 
is also internally democratic, since representatives are chosen from the camps and settlements up (Boulos, 2015b). In comparison with the MST, the MTST is less bureaucratic, although much of the perception of the movement ends up concentrated on the persona of Guilherme Boulos, as is the case for the MST regarding João Pedro Stédile, one of its national coordinators that also acts as intellectual leadership for the movement. This is often the case with large social movements in Brazil due to their efforts to build popular reference and break through media barriers. The MTST comes with its own contradictions in terms of government negotiation, which is natural to social movements in comparison to political parties without pressing demands from the base. This has led to criticism from the PSTU and the PCB, for example, which often characterize the MTST was having given into the governista camp or making itself too vulnerable to the PT and its project (J. M. de Almeida, 2015; Iasi, 2015). Many of the demonstrations organized and led by the MTST would count on support from the PSOL but not as much from the PSTU and PCB, although the PCB has come closer to the MTST since 2015. The PSTU has opted to openly support schisms from the MTST, such as Luta Popular, as well as leaders who have been expelled from the movement for a variety of reasons.

The Luta Popular movement was born in 2011 from a schism inside of the MTST and one of its main public figures is Helena Silvestre, a former MTST coordinator. The movement is focused in the state of São Paulo, but also acts in another five states. It is affiliates with the CSP-Conlutas and animated by the PSTU as a space of action on popular struggle. Interestingly, shortly after the formation of the Luta Popular, the MTST, which was affiliated with the CSP-Conlutas since the foundation of its current composition in 2010, left the union central in 2012. In its exit letter, which was circulated among the left, the MTST stated that it 
was leaving due to political differences with the PSTU members who were the majority in the union and argued that some of this distress was caused by PSTU militants that had been trying to poach MTST militants to join the PSTU's housing movement of choice (Luta Popular) (MTST, 2012). A recent case, which I followed closely in Brasília, pertains to a group of regional coordinators of the MTST who were expelled for charging fees from the MTST base in the region, which is forbidden by the movement. These coordinators proceeded to create a new movement, the Popular Resistance Movement (MRP), which has received support and solidarity from the PSTU and Luta Popular despite warnings from the PSOL and independent militants regarding the basis for their expulsion. This example corroborates suspicion that some of the differences between the PSTU and the MTST may have to do with grievances and desire for influence rather than with strategy.

Yet, part of the general critique by the PSTU and the PCB is valid, for the MTST has opened up space for the PT to make its case, including Lula, and this certainly impacts the connection between the MTST base and the moderate left. The MTST has also suffered from cuts made by the Temer government after Rousseff's impeachment process to the housing programme, which weakens the movement's relationship to the part of its base whose struggle has not expanded beyond housing yet. I reject the argument, however, that the MTST is too connected to the moderate left camp (or not radical left enough), since the contradictions that pertain to a close relationship with the moderate left have not resulted in co-optation or radical compromise. The MTST has continued to criticize the PT and its governments openly, including Rousseff during the impeachment crisis, which is the opposite of what moderate left organizations such as the MST and the CUT have done. The MTST also promotes politicization of its base from a radical left point of view (from anti-capitalist to socialist 
depending on the context), despite the difficulties in politicizing beyond single-issue demands found by social movements with a still limited operational structure and independent financing.

From June 2013, the MTST grew as a protagonist of the radical left in Brazil and it became seen as an aggregator that could temporarily unite most leftist sectors (moderate and radical) around certain demands and other topical issues. The degree of involvement of each organization varied, of course, and sectors from inside the PSOL, the union confederation Intersindical (Central), youth collectives and movements from the Urban Resistance front were more likely to recognize the MTST as a conjunctural leadership and find the most points in agreement with the general agenda set for demonstrations and collective courses of action. While some view the MTST as the organization that could probably reunite the left, Guilherme Boulos is careful to add that although the MTST is indeed in dialogue with many organizations, it can only serve as a point of reference in the social realm, and other organizations are needed as proactively to fill the political gap (Boulos, 2015b). This is echoed by other members of the movement's national coordination who feel that the level of responsibility put on the MTST by radical left members may lead to undue pressure and criticism on a movement that is relatively young and deals with its own challenges around the government and fulfilling demands from the base in a context that remains far from enabling urban reform (Fernandes, 2015). The failed attempts to create the Frente de Resistência Popular (FRP) in early 2015 indicate the same as well as the difficulties to unite radical Left and moderate left sectors over a common agenda. Ever since, sectors involved in the early conversations over the FRP have split in two different fronts: Frente Brasil Popular, led by the MST and the CUT, with an evident governista tone and whose actions focused on resistance against the impeachment of Rousseff, and the Frente Povo Sem Medo, led by the MTST with the support of other radical 
Left organizations to fight the impeachment and for popular reforms. Another front, whose organizations were not involved in the FRP, was also created called Espaço Unidade de Ação and is mostly composed of sectors associated with the PSTU and the CSP-Conlutas union. These fronts and the possibilities and impossibilities of alliances in the left are part of the discussion of fragmentation in later chapters.

\section{Brigadas Populares}

The Brigadas Populares (BP) is the second largest movement from the Urban Resistance front of urban social movements connected to the housing struggle and was founded in 2011 from a fusion between four movements and collectives. Its birthplace is the state of Minas Gerais and although the organization has grown to other states, Minas Gerais remains where it is most active and influential, especially in local politics. After getting to know the BP and its militants, as well as the large urban housing occupations it helps to animate, such as Dandara and Vitória in Belo Horizonte, I fell under the impression that the BP was not a strict kind of social movement, for its direct interest in thinking politics through various places of action (housing, anti-prison, culture, mobility etc.) and the way it articulates with other groups of the city gave it an appearance of movement-collective that at times was also extended to the organizational horizon of a political party. The BP is very involved in the housing struggle in Minas Gerais, but it is not a movement based on single-issue demands. It has managed to act on different matters in an integrated manner, which makes it a reference in Belo Horizonte and Minas Gerais as a whole. The movement is built both by militants from the university, public sector, and a surprisingly large number of lawyers, as well as grassroots activists from the communities where the BP operates. This enables a dynamic where the BP helps to mobilize housing occupations but the immediate leadership of the occupations is local 
and relies less on central figures of the BP as is the case with the MTST and the MST. Although the BP has no immediate aspirations at party formation, it maintains good ties to the PSOL and democratic affiliation is an accepted practice so that the BP can promote their own candidates during elections. It is also close to the PCR through the party's involvement in the MLB, which is a housing movement of significance in Minas Gerais. The Brigadas is one of the most active organizations in the construction of the Popular Committee of the Affected by the World Cup (COPAC) in Belo Horizonte in June 2013 and after, in addition to having been a vocal actor during the Fora Lacerda protests in 2009-2010. As a movement involved in right to the city struggles and social justice in general from a Latin American integration point of view, the BP has been an important articulator in Minas Gerais in terms of bringing different forces from the socialist radical left (parties, movements, unions, collectives) as well autonomists and anarchists together in important struggles. The movement is still small in influence in other states, but this collaborative role could already be noted in the Federal District, for instance, where the BP was founded in early 2015.

The Brigadas Populares has a socialist, nationalist, and popular programme that also puts forward the idea of revolutionary nationalism (Brigadas Populares, 2011; Telésforo, 2015), which is less common in the Brazilian left and has been put aside from places of struggle due to the strong usage of nationalism by right-wing movements and parties. The right-wing version of nationalism, known as ufanismo (discussed in Chapter 4), has been mobilized to depoliticize issues and strengthen conservative values. The BP argue for a revolutionary nationalism developed in the context of Latin American struggles to promote selfdetermination, and to mobilize against imperialist interests in the region and for the protection of natural resources, such as the pre-salt in Brazil or national gas in Bolivia. This offers an 
interesting contrast to Trotskyist and Marxist-Leninist institutions in the radical left that focus more on the idea of internationalism, especially those affiliated with a communist international. Since the BP's nationalism does not negate the importance of internationalism, this is not a source of conflict between the organization and the internationalist left, despite distinct focuses and conjunctural analyses. The politics of the BP is centred around the idea of "open unity", which proposes that the BP should be open to working in collaboration with all organizations that could strengthen the causes in which they are involved, independent of political differences. This high level of flexibility is subject to the BP's own criteria of how the causes could be strengthened, defined according to the struggles of the revolutionary nationalists, socialists, and communists in Brazil, and helps to overcome isolation in the radical left while preserving the identity and development of each organization (Brigadas Populares, 2011). The BP has issued statements and worked together with other organizations to promote this view for a broad political front that still maintains the particular identities of each organization. This perspective is in line with the view of left reorganization expressed by Israel Dutra (from MES) earlier in this chapter, although his organization differs tactically from the BP in terms of which alliances should be pursued.

\section{Terra Livre}

A smaller movement that makes up the Urban Resistance is the Terra Livre, which is a movement born in 2005 with the intent to fight for urban as well as agrarian reform. Therefore, the movement has made occupations in cities, such as São Paulo, as well as in rural areas. Its urban occupations, however, differ from those made by the MTST because the Terra Livre gives preference to occupying abandoned buildings in what are known was vertical occupations, while the MTST prefer to occupy large empty lots of land used for real estate 
speculation in the shape of horizontal occupations populated with tents and precarious structures that ought to eventually make space for the construction of buildings and houses through the government's social housing programme Minha Casa Minha Vida (MCMV). By not using the MCMV as a parameter for their occupations, the Terra Livre manages to secure a higher degree of autonomy from the federal government when it comes to their occupations, although this comes at a cost in terms of actual influencing housing and urban programmes at a wider level. In comparison, the Brigadas Populares have promoted both vertical and horizontal occupations in the past, with horizontal occupations being the current norm. The BP promote the immediate construction of permanent housing in the horizontal occupations by each dweller, instead of promoting a public funded housing project like the MTST.

In the countryside, Terra Livre arrived as an alternative to the MST, especially in areas where the Landless Workers' Movement was promoting politics moderated by the federal government. Terra Livre is not connected to any party, and its militants are free to have their own partisan options. In São Paulo, Terra Livre militants were very active in the Popular Committee of the World Cup and the organization maintains a collaborative relationship with the Free Pass Movement (MPL) (Giva, 2015). Its leadership maintains a supportive relationship with the Brigadas Populares, but there are tensions with the MTST because of the MTST's negotiation patterns with the government and its relationship with the moderate left.

\section{$\underline{\text { Labour Unions }}$}

The trade unions of the radical left were created to respond to the level of bureaucratization and governismo by the CUT and the CTB to promote a more socially integrated unionism that was concerned not only with the direct economic interests of the workers represented but also with the general struggle of the working class from a socialist 
perspective. These unions also operate in opposition to right-wing union confederations such as the UGT and the Força Sindical, which together with the CUT and the CTB, represent almost $70 \%$ of Brazil's unionized working force in a scenario of thirteen union confederations (Batista, 2016). The three key trade union confederations of the radical left are the CSPConlutas, the Intersindical- Central of the Working Class and the Intersindical - Instrument of Struggle and Organization of the Working Class. Current numbers from the Ministry of Labour indicate that the CSP-Conlutas represents about 2,24\% of unionized workers, whereas the Intersindical amounted to $0,01 \%$ (Batista, 2016). ${ }^{30}$ This demonstrates the still limited representativity of these unions, which is partly related to their recent history and the difficulties encountered when competing with the CUT and the CTB from within the leftist terrain. In addition to being relatively new, these unions have undergone continuous changes in relation to each because of schisms, fusions, and failed attempts at a fusion. Because of this, they are approached together in the next section.

\section{CSP-Conlutas and Intersindical - Central and Instrumento}

The CSP-Conlutas, originally Conlutas, was idealized in 2004 and consolidated in 2006 through the initiative primarily of the PSTU, although other organizations have ever since become involved with the union such as the PSOL tendencies the MES and the LSR. The leadership of the PSTU in the union confederation remains until today and is often seen as a problem by other actors in the radical left, partly due to concerns over "aparelhagem" (excessive control of an apparatus) of the instrument by the PSTU and allies, and partly due to the view that such an instrument should serve the purposes of a wider front of organizations,

\footnotetext{
${ }^{30}$ The Ministry data does not differentiate between Intersindical Central and Instrumento from a conclusive standpoint. Based on my conversations with members from both union confederations, the Ministry numbers may also be underestimated.
} 
and not the opposite (Moura, 2011, p. 69). For CSP-Conlutas members who are also militants of the PSTU, this is not as much of a problem because the union has democratic structures that facilitate the participation of other organizations through the local labour unions with which they are involved (Garcia, 2015; Prazeres, 2015).

The Intersindical used to be one trade union confederation, which split up into two different organizations carrying the same first name. This is due to the schism that happened after the failed attempt to promote a fusion between the Intersindical and the Conlutas in the Congress of the Working Class (CONCLAT) in 2010. The event not only exposed the impossibility of a fusion of organizations that could have resulted in a central union capable of standing up to the CUT but also intensified internal disputes inside of the Intersindical that led to a split into the Intersindical- Central of the Working Class and the Intersindical - Instrument of Struggle and Organization of the Working Class. Intersindical - Central was officially founded in 2014 while Intersindical - Instrumento makes claims to the 2006 original foundation. Despite the failed fusion, the Conlutas is refounded at the time as Central Sindical e Popular - Conlutas (CSP-Conlutas) due to the adhesion of movements such as the MTST and the affiliation of the youth, women's, and black groups associated with the PSTU (namely ANEL, Movimento Mulheres em Luta, and Quilombo Raça e Classe). Today, the MTST not longer participates in CSP-Conlutas, and the general state of the relationship between the two organizations consists of topical collaboration and solidary in an overall tense terrain.

While the CUT remains the most important central union in Brazil, albeit its loss of credibility, the CSP-Conlutas and the two strains of the Intersindical have fought for larger and larger space, especially after the wave of disaffiliations from the CUT since 2013. The PSTU continues to be the majority organization at CSP-Conlutas, even though the MES has 
established some regional influence in some states and members from other tendencies of the PSOL may find the freedom to be militants in the CSP-Conlutas, although mostly at the base level, such as Insurgência. Some of the other PSOL tendencies participating in the CSPConlutas are the LSR, and the CST. The Intersindical-Central is animated by the APS, Fortalecer o PSOL, Rosa Zumbi, militants from Insurgência and even some from MES (which builds the CSP-Conlutas), among other members of PSOL and independent organizations (Índio, 2015). The Intersindical-Instrumento is built by organizations and collectives such as the Associação Sindical Socialista (ASS) and is close to the PCB. The PCB was against the attempt at a fusion in 2010 from before the congress and recognizes Intersindical-Instrumento as the original Intersindical, although it no longer builds Intersindical-Instrumento internally.

\section{The radical left in the fragmented context}

This chapter painted a picture of a radical left so fragmented that many of its smaller pieces do not manage to influence the conjuncture at a considerable level that goes beyond local incidence. Other organizations, despite their small size, have strong incidence beyond their base and manage to articulate collectively with the body of organizations of the radical left in order intervene in the conjunctural power relations in their own capacity. This is particularly important as the moderate left project loses credibility and gives into the centreright liberal project in order to save its hold to institutional power. This crisis presents an opportunity for the radical left to grow, but its capacity is mined by its own crisis of praxis that makes it difficulty to present cohesive and sustainable alternatives to the depoliticized scenario and from a fragmented standpoint. The following chapters examine the problem of depoliticization in-depth and offer an analysis of the different aspects of fragmentation in the 
Brazilian left so that it may contribute to solutions and dialogue that may address these problems more consistently. 


\section{Chapter IV: Depoliticization: post-politics}

The call for new politics, or at least different politics, that echoed in June 2013 set off a discussion in all ideological political spectrums over what this would look like and how it could be used to interpellate the June crowds in the favour of any particular political actor and organization. These discussions principally revolved around anti-partisanship, anti-politics, and anti-leftism, though there was also a "post-left" character focused on post-capitalism, postMarxism, and hegemonic renewal rooted in a putative step "forward" from the fall of the PT project. Here I want to introduce the concept of "post-politics" as the key to a myriad of debates and non-debates over depoliticization because it incorporates all of these elements, and most importantly their lasting effects in the continuing reproduction of depoliticization in Brazilian society. Although not a popular concept among the intellectuals of the Brazilian left, it accurately reflects many of the ideas critiqued by participants during interviews, and also the challenges faced by party militants when reaching out to the majority of the population during elections, the organizations of demonstrations, and everyday base-building work. Post-politics helps to explain why the radical left has found it so difficult to connect to the masses at the level the Workers' Party once did, and even more difficult to break through the dichotomous paradigm established by the PT - that of the PT versus the right - without further depoliticizing the debate.

Depoliticization is a complex process. In contrast to 2013, the mass protests of 1984 demanding direct elections in Brazil, known as the Diretas Já movement, and then again in 1992 in favour of the impeachment of president Collor, were more massively politicized processes around the very specific issues at hand, and both of them included various levels of 
leftist organizing and mobilization. While the first episode was motivated by the need for more direct democracy, the second consisted of a conversation between anti-corruption and political betrayal. Even in the second case, when anti-corruption could have turned against the left (as it did in 2013), the Fora Collor movement connected the fight against corruption to the need for legitimate representation in a way that favoured the left that had helped to lead the mobilizations. This demonstrated a somewhat successful interpellation by the left at the time. The problem of representation revolved around Collor and his part in the establishment of power, while the crisis of representation of 2013 revolted against the establishment of representation itself, which had the effect of placing political organizations and the very act of politicization into the same basket. This blanket form of looking at representation would eventually create a scenario favourable to the right and its forms of depoliticization (See Chapter 5).

When evoked by the crowds of June 2013, similar themes were captured and co-opted by right-wing forces that would polarize the country ultra-politically. What lies between the 1984-1992 period and the 2013-2016 period is a long interval of mass depoliticization, which was not the case prior to 1984 because of the direct leftist struggle against the military regime that kept politics alive. While political action and antagonism were the markers of the popular resistance during the dictatorship, the attempts to remove class consciousness from the day-today experiences of the people and demobilization (through consent and coercion) that took place after Collor fell and then, in its own particular form, after Lula came into the presidential office, entrenched depoliticization as a mode of ruling, only made worse by the strong fragmentation of the left that crippled the latter's ability to stand as a politicizing force. 
Depoliticization in Brazil is the indirect result of class conciliation, methods of coercion and the construction of consent to the forces in power as well as the direct result of the rightwing project to remove, dilute, or contort ideology, alter mass consciousness, control cultural production and their outcomes, disseminate manipulated and biased information as legitimate, withhold critical thinking, and deter collective organization and mobilization ranging from political party action to local rallies. Although both coercion and consent are utilized to maintain a people depoliticized, the effects of consent creation are more long-lasting and are more efficacious at preventing the dissent that could eventually become very politicized (Gramsci, 1971, p. 80). Whenever fragments of politicization become public, however, and present a threat to the order of things, coercion may be employed, especially ultra-politically (see Chapter 5) to separate the politicized as radical, unruly, anarchistic, and worthy of repression. Marco Aurélio Nogueira explains that depoliticization acts in two ways: (1) it directly distances the people from the political by creating barriers to political consciousness and disqualifying current political practices; (2) and it marks the emergence of diffuse and erratic alternative politicizations that focus on the individual and whose dismissal of the need for alternative institutional and organizing practices creates self-exclusion and prevents the appropriation and transformation of the State (Chauí \& Nogueira, 2007, pp. 220-221). These practices form the bedrock of both the post-political and the ultra-political, as these are distinct though not contradictory systems of depoliticization that guarantee the status quo and hegemonic renewal. In fact, they can occur simultaneously and in a complementary fashion, as is the case in Brazil. Thus, the problem of depoliticization is a complex one that deals with the questions of those responsible (in the beginning and now), those who ignore it as a problem, those trying to solve it, and the lasting effects of the process. It could be said that since 2013, 
Brazilians are more politicized because of the heightened attention to political events and actors. Yet while interest is a precondition for politics, it is an insufficient one, and post-politics offers a channel for political interest that not only stops short of deep politicization but actively opposes it.

\section{What is post-politics?}

Post-politics acts in the realm of common sense as a form of post-ideology, wherein matters related to political, social, and economic status are effectively managed, rather than struggled for, without the influence of ideological positions; that is, the making of politics becomes subordinated to a presumed impartiality attributed to technocracy and enlightened specialists. In Slavoj Žižek’s words:

In post-politics, the conflict of global ideological visions embodied in different parties which compete for power is replaced by the collaboration of enlightened technocrats (economists, public opinion specialists...) and liberal multiculturalists; via the process of negotiation of interests, a compromise is reached in the guise of a more or less universal consensus. Post-politics thus emphasizes the need to leave old ideological divisions behind and confront new issues, armed with the necessary expert knowledge and free deliberation that takes people's concrete needs and demands into account (Žižek, 1999, p. 198).

Post-ideology, of course, is a highly ideological farce created to legitimize conservative and neoliberal positions with common sense versions of efficiency, governance, and neutrality. Post-politics compresses the various layers of post-ideology in economics, in elections, in fiscal and social policy, among others, and packages them in a broad paradigm that dictates how one thinks of politics and the coordinated efforts to depoliticize debates and issues in order to subject them to the constraints imposed by the hegemonic order. Japhy Wilson and Erik Swyngedouw explain that post-politics is a colonization of the political by politics, which is "understood as technocratic mechanisms and consensual procedures that operate within an 
unquestioned framework of representative democracy, free market economics, and cosmopolitan liberalism" (Wilson \& Swyngedouw, 2015, p. 6)j

Technocratic answers appear in order to give credibility to new packagings for common sense and to create insufficient yet seemingly satisfiable technical solutions, while promoting an underlying dilution of themes and struggles. For Jonathan Darling, post-politics marks "a specific modality of depoliticization, in which particular issues are removed from the realm of political antagonism in specific ways" (Darling, 2014, p. 73). This model erases "the ontological instance of antagonism" from the political questions at hand and fills it instead with "consensual modes of political decision-making, business negotiation and populist compromise" (Darling, 2014, p. 72; Paipais, 2014, p. 361). Vladimir Safatle critiques this by arguing that the real intent before denying a separation between left and right politics is connected to the conscious project to "give the impression that no radical rupture is in the political camp agenda or, to be more clear, that there is nothing more to expect from politics" but the management of hegemony (Safatle, 2012, p. 14, my translation). Post-politics leads to the pretence that there is a plural of choices beyond the ideological camps by actually foregoing choice and trapping politics within the hegemonic boundaries.

Post-politics despises antagonism and rejects it as connected to radicalism and extremism that is contrary to common sense and the idea of being reasonable and tolerant in society. At the same time, it denies the existence of these expressions when connected to capital and structures of oppression. This is clear, for example, in the context of the post-political praise for inclusion and tolerance in its overvalue of consensus politics over addressing the actual sources of social conflict. In post-politics, the left's attempts to expose antagonistic relations in society to the benefit of raising class consciousness and politicizing are seen as 
divisive, unfair, and as a promoter of intolerance by pitching the poor against the rich, the black against the white, and so on; that is, the left's legitimate needs for exposing antagonism are read as artificially creating antagonism where there should be only consensus. This is the reasoning behind claims that there is no class war, only the one the "radicals" are trying to instigate against the "fair", "hard-working" and "meritable" rich. Rather than direct consequences of a system of exploitation, the ubiquity of exclusion and intolerance becomes the fault of the left, which is deemed too radical and too intransigent for being an open ideological actor. As such, post-politics has a particular role in depoliticizing the economic sphere in order to reduce its complexity to a simple and objective state of management (Žižek, 1999, p. 353). Any possibility beyond this, which is in the essence of radical thinking and action, is thus foreclosed. This foreclosure of politics is why Žižek considers post-politics to be a stronger negation of politics when compared to other modalities of depoliticization (including the ultra-political) (Žižek, 1998a, p. 70). This is also why post-politics has an inherent incompatibility with leftist politics, because it creates a false dilemma by positing that the problem of conflict is not conflict itself but the left's refusal to compromise and engage in debates that would only legitimize technocratically the disproportionate voices of capital and oppression in a very unfair and unlevelled playing field (Žižek in Dean, 2005, p. 173).

The PT's gradual detachment from leftist politics occurred for many reasons, such as bureaucratization, a failed pinça strategy, the limits of the popular democratic programme, and lulo-petismo. These all took on a post-political form. As Saad-Filho and Boito argue, the PT's hegemony had become dependent "on perceptions of 'managerial competence', the absence of corruption scandals, continuing growth and distribution, and stable political alliances" (SaadFilho \& Boito, 2015, p. 220). By choosing to govern through post-politics as a pacifying tactic 
to sustain class conciliation, the PT renounced its supposed role as a conduit for class interests in the state. No wonder that when its efficient, administrative, and ethical appearance became attacked, both the PT government and the party came into crisis.

In many ways, the solution offered by the PT was to combine representative democracy with social movements (Žižek, 2013, p. 67). However, such a solution fails because the premise is based on a post-political view of democracy and a depoliticization of social movements, especially through the co-optation of their leadership, in order to subordinate them to the democratic order. Democracy or the idea of it plays an important part in the construction of post-politics, one that is especially central to the discussion of post-politics in Brazil. It concerns how post-political proposals often capture the notion of democracy to represent a technocratic negotiation of interests without any room for ideological motivations. Thus, it is used to justify their ideological dismissal of ideology. Democracy is promoted as the result of a battle of technocratic wits, in which the rules of the game are established as to allow for a neutral ground wherein the most efficient and appropriate ideas may flourish. This is, of course, a fetishized understanding of liberal democracy, but the matter of fact is that the prevailing view of democracy in liberal democratic societies is indeed fetishized so that it can be ideologically summoned whenever questions to legitimacy and over the suppression of struggle in the hegemonic cycle arise.

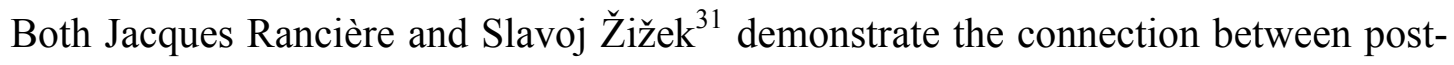
politics and this employment of democracy, particularly as it pertains to the intense process of

${ }^{31}$ The two authors offer a different view of post-politics that is related in the end. Rancière sees it as a disavowal of politics and Žižek as a foreclosure of politics. This pertains to the form of depoliticization that follow, since Rancière proceeds to focus on archi/meta/para politics, which are not the concern of the arguments of this dissertation, while Žižek, who informs the 
depoliticization that can take place and be validated through a democratic evacuation of the political and disavowal of the "dispute of the people" (Dean, 2005; Rancière, 1999, p. 110; Žižek, 1999). The main understanding is that democracy plays an important role in postpolitics because it can be appealed to as the primary solution to any trouble. If there is discontent, it must be due to a lack of ethics, good citizen morals and appropriate channels for voicing demands and having them tended to in the current democratic scenario. Thus, discontent can be fixed by also fixing democracy (and its rules), while hailing the apparent functioning part of democracy as good and impartial for making it possible for those demands to be voiced. The post-political fetish of democracy makes it less a system of political representation and regulated values (Ranciére's original parapolitics) and more into a business model fixed around negotiation and compromise (Žižek, 1998b, p. 995). The State itself is not in dispute, but perceived as the policing agent for any new consensus that is formed (Žižek, 1998b, p. 997). Such a transition is illustrated in June 2013: the discontent towards the corrupt State is reoriented towards the corrupt government, the corrupt representatives, and finally the corrupt politics. This ties anti-political tendencies to post-politics to consensually argue for a democratic re-foundation of the State through the illusion of political reform under the protection of that very State. This same moment excludes otherness, primarily those in struggle against the State and politicizing through this channel, because the values of the negotiation are set according to tolerance and consensus (Žižek, 1998b, p. 998). At this point, post-politics excludes the left because authentic left activity relies on the notions of antagonism and intransigence to respond to exploitation and dispossession.

chief definition of post-politics in this study, is focused on its effects as post-politicization (Gill et al., 2012, p. 511). 
The main dilemma concerning the mix between democracy and post-politics in the Brazilian conjuncture is evident in the political crisis generated by the impeachment of Dilma Rousseff from the presidency. The confusion caused by democratic ideals in times of high depoliticization can be seen from all angles. The crisis of representation of June 2013 makes room for two distinct but complementary political phenomena that revolve around the hegemonic status: post-political renewal and ultra-political offense. When ultra-politics is present, there is a false polarization that sustains a false rupture between the Workers' Party government and the right-wing opposition, which through nationalist and anti-corruption weapons is able to use post-politics to mobilize for ultra-political purposes. After Rousseff's impeachment was approved in the Chamber of Deputies, the left remained with the only opening possible for mobilizing under anti-leftism and depoliticization: democracy. The attack on Rousseff has been indeed anti-democratic because of the unconstitutional nature of the process against her and the level of political manoeuvres used to manipulate the political establishment towards the impeachment scenario. The moderate left, which wants Rousseff back as president, hides under the cloak of democracy to mobilize, whereas the radical left, which wants nothing to do with Rousseff, still has to mobilize in favour of democracy because of legitimate principles around representation and basic democratic rights in non-revolutionary conjunctures (and, of course, the very real political and material consequences of such a rightwing coup). The trap lies in having to ultimately defend democracy and produce discourses around democracy in order to reach out to people, since antagonistic and radical demands do not currently resonate. The reason why they do not resonate is because post-political covers such as democracy have been used by the right to depoliticize, sometimes going as far as using faint concepts around democracy to argue against constructions such as the existence of a "PT 
or communist dictatorship in Brazil" (as often stated by right-wing columnists such as in the conservative Revista Veja).

In regular scenarios, "to argue for democracy is to argue for more of the same" (Dean, 2009 , p. 24). In a scenario of post-political demands tainted by false polarization, the answer is similar though not as simple. To ask for democracy may simply empower a comeback for Dilma Rousseff and the PT's business as usual around governability, capitalist pacts, and more depoliticization, which falls into the category of "more of the same." At the same time, democracy represents one of the few points for the left to hold on to during a right-wing offensive that has helped to distort the meaning of the left alongside the PT's years of misrepresentation. During such an offensive, to ask for democracy could be something different, even if it is not something new, radical, or the necessary answer out of the crisis. Democracy could indeed be used as a demand to fight against the violation of democratic rights, but this would require a careful politicization to target the principal actors behind the violations instead of an aimless approach based on the reduction of the economic exploitation sphere to matters such as corruption, order, and morals.

Of course, this particular trap around post-politics and democracy needs to be traced back to the original problems of a crisis of representation and the post-political crowds of June 2013 in order to make sense. The following sections explain this challenge with a focus on June 2013, when post-politics erupted as a modality of depoliticization, and lay the ground for looking at post-politics in relation to the left in the conjuncture more broadly. 


\section{Crisis of representation $\mathrm{x}$ post-politics}

There is no denial in the Brazilian left that a crisis of representation is one of the big markers of the Brazilian conjuncture, especially since it was flaunted in June 2013. This is true even for the moderate left, whose interests lie in undermining the size of this crisis and the responsibility of the PT for it. In Chapter 1, I spoke of the difference between a crisis of representation and a crisis of praxis, the latter being the more defining characteristic of the conjuncture faced by the left and which encompasses the former. Now, it is important to turn to the two different interpretations of this crisis that, I argue, actually refer to the two expressions seen in June 2013 and beyond: one that has existed from before and its appropriation into post-politics, which grew into and after June.

There is a legitimate crisis of representation in Brazil and that was exposed in June 2013. Regarding the left, this crisis of representation is also symptomatic of a larger crisis of praxis, since a less fragmented left - whose efforts were more successful at fighting the entrenchment of forms of depoliticization in Brazilian society that have now spun many years - would also mean progress towards more authentic representation in Brazil. This is based on the notion that the radical left ought to contribute to the conciliation of contradictory consciousness; thus, establishing a representative link with the class through politicization and organizing. In general, a people politicized by the left should feel more represented by this left. Because of this, a crisis of representation happens with politicized as well as depoliticized subjects, the difference lying in the sources identified for misrepresentation and the content of demands for representation, which could be progressively transformative on the politicized side or result on an outright rejection of representation on the depoliticized one. For instance, those in the left, such as Mauro Iasi (PCB), also felt that there was a problem with what political 
parties had become (Iasi, 2015), with the inequality of the structures of representation, and importantly, with the impacts of governismo over more than a decade. A depoliticized people feel represented by no one, althought the right is capable of channeling the indignation behind lack of representation in its own favour by misdirecting this indignation against leftist ideals. According to Alfredo Saad-Filho, June helped to expose the legitimate aspect of the crisis by revealing "the atrophy of traditional forms of social representation (the media, trade unions, NGOs, political parties, and so on), which have become unable to channel discontent and resolve disputes between social groups, either because they are tightly controlled by the elite, or because they have been disempowered by neoliberal reforms" (Saad-Filho, 2013, p. 664).

Whereas the perceived lack of legitimacy of political parties, particularly the PT, is expected given the bureaucratic nature of Brazilian politics, the smearing of credibility by everyday corruption, and a strong history of forgotten campaign promises led to political parties being accused of more than the problems normally associated with fragmented pluriparty systems. The crowds accused all political parties of being the same and the clashes with militants from social movements, moderate and radical left parties, and labour unions were based on a fear of co-optation. This is related to passive representation becoming the norm under depoliticization, as evidenced by a survey of protesters showing that only $4 \%$ of the surveyed were affiliated with a political party, and only $11 \%$ felt represented by a political party $(\mathrm{G} 1,2013)$. The ideological positions of the crowds were also widely distributed across left and right and those who did not identify either way (Singer, 2014, p. 36). The meaning of left and right for the surveyed at the crowds may have also been diverse, given the underlying period of depoliticization. Within a few protests, non-partisanship was conflated with antiparty sentiment, and leadership figures from social movements were also called out for having 
too specific interests that posed a threat to unity during the protests (See Table 1 - Chapter 1). The clearest example of this in São Paulo was when the Free Pass Movement refused to go beyond the "just 20 cents" platform, withdrawing from the protests at a time of massification and diversification of demands. Post-politically, consensus was privileged over antagonism, even if this sense of consensus and unity was artificial in its erasure of the politicized social and economic content of the struggle.

This issue of misaligned representation is related to a cynical view of politics given widespread corruption and a general lack of cohesion in party coalitional politics. The cynicism contributes to the state of broad depoliticization conveyed in the disinterest in traditional forms of representation without strong and organized intentions of re-claiming them and thoroughly transforming the political space. There is an assumption of the political space as tainted, mainly due to the emphasis on corruption by individual politicians and entire political parties. Not that corruption is a small matter in the political space, as I will explore later in this chapter. But the gap in the conversation is usually the result of a misplacement of trust (or distrust), namely blaming politics in general for how they breed corruption rather than the capitalist vehicles that make it possible. Further, the rejection of the political speaks to the tradition, of the masses as well as of the organized left, to focus on the "anti" aspect of demands. We know what we are against - corruption, injustice, poverty, and violence - and in the politicized left we even formulate it as our anti-capitalist struggle. Yet, weak representation and the reification of political consciousness are obstacles to the formation of a collective project, which helps to answer to the more difficult question of "what do we want?" and how to move beyond denunciation and critique (Ferguson, 2010, p. 167). 
The problem of claiming that no one represents you is that it ignores that large societies are, commonly, organized through systems of representation: from formalized political systems to daily petty interests. Representation is not just the practical instrument of a hierarchical structure (as enthusiasts of horizontality would have us believe); rather, it implies systems of support that exist with and without hierarchy, and if the people reject attempts to be politically supported they become vulnerable to the one thing they want to avoid: cooptation by consent. The efforts to conceal and stifle antagonistic relations effectively reinforce the status quo that is maintained through the exploitation of these relations. By pretending that these relations do not exist, the large crowds show refusal to examine the underlying causes of poor access to education and health care, corruption and greed, and rising public transportation costs (among others). They take their practical experience as given and perceive critical inquiries as disruptive to the union of the people against the failed representatives.

The fact of the legitimate crisis of representation in Brazil is that a strong period of depoliticization inevitably results in a mismatch in the practices of political representatives and popular demands. If these demands are progressive, not tending to them is to break the representation pact from the right; if the demands are regressive, as they could be under depoliticization, such as by pushing for privatization in times of precarious public services, not tending to them is progressive but only if the underlying reasons for the depoliticization are also being tackled (i.e.: the public service improves). The tenure of the PT in power failed in both ways. In the meantime, the pluralism in parties in Brazil grew to favour structural fragmentation, electoral opportunism, and more ways of reaping institutional power in the favour of elites and representatives through corruption. Combined, these elements created a 
high level of distrust in the democratic representative establishment, especially regarding the party form. The value of acknowledging that there is a crisis of representation is progressive as it exposes the problems related to depoliticization and the call for political change, even if the content of this change is undetermined by the crowds at large. The responses to it and the way post-politics manages to capture this demand in order to morph it into a watered down version of itself are a different matter and should not be seen as progressive but rather as a point of pressure for self-critique and radical re-positionings by the left, even the radical left which so often excuses itself from its smaller share of responsibility in the process of demobilization and depoliticization advanced by the PT.

The post-political forces behind depoliticization in Brazil, especially concerning demobilization efforts that would replace radical action with management tactics (e.g.: participatory budgeting) and remove antagonism through the discourse of class conciliation at the pinnacle of the lulo-petista project, were quick to overflow after the legitimate aspects of the crisis of representation became apparent in June. This entails the presence of something like a second version of the crisis of representation, one whose centrality lies in corruption and management issues rather than the systemic problems around depoliticization and the state's partnership with capital despite the democratic institutional scenario. This is illustrated by the way corruption stole the scene in June and continued to play such an important role afterwards that it would nullify other demands, promote more depoliticization, and be instrumentalized in an ultra-political way by the right from the 2014 elections onwards. This has led to intense consequences in terms of anti-leftism. Of course, the PT must be held responsible for its own corruption scandals, but the way these scandals were approached by the media and the rightwing forces caused the anti-petismo that had grown out of anti-corruption as well as an elitist 
repudiation of the PT's social policy to flow into anti-leftism in general, which became a problem for the radical left as well. It did not matter how many times and in what ways the radical left tried to communicate to the crowds that it was different, it was clear that the crowds were not even familiar enough with the radical left to judge its activists by their words $-\mathrm{a}$ common problem of daily invisibility of the radical left. Its high fragmentation, which is by all means also connected to the PT dilemma (see Chapter 6), hindered its ability to politicize amidst such ostensive depoliticization efforts. Even when it did reach out to the crowds, it ran the risk of falling prey to the early signs of anti-leftism or or to be ignored due to a rejection of traditional leftist organizing (especially the party), low level of base-building work if compared to the early PT era, and a mix of defensive or self-proclamatory stances that did not connect to the present state of consciousness of the masses then nor recognized how terribly and why a portion of the masses had turned away from leftist consciousness (See Chapter 3 for the conflicts between the PSTU and the crowds and the party's organization of parallel demonstrations). The way the crisis of representation around corruption still backfired on the radical left is evidence that there had to be more to their rejection than just being victims of their association with the PT. Therefore, when the radical left overvalues the progressiveness of the crisis of representation, it neglects its post-political facet and how this impacts their own share in the crisis through the larger crisis of praxis of the left. It also makes the radical left more susceptible to giving into leftist post-politics later on in order to see faster results in representation, even if they do not fix the first facet of the crisis. This is the subject of the third section of this chapter.

If what was revealed in June 2013 had indeed been just a crisis of representation, I would agree with some of the interviewees that this crisis was progressive and generally 
favourable to the parties and organizations of the radical left that were not directly associated or responsible for the reason given by the crowds (corruption) to reject current politics. Yet, despite the fact that the radical left had been fighting the organizations of the status quo and even taking a stance against corruption, the radical left got swept under the rug with its opponents. Most crowds did not differentiate between the non-corrupt, system-fighting parties and the majority of the party system. The reason why they do not differentiate is the moralist sentiment around corruption that, in a post-political technocratic way, focused on the format rather than the content, in this case organized politics and primarily the political party form. Radical left demands closed doors for crowd validation, since these related to the politicized economic sphere, and were associated by the crowds with the Workers' Party.

This is the main difference between the legitimate crisis of representation that is real in the Brazilian conjuncture and was indeed exposed in June 2013 and the version enacted postpolitically through appropriation. The crisis of representation was reduced to a crisis of partyform representation, which, coupled with the simultaneous sentiments of anti-leftism through moralist anti-corruption and the foreclosure of antagonism as a political element, evolved into a crisis of representation with major negative effects for the left and prospects for leftist politicization. By erasing the class-based, systemic, political reasons for a crisis of representation under depoliticization, post-politics also offers itself as the answer to this crisis. This challenge is evident in the struggle for the crowds of June 2013 and afterwards, especially as society becomes more polarized through ultra-politics and the temptation to capture them through populist, post-political appeals grows together with the leftist desire for new victories, even if less politicized than they should be. 


\section{Post-political crowds in June 2013}

Introduced in Chapter 1, and used so far to refer to the people collected in political events, Jodi Dean brings in the concept of crowds in order to make sense of the complexity of mass protests against the problem of collectivity. Her discussion is very pertinent to the case of June 2013 because of the positioning of the crowd in relation to being a political subject. She states that "The crowd does not have a politics. It is the opportunity for politics. The determination whether a crowd was a mob or the people results from political struggle" (Dean, 2016, p. 8). In June 2013, the crowds were evidently being struggled for, and whether some emerged post-political, ultra-political, or captivated by politicizing (or even the selfproclamatory) efforts of the left depended on this political struggle and what actors were willing to vie for it. The willingness to struggle for the crowd indicates why the refusal to do so by the Free Pass Movement (MPL), for instance, led it from being a singular reference in the beginning of June to ultimately being affected by a rejection of leadership after removing themselves as protagonists due to the successful negotiation with the city of São Paulo over the hikes. The movement's objective was to cancel out the fare increases (Singer, 2014, p. 30), but the crowds had already moved beyond that in positive and negative ways. In the context of Žižek's account of political protests, the MPL as a voice of a single demand abstained itself from the universality (even if diffuse and ultimately captured in a depoliticized manner by anticorruption) of June. The right, on the other hand, was intent in disputing the crowds from the beginning, first to demobilize them, later to co-opt them. This was done primarily through the mainstream media, but also through social media, whose neutrality comes into question after so much celebration over it during June 2013. Mostly, the sublimation of a politicized classist crisis of representation into a moralist one centred around corruption instead of capital may be 
the biggest triumph in the right's political struggle for the crowds in June. What remained for the left, in its fragmented state and caught up in the backfire of anti-petismo, was to aggregate those it could around a new vanguard, very youth-based, and find alternative forms of politicization. As Dean affirms, if the left is disorganized, it neither can make something out of crowd outrage nor build out of the crises it encounters along the way (Dean, 2016, p. 71), a crisis of representation included. In the Brazilian case, this disorganization has to do with fragmentation, disconnected dialogue, and internal disorganization rather than a problem of form. Also, being in an already depoliticized terrain alters the rules of the game in favour of the right, and even alternative politicizations might be themselves contaminated by postpolitics and ultra-politics, which will be demonstrated later.

This political struggle over the crowds has to do with its interpellation. From my interviews, I could tell that the radical left is still struggling to interpellate the "crowd" of 2013, as it tried to back then in a faster, more pressured, and more contentious moment. One way to do so is by saluting the "crowd" as inherently progressive because of the progressive potential of mass indignation. The difficulty lies in the recognition that while June 2013 was indeed a progressive event as a political school, there was not one crowd but multiple ones to be interpellated. Even the less progressive, post-political crowd can be interpellated, but the task and the trouble involved is of a different quality than the more politicized crowd that has managed to be connected with the left in varying degrees since 2013. To attribute just one crowd to June or to make only one crowd the bearer of a singled out "essence of June" creates a fetish. The crowd is seen as the complete political subject instead of the gap for political subjectivizations in order to promote June 2013 as a rupture, even if this justification is not necessary from this standpoint. Dean argues that these breaks and gaps are crucial because they 
are how politics is manifested, so that the "crowd is a necessary but incomplete component of political subjectivity" (Dean, 2016, p. 115). The gap between the crowds is what is important in this context, because it exposes the encounters and deviations around politicization and depoliticization in June and allows us to move forward towards a project that tackles postpolitics responsibly, rather than isolating it out from the chosen progressive crowd that also embraced (and less intensively) continues to embrace some of the post-politics in a more leftist packaging. For Dean, post-politics creates particular obstacles to the left because it forecloses such political gaps by creating the appearance of the political (e.g. being in the streets and making demands) "without actually taking the risk of politics" (e.g.: organizing, making proposals, fighting the status quo instead of optimizing it) (Dean, 2009, p. 35). This is exemplified in the packaging of demands to exit the crisis of representation through political reform, which although necessary in its more radical shape and content, was proposed by the PT government to capture June (Machado, 2015) and subsumed into a series of technocratic adjustments that would be put forward as counter-political reform two years later by Eduardo Cunha (PMDB) as a right-wing leader in Congress. For Givanildo Giva, from the PSOL (Coletivo Retomadas) and Terra Livre, the political reform agenda has been a heavy bet by the right as it also tries to capitalize (or save itself) in the crisis of representation (Giva, 2015).

Žižek provides an interesting account of the politicizing nature and effect of popular protests, here in the context for a protest with a single demand. He writes:

Let us recall the standard example of a popular protest (mass demonstration, strike, boycott) directed at a specific point, that is, focusing on a particular demand ('Abolish that new tax! Justice for the imprisoned! Stop exploiting that natural resource! ' ... ) - the situation becomes politicized when this particular demand starts to function as a metaphoric condensation of the global opposition against Them, those in power, so that the protest is no longer actually just about that demand, but about the universal dimension that resonates in that particular demand (for this reason, protesters often feel somehow 
deceived when those in power against whom their protest was addressed simply accept their demand - as if, in this way, they have somehow frustrated them, depriving them of the true aim of their protest in the very guise of accepting their demand) (Žižek, 1999, p. 204).

Although this narrative deals with a single demand, it speaks to a particular moment in June 2013: the communication that the millions in the streets were protesting for more than just 20 cents (the fare hike in São Paulo). The myriad of demands beyond public transportation hikes was symbolic of a political engagement of the crowd that was progressive and politicized, especially because the successful negotiation between the Free Pass Movement (MPL) and the city of São Paulo did in no way diminish the fuel of the protests; in fact, it might have sparked the need to push for more demands than before in many places. The problem occurs when postpolitics comes into play more evidently, since elements of it were even present in progressive demands such as the indignation beyond "20 cents," when it evolved into an erasure of the antagonism present in the struggle for the public good and space by appealing primarily to corruption as the source of all problems (see next section). The point is that when post-politics becomes more dominating, to the length of taking over large portions of the crowds, it creates a reverse, highly depoliticizing effect. Post-politics manages to reduce the overall demand(s) of the crowds into one particular demand, in this case anti-corruption for the good of the country/Brazilian democracy, through experts, in this case the media (Žižek, 1999, p. 204). What ensues in Brazil after this fits perfectly within the narrative that "this suffocating closure gives birth to 'irrational' outbursts of violence as the only way to give expression to the dimension beyond particularity" (Ibid.).

The public transportation issue is inherently economic (and social), and the particular impact of public transit fare hikes in a country where public transit is predominantly used by the poor working class and whose cost burden is only second to housing in their pockets, this 
issue needs to be seen through class lenses. What happened in June 2013 is that as the protests grew, the original class content of the demand became dissipated. As soon as demands went beyond the 20 cents, they were still class-based in the ways that they appealed to the state's abandonment of other public services such as health care and education. Class was removed when "not just 20 cents" became justified by corruption, lack of ethics and order, and a moralist view of the problem that depoliticized away from the economic, exploitative reasons that created more profit for private administrators of public transit and the expansion of the private sectors of health and education, all the while pushing precarious public services on the majority of the population who cannot afford cars or private care. For Andre Singer, "the basic framework of the country's socio-economic order was not called into question" in June (Singer, 2014, p. 19). Instead, all social and economic ailments were explained by the failure in technocratic management of resources due to corruption and politicians' disregard for faithfully representing voters. This is what Žižek refers to as the depoliticized economy, which drives the reach of depoliticization into other spheres.

When Lula became president and vowed to act in the name of class conciliation, he depoliticized the economic aspects of the lives of Brazilians by promoting a false sense that everyone could win even under a system that depends on the exploitation of the many by the few. He did this through increased consumption based on easy access to credit, which is based on the same reasoning that leads the crowds to believe that it was a matter of managing access so that everyone could afford the private (or the commodified public), rather than focusing on the essence of profit at the core of the system itself. This depoliticizing effect buries the original anti-capitalist sentiment in June, even though there were still some minority crowds, 
consciously or unconsciously oriented by left politicization, that continued to carry this sentiment and employ tactics such as Black Bloc to target the capitalist establishment.

For Dean, post-politics captures that need for change and sublimates in democratic drive $^{32}$ in a system in which democracy is prone to favour hegemonic re-adaptation. Thus in Brazil, political reform necessarily acted as a post-political mechanism, no matter how radical such a demand could have been when and if articulated by the left. In the specific June context, political reform was hijacked from the beginning, for it was "capable of foreclosing political moments before they ever develop[ed] into claims that require[d] anything other than a managed, technical response" (Gill, Johnstone, \& Williams, 2012, p. 510). It was put forward as a pacifying method, without any intent of jiggling the system, and even the notion that a political reform could curb corruption was limited (Santos, 2013, p. 22). This expresses why part of the left already recognized that the demand for political reform had been stillborn (Iasi, 2015), and why its political meaning could not be retained beyond 2015. The transition from the first efforts to form the Front for Political Reforms (FRP) led by the MTST, the PSOL, and other organizations, which was perceived as very focused on reforms, especially the political reform (Almeida, 2015; Iasi, 2015), to the stronger and more cohesive front Povo Sem Medo, focused on fighting the right-wing offensive and government austerity, illustrates how political reform weakened gradually as an agenda the more post-political it became materially.

Another example of a post-political appropriation that had to do not only with the democratic drive but also with elements of the crisis of representation, such as the anti-partisan

${ }^{32}$ Dean defines drive "as a way that the subject arranges her enjoyment" (Dean, 2012, p. 65). It is possible, though, to talk about democratic drive without getting into Lacanian terms, by framing it as a desire that becomes stronger than its objectives, therefore conducting the process in and out of itself. 
sentiment, is the fetish of horizontality. The focus on process and format rather than content, and the necessity to shun parties and push the organized left from spaces for fear of appropriation in June 2013 and afterwards is post-political. There was a strong focus on management, consensus, and the contention that these partisan or party-friendly organizations need to be brought down to the level of the individual as not to impose their weight as an already formed and politicized collectivity. The "não nos representa" call in 2013 was symbolic of the crisis of representation and while part of it focused on managing better representation through political reform, another part retained suspicion over the ability to represent and moved into horizontal processes that led to the same impasses as those faced in Occupy all over the world. Anti-partisanship could be seen in the crowds, regardless of their political affinity. Political reform was seen as an answer to the post-political crowds oriented in the centre, and the radical left became somewhat enthusiastic about the notion of political reform if it could be arranged to favour leftist organizations. The horizontalist answer, however, was more exclusive to the left-leaning sector, in autonomist and anarchic circles, as well as in those factions of the organized left that had previously suffered bad experiences with hierarchy and co-optation.

The debates over horizontality are vast and even polemical, so it would be easy to get side-tracked by them. However, it is important to mention them in the context of post-political crowds because such crowds remain, and the ability to politicize them for the left and even contribute to the struggles in which they are engaged depends on overcoming questions of format. Different from the post-political crowds focused on political reform, the ones engaged in critiques of hierarchy and proposals for more horizontal and consensus-based politics tend to organize autonomously and independently, especially in the student movement, which is 
filled with new militants from the June 2013 political school and whose view of the party form is just as negative as the hegemonic one in the crisis of representation, or perhaps more, due to long exposure to the vices and predatory practices of the student movements at universities and student unions. This creates an enormous obstacle for the left as it organizes within these circles and tries to empower the youth as a central political subject for the present political struggle. The youth was indeed a powerful voice in June that, even when captured by postpolitics and disdainful of the organized left, managed to become somewhat politicized and participate in progressive/democratic struggles that held the ground against the right-wing offensive in many places. The problem, of course, is that the post-political inclination towards consensual management in lieu of leadership (which exists even in the most horizontal spaces) limits the ability to integrate struggles and take them further, all the while contributing to the permanence of the crisis of representation, weakening spaces of intervention, and creating conflict of a small political nature that acts in detriment of the struggle. This indicates that although June 2013 was important for the politicization of this crowd, post-politics did not completely escape this crowd either and has continued to operate post-June through an artificial reading of horizontality that contributes more to the isolation of the organized left from places of struggle than to the decision-making process that could enhance that struggle. The rejection of party lines, sometimes even requiring party militants to opine and argue only as individuals rather than part of a separate collective, is an attempt to avoid division by creating division; that is, expelling from the process those who focus on antagonism and the many theoretical and ideological lines that stand before any unity can be achieved. In Jodi Dean's words, “they displace their energies onto procedural concerns with inclusion and participation, as if the content of politics were either given - a matter of identity - or secondary to the fact of 
inclusion, which makes the outcome of political struggle less significant than the process of struggle" (Dean, 2012, pp. 56-57). Individualism and disorganization became the norm (SaadFilho, 2014, p. 25), exactly the opposite from what the left hoped for. It creates a risk that even incomplete post-political crowds, the ones more politicized but disdainful of leftist organizing, may be lost back to depoliticization or to the disorganized space around a fragmented left. The post-political element lies everywhere from the depoliticized unfamiliarity with the radical left, the focus on process, and how this process drives politics as democratic desire rather than a politics that can be better communicated and advanced through one process or another. The fact that there is due criticism to authoritarian practices inside party organizations (and sometimes a democratic centralism that is more centralism than democratic), post-politics acts to neutralize party intervention outside of itself (in terms of politicizing, organizing, and growing) rather than as a critique for party decision-making reform.

This presents a particular challenge for the left in terms of building dialogue, trust, and politicizing further, since here issues such as the jumbling of the moderate and radical left together in the collective imaginary is the result of a more conscious critique of the organized left in general and not simply a depoliticized effect of the betrayal of the PT. It shows that it is insufficient and even unproductive to hail the youth as the subject of June if there are still such obstacles to dialogue that require much more work than declarations that these crowds just need to accept parties and partisan organizations because the left has been building this struggle for longer. Although this concern was expressed many times in the interviews (Carneiro, 2015; Genro, 2015a; Giva, 2015), there is still little idea on how to tackle it beyond being patient and showing service, which reflects the general feeling that left re-composition and repoliticization will be a process of many years and not as short-term as many organizations 
hoped right after June. To proclaim the left as the authentic representative of these struggles is not enough in times of depoliticization. The response and patient negotiation also depends on whether this disdain is still read as ultimately positive, in the sense that it forces the left to rethink itself and engage in self-criticism, as put forward by the MES (Dutra, 2015; Genro, 2015a), or if it becomes read more negatively because of the post-political consequences it has had that are unjust towards the revolutionary and democratic qualities of the radical left that get dismissed due to format and general mistakes that incur in throwing the baby out with the bath water. In this sense, Mauro Iasi, national president of the PCB, offers an interesting reflection, based on the interpretation of an unjust generalization. I agree with this reading and I add that this injustice is a result of post-politics and that the continuous preoccupation of format, such as through a horizontality that snubs party actors, indicates the presence of these post-political remains and the incomplete politicization of the some of the radical youth crowds of June.

We were the first to salute this as positive, because it as a healthy reaction to a party form that had prevailed in the last period [...] [The reaction] is unjust because it is generalizing, it will believe that the problem is in the political form and not in one determined political form [...] You transform parties in a mere electoral platform, then it is really useless and must be criticized. Now that effort that can't be dismissed of militants inserted in concrete social struggles and who have reference in programme, strategies, get formed [politically] and act organized and disciplined, this is an important instrument (Iasi, 2015).

Finally, it is important to highlight that since "the crowd is a temporary being" (Dean, 2016, p. 9), the tendency to make a fetish out of June 2013 might be a deterrent for finding alternatives in and out of itself. The excess of revolutionary energy of June will still be felt, but due to its characteristic as a political school, and not because its crowd is a permanent 
agent. $^{33}$ The tendency to see the crowd as an agent is detrimental to the Brazilian left. One reason is because it overvalues political action around political events, and leads us to think that political power can be measured or found according to one's ability to mobilize particularly in the streets. This makes the game of comparing the numbers of protesters taken to the streets by the right and by the left (divided into radical and moderate) since 2013 a very frustrating one, for it misses the point that these crowds are mobilized by very different politicizing or depoliticizing powers and that, in any case, much higher numbers are required of the left to transform political action into political power beyond acts of resistance. The other reason is that holding on to the crowds of June 2013 as if their sentiment is present today or could be encouraged today presents a reified view of the event that is both melancholic and negligent of the need for ultimately different and more politicized crowds. Is the point to build a new June 2013 or something better than it?

\section{$\underline{\text { Ideological relationships }}$}

The previous account of June 2013 demonstrates the need to contextualize the crisis of representation exposed in that moment through its later expressions in corruption and ufanismo. Without this, it is easy to homogenize the crisis as wholly progressive and forget how its appropriation by post-politics denies the roots of the crisis and portrays it back as a crisis of representation caused by corruption, absence of order and the appearance (in the sense of instrumentalized illusion) of ethics. The two main elements that helped to appropriate the

\footnotetext{
${ }^{33}$ Here I make reference to Slavoj Žižek's statement on potential beyond the immediate effects of an upheaval: "In revolutionary upheavals some energy - or rather some utopian dreams take place, they explode - and even if the actual result of a social upheaval is just a - commercialised every day life, this excess of energy, - what gets lost in the result, persists not in reality, but as a dream haunting us waiting to be redeemed" (Žižek in Fiennes, 2012).
} 
crisis of representation as well as the myriad of demands in June 2013 for post-politics are corruption and ufanismo, and they continue to be a problem for the left in trying to politicize (as they were in a less dramatic and impactful extend before 2013).

\section{Corruption}

Alfredo Saad-Filho and Armando Boito suggest that the events of struggle against corruption in Brazil have had little impact on how ubiquitous corruption continues to be in Brazilian politics; yet, the same campaigns have had negative effects for the left (Saad-Filho $\&$ Boito, 2015, p. 223). Part of the challenge for the left derives from the common sense tendency to approach it through moralism rather than systemically. As a result, the focus on corruption tends to grow beyond the daily corrupt practices of a government and the scandals that arise to create a sort of moral panic around it. This depoliticizes the issue further and eases the terrain for the right, whose political modus operandi is historically linked to corruption, to take over the struggle for its own purposes. Since June 2013, there has been an understanding that the radical left needs to learn to approach the problem of corruption and politicize it in ways that can remove it from the right's opportunistic agenda, and to articulate an anticorruption agenda to progressive change. Some of the potential to do so is found in the political reform proposals, which explains why part of the left has still held on to political reform as a platform, but still falls prey to addressing the problem of corruption as through a technocratic management of how capitalism allows for legal and illegal donations for politicians. Fernando Silva (PSOL - Insurgência) is correct to point out that there could be no truthful denunciation of corruption without talk of campaign donations and popular transparent control of public companies (Silva, 2015). The problem rests in how hard it is politicize these issues beyond simply "corruption", to actually deal with capitalism when the language of the crowds is 
immersed in post-politics and its reduction to all economic, social, political and even cultural problems of Brazil to corruption and lack of ethics. Post-politics is directly tied to moralism in this context, because moralism depoliticizes by erasing systemic causes rooted in antagonism while favouring rhetoric over action. In the meantime, the right continues to capitalize on it, through a moralist and hypocritical discourse that has helped to associate right-wing politics with ethics and order and a tough, although false, approach to corruption (Silva, 2015).

In June, anti-party politics mutated into anti-political politics embodied in moralist claims against corruption, and at the same time for order, utopian democracy, and good political morals illustrated by the image of the righteous peaceful protester with no ulterior motives (especially no party militant motives!). When a diversity of moral perspectives is displaced by one version of moralism as a doctrine, in this case conservative moralism that targets progressive sentiment, only easy answers are allowed, history is not as important as the facts of current practice, and people have to position themselves within the moral dualism: "a good Brazilian is against corruption, and if a Brazilian does not position him/herself against corruption in the manner established by the crowd, then he/she must be a bad Brazilian." This anti-political scene is very much part of the milieu of post-politics. It relies on the illusion of politics outside of politics (not just an anarchic kind of politics outside of organized politics) since the belief that the political is inherently tainted by the possibility of corruption predominates. The accentuated fear of the Evil of corruption led into anti-party action and even the aggression against party militants, with the PT as a main target following the mensalão corruption scandal that has been kept fresh in popular discourse by the mainstream media. ${ }^{34}$ In

\footnotetext{
${ }^{34}$ For an overview of the mensalão see Wainwright, H. and Branford, S. (2006) In the Eye of the Storm: left-wing Activists Discuss the Political Crisis in Brazil. Amsterdam: Transnational Institute (TNI).
} 
some circumstances, even the existence of multiple political parties in Brazil's pluriparty system was also questioned, which some conservative groups took further by arguing in favour of re-establishing military power in Brazil to restore "order" (Sakamoto, 2013).

When corruption is dealt with as a moral, rather than a political and economic problem, it is instrumentalized to replace actual sources of antagonism with primarily (self-serving) moralist claims set in circular reasoning. For Žižek, depoliticized moralism leads into philosophical dualism because "those who directly translate the political antagonism in which they participate into moral terms (the struggle of Good and Evil, of honesty against corruption) are sooner or later compelled to perform the political instrumentalization of the domain of morals: to subordinate their moral assessments to the actual needs of their political struggle 'I support X because he is morally good' imperceptibly drifts into 'X must be good because I support him'" (Žižek, 1999, p. 75). Doctrinarian moralist approaches are depoliticizing because they focus on attitude or individual action instead of on the various dimensions of the exercise and control of power (Brown, 2002, p. 383). When movements such as the indignados in Spain, Occupy Wall Street or the June events in Brazil reject corruption on the basis of ethics and morals (mostly built around the hypocritical figure of the "cidadão de bem" or good citizen), they encourage a paradigm of change that favours the view of an ethical revolution that would put capitalism to work for the people instead of against it rather than a fundamentally anticapitalist paradigm (Žižek, 2012, p. 79). Speaking directly of the indignados, Žižek worries that revolutionary potential is subsumed into the desire for honest politics, simply because the problem of corruption is perceived as a problem of the "entire political class" (Kioupkiolis, 2016, p. 101; Žižek, 2012, p. 79). This perception is contradictory because while it associates corruption with left and right in the system of representative democracy, it assumes that it can 
be fixed by simple representative democracy. The moralism behind it generalizes the problem only to those that can be held responsible and punished as individuals, thus failing to examine how the general reach of corruption has to do with systems and structures otherwise perceived only as imperfect or not perceived at all.

The moralist approach to corruption depoliticizes the issue and the system around it to the crowds at such an intensive level that it creates a myriad of paradoxes of demands and protests. Corruption ends up standing in for all other issues and becomes the scapegoat for the crisis of representation as well as the economic slowdown that has tormented Brazil for the past years (Braga, 2015). For Douglas Belchior, one of the difficulties in communicating with the crowds in the last period has to do with the confusion generated when people take to the streets to protest against corruption but also end up supporting an offensive against their own rights. His worry as an organizer is that when one issue covers others up in such a powerful way, the common sense around it reaches even those from the favelas who may not join the privileged classes in a nationalist anti-corruption call downtown, but will still feel connected to it through indignation (Belchior, 2015). If corruption is everywhere, then there is no point in distinguishing the left from the right. To make the foreclosure of politics worse, not even the dream of perfect democracy may be a functional demand and answer to the problem in the case of the favelas. The most marginalized in Brazilian society have so long been excluded from the rule of law (or only seen its oppressive facet) that simple management of representation would not do it, but under depoliticization neither would the left that they associate with the PT and its empty promises of redistribution and social justice. For them, the relationship between the left and democracy is already tainted, so that the left's appeal to penetrate the cloud of depoliticization by appealing to a fuller, more radical, democracy may 
resonate with the medium population, but not necessarily with the majority of the working class. The appeal to the democratic drive may not pay off for the radical left because it might not resonate with the target base, all the while reinforcing post-politics and the sublimation of the actual struggles into moral struggles such as about corruption.

The radical left has attempted to deal with the fact that anti-corruption claims have become depoliticizing in different ways, though all organizations seem to work from the argument that corruption is a problem of capitalism. This premise is used to exempt the radical left from association with the corruption in an a priori manner, and part of it has to do with explaining the PT's growing problem with corruption through its capitulation to capitalism. This, of course, is a flawed reasoning, since corruption based on favouring capitalist enterprise or personal profit is just one kind of corruption. Even if this corruption is the one at the heart of the struggle and the source of moralist depoliticization, a more honest debate would be necessary in order for the radical left to avoid promoting a moralism of their own based on a simple "we are good and they are bad" framework. Corruption, as a misrepresentation and tarnishing form of politics, also operates in the radical left and does damage to unity, trust, strategic alliances, daily activities and political formations, all of which are issues that depoliticize and are connected directly to the state of fragmentation. Here I point to two examples that were mentioned frequently throughout the interviews: the dirty syndicalist practices of the labour union sector and the questionable processes through which political parties elected their board officials, leadership and the politics to be prioritized. This is not to mention that stricter rules against electoral campaign donations may safeguard the general integrity of the parties but are not guarantees against personal dealings and under the table financing. 
The case of the unions is clear because of how their structures tend to favour a strong attachment to the apparatus over time. The clearest example of this is the CUT, especially through PT influence in the union. Given this, some in the radical left would argue that this is a problem of the moderate left, but Ruy Braga, a long-term militant first at the CUT and then at the CSP-Conlutas and researcher of the sociology of labour in Brazil, argues that such problems are endemic to situations in which union power is reproduced through uninterrupted control of the apparatus (Braga, 2015). This tendency promotes union gangsterism and that, in and of itself, takes corrupt practices such as union election fraud to a whole new level through threats and violence. Election fraud is also a complaint by the radical left at the elections for the National Union of Students (UNE), which has been controlled by the youth movements connected to the PT and the PCdoB since 1980 (Paiva, 2013, p. 63) and operated with strong loyalty to the PT governments since Lula's election, as it became evident through its defence of the regressive University Reform (Iasi, 2015; Paiva, 2013, p. 126; Tavares, 2015). In the example of the parties, election fraud is a special concern at PSOL congresses (Telésforo, 2015; Varela, 2015), where internal dispute tends to be heated and close, while parties with democratic centralism experience their own kind of internal fragmentation as democratic centralism principles become corrupted to favour and legitimize hegemonic, traditional views, and stifle dissent. This last element, for instance, has led to internal critique inside the PSTU, including the exit of prominent militants and intellectuals from the party.

These processes suggest that although there is a desire by the radical left to politicize over corruption and take the anti-corruption struggle away from the right and into the leftist critique, the self-exempt way that the radical left has approached the corruption issue may not be resonating with the crowds as it had hoped. I argue that this is because simply relegating 
corruption to a problem of capitalism neglects the implications of corruption in anti-capitalist scenarios that must be addressed if the left hopes to politicize about it effectively. The radical left suffers from the association with the PT and its corruption scandals, but fails to differentiate itself because simple speech cannot penetrate the dualism around corruption and anti-leftism. In fact, the radical left has been shouting how different it is from the PT to all corners from before June 2013 and the effects have been minimal and fragile. While the PSOL has grown considerably in institutional representation, partly due to its credibility and combative stance regarding internal corruption, the growth is still small if we consider that the PT, which is associated with corruption, continues to be the hegemonic force of the institutional left despite recent (steep) decline. This indicates that betting on growth around being ethical does not translate into institutional gains as well as it does for the right, for example, which has a perfect domain of (hypocritical) moralist speech. And if it has not helped institutionally, this differentiation means even less with the target base, since its change of consciousness depends on slow base-building work that may become more contradictory before it resolves itself. Finally, the confusing, fragmented, and predatory practices inside of the left prevent it from creating a praxis that tackles corruption without any remnant of moralism and makes it difficult to politicize without deferring to a post-political solution such as political reform based on electoral rules and structures.

\section{$\underline{\text { Ufanismo }}$}

Ufanismo refers to the nationalist and patriotic sentiment promoted by the exaggeration of the riches and qualities of Brazil as a nation. It was part of the strategy of the Brazilian military dictatorship to contain anti-dictatorship views and was evident in the amplified patriotic culture displayed during the 1970's FIFA World Cup (and, to some extent, at every 
other World Cup since, through the personification of the Brazilian national soccer team). Although many protesters targeted the 2014 FIFA World Cup in Brazil as a source of improper public spending and questioned the legitimacy of FIFA's intervention in Brazilian politics, this did not prevent the protests from being absorbed into the same sentiment of ufanismo that prevails nationally during international soccer events every four years. Calls for wearing the Brazilian flag as a vestment piece during the 2013 protests were followed by the repetitive and arguably mechanical practice of singing the Brazilian National Anthem in unison. As the issue of corruption received emphasis during the bigger protests, the ufanismo displayed began to allude to the 1992 protests against Collor, when the student movement was often identified as "cara pintadas" in reference to having their faces painted in the Brazilian national colours of yellow and green. Given the anti-corruption theme of the 1992 events, the appeal to the national colours has carried through symbolically as a way to unite all the Brazilian people who stand against corruption.

As a phenomenon in June, ufanismo was successful in concealing antagonism and quashing the attempts by social movements, political parties, and radicalized protesters to highlight the connection between the issues of corruption, poor public infrastructure, and police repression as symptomatic of a larger structure that favours a dominant group over the others. That being so, ufanismo contributed to a process of consent by preventing radical groups from taking advantage of political unrest to promote a radical politics that is dependent on the critical cognition of one's problems in the context of structures of domination in society. It shows that we are dealing with more than a crisis of representation. Jodi Dean argues that while the autonomous and horizontal character of the Occupy Wall Street movement was inevitably connected to issues of representation, the movement's ability to promote a collective 
vision that still recognized a fundamental antagonism in society demonstrates that their crisis of representation did not degenerate into a rejection of representation (Dean, 2012, pp. 226229). Rather, the articulation of the division between the $99 \%$ that made up the movement and was represented by it against the $1 \%$ presented a reinvention of politics. Despite issues regarding long-term organization and sustainability of the movement, this articulation suggests an attempt by the $99 \%$ to reclaim politics from the domain of the $1 \%$.

In the major 2013 Brazilian protests, voices for the reclaiming of political space were silenced by the historical hold of ufanismo that would instead appeal to an erasure of political space and its replacement with dangerous strains of patriotism illustrated in claims that "My party is my country!" National pride silences those willing to confront the state and its relationship to capitalism, and as such can be a useful tool to repress radical voices. The erasure of antagonism and promotion of false unity in ufanismo connects deeply to the post-political anti-party stance of the crisis of representation. As the 2013 protests unfolded, it became very clear that this would take on an ultra-political turn, since it empowered right-wing parties at the expense of left-ring parties. Douglas Belchior, an influential organizer in the leftist black movement and militant in the PSOL, states that this is partly due to the fact that the right never did much work in associating their political project with the notion of the party, while the party remains a fundamental part of the leftist project because of the need to build instruments for class power (Belchior, 2015). Yet, at the time, the simple rejection of the party form led part of the left to see it simply as a symptom of the crisis of representation. The difference is drawn when we observe how it was not only the party form that was rejected, but the primary notion that a political party ought to be an instrument for political intervention. Since anti-partisanship relied heavily on the rejection of the PT as party that failed and also brewed corruption deeply 
in its ranks, the rejection of left-wing parties was qualitatively different from the rejection of right-wing parties.

The association with corruption, lack of ethics and morals, an an ideological ground built on conflict, made the rejection of parties on the left post-political in the way it would promote consensus instead, shun antagonism, and dismiss political ideology as subordinate to the needs of Brazilians and the country. The right, on the other hand, suffered less because its parties are not instruments for the masses but for the elite, so the mass rejection did not alter its status. Further, the lack of ideological commitment of the right and its ability to hide rightwing ideology in the common sense, made their parties mostly a target of the party form criticism rather than their existence as political tools. When anti-partisanship morphed into the "my party is my country" motto, it nationalized consensus and tolerance through ufanista depoliticization. Ufanismo acted as the signifier that has to be raised to promote an "impossible political alliance between all these divergent and potentially antagonistic positions" by appealing to simple unity beyond all political differences (Žižek, 1999, p. 178, emphasis in the original). The antagonism core to class consciousness (and left mobilization) was rejected because it divided the country and, therefore, acted as an obstacle to progress and development for a "mythic, impossible, all of us" (Dean, 2012, p. 100, emphasis in the original). At the same time that the left suffered from the anti-party sentiment because of its commitment to the political party project, it also became more distanced from the crowds and its opportunity to politicize them because, like the matter of corruption, the left also does not have a good grasp on how to handle the nationalism question, even if not in the ufanista depoliticized facet (Madeira, 2015). The Brigadas Populares is the only organization studied in this dissertation to deal with nationalism as a central factor, which it does from the perspective of a 
revolutionary nationalism, grounded in anti-imperialist struggles (Telésforo, 2015). Yet, nationalism remains mostly a depoliticizing tool through ufanismo and favourable to postpolitics to hide antagonism and to ultra-politics to empower nationalist conservatism.

While ufanismo prevented mass politicization, conservative voices from the right were able to infiltrate the protests disguised as non-partisan under the banner of free speech. Therefore, once ufanismo became consciously employed by political actors in the right, it began to serve an ultra-political purpose as well. Signs and posters that made apology to the conservative wave in Brazil currently fighting against equality and civil rights were not uncommon. Anti-party sentiment was easily manipulated into anti-PT and "anti-Dilma" campaigns, going as far as calling for president Dilma Rousseff's impeachment, seemingly due to the perception of an impeachment as a viable solution for political "buyer's remorse."

Although ufanismo and extreme nationalism were entirely captured for right-wing purposes afterwards, evident in the nature of post-June 2013 right-wing social movements and the sea of green and yellow vestment in pro-impeachment, right-wing protests, ufanismo continued to produce post-politics as well. It is no wonder then that when Marina Silva, then a member of the centre-right PSB, ran for presidential office in 2014, she appealed to nationalist values in a post-political sense all the while rejecting left or right labels and devaluing the role of the party in politics (Fernandes, 2014). Her political project was significantly right-wing, and her endorsement of PSDB candidate Aécio Neves later on would demonstrate that more clearly, yet she was able to employ and benefit from the political discourse, as well as the

${ }^{35}$ More evidence to this is provided in the next chapter, especially regarding 2014-2016 in Brazil and the presence of ufanismo both to erase antagonism and to deepen a militarized form of polarization that serves conservative interests. 
ambiguity of her own ecocapitalist project, in order to capitalize on the post-political crowds of June 2013. Her error of analysis consisted in how the conjuncture at the electoral level had turned ultra-political, whereas part of the post-political sentiment had translated into annulled and blank ballots at the voting stations. Still, it is important to notice that her post-political discourse was able to deceive those whose politicization remained in dispute since 2013, a fraction of which was confused when she endorsed Neves. Even more worrying is the fact that Silva's connection to part of the people through post-politics indicates how far the left remains from politicizing coherently this portion of the population that did not turn immediately to siding with the right because of their rejection of the PT but instead were fooled by Silva as they looked for alternatives, for a third political camp that ended up being in fact a third way post-political one. Rafael Madeira, from Insurgência and a candidate for Congress through PSOL (in 2014), expressed concern over this when we discussed difficulties the left faces to enter into dialogue with the lower and middle classes, since the post-political scenario effectively shuts the door to conversations at the core of left politics (Madeira, 2015). This creates a challenge around the fact that the left has lagged behind in base-building. It had an opportunity in June 2013 but was backed into a corner by post-politics and ultra-politics, all the while having to watch third way actors take the stage empowered by such post-politics. With the lack of credibility around the party-form, the right and the post-political centre learned to manoeuvre around the Brazilian identity to reach out and gain support from people in all of the different tracks of depoliticization. The danger lies that in trying to find ways to connect to the base in the post-political mind-set, the left might compromise on elements that make the left what it is and operate as politicizing factors, therefore giving into post-politics itself and 
becoming more entrenched into the cycle of depoliticization that maintains the radical left, especially, on the sidebar, small, and without a cohesive project.

\section{$\underline{\text { Leftist post-politics }}$}

The crisis of representation exposed in June 2013 and the fact it was accompanied by anti-leftism and the birth of new right-wing social movements aimed at capturing the more conservative voices of the crowds indicated one thing among others: the radical left, and even parts of the moderate left, was puzzled at how to capture the crowds back fast enough that results could be seen and the right-wings voices could be muffled. It is known to all that the population is very depoliticized, and every person interviewed for this study was in agreement with this. However, to re-politicize may take years, decades even. After all, the process of depoliticization itself was not immediate.

As mentioned before, the ability to politicize an issue in the meaning of making it political is not exclusive to the left, though to politicize in the meaning of making the politicized into subjects who actively make politics is a terrain of the left and the one applied in the Gramscian-Marxist view of politicization employed throughout this project. This entails conscious efforts by the left to ensure that during times of massive depoliticization, all efforts to politicize have clear objectives that cannot backfire because of its form or content, or both, and end up depoliticizing in the even through common sense or methodology that aids in hegemonic renewal. The clear example of this is how the employment of post-political discourse or the prioritization of a post-political format, in the way it could portray the left as more palatable by removing the "hard" parts, actually turns back on the left and feeds a vicious 
cycle of depoliticization. This is seen in the PT project but also in situations where leftist actors given in completely into neoliberal social democratic programmes.

Jodi Dean contends that post-politics also represents a theoretical fantasy: "the fantasy of a politics without politics" (Dean, 2009, p. 24). Although such fantasy permeates the writings of some left scholars, and by consequence the actions of some left organizations and actors, its direct meaning takes us to depoliticization. The politics without politics in the left makes identity and the local the primary struggle, rather than the structure elements that could raise the antagonism necessary for the radical and eventually the revolutionary, which by consequence naturalize identity and the local in the first place in its inability to build the universal. If antagonism is not palatable, neither is the construction of the universal as a terrain of struggle. In this context, post-politics erases the potential for rupture that happens when one dares to assert a particular truth about reality and replaces it with tangents, relativity, and neverending processes of reformation. When the left begins to operate in post-political terrain, it forfeits the "act" (in Žižekian terms) that is essential for revolutionary demarcations, and it does so for need of being legitimized in advance (Dean, 2005, pp. 174-175). This avoidance of risk is, in other words, a choice for palatability (explored in a later section) in a time when fighting depoliticization is one of the most necessary tasks but also one of the most defeating ones for a left facing deep fragmentation. In an attempt to negotiate the difficult parts, the left may turn to post-political populism, sometimes unaware that this terrain is also one the right has gradually learned to navigate well. Further, what seems to be only post-political tactics can easily alter the path of leftist strategy, since it involves the element of depoliticization that goes against the path that leftist praxis should be taking and creates a hierarchy of left intervention 
more focused on action (especially impactful, potentially Event worthy action) that could cause reversions to class and oppression consciousness at the same time.

\section{Post-political populism}

Having to deal with the two facets of the crisis of representation presented above and its consequences during and post- June is one of the biggest challenges for the radical left. While the moderate left retains its priority of saving itself at all costs, even through more depoliticization and through opportunistic practices around mobilization, the radical left must choose its tactics carefully, for its existence and sustainability depends on the ability to politicize again. This dilemma is well illustrated by Madeira:

I think the right achieves this [victory] in the moment that it speaks, in a crisis of representation, that no party represents us and individualizes it to 'I don't vote in a party or programme. I vote in the individual whose ethics is appealing to me.' This is a debate that we [the radical left] have lost a lot and haven't managed to reverse it. There was a part of the left that really got into the question of the crisis of representation and this was taken through a very official discussion. There was another part that admitted it and didn't manage to make the discussion for fear of distancing people, not finding the words or not wanting to use the key words (Madeira, 2015).

Left fragmentation and the discovery that the crisis of representation could impact the radical left in almost personal ways, such as by pushing party militants out of their own spaces of activism because of their party association, led the radical left to seek options for intervening in the conjuncture without the risk of further severing their now weak ties to the crowds. This is not even considering the presence of fascist actors in the crowds that targeted precisely leftist flags and militant with threats and acts of violence (C. Garcia, 2015; Santos, 2013, p. 18) and whose violence continued after 2013.

While there has been a rise in right-wing populism in Brazil since June 2013 (see Fernandes and Paulson - forthcoming), I have also identified efforts that could be categorized 
as leftist post-political populism of a kind different from Lula's populism. The populism present in lulo-petismo, and in other versions of leftist governments in Latin America, consists in matching symbolic popular appeal and redistributive efforts, as in the case of programmes such as Fome Zero and Bolsa Família (Reis, 2010, p. 70). Whereas it does carry negative connotations through ties to personalism, discourse manipulation, and depoliticizing propaganda, the lulista populism is well-remembered for being efficacious regarding these specific measures. Although Lula did not promote agrarian reform (or any radical reform, for that matter), his developmentalist focus and work towards inclusion through consumption and credit and the eradication of absolute poverty makes his populism more believable and even desirable by some, even if it means an incomplete leftist transition and broken promises.

Leftist populism should not be written out just for being populist; it is the post-political kind that concerns me given the arguments laid out throughout this chapter. There is a tendency in the radical left to appeal to post-political populism as an answer to both lulista populism, which resulted in deep depoliticization and support for setbacks under moderate leftism, and to right-wing populism, which has grown recently as an attempt for the right to make itself more palatable as an option to those who had opted for the moderate left since 2002 (explored at the end of this chapter). The right has been immensely more successful at mobilizing through post-political populism than the left, which is evident in the green and yellow protests against corruption in 2015 and 2016. What also changes for the right is that it mobilizes through ultrapolitics too, by using the post-political realm of anti-corruption struggle and ufanismo to polarize against the PT, the Dilma Rousseff government and leftist ideology in general. This, of course, also nurtures an extreme right, that although smaller than the populist right, should not be dismissed. The radical left must find quick ways to appeal to the working class before 
they get captured or recaptured by these options by positing itself as an alternative. However, to be seen as a viable alternative requires politicization, which is part of a long-term process of base-building work and debate. Yet, by making compromises and choosing simplistic tactics in the level of the moderate left and right-wing appeals, the radical left may see some shortterm gains. The problem is that these gains are temporary and may soon dissipate back to the status quo options for lack of politicization and, worse, new depoliticization resulting from the radical left's dabbling in post-political terrain.

One of the main examples of this is how some left organizations have gained ground since June 2013 by negotiating around the party strategy and through more flexible party and participation format. This tactic was seen as fundamental in order to keep the right to remain in the protests of June when parties from all sides were being called out and thrown out of the demonstrations. The MES, for example, opted to remove references about the PSOL and to intervene through its youth arm, Juntos (Dutra, 2015). In Brasília, other PSOL groups engaged in the same strategy, as it was unthinkable not to participate in such a relevant moment because of the eventual unfairness of a rejection that, at first, was perceived by the organized left as a legitimate expression of the crisis of representation. ${ }^{36}$ In the words of Rodolfo Mohr (PSOL MES), the overall rejection was part of a specific asthetics of June that the left could not simply ignore (Mohr, 2015). This put groups inside of the PSOL in a delicate position by having to hide the party's presence and the right to being present at the June events; however, the tactic allowed the groups to fight over the meaning of the crowds through other instruments better

\footnotetext{
${ }^{36}$ This pertained to the first crowd moments when partisanship was rejected in fear of political party co-optation, rather than when anti-partishanship derailed into anti-party sentiment and action that dictated how individuals and groups could express themselves politically during June.
} 
than the PSTU, for example, which insisted in its right to be with the crowds due to its historic practice but missed opportunities to compete for the direction of the crowds because of the outright rejection. In both situations, the organizations had to give up on something and to compromise in other things. However, based on the growth of the PSOL after June, this tactic seems to have paid off more, but it is likely that the PSTU tactic would have produced higher degrees of politicization had they managed to be accepted by the crowds.

The radical left did not have many options in June besides hiding its own party references when these were rejected by the crowds or insisting on them in hopes they would be heard by some, but this trade-off is not the only set of choices today, even though anti-party and anti-left sentiment remain. This is why I introduce a critique of leftist post-political populism, because some organizations in the radical left still seem torn between these two choices in fear that the urgent nature of the conjuncture will only favour the same tactics employed in June. In the case of the MES and Juntos, for example, it is not a matter of hiding the PSOL anymore, which after Luciana Genro's relative success as PSOL's presidential candidate would be a fruitless effort. Instead, the organization had shown a propensity towards post-political populism through a flexibilization of tactics (Dutra, 2015). This is not a matter of using labels such as "socialist" and "revolutionary" in all communications and events, as I heard from PSTU members in the ethnography who thought such affirmations were important to qualify one's programme as non-reformist or at least to try to indicate it so (Fernandes, 2015). One can have, after all, a socialist programme without using the word socialist as a label. The opposite is also, of course, true - as demonstrated by the PT, whose popular democratic programme was strongly reformist but appealed to socialist discourse whenever it was necessary to appear more radical (Almeida, 2015). You might not use the word socialism 
in everything, which is important in delicate times of depoliticization and anti-leftism, but it matters what you replace it with.

The MES was very connected to the Greek scenario through Syriza when I did my interviews in 2015, and there was an obvious appeal to Syriza's own populism (Kioupkiolis, 2016) as a road to something bigger that only the people did not know yet. This promoted their view that even though Brazilian society was still very depoliticized, there had been enough politicization in June as a whole already to lead into new events and strengthen organizations willing to be conduits to these events, which this dissertation contests in terms of the postpolitical hold of some apparent politicized expressions and of the heterogeneity of crowds. This enthusiasm around June, which was more dominant in the MES than in any other organizations I studied and worked with, was positive because it made the organization bolder, but also negative in the way that it prioritized visible acts of resistance - the more visible the better - as part of an "Event" (discussed in earlier chapters) and as major politicizing instruments. Incessant activity, however, is not guarantee of politicized crowds and may actually distract from the long and arduous process of politicization necessary to prevent what could eventually be regarded as the 2015 Syriza fiasco. The organization's own comparison with Podemos is also important here, as Podemos' populism relies on a much more postpolitical basis than Syriza's, which I discussed during the interviews (Dutra, 2015; Genro, 2015a), and is sometimes qualified as "post-political governmentality" (Kioupkiolis, 2016, p. 100). Its populism relies heavily on positive tones, a focus on victory and an "inspiring confidence in the possibility of imminent rupture and change" (Kioupkiolis, 2016, p. 103), all of which are common themes in the communications of the MES and in other communications of PSOL tendencies whose agitative intent tends to recognize defeat while dismissing its 
weight in the face of overvalued small victories (MES, 2016). It also promotes a constant realignment of positions according to which ones seem to better answer the crisis of representation at the time (e.g.: Genro's critical embracing of que se vayan todos in 2015 and its use to support the Lava Jato investigation as a progressive endeavour) (Genro, 2015b, 2016).

Podemos is a special leftist populist role model because it deals with the problem of a crisis of representation, which is also a fact in Spain, through its reinvention as partymovement. This discussion has been part of the MES since the late 90s (Dutra, 2015), but I suggest it has gained a new aesthetic layer since 2013 and inspired by the success of Syriza, and primarily Podemos as an organization within this model. The matter is that June and the indignados do bear similarities to each other, but these are not necessarily positive. For instance, the more you overvalue the progressive element of the crisis of representation in either case, the more necessary it seems to flexibilize and compromise in order to fit into the type of representation that could appeal to those crowds. As a result, if the crisis of representation had post-political elements, the organizations focused on legitimizing the crisis as a whole would have to embrace some of the post-politics, too. This is observed in personalism (most prominent during elections), populist discourse of an overly agitative nature (common in the organization's social media engagement over victories and prospects), willingness to compromise and share alliance and electoral spaces with the moderate left to appeal to a wider base (very present in the 2016 electoral campaigns), and the incorporation of potentially damaging discourse in order to appeal to the depoliticized (yet evaluated as more politicized) crowds (e.g.: support for the right-wing led Lava Jato investigation, promoting a Fora Todos/General election tactic before Rousseff's impeachment crisis was consummated). Fortunately, what prevents the propensity towards post-political populism from taking over in 
the MES is the fact that the organization also invests in base-building work in the student movement, the labour movement, as well as around feminist and housing struggles, all of which make up a very politicizing terrain. This creates an advantage in relation to the PT, for example, which abandoned base-building as a foundation of the party the more dominant lulista populism became.

Although I use the MES as an example here, it is by no means the only organization in the radical left to give into post-political elements in their own attempts to politicize and gain a wider base. I mention it precisely because of its growing visibility and leadership inside of the PSOL, so to encourage a rethinking of the elements that bring it closer to the Podemos and may lead to electoral victory at the expense of inadvertently reinforcing the post-political spectre of the crisis of representation and the vicious cycle of leftist electoral wins under lessthan-desirable permanent politicization. The APS, for example, as the leading organization inside of the PSOL, suffers from similar problems, although it could be argued that they are linked to the nature of the less radical popular democratic programme defended by the tendency and whose idealization inside the PT is connected to the depoliticization period that gave rise to post-politics as an answer in the first place. In fact, organizations inside of the PSOL or closer to the PSOL are much more likely to flirt with post-politics than the PSTU or the PCB. Part of this relates to the gains of the PSOL in June and how it suffered less from anti-party sentiment than the centralized parties in that period. ${ }^{37}$ It had a greater appeal to the youth then and continues to be appealing to militants migrating from the PT (and other parties) who would like a more plural home. This advantage makes it more vulnerable to engaging in post-political

${ }^{37}$ This has changed partially because of growing protagonism, which right-wing opponents have used to warn of the PSOL's leftism. 
approaches, while the centralized parties are more vulnerable to promoting vanguardist and sectarian positions that could be harmful under ultra-politics.

Incessant activity seems to be the trend in the left post-June. Since June had protests every other day, it reinforced the idea that mass explosions can be encouraged in a similar way, perhaps even scheduled. This is evident in how demonstrations were scheduled sometimes months ahead of time for the rest of 2013 and with repeated promises of being the largest Brazil had ever seen (BBC Brasil, 2013). The expectations of the radical left for protests around the World Cup in 2014 were frustrated after realizing that social media agitation had dwindled, that fear of police repression was widespread, that the moderate left was strong enough to remove their share of the crowds from the streets, and that protest calls alone could not mobilize if the topic of protest required strong politicization this time.

Protests that can take hundreds of thousands to the streets for a sustained political purpose require previous politicization, and cannot occur the same way June did around a crisis of representation and post-politics. Yet, they continue to be a focus for the left in recent times, despite the fact that, in the case of Rousseff's impeachment crisis, for example, the majority of the class has abstained from the process due to lack of faith in it or a depoliticized approach to the impeachment as answer to the crisis. Considering this abstention is important because it is not necessarily linked to depoliticization, and might indeed communicate a true political act, in Žižek's terms, as “it forcefully confronts us with the vacuity of today’s democracies” (Žižek, 2008, p. 217) and thereby exposes the meaningless of incessant activity as attempts to connect with a post-political crisis whose performance was tied to protests in June and to respond to the melancholia of a left looking for any victories it can get. Continuous and frequent activity is important for the left and should indeed permeate all tactics employed. The problem occurs, 
however, when it takes over the complexity of other tasks, whose arduous results cannot be verified as quickly or openly as work leading into a protest. It can be less politicizing than leftist activities at the time have to be, or even depoliticizing if agitation is geared towards numbers rather than content. The first is the case when the radical left is entrapped by incessant activity (explored in Chapter 6), while the latter is common to the moderate left and its corporativist calls for membership and base to show up at events that may not even represent their own interests (e.g.: defending the Dilma Rousseff government when it is possible to stand against the impeachment without doing so). The less than desirable politicization around incessant activity and the way it usually ties back to a celebration or defence of democracy is worrisome because it curtails the revolutionary potential of the radical left, in particular, and contributes little or in contradictory way to the tasks at hand during a double-faceted crisis of representation such as the one prevalent in Brazil today. This is detrimental to the long run repoliticizing task of the radical left and it is why post-politics, including its populist elements, must be approached carefully and cynically. The repetitions of incessant activity result in getting rid of the old in order to embrace the new (Dean, 2012, p. 177), but it is unclear what the revolutionary potential is for the new in a context when newness has become associated with post-ideology, technocratic revival, and efficient management of politics.

\section{Palatability}

Finally, there is a warning of post-political elements in the Brazilian left, including the radical left, regarding the need to be more palatable under a crisis of representation and what palatability means in terms of a post-political environment that is not keen on the antagonism that ought to be at the core of radical left politics. By palatability I mean a tactical dilution of some struggles and statements in order to appear to a wider base. It entails a particular 
aesthetics of the political party, social movement, labour union and collective that is welcoming and less defined by arduous work, external and internal conflict, self-critique and constant dealings with antagonism.

When political intolerance means political antagonism (which is different from ultrapolitical "violent" intolerance informed by hatred), the promotion of political tolerance instead may weaken the left's prospects for politicizing important subjects, especially in terms of class exploitation. It is problematic to embrace tolerance as the opposite of antagonism (and as an ideal post-political tactic) for a few reasons. First, it appeals to a kind of moralism that often turns against the left through misinformation and the rejection of ideological stances. The left may try to appear as the good guys who are tolerable and understanding, but to do so is fruitless when the hatred promoted involves a consolidation of the view of the left as "communists who eat children", as one interviewee who deals with the challenge of politicizing an audience captive by common sense and right-wing media punditry put it (Basso, 2015).

In efforts to appear friendly, the left may end up relegating the loud antagonistic aspects that are fundamental to politicizing its own side of the struggle. This critique is often made of Podemos in Spain, which is perhaps the most visible example of a conscious softening of positions "in order to become more palatable to voters of a more centrist persuasion" (R. T. Garcia, 2015). More often than not, such softening has to do with electoral aspirations, where victories are in need in a much faster pace than can be achieved even if the left was whole and even in the fastest mode of re-politicizing under the current circumstances. In Brazil, palatability is connected to the same elements mentioned before, primarily the notion of radical or full democracy. One of the PSOL's television inserts in 2016 illustrates this well, since it constantly attributes benefits of social struggle, building poder popular, and what ultimately 
is the fight for socialism into the results of a more perfect democratic experiment (PSOL, 2016). This is concerning because to appear as an electoral alternative, the party opts to promote its class-based struggles as democratic struggles instead, which may result in depoliticization by associating social and political gains with ideals around human rights and social rights rather than social justice and the antagonism that expresses that a democracy of the people would actually entail taking away the privileges of a majority that just will not allow it come easily. Promotions like this one have led the PSOL to be seen as a palatable alternative (C. Garcia, 2015), since arguments around democracy and human rights are more easily digestible to the working-class and those sitting in the middle under a period of depoliticization. It does not mean, however, that this makes the PSOL "less revolutionary", since the opposite tactic of self-proclamation and vanguardism hurts revolutionary prospects all the same. What it means is that a softening of political positions (much more than any concern for a softened speech) indicates a strong focus on palatability as a way to have victories under intense depoliticization. It implies molding one's programme to common sense, rather than politicizing from common sense into good sense. Since the crisis of representation has had such a post-political focus on democratic drive, it is understandable why organizations looking for such gains may deposit so much effort in the promotion of democracy as a system for which to struggle.

Jodi Dean argues that the defense of democracy can indeed be radical and important for the left and I believe this is the case when, in an ultra-political struggle, one has to defend basic democratic principles in order to prevent more attacks on the working class. This is clear to see when the radical left has to appeal to democracy during the period of right-wing offense that led to an illegal process to remove Rousseff from the presidency. However, the appeal to 
democracy has most often appeared in contemporary leftism as a goal in itself, a substitute in the struggle for socialism (or communism), as if one could struggle for democracy and then the rest would follow (Dean, 2012, p. 57). The fight for social rights becomes associated with the fight for deepening the democracy in Brazil, a sort of "democratization [...] of power" (Rahmeier, 2016) which (inadvertently) sublimates into democratic drive under post-political hegemony. To speak of democracy is easier than to speak of socialism, and to attach "democratic" before "revolution" certainly makes things more palatable without the need to get into definitions, history, practices, political tradition, and, most importantly, the antagonism that democracy does not harness but quashes; that is, all that baggage that surely accompanies politicizing efforts. The problem is that if you only speak of democracy, or attribute to democracy victories that it can never lead to, the essence of the struggle becomes subordinated to democratic process.

The promotion of mottos such as "You don't have to agree, just to respect" to the deepening of post-politics by normalizing and managing conflict, rather than engaging in it with the intention of resolving it through counter-politicization. While there is an effort to remove the element of hatred, which is at the core of the ultra-political scenario, the notion that conflict can be managed through tolerance/respect is depoliticizing in and out of itself because of what tolerance replaces: a political approach to antagonism and its important role in creating

\footnotetext{
38 The "Não precisa concordar, basta respeitar" statement refers to a campaign promoted by the Presidential Office at the height of the discussions around the impeachment of Dilma Rousseff. Instead of tackling the problem of hatred by deconstructing it, the campaign opted for accepting disagreement informed by hatred (of the poor, of the indigenous, of blacks and of women) as long as it was limited by overt expressions of hatred. The point was to encourage freedom of speech without condoning hate speech, but failed to acknowledge that not all hate speech comes out bluntly as hatred and the structural oppression in the right-wing political oppression needs to be combated, not simply tolerated.
} 
class consciousness, and the difference between conflict management and actual political, dialectical, dialogue. It fails to see that real dialogue is intolerant, in the sense of being intransigent, since it engages with the right-wing other without having to accept the premises around privilege and exploitation that inform their side of the struggle. It also tells the difference of those you can engage in dialogue with, with politicization involved, and those you ought to be strongly opposed to in all aspects (e.g.: the anti-fascist fight). To manage conflict by establishing respect as an imperative covenant forecloses the possibility for rebellion, whereas dialogue allows for rebellion and antagonism at the same time it may also endeavour to surround most environments with respect because of its productive effects, rather than respect as a stand-in for passivity and tolerance. Internal intolerance inside of the left, often confused with intransigence (see Chapter 7) isolates organizations from each other, which cannot be the case in re-politicizing efforts. This indicates that by being palatable, promoters of consensus and tolerance, the left may be giving up on important opportunities to politicize, which further enforce post-political tactics while leaving the left to drown in the growing hatred of ultra-politics. Given this, it is important to expand the discussion from postpolitics into ultra-politics, which is the subject of the following chapter. 


\section{Chapter V: Depoliticization: ultra-politics}

This chapter faces a challenge bigger than the previous one on post-politics. Contrary to its counterpart, the concept of ultra-politics is much more underdeveloped and underused. Yet, what we currently have on it presents valuable insight on the other dominating modality of depoliticization in Brazil today, especially since June 2013 and regarding the sense of false polarization and inescapability from a vicious cycle of depoliticization whenever the left tries to differentiate itself and mobilize more openly. The goal is to explain ultra-politics and the important role it plays in the current state of depoliticization in Brazil and how even the ultrapolitical aspects that appear as opposed to post-politics work to complement it in different spheres, presenting a more difficult challenge to a fragmented left.

\section{What is ultra-politics?}

The most well-known definition of ultra-politics is provided by Slavoj Žižek in a general footnote in The Ticklish Subject: "Ultra-politics has recourse to the model of warfare, politics is conceived as a form of social warfare, as the relationship to Them', to an Enemy" (Žižek, 1999, p. 241). This definition is simple at first, but its meaning can be unpacked into the multiple facets of ultra-political depoliticization. Ultra-political conflict is militarized in the sense that it constructs the identity of an Enemy and promotes it as the core of the social and political relations. This is different from class antagonism, in which the relationship between the proletariat and the bourgeoisie is oppositional in the nature of the exploitation of one class by the other. The militarized ultra-political scenario, on the other hand, depoliticizes the sources of conflict and tends to empower those who already benefit from the status quo due to its conservative moralism and the victimization of a class or group of people who do 
not want to give up their ruling status. Unlike class antagonism, ultra-political warfare is waged against a constructed Enemy, but as depoliticization it ends up reinforcing the hegemonic state of things. The left may be an active agent in the promotion of ultra-politics, especially if it gives into false polarizations, but the ultra-political results will be antithetical to the objectives of a radical left. In his comparison with post-politics, Vassillos Paipais describes ultra-politics as when "the political (as the ontological instance of antagonism) assumes full domination over politics. The political adversary is seen as an enemy to be destroyed by all means. Once more the difference between politics and the political collapses, this time on the side of the political which politics is supposed to enact in an immediate way. The ontological ground/abyss appears directly into the ontic realm with often catastrophic effects (total war, revolutionary terror)" (Paipais, 2014). A post-political scenario will foreclose antagonism through fantastic notions of technocracy and tolerance towards social conflict and exploitation. Ultra-politics reifies antagonistic relations through a false radicalization around pure power and pure positions. This purity prevents real confrontation (Chambers, 2011, p. 308), in the sense that the antagonism reified into a constructed Enemy becomes meaningless and cannot be resolved, but violence, hatred, and other expressions of political disavowal become the norm through depoliticized confrontation.

Ultra-politics depoliticizes the conflict at hand by pushing all of its facets to the extreme, in a false radicalization that reifies the "us" versus "them" identity. This direct militarization of politics forecloses "political returns" through a false display of trying to solve the political deadlock (Žižek, 1998, p. 66). For instance, the making of "corruption" and the "corrupt" into the enemies transforms the conflicts around a crisis of representation into a war against corruption. Corruption as the most important explanation for a political crisis is post- 
political, since it negates other sources of antagonism. Corruption as the symbolic expression of antagonism evolves into ultra-politics and adds more enemies in the form of threats. The coup of 1964 found its social base in the fight against corruption (Boulos, 2015a, p. 71), for example, which was an Evil brought and promoted by the threat of communism. Today, the threats also include the PT, and the left in general - four elements that are associated but are not the same thing - as well as depoliticized distortions of leftist politics such as "ideology of gender" (a.k.a. gender equality and rights). The false radicalization under ultra-politics encourages manichaeistic thought, which is natural to common sense, wherein if you are not engaged in the war against the Enemy (in the terms set by ultra-politics), then you must be with the Enemy.

An ultra-political scenario can take place in isolation, but it has gained ground in Brazil as a filler for depoliticization whenever post-politics and post-ideology did not resonate with the crowds. Even though the ultra-political and the post-political handle antagonism in different, seemingly opposite, ways, they are two sides of the same coin of depoliticization. The gap that is opened by the depoliticization of one may be filled by the re-appropriation of the depoliticized issue by the other. For Erik Swyngedouw, this is often the case when the populism of a post-political order annuls real democratic engagement, thus either eliminating conflict through its management or elevating it to a new, ultra-political, kind (Swyngedouw, 2009, 2010). As the politicized clusters fight to escape management of conflicts and for properly addressing their root causes instead, a different disavowal of politics takes place and depoliticizes the conflict by repackaging into a false polarization designed to delegitimize the real sources of antagonism and to protect the ruling class from the consequences of the sparks of politicization. While some crowds of 2013 were re-assimilated into post-politics as an 
answer to the crisis of representation, the possibility of political rupture brought forward by the more politicized crowds highlighted the need for hegemonic renewal by the ruling classes and their representatives. The ruling class reacted by offering the ultra-political Enemy as a replacement for political antagonism and right-wing proposals as solutions to the crisis in alternative to the already deconstructed and demonized version of the left embodied by the PT.

The concept of ultra-politics is very underdeveloped compared to the literature on postpolitics. Yet, I believe that to consider what ultra-politics entails in this Brazilian conjuncture is a useful exercise to understand why we have lost "civility" in politics and why there is so much hatred and polarization in a way that goes beyond the immediate responses of the crowds and the organizations involved. Because ultra-politics creates false polarizations and reduces issues to immediate sensation, it is empowered in contexts where there is depoliticization tied to disbelief, betrayal, and a loss of privileges. All of these elements are common to the current conjuncture, especially in relation to the PT, although they are expressed differently across classes. Not only does ultra-politics thrive well in a scenario of general fragmented consciousness, it furthers this fragmentation by positing individuals and groups against each other in a distraction from the structural explanations and consequently nurturing feelings around hatred, prejudice, and disparage against the other. This is a particularly complicated scenario to politicize, since it fights back in reactionary ways, and it is even harder when the left itself is fragmented and had failed to reach consensus and syntheses around important things, such as the roots of false polarization. Depoliticized debates under ultra-politics create peculiar contradictions for the working class, potentializing on the prevalence of a contradictory consciousness disconnected from efforts to expose practice to theory. Douglas Belchior describes this phenomenon as follows: 
"We [the left] suffer from this routinely. Since we don't have a machine apparatus for showing off the big differences, in the mentality and vision of the common citizen, everything is still very alike, and then you will connect the PT to the petista ideas, which are overexploited in a pejorative way [...] It's been very instrumentalized, provoked by these sectors so that people take to the streets without discerning what is left and what is right, mixing the left and right with situation and opposition and primarily mixing this with the historical agenda of the workers. So they go to the streets to protest corruption, defending a proposal that will take away rights, or not realizing that those calling the protest are those who defend projects that take away the rights of those protesting. Because the protest is no longer something mobilizing just the bourgeoisie, only the middle class, only the coxinhas. Although the neighbourhood, the favela won't come down to protest, their sentiment is the same, and of course again contaminated and fed by the big media. So the police can repress more, it can beat up more; the common sense endorses it." (Belchior, 2015)

\section{Ultra-political instigators}

While I mentioned the ultra-political context in Brazil with respect to populism briefly in Chapter 4, it is important to analyse what actors have contributed to the deepening of ultrapolitics, even as they are expected to fight it it. This highlights the discussions around the onda conservadora (conservative wave) that is thought to have permeated Brazilian politics more openly since the right "came out of the closet" in June 2013 (Boulos, 2015a, p. 83). The hatred propagated now is not new; it has shown its constant presence in mainstream media for over a decade. What is different now is that hatred has become "authorized" again, thus it is louder and has the capacity to reach more people and self-reproduce. Haters are not ashamed of their hatred under ultra-politics and have no interest in avoiding it (Tiburi, 2016, p. 30). There is a degree of disagreement in the left over the meaning of a conservative wave and whether it actually exists or is a product of ultra-political fears and moral panic generated by the PT to retain support. I put forward that there is a conservative wave indeed, which is characterized in the form of a conservative offensive taken up especially since June 2013, in the efforts to struggle for the meaning of the crowds and posteriorly instrumentalize them, but has been in construction throughout the PT mandates. As the consent generated by the PT through 
consumption and social programmes began to deteriorate during the first Rousseff administration, the right was already intent on adding more conservative elements to common sense that could capture part of the PT base and benefit from the general depoliticization derived from a leftist government with a neoliberal record. June, however, presented the perfect opportunity to try out some more conservative (and reactionary) speeches due to antiparty sentiment, the focus on corruption, the ideology behind ufanismo, and the overall disdain for the PT that would ricochet on the left in general. The right managed to perform well in June by first employing post-political speech and encouraging the negative side of the crisis of representation embodied in generalized rejection of representation. The rejection of the PT is important for the growth and empowerment of the conservative wave because it consists of the sequestering of the reasons why the PT should be rejected. The PT governments are considered to be symbols of leftist and popular betrayal. The short life of some of the inclusion and advancement benefits that the PT administrations had extended to the underprivileged and the middle-class was the direct result of the failure of governability and the PT's eagerness to please the elites; though these elites would still prefer to see this project implemented by the traditional right. Yet, the dispute of meaning by the right means that these failures could be attributed to corruption and the leftist essence itself. While the PT failed for not being left enough, the conservative discourse employed to capture the dissatisfied sentiment of the crowds in June proposed that the PT failed for being too left. The hatred of the PT as a leftist entity is more reflective of a hatred of what the PT once was (or could have been) than what the PT actually stands for today (Demier, 2016a, p. 56), which is closer to the politics of the traditional parties behind the conservative wave than the radical left politics targeted for hatred. With hatred as a tool and the construction of a false polarization with the PT, the right was 
abled to come forward more openly by switching from post-politics to ultra-politics, although the post-political elements of ufanismo and hypocritical anti-corruption claims continue to be widely employed to legitimize their actions, to maintain a long reach for their message, and to depoliticize in situations where hatred does not penetrate easily and the right-wing actors prefer to negotiate their image as centrist, post-political, or leftist sympathizers (e.g.: part of the tactical approach of parties such as the PSB and REDE).

Despite the rise in hateful speech, there is some questioning on the left about whether there is an actual conservative wave or if this is just panic over the clash between right and left due to the leftist social struggles promoted since June 2013 (J. M. de Almeida, 2015; Dezorzi, 2015; Garcia, 2015). According to Caio Dezorzi from the Esquerda Marxista, there is no conservative wave because the 2014 elections did not actually indicate a growth in terms of conservative/right-wing votes, but instead point to the dilution of the PT base and the presence of blank and nullified ballots in addition to Marina Silva's strong show (Dezorzi, 2015). While an analysis in terms of numbers is important, I contend that the issue at the heart of the conservative wave is the manipulation of consent through a conservative political consciousness in a way that fosters false polarization that pushes radical left alternatives out of the dispute. Marina Silva's post-political discourse is one that benefits the right, whether or not her electorate identified as right-wing, left-wing, or nothing, and the rejection of representation symbolized by blanks and nulls cannot be read as solely progressive for the reasons outlined in the previous section around the meanings behind the crisis of representation.

What is important when looking at the conservative wave is not necessarily quantitative growth, but the hegemonic battle for common sense that has been fiercely and openly waged 
by right-wing actors before June (through the media, primarily) and after June through a more varied expression of actors. These include new right-wing media outlets, think tanks, protofascist groups, and social movements such as Movimento Brasil Livre and Vem pra Rua, all of which have as much or more party power than standard electoral parties - which are more subject to the anti-party sentiment of the crisis of representation - from a Gramscian view of the the functions of a party (Gramsci, 2007 [1957], p. 147). In terms of politicization and depoliticization, the battle at large is being much more successfully fought by the organized right than the organized left (with the exception of counter-hegemonic expressions such as the resistance to austerity by the student movement), so that it can be inferred that the power of the right-wing groups acting together and organized amounts to a conservative wave/offensive. The Brigadas Populares has also engaged in similar analysis in the past by arguing that the effects we observe are more connected to a democratic gap in representation than an offensive in general, but the level of coordination at the institutional and non-institutional level by the right (including condoning or encouraging proto-fascism in their associated cadres) indicates how the wave has operated as a constant signifier for this very gap (Brigadas Populares, 2015). Therefore, to speak of a conservative wave is to talk of a depoliticizing power that has been successfully expressed in the ultra-political conflict, and to underestimate it due to the precise size and number of right-wing organizations and the still long distance between right-wing consciousness and the general consciousness of the masses pays no service to left strategy. After all, the left is not closer to the consciousness of the masses when struggles for housing are counterbalanced with popular support for lowering the age of criminal responsibility and agreement towards privatization if it might improve the very precarious public services the working class relies on. Intellectuals such as Vladimir Safatle have also supported the thesis 
of a false conservative wave by proposing that the idea of the wave paralyzes the left and that the real cause for current ailments is an organizing failure by the left (Safatle, 2015), which is refuted by Demian Melo, who asks if this decomposition is not indeed one of the factors that favour a conservative wave (Melo, 2016b). Further, the impacts of conservatism on common sense beyond the PT versus PSDB dispute seen in 2016 have provided more foundation to the thesis, such as the Escola Sem Partido (School without a party) project that, though a postpolitical façade of good educational policy without political ideological influence, intends on institutionalizing depoliticization through the replacement of critical thinking by conservative and traditional morals. The project and the movement behind it claims to fight a supposed Marxist indoctrination at Brazilian schools, while its true meaning is closer to another conservative wave motto: "Less Marx, more Mises" (Melo, 2015). Since 2015, the radical left organizations above that question the existence of a conservative wave have joined together with the Frente Povo Sem Medo, which, perhaps due to the recognizable leadership in the MTST, has reasserted the thesis of the conservative wave. Povo Sem Medo has since shown that it is possible, though not easy, for the left to organize under this realization, even if it has to deal with the indeed almost paralysing fact of sharing similar conclusions about the wave with a moderate left that is eager to use it to promote false left unity under PT leadership. In fact, the reach of the moderate left in the front, especially through the influence of the CUT and the MST through Frente Brasil Popular has to be examined in terms of how the moderate left has mobilized fear of the wave to try to co-opt Povo Sem Medo spaces as well as other struggles against the right and the impeachment.

The PSTU worries that the argument behind the existence of a conservative wave favours the PT (and is mainly authored by the PT) in order to retain dying support and build 
alliances in the radical left through fear and panic of a coup and establishment of a right-wing government that would end up implementing the same programme the PT already has (J. M. de Almeida, 2015; Garcia, 2015). Valerio Arcary, before leaving the PSTU, argued that the Dilma Rousseff government and its supporters have used the fear of a conservative wave as an alibi (Arcary, 2016, p. 116), which is indeed the case, but only with respect to the way the PT has manipulated and instrumentalized debates around the wave, sometimes through populism and demagoguery as well, especially when it comes to using the wave to project Lula again (including as presidential candidate). The PSTU's reading that the level of hatred the PT experiences today is a direct result of the PT's betrayal is correct, but it is not the only reason for hatred nor does it answer responsibly to how this hatred has affected the left as a whole, including the PSTU (PSTU, 2016). This position has caused disagreement inside of the PSTU and contributed to the schism that led to almost 700 militants leaving the organization in July 2016 to form the MAIS organization, in addition to previous "waves" of members leaving the party in 2015, which points to the amount of stress an ultra-political conjuncture can put on an already fragile radical left and the need to look for answers outside of the traditional proclamatory answers employed since the first schisms from the PT. The MES has shown a similar position and yet a slightly different approach. It has overall minimized the impact of a conservative wave in the style of Safatle's argument, but has acknowledged it when necessary, especially in the face of evidence, by also focusing on the PT's contribution to it (MES, 2016). This nuance is important and I will return to it later. For now, it must be acknowledged that the PT's mobilization of the warnings against a conservative wave is indeed a real concern for the radical left, as it deals with the ghost of the PT at every tactical corner under ultra-politics and must always ensure that a defence of constitutional principles, for example, does not 
translate into a defence of the Dilma Rousseff government in the impeachment scenario. However, this concern is no reason for undermining the power of a conservative wave in penetrating common sense, renewing the hegemonic status of the traditional right, and removing rights and reparations faster than even the austerity-prone Dilma Rousseff government could have done it. Moreover, to reduce the presence of a conservative wave to electoral results or the impeachment dispute is short-sighted when the wave has to do with ultra-politics in general, which has real consequences for the ability of the left to gain ground and politicize and for the masses in terms of materializing its contradictory consciousness into real losses and more social injustice.

Felipe Demier sustains that, from a Marxist perspective, the existence of a conservative wave must be acknowledged and this does not have to lead into a defence of a government and a party that are ultimately responsible for the awful correlation of forces wherein the left finds itself (Demier, 2016a, p. 51). One can, however, recognize the PT's role in the mess we are in (from post-politics to ultra-politics) without resorting to minimizing the overall negative impacts and the strengthening of the right as an active actor. One can also recognize the existence of a parliamentary coup through the impeachment process while acknowledging the PT's own role in the political context that made the coup possible; after all, it is naïve to reduce the coup as against the PT, rather than against the republic and the people's representation, as unreliable and treacherous as Rousseff's form of representation was. There is no need to dismiss right-wing strength and reach in order to hold the PT accountable as well. In fact, if one falls for this mistake, they might become stuck in politics tailored to respond to governismo alone while the right advances to new territories. The thesis of the existence of a conservative wave is important because it highlights the gap the right has been able to fill more and more 
prominently since June 2013 and how it has led to speedy results in terms of cuts, violations, and a regressive political consciousness that has empowered prejudice, discrimination, and hatred in the average mind. Ruy Braga argues that we are currently experiencing a militarization of social conflict, which is in line with the ultra-political interpretation, and this is related to the more open exposure of capitalism's own authoritarian structure (Braga, 2016, p. 50). This hegemonic enforcement is related to depoliticization as well as a reformation of consensus so that whatever part of common sense was progressively impacted under the levels of social progress experienced through the PT governments can be reconceptualised into a conservative sense through hatred, envy, discrimination and especially by encouraging the upper classes to hold on to their privileges in a sort of class protectionism.

Žižek considers this from the point of view of a middle class that condones depoliticization and hangs on to common sense, just as the Brazilian middle class has done since it realized the consumer gains it experienced under Lula were limited. The problem is that the middle class gives into a fantasy over becoming the ruling class without realizing that this cannot be achieved as a class through the right either, which makes it a perfect crowd to be manipulated (massa de manobra) through fear and false promises. He writes that "on the one hand, the middle class is against politicization — it just wants to maintain its way of life, to be left to work and live in peace, which is why it tends to support authoritarian coups that promise to put an end to the crazy political mobilization of society, so that everybody can return to his or her rightful place" (Žižek, 2012, p. 24). This is clear in the engagement of the middle class in the impeachment process and phenomena such as hitting pots and pans to protest the PT in privileged neighbourhoods, ostracizing Paulo Freire and his internationally praised pedagogy, and their strong adherence to ufanismo and green and yellow as a protest 
uniform. Such an engagement would not be possible without a direct participation of rightwing forces into moulding culture, manipulating information (especially through the press), and creating likable leadership based on middle-class beliefs around meritocracy and being homens de bem (good traditional citizens). For Alvaro Bianchi, this is part of the crisis that has opened the doors to a conservative wave since the dominant modus operandi of the left, centred on union corporativism and parliamentary spaces, was insufficient to foster a progressive culture strong enough to resist an attack through the affirmation of the conservative way of life (Bianchi, 2016, pp. 122-123). The conservative influence extends beyond the middle class and into the periphery where the workers' betrayed by the PT are fed false hopes of job creation and security through neoliberal economics and are lured into conservative thought through the consolidation of reactionary common sense around rights and identities (Basso, 2015). Other cultural elements, such as religion and punitivism, also contribute to this phenomenon.

Of course, part of the problem of having to deal with the PT and governismo as an obstacle to politicization under ultra-politics pertains to the PT's own contribution to the current situation. There is consensus in the radical left over the fact that the PT is responsible for hatred towards the left. This hatred derives partly from resentment over the PT's betrayal of its popular support and historic militants. This resentment is felt both by the politicized crowds, which are aware of some of the reasons behind the PT's path as a party of order, as well as those who only have an inkling about what went wrong and thus focus on the PT as a traitor organization. Thus, hatred towards the PT can be experienced by people who retain general progressive sentiment, but feel represented by no one, as well as former PT supporters who have gravitated towards the organized right. There is also a second kind of hatred for the PT, which results from the long process of depoliticization and demobilization that the PT 
engaged with as soon as Lula was elected (or right before so, through symbols such as the Carta ao Povo Brasileiro). This depoliticization leads to hatred that may have no apparent justification, or at least no justification rooted in the PT's betrayal. In fact, it is hatred based on the promotion of values that would make the PT's betrayal acceptable and even hope that the PT had ditched its progressive and classist roots completely to either join the traditional right or give in to the traditional right as the rightful owner of neoliberal government.

I argue that while the PT's demobilization and depoliticization were instruments to maintain its hegemonic project of class conciliation without disruption from a radicalization of consciousness, this balance also depended on favourable economic conditions and a willingness of the traditional right to let the PT implement their common project with a few social policy twists. The latter was an illusion, but rather than retracting to push for politicization and a PT focused on left politics again (or finally), the party and its bureaucrats opted for more depoliticization on all sides with the expectations that a depoliticized left and right would meet in the middle through class conciliation, which has been at the core of the lulo-petista programme. This clearly backfired on the PT, and the right's own politicizing efforts, which consists of instrumentalizing depoliticization for right-wing purposes, expanded hatred towards the PT into hatred towards the left in general. Since this kind of hatred can grow strongly under a crisis of representation, another effect of depoliticization, the rejection of the PT and the left in general has become more vocal since June 2013 and efforts by the right to keep it so are ever more directed and targeted. This makes the PT one of the actors directly responsible for creating the breeding ground of ultra-politics. It is not the only one responsible for hatred and anti-leftism, as radical left organizations such as the PSTU have argued to reason their type of opposition to the PT. It has, however, contributed to ultra-politics by continuing 
to promote depoliticization in the current conjuncture, even whenever it was pressed against a wall such as during the impeachment process. Mauro Iasi describes the involvement of the PT in depoliticization as a two stage process: first the party demobilized the progressive social forces, though co-optation and legitimizing techniques for its own trasformismo, then it invested in delegitimizing authentic leftist discourse and acting to divide the left and label the radical left as sectarian for not giving into the PT's politics. (Iasi, 2015). This connects the PT's material betrayal of class interests and their base to the depoliticizing efforts around it, which end up reducing the betrayal to leftist symbols and thus also contributes to ultra-politics by adding fuel to anti-leftism.

The challenge of fighting ultra-politics involves the problem of the media in general and the production of information. In an article, Guillermo Boulos speaks of how certain media outlets have empowered a "delirious" side of right-wing discourse and its representatives (Boulos, 2015a, p. 125). While this is certain and outlets such as the evening newscast Jornal Nacional have influenced public opinion against the left for years, the role of the media in instigating hatred, anti-leftism and depoliticizing issues to prevent a rise in consciousness must be weighed in the context that this is not a recent problem and was noted long before the PT rose to federal government. While barriers to politicization such as the media monopolies could have been removed or weakened by the PT while in charge of the federal government, Lula deliberately chose to do the opposite, even as he now complains about the media attacks against the party (Iasi, 2015). The Globo group network alone received 6.2 billion reais during the Lula and Rousseff mandates (Capital, 2015). Veja Magazine, one of the main antagonists of Lula and the PT, reportedly received 700 million reais in the same period, while Carta Capital, known for its leftist readings (sometimes even governista) only received $16.4 \%$ of that amount 
(Ibid.) The room given by the PT to the media monopolies must be considered because these monopolies have an important role as political instigators. Aside from poor journalism and the production of false information, these outlets openly favour right-wing policies and right-wing personalities (and parties), often switching positions only when common sense has changed towards one or the other. One example is the turn against Eduardo Cunha, former Chamber of Deputies president and one of the orchestrators of the impeachment process, by national newspapers and even the conservative magazine Veja. In such a situation, the discourse is carefully crafted to individualize the issues and find scapegoats, while continuing to depoliticize the situation and target left-wing policy and organizations as the wrong way out to the economic and political crisis. This is why matters related to the democratization of the media in Brazil are so important, given that there should be no illusions around social media as a democratic and open alternative to the media monopolies. Yet, the fact that the PT held the opportunity to promote the democratization process for 13 years while in government and chose to continue to fund outlets such as Globo instead indicates that the ultra-political conjuncture goes beyond access to proper information. The more recent support for left-leaning media, such as Brasil de Fato and Brasil 247, by the PT governments also shows the other side of the coin: most of these vehicles portray issues from a governista perspective and shamelessly promoted a defence of the PT and the Dilma Rousseff administration when reporting on the impeachment protest, which is an example of depoliticization from the left.

The PT contributes to a nurturing scenario for ultra-politics because it does not politicize for the left, maintains its image as one of the false poles in the polarization with the traditional right, and refuses to open room for the radical left through actions that would require, more than anything, authentic self-critique of the party, its bureaucracy, its 
governments and its public personalities. João Pedro Stédile (MST) has recently stated that the PT needs to engage in profound self-critique, but proceeded to point to Lula as the one who can answer this and restore the faith in the party (Baldini, 2016). Such statements in the moderate left have become common since 2015, especially the less popular Dilma Rousseff became. They are dishonest in the way they attribute the failures and betrayals of the PT and its governments to a more recent phenomenon, often scapegoating Rousseff in the process in order to deny that Lula's politics are the precise instrument promoted by the party's direction that contains the majority of bad politics around the PT's trasformismo. Arguments like Stédile's demonstrate the unwillingness of the moderate left to engage in real self-critique, one that would necessarily dismantle the bureaucracy inside of the PT, the MST, and the CUT. It promotes the idea of a PT re-foundation from the left, but without any allegiance to left principles that require the end of lulismo, class conciliation, the prioritization of governability and the PT's strategy of weak reformism. Therefore, current attempts by the PT to engage with the ultra-political conjuncture continue to empower it, since it relies on depoliticization and an emphasis on the PT as the only party that may occupy the role the PT began occupying in the 1980s, when the left was nowhere was fragmented as it is today and actually converged around the Workers' Party project in all its nuances. By refusing to make room for the new to be born, the PT occupies its old space in a self-necrophagous fashion. It encourages the idea that its dead remains can be packaged and repackaged over again to guarantee the self-reproduction of bureaucratic and institutional power. This creates more opportunities for the PT to be attacked in their arrogance and continuous track of mistakes and betrayals, all the while smearing the whole of the left and the classist programme, and clouds the view of a possible third camp. 
The other problem is surely the fact that the radical left "third camp," despite nice speeches and good intentions, is not ready to be born. This is exemplified in the difficulties in creating alternatives the radical left encounters under ultra-politics (examined at the end of this chapter), but also due to the fact that the radical left is more and more fragmented and is yet to make sense of the PT's slow death and refusal to accept it. Ruy Braga states that while the PT is largely responsible for depoliticization, responsibility must also be extended to the antigovernista left for not occupying or fighting harder to occupy the spaces that had to be politicized (Braga, 2015). It seems that the notion that the PT would fall apart on its own and thus give up space for the radical left prevailed until 2013, when the crisis of representation also exposed deficits in praxis by the left. But the PT will not go easily and continues to mine mobilization that is not in its favour, while reasserting traditional right politics in their own cadres and actions. The continuity of depoliticization as a tactic by the PT maintains a gap in the consciousness of the masses. Given the unpreparedness of the radical left in trying to politicize it, the right, which comes out of 2013 more organized than before, has been able to signify it ultra-politically. This creates even more challenges for a radical left that can barely figure out its own path to unity, let alone how to show itself as an actual polar force against the depoliticizing efforts of the PT and the right.

\section{Polarization and false polarization}

A few ultra-political elements could be observed in Brazil before June 2013. Although this is most obvious in electoral periods, when overt polarization becomes the norm, it is also notable in the approach of the mainstream media to the PT and its governismo in regards to the promotion of social rights. Ultra-political elements around hatred and the division of society between the good deserving citizens and the bad undeserving citizens could already be seen in 
the selective indignation around Bolsa Família (Boulos, 2015a, pp. 136-137) and in the xenophobia expressed against the PT electoral base in the Northeast of Brazil. Rather than the antagonism from the working class towards the ruling class, the ultra-political version of polarization relies on the depoliticization of conflict as is, and its channelling into a conflict that can be put into a simple, moralist, and dualist frame in the terms of the ruling class and the prevailing common sense. After June 2013, these elements became louder and emboldened by the active role taken by the right to fight over the June crowds and their meaning (through the conservative wave) and the progressive weakening of the PT both as government and alternative. This had led to a process of many different binaries, in the sense of a society divided mainly into two sides, but also a false polarization, since it regards two similar projects as if they were thoroughly different (i.e.: the PSDB/PMDB project versus the PT/PCdoB project) and negates a third radical left camp that stands in opposition to the moderate left, the dominant right, as well as the extreme-right, whose protagonism has grown in the promotion of hatred and fascist discourse linked to praise for the military dictatorship (including its methods such as torture), as well as overt racism, homophobia, and sexism. The extreme-right promotes the idea that it is the "communists who are dividing the country", as João Telésforo observes (Telésforo, 2015), which is dangerous in the way it blames the left as solely responsible for the ultra-political situation. This aspect does not define the false polarization or the ultra-political conjuncture, but it does feed fanatic sentiment and violence in a way that is detrimental to new politicizing activities and feeds into the traditional right's project of taking away more and more rights. Some examples of this can be seen in the support for congressman Jair Bolsonaro, a known fascist, supporter of the dictatorship and prominent symbol of bigotry in Brazil. One of his sons, who is also in politics, made news in 2016 for 
proposing the criminalization of communism as terrorism (Melito, 2016). Although the bill is far from becoming a reality, it is intended to be sensational and to inflame Bolsonaro supporters and small fascist groups by feeding more hatred and anti-leftism in the conjuncture. Projects like this one appeal to the proto-fascist elements of June 2013, which despite being a minority, were significant for appropriating the crisis of representation and anti-party sentiment to burn the flags of leftist parties and attack leftist militants violently during that period. In addition, figures such as Bolsonaro invest in right-wing populism for fascist purposes, thus finding ways to influence common sense in his own favour even in the working class. By appealing to intolerance as homophobia, sexism, xenophobia and racism, well-known bigots close the doors for left politicization in areas where class consciousness could be instigated. The prominence of evangelical pastors such as Silas Malafaia and Marco Feliciano are further proof of that, since an often mentioned concern in the radical left relates to how religious fundamentalism has a much stronger base-building power than the left today and how fundamentalism has certainly filled right-wing purposes with no concern for its impact on violence and hatred. Žižek argues that the core logic of fascism is ultra-political (Žižek, 1999, p. 193). This entails a particular challenge for the radical left as it attempts to politicize beyond false polarization, since the organizations must consider how there are fascist forces feeding into ultra-politics in a way that is dramatically beneficial to the right and dangerous to leftist militants and radical left revolutionary politics.

The notion of a false or asymmetrical polarization is common in ultra-political scenarios, including the complicated relationship between Democrats and Republicans in the United States. Paulo Arantes sees it as an opposition of centrist forces that will prioritize governability as they attempt to make each other's attempts at government impracticable 
(Arantes in Melo, 2016a, p. 71). In Brazil, this means that the ultra-political conflict, in all its ideological and cultural aspects, is established in relation to the dispute of institutional power (e.g.: often through the alternation of the PT and the PSDB, empowered by the PMDB's support for whatever government it prefers). Because the dispute revolves around the centre of power, the PT will attempt to occupy all left spaces in its own way, hurting the construction of the radical left, while the PSDB will ensure a level of populism and moderation to attain power while benefitting from an extreme-right (even fascist) that is currently in no position to vie for the most prominent offices.

The anti-corruption clamour in June made room for post-politics by associating corruption with the entire political system and the whole class of political representatives. Anticorruption was soon re-signified by right-wing discourse as anti-petismo and also added to a depoliticized association with communism and all things leftist as sources of corruption (SaadFilho \& Boito, 2015, p. 223). This added to the enemy-based arrangement of ultra-politics by giving a face to the Enemy that could make conflict more palpable and long-lasting. Corruption is a fitting enemy for ultra-politics, but an abstract one that may be interpreted differently despite attempts to signify it in specific reactionary ways. The job of associating the PT with corruption, done with the help of the PT itself and its own involvements in many corruption scandals, creates a target Enemy that helps the right to fight the risk of having corruption as a sole enemy turn against itself.

Since the conjuncture is depoliticized, the use of ideological terms also becomes meaningless in a way. While the PT hurts the left by continuing to promote itself as left (holding own to a space that it is not theirs anymore), the right uses it to attribute all the problems of the PT to the left as a whole. This ignores the current state of fragmentation of the 
left and creates a difficult trap for the radical left, wherein it is hated for its association with the PT in two paradoxical and untrue ways: it is either hated for being too left (i.e.: the communist/bolivarian threat) or for not being left enough (i.e.: The PT is a traitor and from the left, therefore the left is a traitor too). This is quite notable during electoral periods. In 2014, Luciana Genro would be accused by the right of helping the PT out even as she criticized the PT and Dilma Rousseff. This association has been prejudicial especially to the PSOL and the MTST, whereas the smaller size of the PSTU, the PCB, and other organizations shield them from a perception of proximity of the PT but still expose them to anti-leftism as anticommunism and anti-socialism. ${ }^{39}$ None of this helps to connect with the masses and makes of false polarization a process of erasure of the radical left as an actor and of its politics as outside of the field of possibilities.

\section{Ultra-political consequences for the radical left}

One of the difficulties encountered by the left in an ultra-political terrain consists of being the "third camp" or the third alternative in a terrain of binary false polarization. With the PT in government, the right was given the hegemonic space for opposition, especially as the PT maintained an effort to co-opt any opposition from within the left. The still common perception by the masses that the PT represents the left and that all other leftist organizations fall somewhere between an outright supportive or at least lenient stance towards the party makes it difficult for the radical left to organize and communicate their position outside of this spectrum. Of course, this is even more tangled when one considers that all opposition coming from the radical left has to oppose the PT in ways that do not damage the image of the left in

\footnotetext{
39 The PSTU and the PCB also share fewer spaces with the PT in comparison with the PSOL and the MTST.
} 
general or the ability to win the remaining PT base over. To escape the depoliticized false polarization, the radical left has got not only to politicize issues but also to deconstruct the image of the PT. This poses new problems of all sorts. One of them is how it empowers a discourse previously used by the PT whenever it faces criticism from the left, especially during periods of schisms and the creation of new organizations by militants leaving the PT. It entails that any criticism, even legitimate critique from those standing to the left of the PT, will actually add to the general demonization of the party that will ultimately benefit the right. This is, of course, a lazy excuse, as all leftist experiments should be subject to critique and reason. The problem is that in the ultra-political scenario, the right is indeed interested in left-wing critique if it helps to destroy the main Enemy and it assumes that the rest of the left will just follow later.

This is most obvious in the difficulties the radical left encountered when dealing with the possibility of Dilma Rousseff's impeachment, a process thoroughly led by the right to replace the PT government with a more traditionally right-wing government that has no need to legitimize its favourable stance towards capital with social policy. The challenges around the impeachment split the left into three sectors. The first sector is made up mostly of the moderate left and is composed by the PT, the PCdoB, the CUT, the MST, and other organizations that lean towards governismo (some in more extent than others) that ultimately organized through the Frente Brasil Popular. This sector equated an opposition to the impeachment with support for the Rousseff government and a possible Lula election in 2018. An intermediate sector, which began organizing through the Frente Povo Sem Medo in late 2015, positioned against the impeachment but reserved the right to also oppose the Rousseff government because of its continuous attacks on workers' rights and the prioritization of 
governability with the elite and centre-right parties in lieu of promoting a more radical politics. It gathered the MTST, the PSOL as party (but not all tendencies), the Brigadas Populares, Intersindical-Central, among others. Their critique of Rousseff was very pronounced, especially in terms of spending and social rights cuts, but they were less hostile to the presence of Lula and his governability-centred speeches at protests made in collaboration with Frente Brasil Popular. A third sector is better defined by those who were calling for General Elections as a solution out of the impeachment debacle from even before it was consummated. This was defended by a separate front, Espaço Unidade de Ação (led by the PSTU and CSP-Conlutas) as well as tendencies from the PSOL such as the MES and the CST (both of which originated from Convergência Socialista, the same parent organization of the PSTU). The General Elections call was followed by a "Fora Todos" campaign which can be critiqued as having both a post-political and an ultra-political angle. While the Fora Todos is strongly positioned against the PT and any hints of alliances with the PT (except perhaps for the MES, which was for the Fora Todos but more flexible regarding the moderate left for electoral alliances), its coherence in the matter was not enough to mobilize around the impeachment. Post-politically, the Fora Todos appealed to the whole of the crisis of representation as progressive in a rejection of all representatives, which could backfire against the left. Ultra-politically, it stood in isolation while it conflated the right-wing politics of the right with the right-wing track record of the PT, which did little in terms of politicization and was insufficient for escaping the false polarization. ${ }^{40}$ The level of depoliticization around ultra-politics presents a tougher challenge

${ }^{40}$ It was not after the impeachment was considered a sure thing that more of the radical left adhered to the idea of General Elections or a plebiscite (with some support too in the moderate left, including from Rousseff herself), but neither resonated as an answer to the problem of ultra-politics, nor did they offer firm ground for the radical left to stand on without giving into the a radical management of democracy as an answer to the political crisis. 
that cannot be answered simply by pointing out complete or considerable equivalency between the two false poles. Further, arguments around the false polarization can also be made from a right-wing perspective in order to reject both the left and the right, but covertly promoting a conservative (even extreme-right) politics hidden post-politically by ufanismo that indicates how the ultra-political conflict is played in right-wing terrain.

Figure 4 "Fora Todos" (left-wing) ${ }^{41}$ and (right-wing) ${ }^{42}$
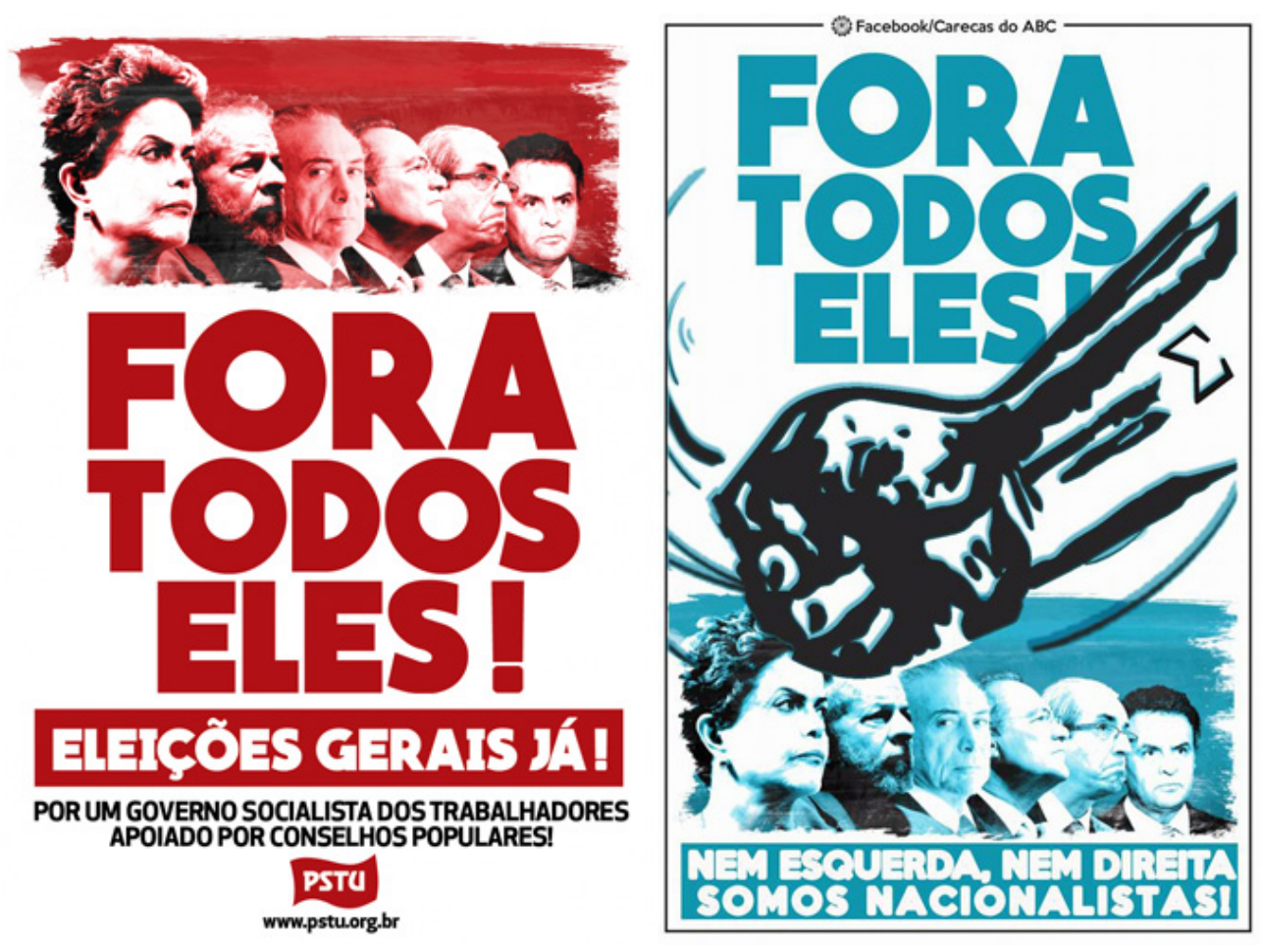

Prior to the vote on president Rousseff's impeachment, there was a lot of discussion inside and among all left organizations pertaining to which strategy would be best to restrain the right-wing offensive, which was the one political phenomenon all organizations agreed on.

41

http://www.pstu.org.br/sites/default/files/paginas/images/PSTU-Nacional_2016-0317_ForaTodos_Cartaz_A2-01-01.png

https://www.facebook.com/CarecasdoABC/photos/a.463033613809502.1073741828.462626 003850263/950486995064159/?type=3\&theater 
Other than that, they diverged on whether the right had grown or simply advanced in terms of a general conservative agenda, on whether Rousseff should end her mandate sooner, if general elections were the best call and even possible, and which political statements were more effective at mobilizing the crowds. An effect of the impact of seeing mass protests again since 2013, and the fact the right too had learned to take to the streets and mobilize crowds through their own devices, crowds and street numbers had become entrenched in the post-2013 view of mobilization of the left.

Competing with the right for the largest crowds in an ultra-political scenario seems almost naïve. There was great acclaim for the power of social media in June 2013 (Rolnik, 2013; Sakamoto, 2013), which is part of the same enthusiasm around social media that influenced analyses about the Arab Spring and hailed it as more democratic. The problem is that while indeed more democratic when comparing to the power of media conglomerates, the power of social media to reach the same number of people is more and more diminished as outlets such as Facebook tweak their algorithms to favour sponsored content while trapping users in an "ideological bubble." This means that alternative left content is unlikely to reach those inclined towards the centre or right. As far as opportunities for the left to reach large numbers of people and make their message known, social media cannot stand in for established forms of political organization, especially as it is unable to contribute to a sustainable pedagogical strategy of politicization because of the poor potential for creation of strong ties between individuals and social groups, and the own fragility of political activity in a space controlled and dictated by capitalism such as the Internet. June 2013 highlighted the power of social media in a way that encouraged a competition for attention based more on virality and less on what Jodi Dean calls the "larger questions of building a political apparatus with 
duration" (Dean, 2012, p. 145). Online discussions and their outcomes also tend to be emotive and quite scattered, diminishing the potential for critical analysis (Brysk, 2013, p. 134). The right, at the same time, can use capital to manipulate social media in their favour while retaining control of the press at the corporate level, including print, radio, and most importantly in Brazil, television. When networks such as Globo support the green and yellow protests to such an extent as to call people to the streets and provide complete live coverage of the events, it is not surprising that a fragmented left with a low base-building record for the past period cannot attract similar numbers. There is also the fact that official records tend to inflate the numbers of right-wing protests while undercounting protesters when it comes to the left, as this provides a sense of strength that encourages fatalism around an already lost battle in the underprivileged. Still, the power of the right to attract many people should not be underestimated, especially since situations consisting of left and right protests demanding opposite things, with the left in a particularly defensive position, as is the case in ultra-politics cannot be fought in the streets simply by pitching one crowd against another. The wall built by the government of the Federal District in front of the Brazilian Congress in April 2016 is an example of this. It symbolizes a social and political division and was designed to prevent physical conflict between the two crowds, since the result of the impeachment vote by the Chamber of Deputies would inevitably create winners and losers as in a sports match. Politics, however, should not be approached as a sports match and the fact that it has reached such a point demonstrates the ubiquity of ultra-politics at the moment.

While it is more important than ever for the left to take to the streets at this point, the quality of street protests and occupations also matters, since the problem of ultra-politics has to do with the depoliticization that will favour the right-wing protests from beforehand. While 
numbers are important for resisting against police repression, resistance beyond the immediate threat of violence requires rooting the action in the politics that motivates it in the first place. This means that the left must also pour resources in the long-term activities that do not involve the creation of a political event, as those can and should continue to be done even when the base is numerically depleted. In fact, the current prioritization of visible events as a tactic of resistance and struggle may create depoliticizing effects on its own. Since repression is likely when in small numbers, there is a temptation in the radical left to frame the subsequent defeats as victories of some kind. This is explored in Chapter 6 from the perspective of agitation over false victories, reflecting a degree of melancholia. It also mischaracterizes the meaning of victories in a way similar to the what the PT attempted to do for over a decade, when it would frame limited social policy progress as victory while the majority of the people were sidetracked and exploited in another now empowered way (e.g.: more electricity through controversial hydroelectric dams or a raise to the minimum wage while the industry lobbied and received billions in subsidies). The way out for the left consists of building more politicized crowds, which undoubtedly requires more invigorated efforts into base-building that also involve conscientization, in the critical pedagogical sense, and political formation. It means that the creation of fronts and alliances needs to involve the accumulation of forces in the left towards base-building, rather than simply having each organization bring its own numbers to the streets for an overall larger crowd as has been mostly the case with the arrangements of the Frente Povo Sem Medo and its joint protests with Frente Brasil Popular.

Another problem in terms of alternatives to escape ultra-politics is that even genuine politicizing efforts can backfire quickly on the radical left because of the war-like nature of ultra-political conflict. One aspect of depoliticization is the reduction of very complex politics 
to their symbols. This is challenging because the ultimate symbol for the left in Brazil continues to be the PT. The party has insisted on a leftist aesthetics when convenient, particularly during elections and in their own populist appeal. When the radical left politicizes issues from an authentic leftist stance, it faces backlash because of the PT's symbolic appropriation of that stance. Since it is only symbolic, the appropriation will be necessarily depoliticized and damaging to the image of the left, especially as the PT often engages with the leftist aesthetics to legitimize centre-right and bluntly right-wing measures of their own (e.g.: austerity). Thus, besides the symbolism behind an ultra-political hatred of the PT and its depoliticized perceptions as "communist" and "red" (Teixeira, 2015), which contributes to anti-leftism at the ideological level, the radical left also has to deal with the fact that the PT's failures as a symbol for the left have associated leftist politics with failure and betrayal too. Prospects change with the decline of the PT cycle, making it crucial for the radical left to establish itself as an alternative to the PT that appeals to the working class at a time of right-wing offensive.

Campaigning for issues that are inherently progressive and leftist is not a simple matter under ultra-politics. One can talk of matters as simple as salary increases and employment insurance and although these issues can easily resonate with the reality and practical consciousness of the working class (as well as the middle class), the demonization of workers' rights in general by the right creates barriers that further enforce what Antonio Gramsci refers to as the contradictory consciousness of the proletariat, aforementioned in Chapter 1 . This contradiction is indeed one of the strongest expressions of depoliticization and the triumph of common sense. Common sense is itself a product of depoliticization, since it adapts to the will and project of the ruling class, which has no interest in politicized political subjects, and reflects the predominant characteristics of society (Gramsci, 2000, p. 344). Because of ultra- 
politics, what could seem as simple solutions for solving the contradiction become tangled in complicated processes around hatred, misinformation, and a false polarization that once embedded in common sense works for the renewal of the status quo and against the political subjects. The contradiction expresses the lack of praxis in the masses, which is harder to promote if the left is dealing with a disjointed praxis itself. Mácia Teixeira, a 2014 candidate for federal congress by the PSTU in the Federal District, illustrates the dilemma well: "There's a great ideological confusion that forces us, in order not to lose contact with the masses, not to lose the channel for dialogue, not to become isolated, we end up going into the confusion to struggle [for the consciousness] inside of it. But we as a part are subordinated to the whole, it's much easier for the confusion to confuse us than for us to solve the confusion from inside of it” (Teixeira, 2015).

In a way, the rise of ultra-politics took part of the radical left by surprise, since it expected more consistently progressive mobilization after June 2013. Rafael Madeira provides a general left self-critique on this matter by arguing that while the idea that June was a dividing point that would reinvigorate street mobilization proved to be true, the left was not all prepared for the conservative content that followed, especially as it announced a right that was no longer afraid of openly defend regressive agendas, the military regime, and the rule of the privileged over the oppressed through limiting and removing rights (Madeira, 2015). While many organizations in the radical left argue that they had expected something like June could occur, this cannot be said for what followed in terms of right-wing cooptation of the streets and the strength of the conservative wave, not matter how much it may be underplayed by part of the radical left. The unpreparedness by the radical left (as well as the PT, which maintained great confidence in its tactical approach to the masses despite the oncoming economic crisis) has to 
do with left praxis and with the difficulties encountered by even the most eager organizations and actors when engaging in effective politicizing efforts, especially base-building work beyond corporativist interests.

In fact, part of the problem is related to how the radical left responded to June, which in the opinion of Givanildo Giva has to do with little investment in base-building work (Giva, 2015). The level of base-building, constituting mostly of work in the periphery of cities and capital, with informal workers, the homeless, and convening around social problems under structural perspectives and critique did grow since June, but only marginally, since the lack of base-building effort continued to be a complaint in the interviews and the ethnographic collection through 2015 and 2016. This is in fact a realization proper to all of the radical left, especially as there is strong recognition of the role the PT had played in base-building for many years and how its co-optation of the base has diminished access and trust in many communities (J. M. de Almeida, 2015). I argue that this is also a problem related to June, in the sense that part of the left expected that the progressive crowds would eventually recognize the left as their due representatives, perhaps not mechanically, but certainly more autonomously; that is, without requiring such long and slow base-building processes. This was part of a mismatch around representation in June, which exposed the limits of agitative self-proclamatory practices and revealed the representational gap between the left and the crowds the left thought it represented. As João Telésforo from the Brigadas Populares puts it, it comes down to building political reference before representation can be established, and this is indeed a matter of base-building, and I add, ultimately, of left praxis (Telésforo, 2015). This is why the MTST is recognized as one of the radical left organizations with the most political authority to navigate the ultra-political scenario (Belchior, 2015; Dutra, 2015; Silva, 2015; Telésforo, 
2015). As much as the MTST faces its own challenges regarding governismo, which relates to the fact that every leftist organization is out to influence the directions of the movement (Boulos, 2015b), and the challenge of politicizing beyond housing demands when their social base is one of the main targets of ultra-political and fatalist common sense (Basso, 2015), it is widely recognized in the left precisely because of its continuous investment in base-building, which translates into being the largest mobilizing power in terms of street numbers in the radical left today.

This struggle for the consciousness of the masses behind every base-building effort, from popular assemblies, to political debates, to individual home visits is fundamental for tackling ultra-politics, but it comes slowly, especially because the radical left is already behind at it. When the moderate left gave up on base-building work (given class conciliation and the co-optation of popular movement leadership), it seems that the radical left became puzzled over its own base-building tasks. Even when base-building was present, it often focused on self-reproduction, which is both a symptom and cause of further fragmentation. For Madeira, the left put base-building at large aside, but organizations such as the MTST continued to do so in a mostly coherent manner, and it is why it maintains itself as one of the few political references for the masses (Madeira, 2015). However, even the MTST runs into contradictions over politicizing the base, especially because its ambiguous position as a social movement that has to negotiate with PT government and respond to immediate needs. If ultra-politics cannot be tackled easily from the point of base-building and politicizing around issues that are increasingly demonized in the conjuncture, it certainly cannot be done through the affirmation of representation under a crisis that has expressed itself post-politically and gave rise to false alternatives of an ultra-political nature. Problems such as the one faced by the radical left in 
politicizing under the impeachment tend to become more common if base-building is not strengthened. The working class feels largely betrayed by the left, symbolized by the PT, and this is not something to change overnight. Rejection of Dilma and even Lula is common in the peripheral crowds, and presenting one's organization as authentic in comparison to the PT is not enough. Each organization's practice matters, and it can only be verified with time. This re-politicization is the viable solution to ultra-politics, but it is slow and it does not necessarily answer the most immediate challenges, such as the dilemma around Rousseff's impeachment, wherein the radical left faced barriers to position itself to the impeachment and even bigger ones when asked what the immediate solution to the impeachment crisis would be without legitimizing governismo or the right. The radical left is torn between fighting "Out with Dilma" without giving into to the moderate left's centre of gravity (as Mauro Iasi puts it in reference to the power of governismo (Iasi, 2015)) that calls for "Dilma, stay." This is also expressed in fighting the patriarchal machismo that affects the rejection of Rousseff, but also the patriarchal hold of her policies and little substantive representation of women. Governismo makes the ultra-political conjuncture all the more challenging, and it must be understood from the perspective of the radical left's still ongoing confusion and indefiniteness of the PT dilemma, partly related to left melancholia, and its impact on fragmentation.

A collective conclusion over what happened to the left under PT hegemony and how it should proceed beyond the PT is necessary for closure and strategy in the radical left (see next chapter), while the matter of re-composition, an overcoming of fragmentation, is important both strategically and in the face of the conservative wave. In fact, unity was perceived as essential in all of the interviewees and stood out as theme during participant observation. For Guilherme Boulos, the costs of trying to resist such a right-wing offensive without left unity 
can be very high and building this unity requires a search for common denominators (Boulos, 2015b). While this is true, the evidence raised for this study indicates that before we identify what is common to each organization, we must build common understandings of what these political challenges are in the first place. To do so, the left has to learn to escape from the shadow of the PT and governismo, with a strengthening of the radical left both as premise and consequence, and to overcome a series of practices that focus on each organization's selfreproduction in detriment of re-composition and some of the theoretical divides, which while fundamental strategically have closed the doors to dialogue when clouding tactical judgment.

This terceiro campo (third camp), as termed by the radical left in Brazil, consists of a camp focused on fighting both the right-wing offensive and a moderate left government (supported by governismo) (Demier, 2016a, p. 56). This construction depends on fighting past and present mistakes embedded in radical left praxis, such as "opportunist parliamentarism" and "sectarian leftism" with as much urgency as possible (Ibid.) Avoiding these mistakes is not simple, however, since they often present themselves as solutions to left in the face of depoliticization. Post-politics, for example, can take over leftist discourse to soften positions towards parliamentary victory. Ultra-politics, on the other hand, creates an urgent and scary scenario of false polarization wherein the radical left may be tempted to act in isolation in order to escape the militarized conflict and win it from the outside. It is futile to strive for the creation, consolidation, and growth of a terceiro campo without acknowledging how the state of depoliticization that emerges as post-politics and ultra-politics cannot be fought without further syntheses around the existence of the left and its internal relationships. To tackle depoliticization, one must also tackle fragmentation, keeping in mind that the fragmented state 
of the left is not separate from but rather a source and reflection of the fragmented state of consciousness in Brazilian society today. 


\section{Chapter VI: Fragmentation: melancholia}

Fragmentation has become normalized in the Brazilian left. This fragmentation can be analysed critically according to its historical impacts and political justifications. We cannot simply assert that the contrary, the prevention of a due schism, is the ideal. The last wellcomposed and unified version of the Brazilian left, signified in the PT, was not formally fragmented and still contributed to the state of fragmentation we see today. The critique of whether a schism is necessary or not, progressive or not, has to do with what the schism departs from and where the new organization and militants hope to go. Timing is also an important factor. It is my task in this chapter and the following one to deepen the thought over fragmentation in a way to escape weak dualisms and the immediate praise of alternatives that claim to work towards real unity but continue to reinforce fragmentation as a logic that goes beyond formal organizational divides There is no way out of fragmentation without effort being put into a concrete synthesis of its normalization, so that it is not enough to lament the current state of fragmentation of the left, as so often was expressed during interviews with all range of radical left actors, if the views on the sources of left fragmentation are themselves fragmented.

Because the practice and speech of lamentation is indeed so common when we discuss left fragmentation among the fragmented left, it seems almost impossible not to respond to other emotions around fragmentation. Radical left militants know that fragmentation, as a state that promotes in-fighting, predatory practices, and portrays the left as an incoherent space, is undesirable and creates challenges for coherent politicization, organized action, and the construction of a programme that is solid enough to oppose the unified project of the right. 
They also know, however, that the trend of fragmentation is a result and not the cause of the problems of left. Through the thesis of a crisis of praxis, I am able to point to its origin well beyond the major signs of general fragmentation in the current period of the Brazilian left. It does not mean that the logic of fragmentation was not already present inside of the Workers' Party, for example, in the 1990s, but that the formalization of fragmentation is a symptom of larger problems inside of the left. In the current arrangement of the Brazilian left, the separation between a moderate and a radical left is symbolic. The moderate left is composed by more organizations and is more unified in action under the PT leadership, while the radical left is smaller and more fragmented among each other and in terms of directions. The moderate left, however, is justified in common sense and trasformismo, whereas fragmentation in the radical left is also a response to the difficulties of presenting a new programme when the moderate left refuses to vacate a space to which it no longer belongs. The conflict that ensues is characteristic of melancholic politics and a melancholic approach to unity and the figure of the revolutionary in the Brazilian left.

\section{$\underline{\text { Left melancholia }}$}

This chapter is less concerned with a thoroughly psychoanalytical analysis of the concept of melancholia and its affective relations and more focused on its political implications in terms of melancholia as a sociological collective expression of lost hopes and entrapped desire during what Antonio Gramsci calls the "interregnum" between what is dying and that which is not yet ready to be born (Gramsci, 1971, p. 276). Three authors that have discussed the concept of left melancholia, though with different implications, are examined in this chapter. My use of the concept is referenced in some parts of this prior discussion but 
ultimately points to a particular understanding of left melancholia in the context of a fragmented left in Brazil. ${ }^{43}$

Jodi Dean speaks of left melancholia to understand lost and recovered desire in the left in general (Dean, 2012, pp. 157-172). To do so, she examines how the concept, which is still quite underdeveloped in this particular application to left collectivity and organization, is employed first by Walter Benjamin (Benjamin, 1974) and then by Wendy Brown (Brown, 1999). Dean argues that Brown has misinterpreted Benjamin's concept of melancholia, which is related to a specific critique Brown had of the modern left in the late 1990s. Brown utilized Benjamin's interpretation of melancholia to further an argument against the left's historical attachments, which she saw as narcissistic and turned inward rather than towards the needs of the class. Benjamin's definition, however, has to do with a left that has forgone all historical attachments and become complacent in its task as to give in to the bourgeois order and political project. Benjamin speaks to a melancholia that distances the left from the historical subject as it becomes closer and more invested in the status quo.

In Dean's exegesis, Benjamin defines melancholia (or melancholy) in the left as a state of complacency wherein the left has given up on a lost object in a non-revolutionary manner. It is prone to making compromises to adjust to the bourgeois order and this is justified by a supposed unattainability of this lost object (Benjamin, 1974; Dean, 2012, p. 160). I engage with this exegesis, because I find Dean's tracing and juxtaposition of the use of the concept

${ }^{43}$ I am aware of the recent publication of a book in Brazil titled Além do PT, by Fabio Luis Barbosa dos Santos, that may have interesting implications around the notion of "grief" that could be engaged with around the concept of melancholia. The book was published in Brazil just as this dissertation was being finalized, but it is my desire to engage with it in the future, especially concerning any publications resulting from this chapter. 
interesting, especially how her engagement with Benjamin, seen through a contemporary historical perspective, is useful to look at the moderate left. Brown misinterprets melancholia to represent leftist actors that place their ideals above the practical terms of reality that could lead to immediate change, instead of Benjamin's proposal that melancholia consists of a betrayal of these ideals and, consequentially, the class they represent. Jodi Dean intervenes to argue for Benjamin's view of melancholia by suggesting that Brown misidentifies what is being lost and retained by the melancholic (Dean, 2012, p. 169). There are certainly leftist groups that fit into Brown's definition of narcissism, or an attachment to a "fantastic object" (Dean, 2012, p. 170). However, her claim that this left ends up lacking in radical critique and contributing to the renewal of the status quo by omission related to an attachment to its own impossibility (Brown, 1999, p. 26) is not applicable to the moderate left nor to the radical left as defined in this dissertation. Rather, it concerns a self-serving form of ultra-leftism that is so steeped in vanguardist readings of reality that it is rendered distant and useless to the working class.

If Benjamin's view of melancholia refers to the phenomenon in relation to what I have described as trasformismo before, another view of melancholia has to be observed to address the melancholic symptoms that can also be found in the radical left. In my analysis of the Brazilian left, considering their proposals, activities, as well as the interviews I conducted, I too noticed melancholic symptoms. One of them pertains to Benjamin's definition of melancholia and it more accurately describes the melancholic state of the moderate left. Benjamin finds melancholia to be tied to fatalism, which he sees as connected to the abandonment of ideals and willingness to compromise. Fatalism, from this perspective, entails the conclusion that nothing else can be done about a situation in the way it was thought out 
before and this leads to resignation before reality and the trade of revolutionary ideals and objectives for palpable, pragmatic, and mainstream approaches. It can occur at various stages of an organization's political trajectory, and it is of special interest to this study when considering fatalism as an element of trasformismo. This melancholia enlarges the distance between the left and the movement of workers and oppressed it claims to represent.

In general, melancholia is defined as deep sadness and the sources of this sadness can vary from lost objects, hopeless longing, and misplaced desire. In Portuguese, the word saudade is often used to characterize a mix of melancholia and nostalgia. Its derivative, saudosismo means a prevalent state of longing or anxiety marked by melancholic and nostalgic feelings. During fieldwork, militants would refer to one organization or another as being prone to saudosismo while others referred directly to a melancholic state as the radical left attempted to make sense of the impeachment process (Fernandes, 2015). This could be related to how the organization defined its programmatic guidelines, how it dealt with the defeat of Soviet socialism, how it connected to the period of continuous mobilization (through strikes and demonstrations) that marked the first era of the PT and/or how it envisioned left unity and the ideal left organization for Brazil in the $21^{\text {st }}$ Century. This suggests another melancholic phenomenon that can be used to understand the radical left, which is somewhat distinct from Benjamin's definition of melancholia and its application to the moderate left. Left melancholia in the radical left, which is still attached to revolutionary ideals, can manifest itself as saudosismo, though it is a more complex and larger phenomenon than it. Rather, it is better understood as a mix of longing and anxiety that is often related to the difficulty in creating definite syntheses about historical symbols and/or actors in the left. This kind of melancholia leads the left to long for better times and victories of the past, often idealizing/romanticizing 
them and/or taking them out of their context of conflicts and defeat. This state also leads the left to overemphasize the relevance of historical experiences for strategic advancement in very different conjunctural arrangements or to look anxiously for redeeming characteristics in failed projects or treacherous actors. It also nurtures a tormented experience in which what was lost cannot be recovered and that what is wrong has not been fixed precisely because of this lost object. This aspect of melancholia, as a sociological phenomenon in the Brazilian left, deters organizations and other actors from seeing possibilities beyond the realm of what was given in the past and encourages tactics based on past formulas that led to uprising, upsurges, and revolutionary periods. This clouded perspective may even lead to emphases on possibilities that do not correspond to the conjuncture, such as a fantastical and reified view of political events as solutions as is often the case with interpretations of June 2013, as a way to remedy the fears and anxieties that accompany persistent longing for what has been but is no longer. This may hinder dialogue between the left and the crowds by appealing to sentiment, experiences, and historical interpretations from a place of authority to which the crowds do not correspond, especially in a context of depoliticization. It may also lead to a confusing approach to new forms and experiences in politics, by either rejecting them because of a longing for the past or overestimating them because of the anxious need for victories and remedies in a scenario of repetitive losses.

This confused approach that affects the critical examination of events and strategies has to do with fears and anxieties in a fragmented radical left that feels responsible for presenting alternative proposals but deals with obstacles coming from the moderate left as well as the right (both traditional and far-right). The conjunctural change that began in June 2013 added to longing and anxiety by the radical left. Longing in terms of what could happen or be 
turned in the favour of leftist ideals with June, and anxiety in terms of trying to come up with an appropriate response to the crowds of June 2013. The latter contributed to the ways in which the radical left gave into post-politics or ultra-politics in attempt to connect to the June crowds without a prior assessment of mass ascension and demonstration as crowds without politicization; that is, a certain level of anxiety that attributed the status of a political subject to something that opened up the gap for a new subject but was not a subject in itself.

In a more advanced case, this melancholia can lead the radical left to also become distant from the class it represents, but for reasons different from the melancholia of the moderate left. This distance does not have to be physical, but implicates in political distance from the needs and wants of the class. An example consists of when a social movement foregoes a negotiation with the government because of the contradictions imposed by this government, even if it means also foregoing the base's demand for immediate shelter or rent assistance given that base's little regard for the contradictions involved in face of its own material needs. It contributes to a vanguard separate from the consciousness of the base because of a contradictory consciousness that should be the object of politicization in the first place. In a way, this melancholia resembles Wendy Brown's view of a melancholic state that places certain left tendencies in a space of comfortable agreement over what leftist critique ought to be but without presenting radical yet viable alternatives that may appeal to the crowds these tendencies hope to represent (Brown, 1999, p. 26). Where this differs from Brown's conclusion, which is based on a misrepresentation of Benjamin's concept in the first place (rather than a new concept of melancholia), is that the results of this distance and failure to represent alternatives are not conservative per se, even though conservatism may benefit from it because of its retreat in struggle. Brown explains this lack of alternative because it is related 
either to lack of deep and radical critique of reality or a left that is so attached to a dead past that cannot think up possibilities. This conclusion is not applicable in the case for melancholia that I make regarding the radical left because the lack of radical critique leads precisely to the fatalist kind of melancholia that Benjamin discusses, which is related to willing, even if discursively reluctant, proximity to the status quo. Second, the radical left has more trouble in promoting possibilities, in the form of politicization, base-building, and the defragmentation of the consciousness of the class, than actually thinking them up (which would indeed have conservative implications if that were the case). Instead, the melancholia of a more distant radical left has to do with the barriers that impose this distance and these of a communicative and politicizing nature. The more fragmented the radical left is, the harder it will be to communicate with the class it represents and to match its proposals to the development of the politics of this class, which ought to be grassroots and not top-down in a Gramscian view of leftist organizations as intellectuals, or in the frame of crowds explored thus far, interpellators. Any distance, in this case, is not a result of narcissism, but of fragmentation and the nature of the crisis of praxis that affects the radical left. The melancholia of the distant radical left has less to do both with a proposed critique of its ideals, as Brown would have it, as with the methods this left hopes will be effective for interpellating the political subject. This can be indeed a problem related to the methods of a dead, romanticized, past of victories thought to justify the losses due to a melancholic state that creates inadequate historical syntheses. A conjuncture of deep depoliticization makes it worse, especially in a scenario where melancholia affects two different versions of the left at the same time but in very different ways. 
Because melancholia is less of a palpable concept or situation and more of abstract phenomenon that occurs at the level of consciousness, albeit with practical and strategic implications, the evidence brought out in this chapter relies heavily on my interpretation of interview content, of comments made to me during fieldwork, of the observation of political events and my analysis of the creation and resolution of political conflicts between the radical and the moderate left in terms of perceptions of victories and failures.

\section{The melancholia of the moderate left in Brazil}

In Benjamin's critique of melancholia, the melancholic subject suffers from lack of will. This lack is manifested as fatalism, which prevents not only action but also will to action because of the reading of reality that is given. In the case of the left, it does not long for what was lost nor for a future that it deems to be unattainable. Past desire for a different future is replaced by complacency towards the present reality, thus replacing the desired object with the status quo in order to keep what is wanted within reach. The melancholia is a symptom of having given up as well as having replaced what was given up with new ideals and desires (e.g.: social democracy, reified localism, etc); that is, the loss of the melancholic may or may not have been voluntary, but its replacement, as betrayal, is an act of compromise. When speaking of the moderate left, particularly the PT, questions arise as to whether this compromise was conscious and planned, if it was part of the original project, or a result of a detour that may have been chosen or followed persistently in error. This melancholia consists of a sublimation of desire and the apathy that surrounds this process.

As Jodi Dean puts it, "Benjamin compels us to consider a Left that gave in, sold out" (Dean, 2012, p. 171). Ruy Braga described it in his interview as a progressive "abandonment 
of a project for the transformation of Brazilian politics" (Braga, 2015). This project was not properly socialist and it was largely undefined, though there is general agreement that it is characterized as a popular democratic project, which was sold out anyway despite how unradical it was. The gradual focus of the PT on gathering and strengthening its institutional apparatus, as well as instruments of struggle such as labour unions, would eventually end up hegemonizing these struggles through parliamentary mandates and towards its own institutional renewal (Giva, 2015). According to Israel Dutra (PSOL - MES), this movement was intensified in 1989, after Lula's defeat in the presidential elections, when the party became more "adapted to the liberal democratic project, by way of the parliament and by way of making deals" (Dutra, 2015). This tactic resulted in the expansion of the melancholia to more organizations, concentrated as the moderate left, and a process of selling out with deep consequences for organizing practices and class consciousness.

To give in to the bourgeois order was not a simple process for the PT, but part of a complex set of decisions that required, above all, to minimize what the so called democratic popular programme was set out to do. The programme, which was never meant to be revolutionary, but still focused on the premise of undertaking basic reforms, was reduced to a series of social policy programmes aimed at poverty eradication, the promotion of access to education (without a threat to the private sector), affirmative action, and job offers through developmentalist initiatives. The objectives of governability and self-reproduction at the institutional level were higher on the list than land reform for agrarian workers and fair settlements for indigenous communities, and areas such as social security actually took a hit (e.g.: Pension Reform) during the PT governments. Some of the justifications by the PT and analysis favourable to the PT had to do with the party not having the proper "correlation of 
forces" to proceed to the reforms that had been promised before the elections (G. R. De Almeida, 2007, p. 55; Lécio Morais \& Saad-Filho, 2011, p. 511). Research participants from the radical left expressed cynicism during informal conversations over this belief because the PT was not forced to promote governability over the reforms but chose to do so (Belchior, 2015; Fernandes, 2015). For Douglas Belchior (PSOL / Uneafro), even the few advances that happened during the PT governments cannot be solely attributed to the goodness and progressiveness of the PT, but resulted from social struggles in the context of a government speaking and acting in the name of the working class (Belchior, 2015).

The problem of degeneration brings up Emanuele Saccarelli analysis of Stalinism in light of Gramsci's discussion of cannibalism (Saccarelli, 2008). Although the case of the PT is far from the Stalinist situation in terms of political form and even speech (both the revolutionary and the authoritative kind), the arguments for degeneration apply to the melancholia of the moderate left. Saccarelli explains that the degeneration may come about through betrayal, but it is more complex in the sense that "as Gramsci's note suggests, these people, still thinking of themselves as revolutionaries, had become unable to realize that they were actually systematically devouring the revolution" (Saccarelli, 2008). The same actors in the PT who continued to speak for the class were the ones undermining and undercutting possibilities for more radical change. This was both a conscious process, regarding the party direction that either distorted the popular democratic programme to fit into their neoliberal agenda or discarded it completely, and an unconscious one, in terms of militants and base that believed that the self-reproduction of the PT had to be prioritized if any radical change was to be achieved eventually. The devouring of the revolution is equivalent, according to Gramsci, to a cannibalism, since the thought and action that the party once represented (independently 
of whether it actually espoused them), is absorbed and transformed in the entrenchment of the political organization as a bureaucratic party, in which the "bureaucratic hierarchy replace[s] the intellectual and political hierarchy" (Gramsci, 1999; Saccarelli, 2008).

This process of subjecting the left to the bourgeois status quo, as if no alternative is possible, is not without contradictions and internal differences, for as bureaucratic as the PT became, there remained opposition and contention at the base and in the lower rank of militants. Whereas a portion of leaders and militants of the moderate left has migrated to the radical left over the years and contributed to the creation of a project distinct from the PT in the general leftist base - that is, against class conciliation - there are those who remain somewhat loyal to the PT and what it represents, hoping for a re-radicalization of the party back to its historical working class roots. These internal differences relate to how one interprets what went wrong with the PT: was the popular democratic project ideal in Brazil at the time? Is the conjuncture a result of the popular democratic project or a result of its use to gather support but without its actual implementation? Is it a matter of the PT going back to its roots or seeking a new leftist project that is not tainted by the contradiction of the popular democratic project? The first reading implies reverting the PT's betrayal (more in this chapter), whereas the latter has to do with finally implementing a project that could work out for the left, assuming, then, that the conjuncture is the precise result of the popular democratic project. This is what organizations such as the PSTU, in the radical left, argue (J. M. de Almeida, 2015). No matter which of these interpretations is preferred, they are both based on the idea that the PT is still useful and should not be thrown away. This helps to maintain the organization's base and militants attached to the notion of the PT as an instrument of the working class that must be (re)radicalized somehow. Aware of this, the leadership of the PT tries to nurture this notion 
in order to prolong its hegemonic position in the left. However, the programme implemented and defended by the PT in the past years indicates that the any remains of the idea of a radical PT is only rhetorical. Rather, its promotion is designed to ensure self-reproduction through a melancholic justification of where the party stands that alludes to a distant radicalization when convenient.

\section{The melancholia of the radical left in Brazil}

The radical left suffers from a melancholia of a different kind than that of the moderate left, the latter which fits into Benjamin's proposal of what left-wing melancholia means. Instead, the radical left is melancholic towards past victories in a way that affects its current strategic horizons. It is not, however, distant from the revolutionary desires of the class it aims to represent, and it is actually looking for ways to diminish this distance even as the PT continues to hold on to its position as a representative of the masses. The problem is that depoliticization and the intense period of left demobilization under the PT imposed a gap between the radical left and the class. While the class is attacked, it is also manipulated away from a revolutionary consciousness (maintaining the theoretical and practical consciousness at odds with each other), the radical left lags behind in base-building because of depoliticization and an underestimation of how much work is necessary to reunite the consciousness of the class and occupy the hegemonic space of the left the PT still controls. These elements are examined below in terms of how the radical left sees the PT and its recent history, the desire for the base and the affirmation of the radical left alternative camp as the only leftist route, and the slow and late process of overcoming and politicizing about the PT project. 


\section{The PT's betrayal}

The Workers' Party, despite its contradictions as moderate left, continues to be the most recognized representative of the Brazilian left. It has managed to maintain a leftist aesthetics embodied in the colour red, the star, the name reference to the working class and the promotion of public figures with ties to the labour movement or the struggle against the military regime, all of which appear as strong symbols of leftism when the meaning of the left is lost in depoliticization. There is also still a concrete and relatively large base behind the PT and other actors of the moderate left (primarily the CUT and the MST, as demobilized as part of this base has become in the recent past). What makes the PT so prominent is its institutional gains, which create an electoral base that is useful for self-reproduction beyond the social movement and union base. The institutional strength gives the PT what Mauro Iasi, from the PCB, defines as gravitational power. This gravitational power keeps the moderate left consolidated and helps to secure governista proposals even from groups and actors that belong in the radical left but collaborate with the PT in some level. Iasi says that "This is the difficulty for every social movement and this is why we need to create an alternative [...] When a social movement of this nature gets close to the government to change the nature of the government, it's more likely that the government will change [the movement's] nature, not the opposite" (Iasi, 2015). For Iasi, this adds to the strength of the PT's base, even the electoral ones, because of the PT's weight in the institutional game that tips leftist action in its favour. The impeachment crisis brought evidence of this, since the PT retreated from active opposition to the impeachment and did not openly call on people to take to the streets. This task fell instead to the social movements and unions involved in the Frente Brasil Popular, as well as some of the radical left organizations that composed the Frente Povo Sem Medo. As the impeachment was 
consummated on August $30^{\text {th }} 2016$, it was MTST militants, from the radical left, who were first arrested for protesting against Temer, whereas part of the PT base was already demobilized. Talks of a possible candidacy by Lula in 2018 had resurfaced, indicating that the party was looking for institutional renewal more than to actually defeat the impeachment through politicized mobilization of its base. The fact that anti-leftism targets the PT as antipetismo also ends up empowering the party as a symbol of struggles it demobilized or neglected.

The realization that despite all betrayals the PT is still the largest symbol of leftist action, institutional and in terms of grassroots mobilizing, in Brazil is bittersweet for many reasons. First, it reminds the radical left today of how close the Brazilian left, in general, once was of doing more; perhaps not close to revolutionary purposes given the PT's institutional focus, but certainly closer to progressive outcomes and social justice than it is today under a conservative offensive and austerity attacks. Second, it enhances the feeling of betrayal that blocks authentic leftist action at every corner. This includes specific acts of betrayal, such as the ones around corruption schemes and Pension Fund Reform that led a group to leave the PT and form the PSOL (Mohr, 2015), as well as the betrayal of the leftist meaning and programme that ultimately implied in a betrayal of the working class (Farias, 2015). For Wagner Farias (PCB), the problem with the interpretation of the PT's failures as betrayal is that the solution to it could be "a future that is a return to the past" (Farias, 2015). This is sometimes argued by the moderate left to present a solution based on rescuing the origins of the PT, as has been proposed by less moderate petistas in terms of need for a "re-foundation" of the PT. It is also observed in the radical left when organizations propose rescuing the meaning of a real revolutionary organization to lead the people as the PT once did from a non-revolutionary 
position. The focus on betrayal fosters a sentiment and interpretations of history that create a longing for the ideal moment of the past when the left was relatively united and was acknowledged consistently as the representative of the masses. Ideally, this would have been a moment of coherence and fidelity to the interests of the working class.

The focus on betrayal is not useful if one believes that the direction taken by the PT was dictated by a series of programmatic choices that were determined before acts of betrayal in government, such as the prioritization of an electoral victory during Lula's campaigns and the growing acceptance of corporate financing of these campaigns (Samuels, 2001, p. 31). According to Zé Maria (PSTU), "the political project of the direction of the PT was never different from this one out there, even at the time of the foundation of the party. There were different political circumstances in the country that led the directors of the party to make a speech more to the left, but Lula, ideologically speaking, was always [what we see today]" (J. M. de Almeida, 2015). Zé Maria's statement refutes the notion of a betrayal by the PT, as is the interpretation of the PSTU, but still expresses the melancholia connected to how the PT represented something that it was not and should have been.

What I consider to be most important in the reading of betrayal is less the concern of whether the PT conveniently promoted one politics and betrayed it in favour of another, but the impact of the politics that was indeed implemented as betrayal of the people and what it understood as the left. Whereas a left that feels betrayed by the PT may depend on a particular interpretation of betrayal, the difference between the PT's rhetoric and pre-government mobilizations and the actions of the party in trasformismo consist in a betrayal of the people, which has had depoliticizing consequences that affect left mobilization from the PT government onwards. This means that whether or not the radical left should feel "personally" 
betrayed, the significant aspect of betrayal by the PT concerns the base and the Brazilian population at large. This betrayal has melancholic effects in the radical left, since it struggles to break free from the idea that the PT had the tools to promote change but gave them up in their own melancholia. It also has an impact in the disillusionment of part of the base that fled the PT in the past years but did not move in the direction of the radical left. The PT may not be seen as an alternative by the people any longer, but there are forces contrary to the left benefitting from it because of how the PT stopped being an alternative (Teixeira, 2015). Instead, this disillusion created an apolitical fatalism that was easily appropriated through postpolitics with arguments of efficiency, against corruption and towards a technocratic politics that is not at risk of ideological betrayal. Douglas Belchior (PSOL/UneAfro) argues that as a result of undoing what was concrete about left politics, the PT also affected what was subjected: "We lost the imaginary, what is worse I don't know, I think that perhaps it's the imaginary. The imaginary sucks because how long will it take for us to be able to talk to the [working] class and have the working class believe that it's possible to have a just society with the left directing Brazil [...] If it was hard to build before having the contradiction [contraditório], what about now that there's one? [...] To see the discouragement of the people [...] (Belchior, 2015). In sum, the PT's betrayal affected the imaginary of the people but also the ability of the left, which interacts with the betrayal in a melancholic manner, to re-connect with this imaginary. This is made worse in a context of fragmentation, which contributes to another element of melancholia in the radical left through the yearning for unity so that left credibility can be restored and the crowds can be interpellated without internal disputes. 


\section{Misplaced desire: united left gone wrong}

The PT was created out of a project for unifying as many progressive organizations as possible to contest the future of Brazilian politics given the opportunities the democratization process would present after decades of repression, struggle and clandestine activities during the military regime. Several militants of the radical left interviewed for this dissertation began to participate in organized leftist struggle through the PT and attested to the consensual view of the PT as a space for unifying the majority of the Brazilian left at the time. José Carlos Miranda (Esquerda Marxista) spoke of the PT not only as the unifier of the authentic left at its inception, but also as the organization responsible, with the help of Lula's influence and charisma, for stirring up the class consciousness of the working class (Miranda, 2015). Despite the perspective that the PT was never intended to be (and never operated as) a revolutionary socialist organization, it was an instrument built by a variety of progressive sectors, including socialist organizations. For Douglas Belchior (PSOL), the party managed to aggregate the progressive sentiments of all groups at the time (Belchior, 2015). Even though the PCB and the PCdoB, for example, did not contribute to the PT project, its role in taking the left forward was widely acknowledged, partly because of the legitimacy given by the initial collective construction of the party. Alexandre Varela (PSOL - APS) described this collectivity as follows: "You could see how everyone had been brought together. They brought together the church folk, the industrial workers, the intellectual, the guys who had opted for armed struggle, those who opted for parliamentary confrontation, so that the unity of all these fights together could make a strong instrument that'd be essential for us to manage to make basic reforms" (Varela, 2015). 
Whether or not one believes that the PT was ever revolutionary, socialist, or even radically leftist, it was the one organization in the Brazilian left to aggregate the majority of leftist thought and initiatives inside of its ranks while coordinating the struggle of the working class with other movements, parties, and unions. Despite of the PT becoming a party of order, it represented the majority of the left in a substantive manner before its trasformismo. This was no easy feat, but the conjuncture following the decades of repression under the military regime called for bold, collective, and widespread leftist organizing if the left was willing to participate and influence important processes such as the National Constituent Assembly (1987-1988) and the first democratic elections after the end of the regime.

The sentiment of betrayal that affects the left that contributed to the creation and strengthening of the PT, combined with the frustrations and conflicts that permeate the current period of widespread fragmentation in the radical left, is worsened when considering that the PT had managed to do something incredible in terms of left unity but gave it away by giving into bourgeois order and giving up on the basic working class values that would make the popular democratic programme of the party something more progressive, more politicized, and more mobilized than what was put forward during the Lula and Rousseff terms, let alone the bureaucratic performances of the party at the local levels. Varela (PSOL) complemented this sentiment by arguing that the PT was the ideal tool for implementing the reforms it was created to make, since there were no illusions that the PT would be a socialist revolutionary instrument. It was a broad party (partido amplo) and this gave it legitimacy to implement a series of reforms, but those in control of party refused to do so (Varela, 2015).

This belief that the left "had it" but "lost it", especially due to a betrayal of its purpose and of the class, still affects the radical left today. Here is a radical left that is principled, critical 
of the PT's politics, and wants to implement the basic reforms and social justice measures that the PT failed to do but does not have nearly the base the PT once had and still has. This deters the radical left from electoral achievements that could help with policy interventions and to curb conservative victories in the institutional ground. It also diminishes the radical left's potential to become a political reference for the crowds and be recognized as a representative of the working class in a variety of struggles. The PT was in possession of an opportunity the radical left wishes it had today, but it does not. This is even more evident given the high level of fragmentation, partly related to how each organization approaches the PT as an obstacle and its relation to the moderate left, partly attributed to the various theoretical and practical divides in the radical left at a time of high depoliticization and a crisis of praxis that is inevitably connected to the low level of class consciousness. This was not the case of the PT, which benefitted from a rise in class consciousness after military repression and managed to take it to an even higher level. The situation of the PT when it had that opportunity and let it pass is very different from the one the radical left finds itself in today, but given the opening up of spaces for intervention and politicization, albeit its challenges and contradictions, since June 2013, the radical left is constantly bombarded with the desire for the opportunity the PT had and for what it could do with it today.

This produces two symptoms. First, the unity behind the PT ends up idealized, since it bore amazing potential in terms of class struggle. The fragmentation of the radical left has become so ubiquitous, that some long for unity on the basis that it is the solution for the current problems. This line of thinking has issues because unity should not be seen as pre-condition to finally get anything done. The PT arose from a conjuncture that aggregated the left first, which created the party second. This is not the case today. In fact, I argue that the tendency of the 
radical left will continue to be towards fragmentation as long as depoliticization remains so rampant and collective syntheses and dialogue are not pursued continuously and routinely. If attempts at creating fronts and alliances so far demonstrate anything, it is that they only work on a campaign to campaign basis and mostly around single issue demands because the radical left organizations are not in a position for high level dialogue. The PT crisis forced the left to rethink strategy and tactics. The conjuncture brought forward in June 2013 raised the stakes, which led to interpretations that this was the time for the left to unite but without a clear perspective on why the left was disunited in the first place. Not all can be blamed on the PT, for if this were the case all organizations would have merged after leaving the party together with those who were not in the PT in the past. In addition, unity for the sake of unity may end up in attempts at co-optation and even militant poaching, as Mácia Teixeira (MAIS - former PSTU) argued in reference to the practice of the radical left of strengthening one's own organization in detriment of a neighbouring organization - with no major prospects of actually growing the radical left in relation to the moderate left and the right (Teixeira, 2015).

Second, the melancholia of the radical left is connected also to a romanticization of the idea of unity for the sake of unity and to even push for collaboration/unified fronts in a mechanical way (e.g. FRP). A certain level of organizational identity needs to be developed to work towards unity as a goal. Further, unity does not always have to be unification into a single umbrella organization, although such instruments can prove to be useful spaces for dialogue on common ground. This is why Israel Dutra (MES) argued to me that the current status of the radical left in Brazil in relation to the conjuncture is of so much complexity that it requires broad parties, such as the PSOL, as long as they have the internal democracy that the PT lacked (Dutra, 2015). He said: "We thought that a renewed left must, for a long while, preserve 
individual and group differences [...] There isn't today a direction with enough political authority to homogenise from above all this multiplicity of identities, of worldviews. For example, the MTST is today a direction with authority that is able to do this from a social standpoint, but not from a political one. Lula managed to do this for a long time, and even so the PT had the right to tendency as one of its entrenchment clauses" (Dutra, 2015). The internal freedom allowed inside of the PSOL is one of the reasons why the party is so appealing to organizations that want maintain their own political identity and to benefit from the access and structure provided by a political party but do not have enough numbers to be a party of their own.

This line of thought suggests that there is awareness in the radical left of the lack of proper syntheses among the groups that prevents unity from being constructed overnight. Even so, the desire for unity is strong. During fieldwork, it was common to hear militants sigh that things would get better "if only the left became united" and/or "got over their little fights" (Fernandes, 2015, 2016). The idea that the conflicts in the left are not big enough to warrant such division and fragmentation suggests some naiveté. Granted, there are conflicts that arise from vanguardism, sectarianism, and wasted opportunities for dialogue based on organizations' desire to be the one authentic representative of the left. Yet, the majority of the differences are complex and have to do with complicated readings of history in relation to what was lost and how one should proceed forward in a conjuncture that, whether one likes it or not, is radically different from the one that gave birth to the PT. The fights between the moderate left and the radical left are not insignificant, and arguments for unity between them often rely on the premise that the PT ought to be the homogeneous and hegemonic force in the unifying space. The conflicts inside of the radical left also revolve around which forces should become 
hegemonic. Vanguardism is a notable problem in these situations (see next chapter). The problem is that as long as unity is perceived as something that could be established at the vanguard level, it will continue to fall apart. Even though the PT was created from an initiative of the vanguard, the unity began at the base that was politicized and mobilized enough to endorse the project proposed by that vanguard.

The melancholia that surrounds the crisis of praxis of the left clouds judgement and conjunctural analyses in ways that are favourable to each organization's existence and performance. If attempts at dialogue break down, is it often the other organization's fault, rarely one's own. In the meantime, the small base of the radical left is seen as something that could grow overnight if only the PT stopped sabotaging the radical left and co-opting common spaces, revealing little political depth about the depoliticization and manipulation of this base. The problem of the desire for the base is examined later in this chapter, but for now it is important to say that the crisis of praxis is partly sustained by this belief that all you have to do is bring people together and then dialogue would flow. Rather than part of a conscious and careful process, dialogue is perceived as a simple means to an end. This makes efforts at dialogue into convoluted exercises instead of concrete steps at resolving differences, making sense of that which is problematic about the PT's hegemonic space, and how depoliticization is a problem for all organizations. Saudosismo related to periods of high mobilization creates frustration when numbers are smaller than desired into more longing for the mobilizing power the PT as an unifier of the left and how the party threw it away. The point is that it is insufficient to think that unity can be achieved through the collaboration of the vanguard as much as it could be by gathering the masses without also addressing the conflicts that keep the vanguard apart and distant from a unifying programme. This was echoed by Guilherme Boulos (MTST) 
in his interview, who argued that anxiety towards unity would not make it happen, and patience was a necessary element because even if a common platform could be built, it would not advance if all other sources of conflict, especially the desire for one organization to direct the process, remained (Boulos, 2015b).

The position outlined by Mauro Iasi (PCB) in his interview is aligned with the view of a crisis of praxis that is connected to the perception of defeat and loss, especially in the way it affects the consciousness of the crowds the left tries to interpellate and of the left militants themselves. He said: "The seriality leads members of the working class to be in the same place, suffering from the same circumstances, but they don't form a collective, they don't form a class. [...] A class defeat leads a process of consciousness to revert on itself. So in Brazil we were in the process of constituting a consciousness for itself $[\ldots]$ with potential elements for the constitution of a historical, revolutionary, subject, that would bring consciousness of itself when we suffered a defeat and this defeat affects the class in terms of its disorganization, it s political fragmentation. [...] In our perspective, the fragmentation of the left is an expression of this" (Iasi, 2015)

The fragmentation of the radical left is visible during the street demonstrations, coordinated campaigns and electoral periods that the radical left values highly, and militants from the base would often express frustration over this, especially because of the predatory competition between the organizations that would lead militants to "talk past each other" and still call it an attempt at dialogue (Fernandes, 2014, 2015). The left may be gathered together all in one place, but since each organization and groups of militants share different positions regarding the defeat of the class, the setbacks in consciousness, and how to move forward, fragmentation will still be the norm in these spaces. This was visible during live debates and 
demonstrations that involved access to a microphone or other means of mass communication, as is the case of the "sound trucks" intended to conduct the crowds at demonstrations. What I observed in the vast majority of events when sound trucks were present was collectivity in the sense that all organizations present were welcome to go up the truck, salute the crowd, and make their own political statements, yet there was no connection among the statements and the people on the ground would either disregard the speakers or only pay attention to those from their own organization. The sound truck presents a situation that appeals to a unified space of dialogue, by making room for all organizations present to have their say, whether they were directly involved in organization the protest or not, but at the same time illustrates the disconnection between the speakers and the crowds, which goes beyond the spaces of protest and demonstration. At the same time, it gives an opportunity for organizations to make their presence and leadership more legitimate, such as the PT when it arranges for Lula to go up the sound truck at a rally mobilized by the radical left with crowds that were negatively impacted by his governments and formerly demobilized by the party. 
Figura 5 Natália Szemerta (MTST) speaks to the crowds on top of sound truck (April 2015)

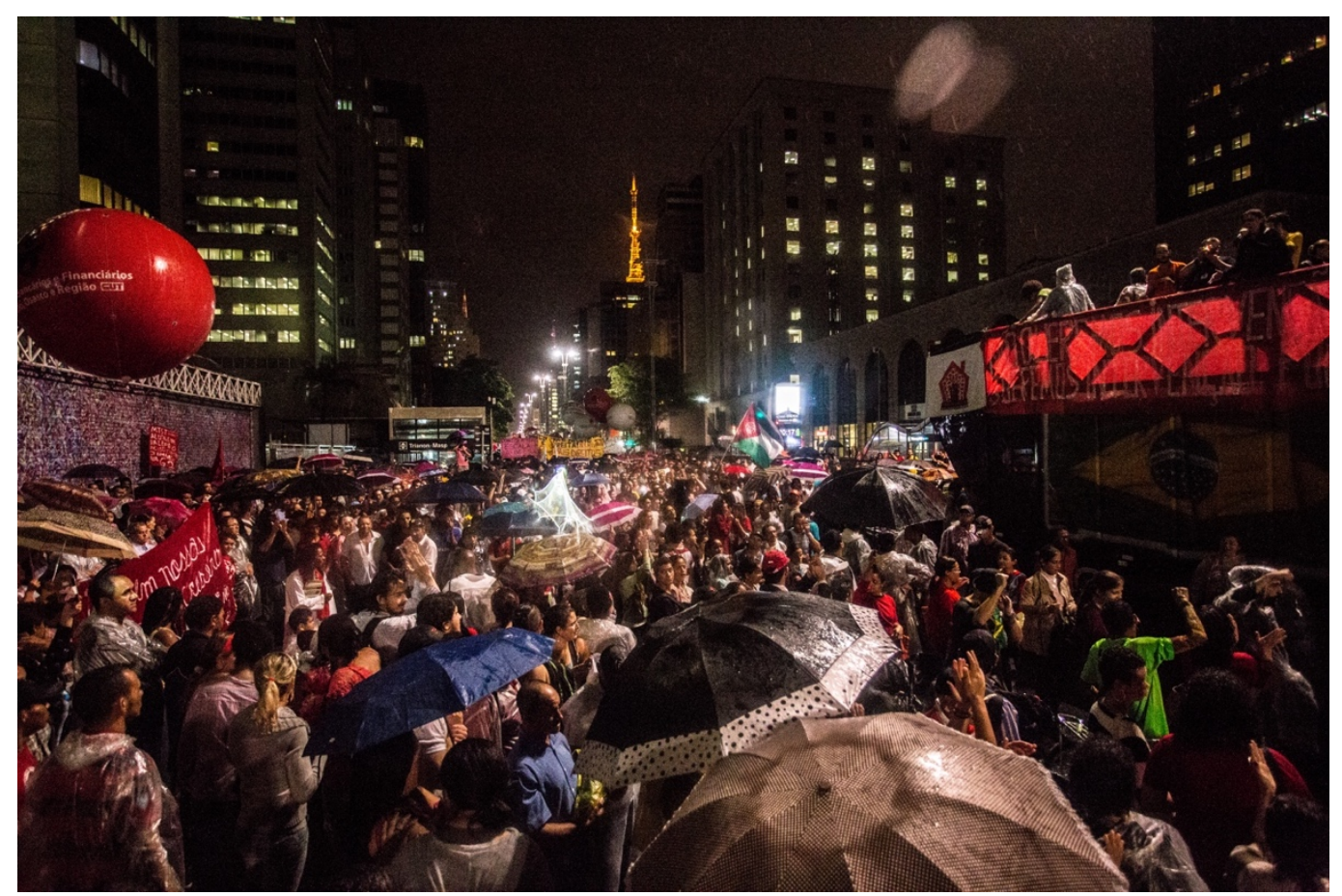

\section{Radical third camp under the PT's shadow}

The current state of fragmentation of the left is so profound that it taints attempts at collaboration by making them look mechanical and artificial, with a fragile appearance. Some of this translates into sectarianism (see Chapter 7), while other aspects fall under a difficulty to organize whenever the PT is present. Part of this artificiality relates to disputes inside of the radical left over the hegemonic space, which are for the most part negotiated in terms of being the authentic left. More than a matter of evaluating leftist praxis, however, the disputes are measured in terms of two elements: sectarianism and the fear of becoming the PT or following in the PT's path. Sectarianism will be analysed in Chapter 7, but the fear of "the path of the PT" needs to be considered in relation to the melancholia of the radical left if we are to understand the difficulties of asserting a radical third camp to the crowds as well as to the radical left itself. 
Part of the problem of the PT's betrayal is how the justified rejection of the party by segments of the working class also translated into a general rejection of the left and all things left. Even though it is progressive for the base to break away from the PT because of this betrayal, the depoliticization that accompanied the betrayal did not lead the base directly towards a more radical leftist option. Further, the PT was also demoralized because of its own corruption scandals as well as conservative critiques of its social policies. This promoted antipetismo in the PT's former base, the right-wing base, as well as those depoliticized that stand in between. Douglas Belchior (PSOL/UneAfro) explains that "by demoralizing the PT, it demoralizes all the political topics that the PT defends historically, even though not in practice, and it demoralizes historically all of those that defend things that the PT doesn't defend by equating them to the PT" (Belchior, 2015). This creates particular challenges for the radical left, which has to differentiate itself from the PT even though the assertion of their differences as a more authentic left may lead to further rejection due to the connection between antipetismo and anti-leftism.

Because this connection is a result of depoliticization, the simple answer is to politicize the crowds about their demands and social antagonism. This is a hard task, however, because radical left organizations continue to have similarities with the PT, for better or for worse. It is inevitable that these organizations will be equated to the PT for defending workers' rights, for example, even if the PT has been responsible for attacks on workers since the Pension Fund reform. In such a case, the contradiction derives from the PT. The problem occurs when comparisons between the PT and the radical left stem from the radical left's own contradictions when trying to politicize for the left but finding opposition/resistance inside the moderate left. It is, for instance, unthinkable to consider making immediate impacts in the lives of the 
working class without being serious about elections, even more when the growth in elected conservative members of parliament has contributed to the impeachment crisis and various setbacks in social rights. Yet, there is no such thing as a formula dictating how properly socialist parties must approach liberal democratic elections, let alone the government if elected. Despite a revolutionary strategic horizon, the organization will most likely have to deal with trial and error, which will vary in result according to the circumstances of the conjuncture. It is depoliticizing, however, to approach errors as identical to the ones committed by the PT or to imply a conscious desire of the organization to repeat the steps of the PT, especially given how the melancholia of the radical left keeps it tied to the present and past of the PT as a hegemonic force in complex ways.

The question is of whether the radical left can indeed assert itself as a viable alternative if the PT and the moderate left refuse to give up their occupation of the leftist space. For Felipe Bruner (PSOL - Insurgência - Rua), the constant co-optation and threat of co-optation of the PT creates a political vaccum that the radical left is trying to overcome, but with great difficulty (Nascimento et al., 2015). This is a question of being a "third camp" (terceiro campo), as the radical left attempted to position itself during the impeachment crisis and during electoral periods, or finding a way to reclaim the leftist camp in its entirety. The first attempt has been mobilized more openly, but it is hard to measure its efficacy under depoliticization, when the ultra-political false polarization, to which the PT conveniently contributes, forecloses the possibility for a third camp to become visible by hiding it under the mainstream leftism of the hegemonic moderate left. Thus, the very notion of being a third camp depends on a radical politicization of leftist meaning, reclaiming it and rescuing it from petista symbols, and the ability to successfully communicate the differences between the radical and the moderate left 
in terms of their principles and capacity to represent the working class. This is not an easy task given that this depoliticization is part of a vicious cycle connected to the crisis of representativity that still affects the crowds in general, even if the middle-class and the upperclasses have found representation, in the right-wing movements and/or returned to the reaffirmation of the centre-right as an answer to their anti-petismo.

Discursively, the radical left has tried to reclaim the leftist camp completely by promoting views of it being the only, authentic, left in Brazil. This is dependent on arguments that the PT has betrayed the left for its own gain. Fieldwork among radical left militants often led to witnessing statements such as "the PT is not leftist anymore" or that "the PT implements right-wing politics" (Fernandes, 2014, 2015). These were usually answers to provocations on the PT's betrayal and trasformismo and, although it communicates that the PT should not be seen as an authentic representative of the left, it was not enough to delineate the boundaries between what the PT is after all and what the radical left if both claim to defend the Bolsa Família as an important assistance programme, for example. Such statements hint at the possibility of politicizing about the influence of neoliberal politics inside of the PT and its governments, but insufficient whenever the false polarization between the PT as the left versus the right (represented by the PSDB and the PMDB - the latter confusing people because of its role in PT governments) would recognize that there is a plurality of positions within the left but only as subordinate to the PT as a hegemonic and historical power.

It is common to hear from smaller organizations that the PSOL, for example, is on the path of becoming the PT, because of the party's engagement with electoral politics and the contradictions involved (Fernandes, 2015). I heard the same about the MTST on several occasions in 2015, in terms of how the movement negotiated proximity with the PT would just 
turn it into the MST, whose base has been manipulated and demobilized by the PT (Fernandes, 2015). Instead of being perceived as matters of strategy, the mistakes are taken as characteristics and flaws of a past politics that was already employed to reach the exact point where the PT stands today. The result is the replacement of constructive criticism with cheap attacks based on simple historical repetitions, such as saying that one organization is selling itself institutionally just like the PT did or that it is lenient towards alliances just like the PT is. These attacks neglect the particular histories of each organization and the fact that even if the same mistakes were made, the path of the PT could not be replicated because no organization in the radical left departed from the same place as the PT. This means that the level of manipulation, physiologism, and trasformismo of the PT could not have happened without the perceived unity of the left around the PT and the role it served as an aggregator of the masses for so long. As a fragmented political force, the radical left may have organizations whose errors are similar to those committed by the PT (whether or not they were errors or conscious decisions), but none of these organizations currently have the transformative or damaging potential the PT had. Further, the politics defended by these organizations, even those that identify with the popular democratic programme (such as PSOL's APS), differ in so many other ways from the general politics of the PT that it is unproductive and predatory to replace constructive criticism in the radical left with accusations of aspiring to become like the PT. This creates more division and prevents the level of synthesis necessary to actually overcome the PT as a powerful co-opting force.

The matter at hand, as Fernando Silva (PSOL - Insurgência) suggests, is the construction of a praxis of internal coherence inside the radical left as part of a strategic vision that considers what the PT did wrong, why it did so, and what alternatives must be considered 
(Silva, 2015). For him, it is not a matter of "we'll accumulate power in the parliament until we're the majority, [because] we know what to do to become the majority in parliament, or to take over the government without a [political] plan, we understood how this is, but it is not a path that it is worth trailing again, [because] the idea is not to be like them" (Silva, 2015). Silva's argument demonstrates the pressure felt by the radical left to trail a path of its own. This is troubling in the sense that sometimes tactics will be forgone on the sole basis that they were wrongly employed by the PT in the past, especially when it comes to elections. This hinders dialogue and creates purism over alliances and collaborative strategies that deter the overall creation of a radical left third camp. The logic of the dispute is reduced to equating the other organization to the PT, so it can be discarded as a new alternative, in favour of one's own organization, rather than working together and fighting over directions under common objectives. The melancholia becomes an obstacle to the very idea of a cohesive third camp because it is dependent on the idea that one organization will be the hegemonic force, rather than the radical left as a collectivity in flux, and on the determination of the dispute for hegemony according to one's replication or whole rejection of all tactics associated with the PT.

To try to escape this subordination to the figure of the PT, some in the radical left even go as far as claiming that the PT is now blatantly right-wing. The critique of the PSTU, for example, has relied on the idea that the PT's betrayal and trasformismo as a party of order has led to equivalency between the party and the right-wing camp so that the PT cannot be categorized as leftist anymore and should be instead be viewed as a representative of the right. Zé Maria, who is the national president of the PSTU, made this argument in his interview: “And we don't have a leftist government in Brazil. We are at this moment fighting off two 
bourgeois camps, all of them, both of them with heavy right-wing people involved. [...] The problem is that there is no way of fighting the right without fighting the PT $[\ldots]$ because the PT heads the main right-wing bloc in the country, which is the bloc sitting in government" (J. M. de Almeida, 2015). This reading contributed to the PSTU's positions during the impeachment crisis in the sense that the claims around the illegality of the impeachment, and the involvement of the right-wing in it, were ultimately irrelevant to the working class because it would result in an equivalent change in power, instead of a change in regime (see Chapter 5). The flaw in this argument pertains to the attribution of equivalency between the right-wing and the PT, as if the PT was now part of the right-wing camp, rather than producing a careful analysis of the PT regarding its trasformismo as a movement towards the right, yet not becoming a right-wing party. The few changes announced by president Michel Temer after the impeachment exemplify this false equivalency, since the PT's negotiation of its own ambiguity as a leftist representative with neoliberal policies led to a more benevolent capitalist government than that of a president who openly represents the right-wing and its interests without reserves. Whereas the PT favoured the private health sector by being negligent towards the public health care system (SUS), Temer's government proposed changes to SUS payments and access right away. The same can be said about public education, which was undercut to fund private education access opportunities under Rousseff and Lula, but remained safely "public" during their mandates with no major threats of system-wide privatization. Therefore, concretely, there is a difference between what a party of order government such as a PT government would do and what an openly right-wing government was willing to bring forward. This weakens the arguments that the PT is right-wing, and so it should step aside so that the 
authentic left, the radical left (or the revolutionary one!) can be seen and recognized by the people.

This constant difficulty adds to the melancholia of the radical left. The radical left has to deal with the frustration of fighting to be heard by the crowds, and not being acknowledged as a viable left alternative, while all the way being sabotaged by the right and the moderate left (including when in collaboration on single-issue demands). Caio Dezorzi (Esquerda Marxista) speaks about this challenge: "The question is that we have two enemies to fight: one is Dilma, one is the directors of the PT, the other is the bourgeoisie itself. They're two different enemies that must be fought through different means" (Dezorzi, 2015). This situation is worsened by the fact that the PT did not simply implement neoliberal policies in power, but also made room for the traditional right in its government ranks. Thus, the challenges to politicize towards a radical left alternative are complex because they involve offering an alternative that is an opposition to the PT and an opposition to the right-wing opposition to the PT (Genro, 2015). Rodolfo Mohr (PSOL - MES - Juntos), summarizes this political struggle as being abble to assert that there is a real left in Brazil, and by being so, it has no ties to the PT (Mohr, 2015).

The ability to make this assertion is muddled by situations such as the impeachment crisis and some of the reactionary elements of the crisis of representation. The radical left finds itself in a position to defend demands that are favourable to the PT because the PT's ambiguity coincides with popular struggles, or because anti-petismo is leading to attacks on the radical left, even though there is knowledge that the PT will use such opportunities to undermine the radical left as an alternative, co-opt leadership and manipulate the base. The power to do so is related to Iasi's aforementioned reference to the PT's gravitational power. In March 2016, for example, in a demonstration against the impeachment wherein the MTST was hegemonic in 
terms of numbers, their influence over their own base was undermined by the presence of Lula who was cheered on and defended by this same base after he gave a speech. This connects the gravitational power to lulismo, among other things, but also exemplifies how the radical left continues to expose itself to opportunities to be undermined and undercut by the PT because of common causes.

This instrumentalization of the radical left by the PT is partly a consequence of the radical left staying true to causes the PT uses out of convenience, but melancholia is also present in the confused approach to the PT's presence in shared spaces. Since June 2013, the radical left has talked about the end of the PT cycle or the end of the PT hegemony. Even part of the moderate left has appealed to this argument, such as Consulta Popular (a moderate left organization with ties to the PT), which argued back in 2004, shortly after disappointments with the Lula mandate led to a wave of dissidence out of the party, that it was necessary to refound the left because of the end of PT cycle (Consulta Popular, 2004). Yet, Consulta Popular remained aligned with the PT during this time. The period between 2013-2016, marked by a crisis of representation, open anti-petismo, and the impeachment crisis, was still marked by various challenges concerning the PT's refusal to give up its hegemonic status in the left. The old may be dying, but it will not go down without a fight, even if it means continuing to sabotage the meaning of the left and betting on further depoliticization to secure institutional renewal. Discussions over a re-foundation of the left from the PT's perspective still revolved around maintaining the PT as the hegemonic force of whatever new left would come along, while such discussions in the radical left would be sabotaged by the PT's influence on the base and willingness to turn further right in government in order to, contradictorily, maintain the status of a leftist government in power in Brazil. One example of this sabotage is the process 
over the creation of the Front for Popular Reforms (FRP) that was attempted in early 2015. The initiative was led by the MTST and sectors of the PSOL, but the governista entities involved, such as the MST, the CUT, as well as the PT and the PCdoB presented a challenge in terms of how they wanted to approach the right-wing attacks on the Rousseff government (Machado, 2015). They derailed discussions, tried to limit participation by other organizations, and made efforts to steer the front towards support for the government before the front even became actualized. When these entities realized that the front would not throw acritical support behind the Rousseff government at the time, such as by refusing to participate in a rally with strong governista tones, these organizations exited the process (Fernandes, 2015). The initiative remained "frozen" (Boulos, 2015b; Machado, 2015) until late 2015 when two different fronts were created: the Frente Brasil Popular (FBP), with governista organizations, and the Frente Povo Sem Medo (FPSM), with radical left organizations led by the MTST.

Finally, the radical left cannot aspire to hegemonize left politics the way the PT once did because a conjuncture that is effectively split between a moderate and a radical left, which have opposing political programmes and objectives, alters the dispute and the content of politicizing efforts towards the base. Rather than many organizations in the left competing amongst themselves to politicize and mobilize towards each of their political projects, the radical left and the moderate left are pitched against each other because their projects do not simply differ in nuance, in whether to pursue reforms or more revolutionary action at a given moment. Rather, they take the country in radically different directions and treat the base in radically different ways. While the radical left hopes to mobilize and politicize the base again, albeit with all the difficulties and contradictions outlined so far in this dissertation, the moderate left continues to promote a politics of depoliticization in order to maintain hegemony 
over leftist symbols and spaces and to demobilize the base away from its interests. In fact, the moderate left, especially the PT, is mostly interested in base mobilization for self-reproduction as preservation, as was the case during the impeachment crisis, former elections, and moments when the PT needed defending. To secure this self-reproduction, the PT would even go as far as to delegitmize the radical left whenever it found it to be a threat:

The leftist character of the government is so because it's a PT government and the PT has a history of struggle from a popular perspective, [but] this doesn't give a working class character to the government. What gives a government a working class character is the politics that this government operates. What [the PT] operated wasn't leftist, as much as we may want to be generous, it was at most centrist, but I think not even centrist [...] Beyond this pacification, which has to do with trasformismo [...] it led the petismo to develop an extremely sectarian attitude towards leftist speech. So what these guys did during all these years was to delegitimize leftist speech, attack leftist speech as irresponsible, as sectarian speech, as ultra-lefist (esquerdista) speech, and this attack was effective. We [the left] are living in very precarious conditions (Iasi, 2015).

\section{Unresolvedness and the need for a conclusive synthesis}

The frequency of this type of conflict between the moderate left, following a governista orientation, and the radical left indicates that attempts to set an expiration date on the PT have failed, and with this the hope that the base of the PT would migrate to the authentic left was undermined, adding to the melancholia of the radical left. A proper synthesis of how all leftist entities that oppose the PT from a leftist critical perspective should act in terms of the PT's continuous struggle for hegemony was never pursued beyond internal discussions. João Machado (PSOL - Insurgência) explained this problem by mentioning how past defeats shape and affect the way the left interprets the challenges ahead: "We still have this great difficulty, the left as a whole, of tuning in the project, the socialist leftist project and so one, to this moment that we're living. We've tried this for a while, at least a good chunk of the left has tried this for a long time, with even more effort after the Soviet Union fell apart, the whole 
crisis, all of the processes of change that gave rise to new movements that beforehand had very little relevance in leftist thought: environmental, feminist, LGBT [...] I think there's still lacking, I feel that we haven't managed to get to a clearer formulation yet, more convincing in general. I think that this makes everything harder. We're still in the middle of a process of changing the leftist paradigms that for part of the left was once very significant, but the process isn't complete yet, it's not stabilized (Machado, 2015). Israel Dutra (PSOL - MES) complemented this in terms of how this process relates to the PT cycle (and/or the end of this cycle), comparing it to a supernova that exploded in the past, specifically in June 2013 in his view, but whose material parts continue to appear and shape up reality: "It doesn't mean that [the PT] won't continue to compete for the hegemony, because it's an electoral machine with the objective of self-reproduction" (Dutra, 2015).

Making sense of the PT, and most importantly, politicizing about the formulated syntheses of it are such a challenge because its trasformismo is not of a simple kind. It does not represent a movement from being a genuinely leftist party to being a right-wing party or a fixed centre party as one normally pictures a party of order. The PT's trasformismo is marked by negotiation and ambiguity, which is why it was always so intent on a conciliatory discourse when it came to class antagonism and social stratification. This ambiguity armoured the PT when it came to radical left critique, especially because it often required a good deal of nuance and explanations that would then distract from the general argument. How to explain that the PT's politics is not what the PT says about its politics? How to critique the PT's promotion of neoliberalism without resorting to false equivalencies? How to speak of two lefts in opposition to each other when, sometimes, these two lefts had to work together against the right? How to be heard when these temporary displays of collaboration usually led to the PT's politics, 
discourse, and infrastructure overshadowing the radical left? How to make the message of the radical left stick after it is heard if the PT is intent on undoing it to secure its hegemony of the left? These are just a few elements of the challenge of politicizing from a left perspective when the PT holds institutional, structural, and cultural power of the leftist imaginary. Some of this power is given by the right, which maintained its attacks on the PT as a way to influence governability concessions while weakening opportunities for a small alternative leftist project to grow as opposition to both the right and the PT.

This means that every time a full-front attack on the left was launched from the right, new debates would be established to set the terms of defending the left alongside the PT. For Maria da Consolação (PSOL - Insurgência), this created "difficulty in how you manage to coexist in this moment of crisis when the federal government is taking away rights, and there is tension between the people and the governista sector, because it has to take it to the streets but it didn't want to go" (Consolação, 2015). This would cause a chain of confusion in the small base of the radical left and in the working class, since the PT was the one responsible for attacks on the left on many occasions, so that any defensive position alongside the PT would be undermined when it came to defending against the PT. This became more apparent during electoral periods, when the PT would attack the radical left for being sectarian and helping the right-wing opposition against the PT project. The ability of the PT to wear a leftist armour when convenient would make politicization and electoral campaigning very difficult, since no matter how much more authentically leftist the proposals of a PSOL candidate would be, for example, part of the electorate still recognized the PT as the only leftist force strong enough to win an election. No matter if the PT was no longer present at the daily struggles of the working class, the PT's electoral influence could ensure the idea that the PT should remain in 
government to secure the social gains acquired during the PT mandates, so that a vote in the radical left, no matter how loyal and more progressive it is, would mean risking these victories by depositing hopes on parties that could not win.

This creates a difficult conundrum, since electoral wins are important for the radical left even if there are no illusions over taking power through elections. The radical left is invested in base-building work, though less than the PT was in the past and also more limited in resources. Rafael Madeira (PSOL - Insurgência) argued in 2015 that in some ways, the left - with the exception of movements such as the MTST - generally forgot how/to do basebuilding work (Madeira, 2015). In the meantime, the PT's once strong base, which is a result of decades of investment in base-building work and a significance relationship with social movements in all areas of progressive demands, may not be as large as it once was, but it remains significantly larger than the base of the radical left. It also appears strong and large enough to give the PT credibility as a real contender in elections when compared to radical left alternatives. It is problematic that the base the PT has retained is actively depoliticized by the party in order to maintain electoral support. For João Machado (PSOL - Insurgência), "the PT holds the most responsibility of all over the depoliticization of the last years, because all it's done since getting to the government is to depoliticize" (Machado, 2015). Mauro Iasi (PCB) described this process as follows:

The PT in the last 12 years produce[d] first an intense process of depoliticization. It did not call on the social base to the political struggle at any moment. It could have, there wasn't a lack of reasons. And it depoliticized to make viable the chosen path of negotiation from above (Iasi, 2015). This tactic has already shown signs of exhaustion. Iasi continued by arguing that "every 4 years, or every 2 years, [this base] votes in the $[\mathrm{PT}]$ candidates but without active incorporation in the process of making politics, of organization, of social struggle. In our perspective, this will generate the current situation where this reference [of the PT] still remains, but it's very weakened. This strategy may 
last for a while, it was efficient for a while, but it ripped the hegemony of the PT in its own social bases (Iasi, 2015).

This means that the PT's depoliticization of the base from social struggle in order to make it into a solid electoral base, which would not require hands-on base-building work any longer, is running into its limits. Active demobilization is part of this as well, as Maria da Consolação (PSOL - Insurgência) argued regarding her experience in leftist organizing in Belo Horizonte, since the governista camp has spent the past years considering street demonstrations, for example, only in occasions when the PT's struggle for institutional power was on the line (Consolação, 2015). This is evidenced by the worsened electoral performance of the PT under Dilma Rousseff and the growth in anti-petismo in the periphery and working class spaces. Yet, the PT governista base, as demobilized as it is, is still larger than that of the radical left. In 2015, João Machado (PSOL - Insurgência) described it as a weakened sector, but with enough infrastructure to keep it going for a while: "The strongest sector in the social movements is the governista one, although it's losing a lot, it's been weakened, it's worn out, I think it still has more strength than the [radical] left. It has a lot of apparatus, it has a lot of political figures (quadros), it has a lot of reference. The MST, for example, is still very respected" (Machado, 2015). This respect is connected to its remaining power of mobilization, international perception, and successful stories of land expropriation. This level of apparatus helps to retain the base, but also ends up instrumentalized towards institutional renewal when necessary despite the PT's diminished capacity to do so in this last cycle. This weakness involves those leaving the PT base (towards the right, the radical left, or an "apolitical" depoliticized position) as well as those who remain loyal to the PT - who perhaps even believe in a possible re-radicalization of the party - but are frustrated and suspicious over the actions 
and decisions of the moderate left camp. What does the continuing, although weakened, hold of the PT over the majority of the leftist base mean for the melancholia of the radical left?

The radical left has bet on the end of the PT cycle in order to capture and captivate the base that would leave the PT because of its betrayal, almost betting on a crisis in the PT to promote itself as an alternative. João Telésforo (Brigadas Populares) argues that this line of thinking is related to past analyses such as those regarding the fall of the Soviet Union that assumed that the defeat of the Stalinist bureaucracy would open up an opportunity for the "true revolutionaries to direct" the masses, when the opposite was happening (Telésforo, 2015). This belief is melancholic because it assumes that the object of desire will return to the rightful leaders in the face of the disaster, but it is negligent towards the fact that the disaster can happen either by the hands of the masses or by the hands of capital. The latter is applicable to the fall of the Berlin Wall and the rise of neoliberalism, but the end of the PT cycle, as much as one could be hopeful regarding June 2013 and the crisis of representation that affected the party heavily, is also marked by a strong right-wing offensive that is made worse by the depoliticization of ultra-politics.

Yet, Cyro Garcia (PSTU) sees this as viable opportunity for the radical left to position itself following June: "If on the one hand the project of power of the PT, because of the weight of the PT on the base, ends up creating in a certain way some difficulties to the sectors more to the left [of the PT], a new situation is opening up right now [...] What is the role of these sectors? To help the class to break away [from the moderate left] more consequentially" (Garcia, 2015). In 2015, the radical left noticed the enhancement of conflict at the bases of the CUT, for example, notably how important union locals were deciding to leave the CUT (Prazeres, 2015), and this led to some excitement over a possible realization of the the working 
class about its true representatives. Ruy Braga states that this signals indeed a crisis in the petista form of unionism (Braga, 2015), but there is a difference between the organized base of the PT, primarily as unionized workers or rural workers organized by the MST (and other movements aligned with the moderate left such as Via Campesina), and the general base of the PT that extends beyond local organization and which the PT successfully captivated over the years in the form of the electoral base Mauro Iasi referred to above.

This process of base migration has not taken place as desired because disillusion about the PT is not detached from disillusion about left politics - a result of the depoliticizing efforts of the PT that reduced the base to an electoral mass. This has to do with the bureaucratization of the political leaders in the organized moderate left and its impact on controlling a base through immediate, corporatist needs. As for the general base that remained attached to the PT electorally, it has also diminished given the PT's worsening performance, but the anti-petismo that influenced their leaving did not translate into the recognition of the radical left, as it was of a depoliticized nature and influenced by the ultra-political conflict of the conjuncture. The demobilization of this base over the years, which was remembered by the PT only during campaign periods, distanced the base not only from the PT but from the perspective of the organized left in general. This was observed by radical left militants in Brasília who expressed frustration regarding the results of the 2014 elections, since despite their own insertion in working class communities through daily struggles, the trust was not enough to translate into a significant amount of votes (Fernandes, 2014). Instead, these votes went to the PT or to candidates from the traditional centre and right that banked either on post-political promises of the "new" (as a response to leftist betrayal) or on conservatism and moral panic around crime and family values (as opposition to a supposed promotion of deterioration of moral 
values by the left and the PT in particular). It is also important to note that even if what remains of the militant base of the PT did migrate in its entirety to the radical left in a new politicized position, assuming the radical left addresses its crisis of praxis, it would not necessarily guarantee radical transformation beyond the shift in hegemony inside the left. This is so because the PT base in terms of the working class organized in leftist struggle is different from its electoral base in numbers and in quality. The struggle to transform the very large electoral base of the PT into an organic base, one aware of antagonism and the need to organize against exploitation, presents challenges that even the PT was not capable or willing to address in terms of politicization geared towards reuniting the double consciousness of the class, forms of popular organizing (building poder popular), and the need to reinvent leftist organizing structures to prevent bureaucratization and the temptation to "direct" the masses from above. This means that the organized base of the PT could migrate to the radical left if it overcomes its own melancholia, but it would have to do so with qualitatively different objectives to transform the other base, the electoral one, into an active and organic sector of struggle. The idea that the PT base is or will migrate to the radical left as is lacks this differentiation that I consider to be fundamental to build a leftist praxis distinct from the one the PT imbued in the minds of its organized and electoral base. Then, it is not a matter of pursuing the moderate left base, but of restoring leftist praxis in terms of politicization and mobilization in a context aimed at defragmentation. This would lead to what Gramsci calls "normal times," when the political will of the masses progresses towards a long-desired intensification of the struggle:

The result is a headlong drive for improvement, an acceleration of the rhythm of production, and a continually increasing output of goods useful to society. And in this drive many fall by the wayside, so making the needs of those who are left more urgent; the masses are forever in a state of turmoil, and out of this chaos they develop some order in their thoughts, and become ever more conscious of their own potential, of their own capacity to 
shoulder social responsibility and become the arbiters of their own destiny (Gramsci, 2000, p. 34).

What part of the radical left seems to expect in its desire for the base, however, is base migration resulting from frustration with the PT's betrayal and that would lead to immediate, revolutionary, intensification of the struggle. Gramsci explains that this would characterize instead abnormal conditions, when the people have suffered so much that their will would become as one almost overnight. This is not the conjuncture in Brazil today, even if many organizations hoped that this had been the case in June 2013. June 2013 was not the result of the unification of collective will, but of the eruption of the symptoms, both revolutionary and reactionary, of the crisis of representation and the crisis of praxis. And even if it has been so, this will would have to be "forged" by socialist praxis (Gramsci, 2000, p. 35), which would have been impossible under the conditions of fragmentation and melancholia of the left.

These elements point to increased frustration over a crisis of the PT that has not necessarily strengthened the radical left but certainly altered the conjuncture in ways that point to a dispute over hegemony with the right. This contributes to the melancholia of the radical left, which longs for the base of the PT but has difficulties to understand how to claim a base that was modified (depoliticized and demobilized) to fit the status quo through fatalism or gratitude to the PT's social democratic gain. In this case, what is desired is not what is given, but the idea of the base the PT once had when it represented a somewhat unified left. This melancholia hurts strategic positionings: conflicting approaches over the PT's current and past base, the repetition of the belief that history will be on the side of the radical left (explored later in this chapter), and the replication of tactics ${ }^{44}$ focused on occupying the space of the PT

\footnotetext{
${ }^{44}$ Not the same as the idea of replicating the PT's strategy, history or path, which I refute in the previous section.
} 
rather than working towards a new proper place (since the space of the PT even as a representative of an unified left was given according to a trajectory focused on the instrumentalization of base-building towards institutional power). The idea behind the creation of the PSOL, for example, was to form a gathering place for the Brazilian left so that it could develop the necessary conditions for occupying the space that once belonged to the PT, but this idea found obstacles in practice, which João Machado (PSOL - Insurgência) attributes to the complexity of the process, given that the PT still existed and that it "continued to exert a very strong attraction over important sectors of the left and over social movements and major sectors [...] in Brazil” (Machado, 2015).

In sum, this reveals the level of unresolvedness of the radical left in face of the PT debacle. Syntheses produced so far regarding what to do in relation to the PT are of a selfaffirmatory nature (e.g.: "another organization is following in the PT's footsteps" or "the PT is now right-wing and we are the left") or based on how to deal with the PT on single issues. They offer little on how to actually move on from the PT as a problem; that is, what must the radical left do to actually ensure that when the cycle ends, something worthwhile in the left can take over the hegemonic position in an entirely different, not vicious, cycle? This entails not the occupation of the place of the PT within its moulds, but the occupation of the hegemonic place in society that is in dispute by the left and the right. Moreover, should the radical left act on accelerating the end of the PT cycle beyond self-affirmation? How?

\section{$\underline{\text { Agitation and anxiety over defeats and small victories }}$}

The absence of a conclusive collective synthesis by the radical left about the PT, the moderate left, and governismo leads to a variety of contradictory approaches: some of them 
further empower the PT to reproduce its electoral base, others depoliticize in an attempt to politicize. Internal competition inside the radical left is also enhanced without constructive dialogue and mobilizations end up instrumentalized to assert a base without clear strategies of what is to be achieved. This section presents a few concrete examples of what I consider to be melancholic symptoms in the radical left. They consist of actions, arguments, and tactical choices that together contribute to the state of fragmentation, hurt politicizing opportunities, and add to the political loop of what to do about the PT to build an alternative capable of occupying (and constructing) a hegemonic space in the left. The fear and anxiety caused by the lack of proper collective synthesis for the whole of the radical left regarding the PT and how to overcome fragmentation in non-artificial ways lead to an overplaying of small victories, in hope that they would overshadow significant defeats, which is followed by a strong focus on agitation around false victories that can be depoliticizing.

Jodi Dean associates the melancholia of the moderate left, that which is fatalist and distant from the interests of the working class, with Freud's description of mania, as incessant activity:

And so now satisfies itself with criticism and interpretation, small projects and local actions, particular issues and legislative victories, art, technology, procedures, and process. It sublimates revolutionary desire to democratic drive, to the repetitious practices offered up as democracy (whether representative, deliberative, or radical). Having already conceded to the inevitably of capitalism, it noticeably abandons "any striking power against the big bourgeoisie," to return to Benjamin's language. For such a Left, enjoyment comes from its withdrawal from responsibility, its sublimation of goals and responsibilities into the branching, fragmented practices of micropolitics, self-care, and issue awareness. Perpetually slighted, harmed, and undone, this Left remains stuck in repetition, unable to break out of the circuits of drive in which it is caught, unable because it enjoys them (Dean, 2012, p. 174).

This description adequately refers to the replacement of revolutionary efforts in the moderate with day-to-day micropolitics that, albeit with important material benefits to the 
immediate base involved, lose potential for lacking systemic focus and serving to maintain consent and movement loyalty in the already established base, though with little potential to grow the base through politicization and the tackling of bigger challenges. One example in the moderate left is the activities centred around the "solidaristic economies," which provide the landless workers of the MST with access to local markets for their products in a way that addresses current demands at a time when the MST has demobilized from agrarian reform if compared to previous decades (Farias, 2015; Ramos, 2015). Further, Wagner Farias (PCB) sees the demotion of large-scale systemic radical demands to micropolitics in the MST (and other moderate left movements) as counting on institutional and governmental support for their activities, which creates dependence and opportunities for co-optation and transforms the dynamics of social movements into that of a bureaucratic civil society organization that manages conflict rather than acts as catalyst for agrarian demands. The same can be said about corporatist choices in the labour union sector that may favour a category of workers in detriment of a broader struggle, which segments the working class and creates obstacles to the politicization and mobilization necessary to promote collective action in the level of a general strike or an organized struggle for the reduction of the working day. Hurt by "the inevitability of capitalism," this left concedes to smaller causes that will improve the standards of living of the base, and somewhat beyond it, but without prospects for radical transformation.

The problem with melancholia is that although the melancholia of the radical left differs in source and reasoning from that of the moderate left, their symptoms may be similar. The history of defeats faced by the radical left because of depoliticization and the barrier that is the PT when it comes to leadership, mobilizing, and organizing (including when the PT governments have negotiated with radical left movements in bad faith), adds to the longing for 
victories both systemic and local. The difference is that local and small victories are more attainable and help to sustain the base through the promise of more improvements and a payoff to their daily struggle. As progressive as the institutions of participatory budgeting, solidaristic economies, and local cooperatives may be in terms of community empowerment, access improvement and transparency under deliberative democracy, and immediate social advancement for the stakeholders involved, if turned into leftist pillars, these solutions often contribute to fatalism over the ubiquity of the capitalist system and distract from the systemic challenges posed to the people in general, not only the few organized in the movements and parties promoting these strategies. In the case of the moderate left, they become tools for keeping the base at bay and connected to the organizations' leadership and political initiatives. The struggle is reduced and depoliticized in order to pacify demands and hold on to the base. In the case of the radical left, these tools provide sufficient access to material improvement and democratic participation to keep the base hopeful, dedicated and mobilized to the struggle, but fails to achieve the desired politicizing potential, so necessary in the radical left, because of the melancholia that troubles the radical left: if demands that lead to easier and more immediate victories are encouraged, the left is more likely to hold on to the base - precisely because of the fear that if the base is faced with the reality of the right-wing offensive, as well as the PT's conservative setbacks, they might give into the moderate left's form of fatalism and be demobilized completely.

The moderate and the radical left make use of small victories in different ways. Whereas the radical left usually aims high but has to settle and celebrate small concessions, given an actual unfavourable correlation of forces amidst austerity and inequality,as well as having to deal with governismo as an obstacle, the moderate left has made a pattern of aiming 
low and offering concessions to the government in spite of working class interests, such as when the CUT and the MST demobilized their base from participating in protests against the World Cup (including those motivated by the death of construction workers) in order to protect the reputation of Rousseff's government (Brasil 24/7, 2014; Fernandes, 2014). Yet, the melancholic effect on the base and in the crowds standing outside or in between the lefts is similar in terms of failing to fulfill the politicizing potential of organized struggle. During fieldwork, I witnessed a few examples of small victories of the radical left being celebrated as bigger victories. Sometimes, after a housing occupation of the MTST, the families occupying the terrain would be invited to leave on the premise that the government signed a deal to expropriate the land towards housing programmes. Yet, the deal would be no more than the signed minutes of a negotiating meeting (not binding) or the land would be offered without prospects of development because of the federal government's slow and faulty commitment to the Minha Casa Minha Vida programme (Fernandes, 2015). Resistance based victories were also hailed as a sign of the strength of the radical left organizing efforts, since resisting the violent eviction of an occupation helps to further mobilize, but offered little advancement in terms of making the threat go away permanently. This is the case of the Izidora housing occupations in Belo Horizonte, for example, which continue to resist the yearly threats of mass eviction by local government, but progress in terms of officially securing the land for its dwellers is limited in between the eviction threats (Fernandes, 2015). 
Figura 6 MTST-DF and Government of the Federal District sign non-binding agreement ahead of the movement voluntarily leaving occupied lands (February 2015)

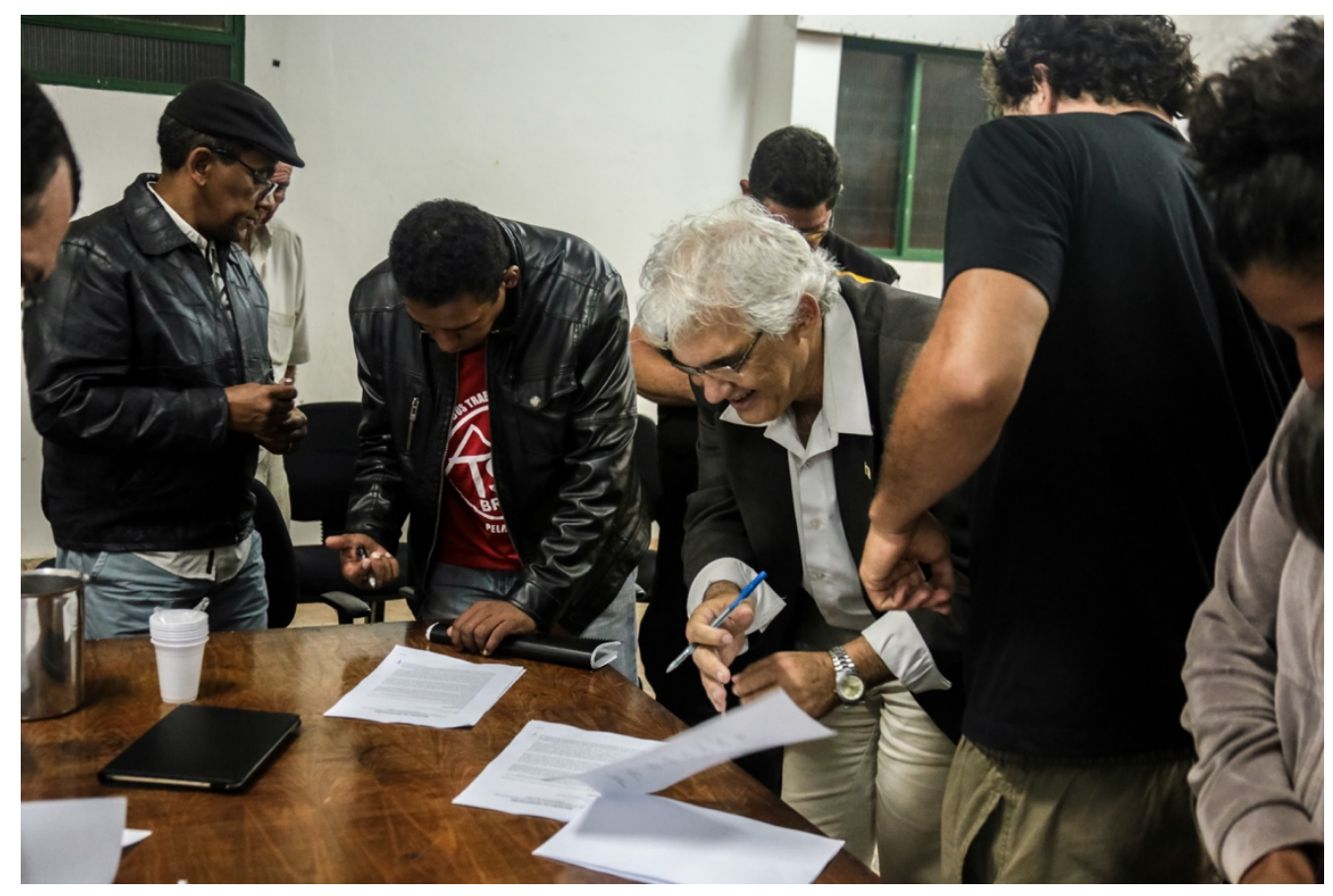

The focus on small victories in an otherwise regressive conjuncture for the radical left is a melancholic symptom related to the desire to retain the base and capture the attention of the moderate left base and the crowds that stand in between through improvements and positive results of organized struggle that were normally associated with the PT years of mass mobilization. The lack of victories, as well as the tendency of moderate left to attribute improvements achieved through organized struggle to itself rather than the will of the people, impact both the ability of the radical left to mobilize and the internal process of re-building a fragmented left. This is echoed by João Machado (PSOL - Insurgência), especially with respect to the idea that the left is still trying to respond to major historical defeats:

What the hegemonic left was, the enormous majority of the left of the 20th Century failed. We have to be clear about this [...] the project failed. The end of the Soviet Union, how it was, it wasn't nothing, because even from the point of view of those who were always critical of it, the Trotskyist for example, we have to acknowledge that the end of the Soviet Union wasn't in the way we could hope for, because instead of opening up a process of 
socialist renovation, it ended up going towards capitalist restoration [...] But I would say something else too, I believe that one thing that has made the re-composition of a leftist project so hard is the difficulty in having victories, because a victory always has the potential of showing how one kind of thing works out, and estimulating others to join (Machado, 2015).

Luciana Genro (PSOL - MES) agrees that part of the challenge of overcoming fragmentation in order to mobilize in higher numbers and quality has to do with the gap where the left finds itself in terms of a past loss, that could be either the Soviet Union at a global scale or the wasted opportunity and betrayal of the PT in Brazil. She says: "I think that since the fall of the [Berlin] wall as a symbol of the failure of "real socialism", we've have this difficulty of demonstrating the real possibility of class conflict and resulting in a better political project that would make the working class the real protagonist of a new model. So this is part of the questioning [I get] wherever I go, it comes back through the debates: 'but what is the model'?" (Genro, 2015).

Figura 7 Debate promoted by the PSOL with Luciana Genro at University of Brasilia (March 2015)

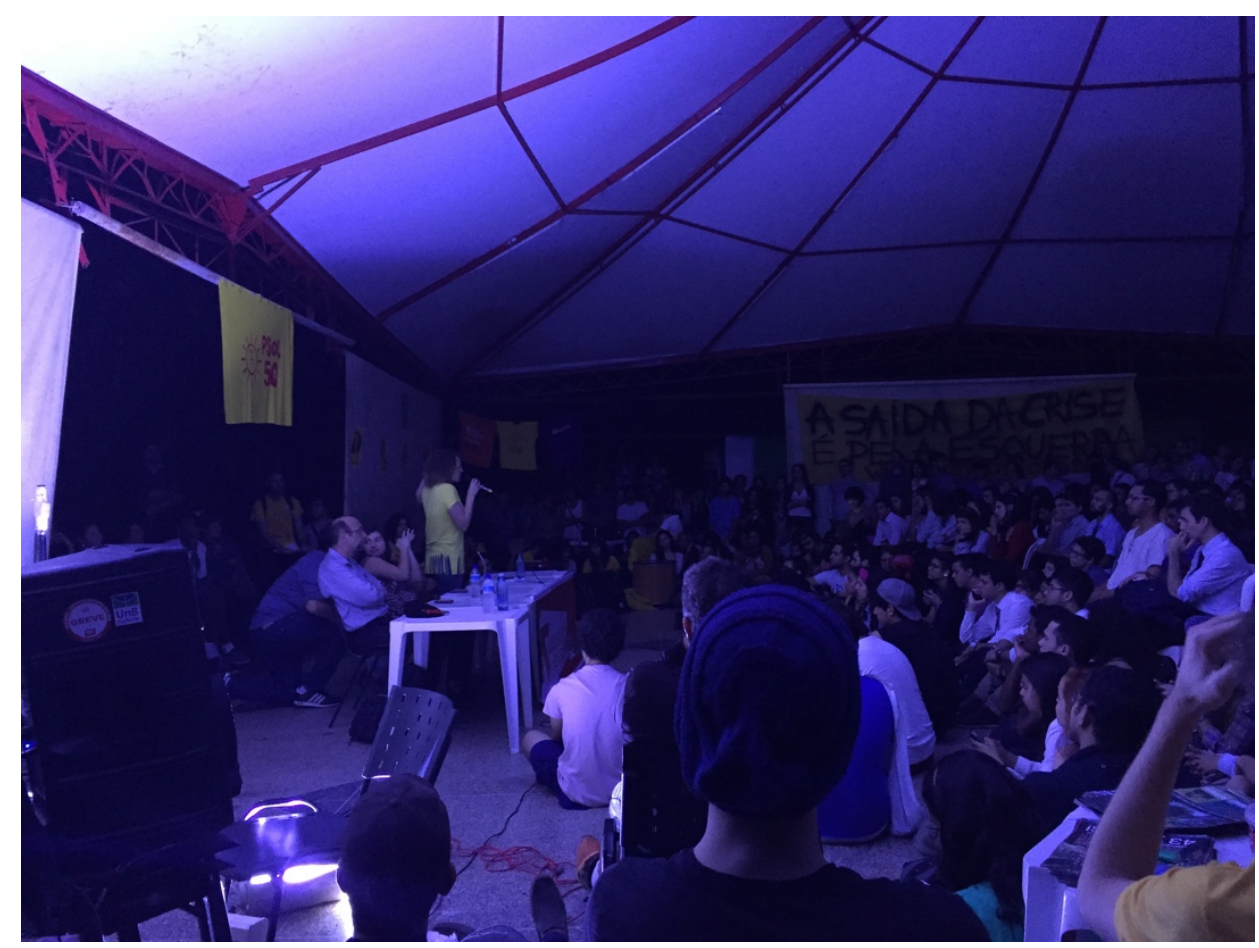


Because I engaged in extensive participant-observation, I was able confirm this difficulty highlighted by both Machado and Genro. Debates, assemblies, and other political events were often filled with well-developed theoretical debates from a leftist perspective, but the organizations and militants would hesitate and struggle when it came to drawing a concrete connection between the programmatic horizon of the left and possible results for the working class (Fernandes, 2015). It was almost as if evidence was needed to support socialist claims, but the past period of defeats, coupled with the challenge of explaining the PT betrayal as a problem of the PT (and not leftist ideals), made it difficult to convey the potential of the radical left programme. To remediate this, organizations and militants would often focus on agitation and propaganda designed to play up the potential and small victories so far as larger displays of radical left strength.

This kind of agitation and propaganda would report larger numbers than reality at leftist demonstrations, frame failed negotiations with government around immediate demands as "promising," praise the political and mobilizing potential a crowd even if it was small or little engaged with the demands, as well as contribute to what I see as an exaggerated praise for the crowds of June 2013 because, if they were progressive in their majority, they could mean redemption for the radical left. For example, the agitation performed in June targeted the base of the radical left and acted as encouragement for the militants applying hard work; yet, there was limited payoff in terms of the growth of the movement and the quality of engagement of those the radical left hope to bring in (both the moderate left base and those standing in the outside) at the time. Although this kind of agitation can indeed be encouraging, it can also backfire by giving the impression that the current level and quality of efforts are sufficient to draw crowds to the streets and make it seem like they are engaging as a ready political subject. 
For Rafael Madeira (PSOL - Insurgência), the result of particular interpretations of June within this line of agitation was an overestimation of the engagement and potential of the working class at the time, going as far as considering a general strike as a real possibility and transferring focus from the already depleted base-building efforts to the idea of a democratic battle through social media (Madeira, 2015). This eventually led to frustration by the most engaged militants when this expectation did not translate into reality in the 2014 struggles against the World Cup and the federal elections.

June had given the radical left an expectation of institutional growth because of the progressive demands made at the time. However, the 2014 elections were a blow to the more hopeful members and organizations of the radical left due to less than desired performance at the ballot box, even though the performance of the PSOL, for instance, was positive in terms of elected representatives and new affiliated members of the party. The mobilizations of June 2013 created hope for a wider reach by radical left organizations and more general interest in their political platform. Even the PSTU, which is known for defending the position that elections should not be a priority for the radical left, was quite engaged in the 2014 federal elections and its militants were very involved and more enthusiastic about the process than in previous elections (Tavares, 2015). The PSOL, the PSTU, and the PCB ran separate presidential campaigns in 2014, which stroke some of the base as odd, since there was hope that June 2013 would help the radical left confront its fragmentation and the need to work together cohesively (Fernandes, 2014).

The current state of fragmentation of the radical left makes it so that electoral coalitions are not simply a matter of building a joint programme to counter the right and the moderate left. In many occasions, the idea behind a collective programme is second to the fact that the 
radical left must be united if it means to grow at all. Television time is limited (and getting even more so since Eduardo Cunha's change to campaign laws) and being in a coalition together means pulling their allotted time collectively to the candidates chosen to be a priority. The expectation that the crisis of representation exposed in 2013 would bring enough strength to the radical left so that single organizations could focus on their own growth and chances of election weakened the possibilities for coalitions between the PSOL, PSTU, and PCB in key parts of the country. Also, the absence of a coalition meant full freedom of direct critique (not always dialogical) instead of having to work together past single differences to build a collective programme that all three parties agreed upon. ${ }^{45}$ For the PCB, for example, having its own presidential candidate in the 2014 elections was a matter of party strategy so it could grow in electoral relevance [iasi]. A progressive June 2013 meant increased chances of exposure, interest and engagement in 2014, but since this expectation was based on an underestimation of the depoliticization (post-political and ultra-political) of the 2013 crowds and the negative impacts of the crisis of representation on the credibility of leftist institutions, opportunities were lost in the 2014 federal elections. Since it has the most electoral reach out of the three, the PSOL has held priority over executive candidacies (i.e.: president, governor, and mayor) in the coalitions and would be the party to benefit the most from a collective campaign. Yet, coalitions are also of interest to the PSTU and the PCB. Maria da Consolação (PSOL - Insurgência) suggests that if a full coalition between the three parties had been in place in 2014 in Minas Gerais, where the radical left had remained relatively strong and

\footnotetext{
${ }^{45}$ Although these disagreements between the parties are used to justify publicly their lack of electoral cooperation, my observations in Brasília in 2014 have led me to believe that the desire to set and promote one's agenda and party identity takes priority over the difficulties that may arise from working collectively towards one joint programme.
} 
credible in June 2013, either the PSTU or the PCB would have been able to elect someone to the state legislature (Consolação, 2015).

Figura 8 Plenary for federal congress candidate Rafael Madeira (PSOL - Insurgência) to set the terms of a "collective candidacy" with PSOL militants (July 2014)

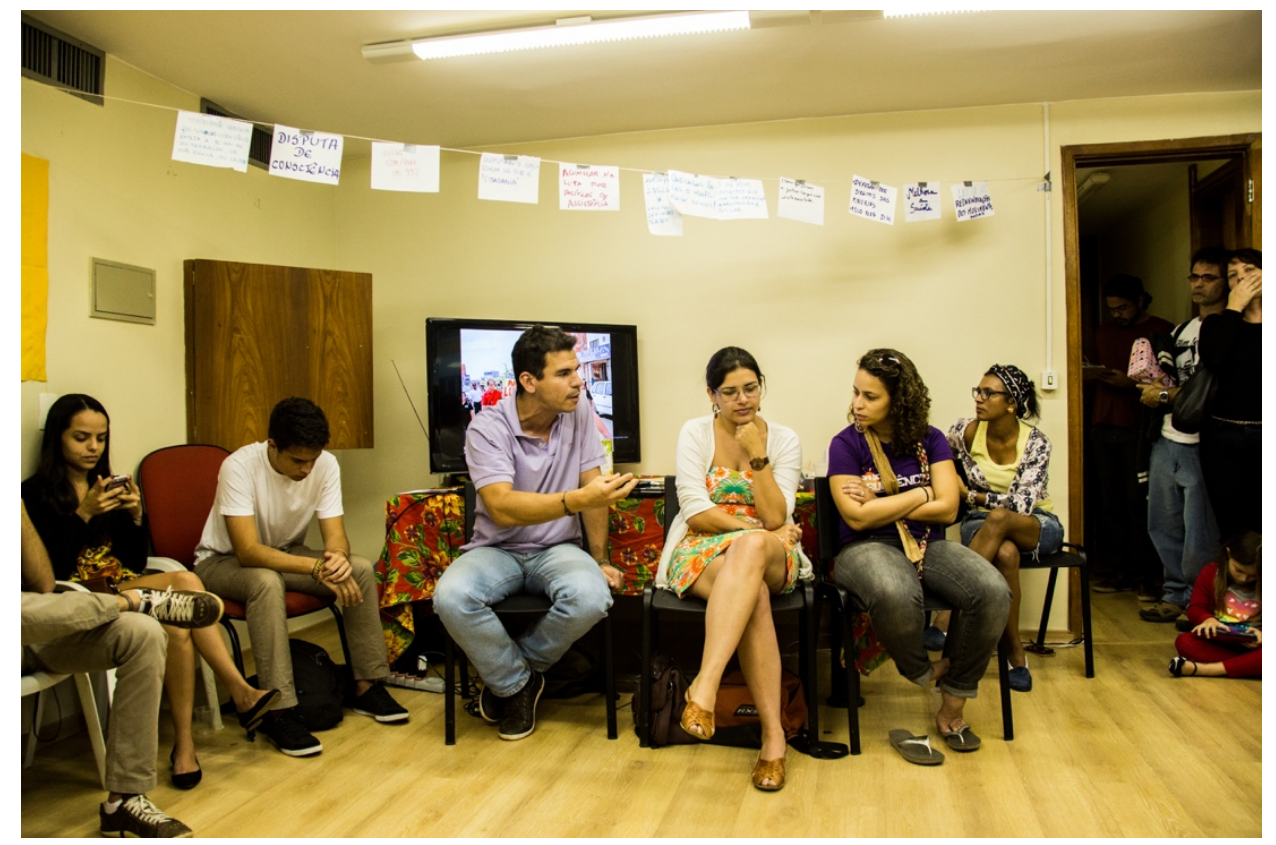

\section{$\underline{\text { Responding without answers }}$}

The melancholic state of the radical left places it in the difficult position of having to answer to the increasing needs and demands of the crowds, especially after June 2013, and to the right-wing offensive following the same period, without a concrete and unified counterproposal to the project offered by the PT until now. As much as the radical left is aware of its differences in relation to the moderate left in terms of economic policies, the promotion of social and civil rights, and even matters such as popular government and the role of elections, the permanence of the PT in important spaces of struggle, which it continues to occupy by depoliticizing it, affects how the radical left alternative is heard. Even harder is to have this alternative be accepted and taken forward through mobilization, partly because the 
radical left often has to respond to the damages caused by the PT to the working class interests and to the idea of a leftist project in general. The fact that the PT sabotages the ability of the radical left to reach out to its base and grow it, often by further manipulating the consciousness of the base and co-opting the fragile crowds that have been mobilized by the radical left and the challenges of the conjuncture, shifts focus and resources into deconstructing the PT and away from coming up with concrete proposals and forms of base-building that go beyond the practices established by the PT in the past. This puts the radical left in a loop that could be described in Portuguese as "enxugando gelo" (drying up ice) in order to keep the progress it has made so far while attempting to prevent the PT and the right from further reversing the consciousness of the class in their particular ways. Effort that could be applied towards effective base-building and/or widespread occupations, for example, ends up channelled towards street demonstrations and one-time displays of resistance, although the reasons for this misplacement go beyond melancholia and have to do with the crisis of praxis in general and the way it creates more left fragmentation.

This fragmentation is more than the growing number of leftist organizations, but also reflect fragmented strategies, programmes and internal politics that could not unite the fragmented consciousness of the people. This is what the next and final chapter of this dissertation examines to show that fragmentation is a problem that has persisted and will persist for a considerable time in the Brazilian left because it is both a contributing factor and symptom of a crisis of praxis. Thus, fragmentation cannot be addressed in isolation, but only if depoliticization and the disconnection of the left in relation to this phenomenon is also confronted. 


\section{Chapter VII: Fragmentation: schisms}

Whereas the phenomenon of melancholia helps to explain leftist fragmentation in Brazil at the level of political formulations, tactics and strategies, it is important to also understand the practical elements of fragmentation at the organizational level of the left. This is because the radical left is not fragmented only in terms of objectives, but also as multiple organizations that still tend towards schisms and breakdown of internal dialogue rather than fusions or coordinated alliances. This is arguably the case whenever leftist forces throughout the world are faced with crisis, be it related to the rise of fascism, leftist betrayal, depoliticization, or a crisis of representation amidst capitalist renewal. It is important to discuss the fragmentation of the left in Brazil, in this particular case, because the current state of fragmentation, unlike the fragmented left during the military dictatorship and prior to it, is faced with particular challenges exposed in June 2013. Because of fragmentation, the radical left has found it difficult to resonate with the crowds it hopes to represent and to present a cohesive alternative to the betrayal of the PT. Also, the schisms that followed the PT's foundation represent more than firm disagreement towards political rupture, since they still bear the melancholic mark of resentment, confusion, and eagerness to provide immediate alternatives before the PT can do more damage to leftist morale and credibility. This has contributed to hegemonic renewal by the right, which has been able to seize benefits from the depoliticization and demobilization present in the PT years and encourage more anti-leftism with them. With fragmentation and melancholia, the radical left has been slow to react, although progress can be identified in sectors such as the student and housing movements and around gender issues (often referred to as a feminist spring in Brazil). 
The Workers' Party was founded on the premise of minimal agreements among leftist organizations in Brazil, so that political work would progress according to these basic tenets and everything else would be determined as per the internal disputes over the horizon of the party. Although ideal from the perspective of a general unity of diverse and distinct organizations in the left - that is, heterogeneous unity - the history of betrayal, bureaucratization, and lack of internal democracy inside of the party in its pursuit of institutional power prevented the various internal forces of the PT from fighting over the political horizon on even ground and led to compromises over the minimal agreements to the point that many organizations chose to leave the PT, most notably the Convergência Socialista - CS (later PSTU) and the tendencies that left to form the PSOL.

The internal crises of the PT and the subsequent schisms it led to mark the origins of the conflicts in the Brazilian left that can be understood as a general crisis of praxis today. Whereas the intent behind the PT was to deepen base building work towards the strengthening of the working class and the advancement of its interests, the reification of the party as an instrument for the reproduction of institutional power, rather than class power, brought questions of theory, tactics, strategy, organizing, and base building to the forefront. Yet, the progressive fragmentation of the left suggests that most of these questions remain unanswered. Even practices and characteristics of the PT that are considered to be at the core of what went wrong with the PT project still need deeper exploration. The problem of poor internal democracy in the parties, for example, is at fault for the control of a direction over the diverse interests and important debates made at the base level in the moderate left, but this does not mean that the radical left is free from this risk, as is the case of complaints during congress 
periods at PSOL and the struggles that led to a significant schism inside the PSTU in 2016 (Fernandes, 2015, 2016).

This chapter contextualizes the more practical elements of the fragmentation of the Brazilian left in terms of a crisis of praxis with evidence from fieldwork observations and interviews. To do so, it analyses the continuous fragmentation of the organizations in terms of a logic of schism, which favours the formation of multiple and new organized nuclei in the left rather than the formation of syntheses and transformation of the politics of these organizations towards converging interests. A synthesized version of the schisms and nuclei of the radical left in Brazil can be found in Appendix C, with an additional look into a few Trotskyist schisms into the PSOL.

\section{The logic of schism}

Schisms are very common events in the history of the global left, from small organizations to the communist internationals. They have also been a constant in the history of the Brazilian left, with periods of more or less intensive fragmentation. Parties such as the PCB have experienced a series of schisms throughout the years, both minor and major, such as the schism that led to the creation of the PCdoB. The foundation of the PT led to a brief period of unity and stability in the Brazilian left, with a considerate number of organizations operating directly inside of the party as tendencies and others collaborating with it during campaigns and electoral periods. This even included organizations that opposed the creation of the PT, for the kind of collaboration experienced in the 1980s was less of a matter of agreeing with a particular organization's strategy and more in terms of responding to the needs and demands of the leftist base in general. It was a period of both low fragmentation at the organizational and 
consciousness levels. Schisms were less common than today in the left because there was a logic of strategic unity around the PT, supported by a variety of progressive sectors in Brazil, from campesino organizations to the Catholic Church of the Liberation Theology (as mentioned in Chapter 2).

The more bureaucratized the PT became and the more it distanced itself from listening to the demands of the class, the more it resorted only to an instrumentalization of these demands to reproduce its own party-institutional power. This means that the PT's base and the people in general were faced with a reduction of the leftist struggle to the PT struggle to attain power. The accompanying factor of depoliticization, still in its early stages, contributed to this by preventing people from realizing the social contingencies that led to their own conditions, rather relying on the PT to shape antagonism and determine which conflicts should be addressed first and which should be undermined because of the inadequacy of the present correlation of forces at the time. The more this instrumentalization of the people by the PT contributed to an ossified individual consciousness in the base, one accepting of the discourse of the limitations of social struggle in the status quo, the more fragmented this consciousness would become at the collective level. This was worsened once the PT reached the federal government, since the improvements in the material standards of living of the class were used as instruments for the party to achieve consent without politicization, reducing the debate to micropolitical matters of social assistance, consumption, and individual inclusion in a supposedly meritocratic system. The current fragmentation of the Brazilian left is directly connected to the trasformismo of the PT and its impacts at the organizational level and in the collective consciousness of the leftist base and the people in general. Trasformismo, in this case, cannot be detached from the PT's governismo and how its transition from party to 
government (or subordination of party to government so that the government is the party) was dependent on fragmenting and disintegrating the interests of the class that could be obstacles to the reproduction of the PT's political cadre. This matches Gramsci's description of the phenomenon: "The government in fact operated as a 'party'. It set itself over and above the parties, not so as to harmonize their interests and activities within the permanent framework of the life and interests of the nation and state, but so as to disintegrate them, to detach them from the broad masses and obtain 'a force of non-party men linked to the government by paternalistic ties of a Bonapartist-Caesarist type"' (Gramsci, 2000, p. 268). Similar to the fragmentation of the left in Europe described by Mario Candeias, such a situation creates fragmentation by marginalizing and possibly forcing out oppositional groups in the left, whereas the base is maintained passive through a marginalization of its interests and co-optation of its leaders (Candeias, 2010, p. 8).

This scenario at the class level corresponds to Mauro Iasi's view of the transformation of the collective consciousness of the working class to a state of seriality that is both alienated and fragmented, given that its own interests were being removed, modified, and repackaged to them in order to sustain the contradiction imposed by the PT's project of class conciliation (Iasi, 2015). This state is also one of a contradictory consciousness (Gramsci, 2000, p. 333), whose contradiction is artificially kept in place by the ambiguous discourse employed by the PT, especially through lulismo, that resonates of the demands of the working class while rejecting it when it comes to political practice. This is why the base of the MST would be able to insist that the PT governments were favourable towards agrarian reform while these governments effectively promoted large agribusiness and allowed environmental protections to be stripped down through the years (Sánchez et al., 2008). The result of the contradiction, 
especially the struggle between the moderate and radical left to maintain it or dismantle it, is how this fragmentation of the consciousness will reflect and be reflected in the fragmentation of leftist organizations. The working class, in this context, is not "pure" in the sense that it can be summoned and mobilized as soon as ideal conditions for an uprising arise (as organizations prone to vanguardist readings of directing the crowds would hope for), but it is in a sense "contaminated" by the influence of reformism and the one-dimensionality of bourgeois culture and ideology (Vázquez, 2011, p. 316).

Leftist fragmentation (both strategic and organizational) in Brazil is connected to this wider phenomenon of fragmentation at the political consciousness level, made evident in this dissertation through the analysis of depoliticization. Schisms may occur in the left when there is considerable cohesive class consciousness as well, for matters particular to the lack of synthesis and different strategic horizons of vanguard political organizations. The case at hand in Brazil is more complex because it poses the challenge of trying to regain unity (or hoping to) at the vanguard level when the class does not tend toward this unity, but it is rather fragmented itself and prone to co-optation by the right or lost to political engagement because of a post-political rejection of ideology and the political sphere in general. This problem entrenches a logic of schism that consists of the challenges involved in trying to match strategy and representativity in the left when the people at large is averse to leftist strategy and representation. Rather than working through strategic problems internally as to present a cohesive alternative to the class, such as through more internal democratic stances, open debate, channels of dialogue with the base and the base of other movements, and listening to voices that are often silenced by a bureaucratic leadership, the left finds itself splitting and splintering in an effort to filter through to what each group feels is the most "authentic" 
embodiment that would be recognized by the people to represent them. This is misguided in the sense that it proposes that the people would take a small fragment of the left that ideally connects with them and raise it to a hegemonic status among the other fragments, but does not explain how small fragments would be seen by the people, let alone be embraced amidst antileftist depoliticization. It also idealizes a process of unity at the organizational level so that if one of the many organizations takes the lead, the rest of the organizations would have to follow, thus neglecting the importance of internal syntheses highlighted in the previous chapter that would foster honest dialogue in the left towards a cohesive strategy more productive than the one found inside of the PT even in its best years, when there were still organizations inside it acting as public fractions.

The ideal unity of the left corresponds to the base and the organizations, so that unity at one level is built taking cohesion at the other into consideration. This entails that even a united vanguard in the radical left would consist of artificial unity if it is not based on creating cohesion in terms of class consciousness through politicization. Without the unification of the contradictory consciousness of the class, the tendency is to politicize through niches (e.g.: organized labour in the auto sector, then organized labour in the educational sector, then those in the periphery demanding housing) in a way that can be dangerously economistic and disconnects the class internally when it is artificially put together in a demonstration or led in resistance to neoliberal attacks that would affect all of them. The problem posed by the logic of schism is that each schism is thought to be more on the revolutionary path than the parent organization, whereas the parent organization remains firm that it is indeed on the revolutionary path and the schism is a reformist deviation. Yet, both new schisms and old parent organizations come out as weaker fragments (in terms of numbers and newfound 
challenges) that will have more trouble to present an alternative and politicize the class about the appropriateness of this alternative than if syntheses and change had been achieved internally as to avoid a schism in the first place. The idea that a fragment will become the most authentic representative in itself and correspond to the demands and needs of the class so as to grow and become hegemonic in the left is erroneous and filled with vanguard fantasies of directing the revolution. It enforces a logic of schism in the left because it proposes that a small group can successfully lead a large group from a hegemonic position, as if this large group were cohesive in the first place (or as if its politicization would take place cohesively) without the disputes, both honest and dishonest, from other fragments that also promote themselves as authentic representatives. Rather than one radical left alternative, the class is faced with a myriad of alternatives, which are embraced and rejected according to the different levels of consciousness present and how desensitized the class is to leftist projects after an episode of massive betrayal (as was enacted by the PT).

The logic of schism is prevalent in the radical left, more than the moderate left that remains hegemonized by the PT, because even the hegemonic position inside the radical left is up for dispute. Discussions over a broad front (frente ampla) to fill this space have not progressed because even so the leftist fragments consider the construction of the front from the perspective of which organization should hegemonize the front (and subsequently would direct the radical left). This is observed in the conflicts over broad front politics in other parts of the world, such as Spain and Greece, ${ }^{46}$ so it is not surprising to see how this expectation has a particularly paralyzing effect in the Brazilian radical left, where I suggest that the class

${ }^{46}$ Particular regarding Syriza and Podemos. Interestingly, conflicts between Syriza and the $\mathrm{KKE}$, for example, tend to become replicated in Brazil in the critique by the PCB (Brazil's counterpart to the KKE) of the PSOL (being a broad party as the Syriza). 
consciousness is significantly more fragmented and demobilized than in the Spanish and Greek scenarios. The contradictory aspect of this logic is that rather than joining forces internally towards syntheses so that more organizations draw out their political projects in synergy with each other (especially by politicizing in similar directions), thus making the leadership of a front more collective and productive in general, the schisms create smaller and more specific vanguards whose tactical and strategic approaches are taken by each other as alternative/opposing rather than suggestions in a desired dialogical environment.

It is noteworthy that the logic of schism does not manifest itself always as organizational schisms, but many times through the promotion of obstacles and impediments to dialogue within a given organization or political environment. In these circumstances, the logic is present through the uncritical desire of a group to direct more collective and democratic processes, especially if it does not have the base or practical evidence to support putting their own strategy ahead of the one promoted by the other groups involved. This leads to attempts at manipulating processes, co-opting leadership, and/or blocking participation of others in order to guarantee their artificial hegemony over the situation. Experiences of this kind were related to me concerning the PSOL congresses and conferences, for example, or failed attempts at forming alliances over minimum agreements between the moderate left and the radical left as well as with only the radical left (Fernandes, 2014, 2015). The process leading up to the formation of the failed Front for Popular Reforms (FRP) illustrates this well (see previous chapter), since groups connected to the PCB and the PSTU were little interested in exploring the potential of such a front based on the principle that the moderate left should not be involved, even though its base would be interested and engaged in the platform. Meanwhile, the moderate left, embodied primarily in the CUT and the MST, was less concerned with the 
interests of this base than with trying to impede the participation of these other radical left organizations and manipulating the minimum agreements to serve the governista interests.

\section{Crisis of praxis}

The thesis of the crisis of praxis converses directly with the problem of fragmentation in the Brazilian left. It speaks of a long process, connected to the split between a moderate and a radical left in the country, through which the voices of leftist actors and organizations became detached or lost resonance, meaning, and significance to the ears and voices of the working class. If praxis is the dialectical synthesis between revolutionary theory and practice, a crisis of praxis is the context whereby obstacles to syntheses prevail (i.e. fragmentation and depoliticization) and the few syntheses that are produced end up obscured by the continuous fragmentation of both the left and the class (in its consciousness and in its structure due to the intensification of reified relations). In general, the crisis of praxis speaks to the Gramscian notion of an "organic crisis," which, in David Forgacs' words consist of:

[...] a crisis of the whole system, in which contradictions in the economic structure have repercussions through the superstructures. One of its signs is when the traditional forms of political representation (parties or party leaders) are no longer recognized as adequate by the economic class or class fraction which they had previously served to represent. It is therefore a crisis of hegemony, since it occurs when a formerly hegemonic class is challenged from below and is no longer able to hold together a cohesive bloc of social alliances (Forgacs in Gramsci, 2000, p. 427).

The PT finds itself in a crisis of hegemony associated with lost legitimacy of the political representative system. The economic structure, whose contradictions result in an economic crisis that heightens indignation, is then addressed and renewed by the efforts of conservative forces to contain the crisis of hegemony to the PT and the current government. This particular scenario of a crisis of praxis in the Brazilian left derives from the fallout associated with the formation of a primitive collective will as per the conditions given in the 
period of mobilization led by the PT and the collective desire for democratization. This fallout leads to the interregnum marked by the split between moderate and radical left, whose complications include an overestimation of the primitive collective will, now close to decimation through depoliticization and demobilization, and a fragmented left unable to seize it and transform it into realized collective will. Collective will, in Antonio Gramsci's perspective, consists of a "working consciousness of historical necessity," without which any movement towards a revolutionary stage would be vanguardist, fragile in mobilization, and unsustainable (with potentially harmful effects on general consciousness) (Gramsci, 2007a, p. 138). The crisis of praxis is situated in this interregnum, for the necessary syntheses over primitive collective will in the 1980s are distorted and instrumentalized due to leftist melancholia, whereas the realization of collective will lies in a distant horizon due to fragmentation and only marginal politicization.

Evidence of this thesis is found in the failed attempts to unite the left over the most minimum of agendas, the pervasiveness of preponderant theoretical readings of social phenomenon that bend practical occurrences to their will, the depoliticization that prevents accurate theoretical readings from resonating with the crowds and keeps the working class also fragmented and at a distance, the prioritization of an organization's self-construction and selfreproduction over the collective interests of the left, ${ }^{47}$ the engagement with minor depoliticizing tactics due to the desire to rapidly expand the base in a quantity versus quality

\footnotetext{
${ }^{47}$ I understand that in a state of fragmentation, leftist organizations must work towards their own self-construction in order to expand their ray of influence and consolidate their own positions. The critique I put forward is regarding organizations that prioritize self-construction with the objective of hegemonizing the left, being negligent of occasions when collaboration and dialogue should be at the core of the tactics employed and the strategic horizon. Some of this is evident in the PSTU's choice to abstain from electoral leftist fronts in the 2016 elections, for example, even though the party had just suffered a large schism critical of its sectarianism.
} 
debate that neglects the long-term negative effects of this anxious trade-off, and the employment of predatory tactics that have plagued the international left for over a century but remain as methods of beginning and/or finalizing disputes. For Ruy Braga (former PSTU, professor at USP), these elements are evidence that the crisis goes beyond the PT and affects the whole of the left, not just parties but social movements and unions too, and creates a a dynamic of internal political alienation that intensifies the effects suffered from the delegitimization of the PT and the moderate left (Braga, 2015).

A mix of these difficulties is described by Rafael Madeira (PSOL - Insurgência) regarding June 2013, especially regarding how the left found itself crippled in terms of understanding the formation and purpose of the crowds at the time. He says:

I think that the big problem of the reading [of the situation] is: if I don't understand properly why [the crowds] went to the streets, I'll make mistakes in terms of them tending to remain and consequentially, to me, [the left] will have a big problem because if I'm waiting for [the crowds] to take it to the streets or mobilize so that then I can have incidence over a political consciousness, debate, or orientation over the demands, then it's [already] over. I won't have the factor of the masses in the streets anymore (Madeira, 2015).

The left was confronted with its inability to represent, interpellate, and even comprehend the nature of the crowds. This was initially masked by immediate readings of June 2013 that had an appearance of definition but eventually contributed to a set of fragmented interpretations that further exposed the crisis of praxis and fragmentation of the radical left, specially, but also the left in general. The melancholia associated with June 2013 created optimistic readings that were challenged by the events of 2014 (low mobilization against the World Cup and right-wing prominence in the federal elections). This contrast helped to outline to most of the radical left that there was a problem in place deeper than the crisis of representation and that it was related to mistaken calls as well as inaction on behalf of the left, with particular emphasis and consequences for the radical left, when it came to the process of 
depoliticization and the fragmented trend of the left. The interpretations continued to differ, however, in terms of whether the process of depoliticization had been interrupted by June 2013 or if it has continued. Organizations such as the MES, as well as readings coming from Belo Horizonte, where the left was less fragmented around the June mobilizations, favour the interpretation of a new cycle of politicization beginning with June 2013 (Dutra, 2015; Genro, 2015; Mayer, 2015). This interpretation does not see June as revolutionary, but setting prerevolutionary conditions through high mass mobilization (ascenso de massas) (based on the numbers seen at the time). My contention is that although June 2013 set off a new conjunctural period in Brazilian politics with politicizing potential, one that is marked in particular by a collective challenge to the politics of the PT from the left and the right, depoliticization remains a problem because it has changed tactically (as in post-political and ultra-political speech) and because the politicization of June was contained to the groups that became militants and/or organized politically. Givanildo Gilva (PSOL / Terra Livre) describes it as a politicized moment - though far from a revolutionary horizon - that the radical left has wasted, partially because it has focused on "events" and action for the sake of action in a manner that may end up alienating the youth and new militants: "they are selling the revolution as something easy, that it'll happen based on good speeches, and this isn't true"' (Giva, 2015).

This is different from what could have happened with a real interpellation of the massive crowds through politicized efforts towards organized action and a reunited consciousness. To the contrary, the consciousness of the crowds remains fragmented, as is the state of the working class in general, since despite a rise in strikes and protest activity, action is still determined through expediency, immediate needs, and an economistic approach (especially at the union level). Since fragmentation has also continued in terms of 
organizational numbers and political divergences, albeit some progress in terms of joint protest action (e.g. Frente Povo Sem Medo), I argue that the left needs to address its own crisis of praxis - its shortcomings when it comes to politicizing, organizing, and mobilizing the people coupled with internal deficiencies towards dialogue, collective strategy, and recognition towards cohesiveness - even more so after June 2013, since the stakes are higher, the rightwing is more organized, and the interregnum is exposed. According to Ruy Braga (former PSTU, professor at USP), the anti-party sentiment that gained stature in June is both a symptom of this complexity of problems and an obstacle to overcoming it:

This is the unravelling of this depoliticization that occurred in Brazil in the last 20 years, in the 90s mostly because of unemployment, in the 2000s because of precarious employment, the distancing of the PT from social dynamics [...] The socialist left wasn't capable of politicizing, of exerting, building a hegemonic bloc. It fragments itself, it gets involved in very internal dynamics. The PSOL, PSTU and PCB also [fragment] perhaps in a smaller scale, but the fact is that we weren't able to offer an alternative (Braga, 2015).

\section{Fragmentation and depoliticization}

Schisms contribute to the entrenchment of a depoliticized view of the left because they create obstacles to the perception of the left as a coherent space of politics and to the concrete opportunities to build coherence through dialogue towards an alternative. According to Murray E.G. Smith, the schisms faced by the Trotskyist movement in the Soviet era were responsible for weakening the movement's ability to present itself as an alternative to the Stalinist domination over politics at the time (Smith, 2014, p. 245). I argue that the same can be said about the radical left in Brazil, and not only the Trotskyist organizations but all of the socialist left. The schisms in Brazil hurt the possibility of the radical left to position itself as a third camp (rather than multiple alternative camps that do no resonate with the crowds at a time of 
high depoliticization and anti-leftism) and further fragment the political tactics, strategies, and programmes in the radical left. This means that while there are schisms that lead to multiple organizations that still bear similar socialist politics but differ in structure and practical approaches, there are also schisms that result in evident splits between the politics of the "parent" organization and the new tendencies, groups, and fractions. Both cases can be identified in Brazil. For example, the schisms involving PSOL tendencies such as the APS and APS-Nova Era whose differences are still managed inside the same party, whereas the schism that led to the creation of the PSTU was based on forming a radically different party from the PT - which can also be attributed to how the CS already viewed itself as a public fraction inside of the PT (Tavares, 2015). The first kind of schism maintains the organizations within the same political horizon, albeit strategies and tactics may differ, whereas the second kind is of a deeper fragmented nature that requires them to be seen entirely different alternatives. Smith sees the second kind of schisms as a problem regarding the Trotskyist tendencies and the subsequent difficulties to promote themselves as an alternative to Stalinism even after their diagnosis of Stalinism had been vindicated (Smith, 2014, p. 245). This kind of phenomenon around schisms demonstrates that the challenge is both to interpret reality in a somewhat cohesive manner and to put forward alternatives that will be recognized and embraced by the crowds the left is targetting (as well as the respective bases of each organizational fragment). The more schisms and divisions occur, the harder it will be to formulate a cohesive project to present to fragmented crowds the left hopes to transform into a cohesive political subject. In Brazil, this presents the problem of the PT not simply because most current schisms spun out of the Workers' Party but also due to the loop interaction between fragmentation and the cycle 
of depoliticization that favours right-wing alternatives instead of the hoped for engagement with the authentic left.

This leads us to consider the relationship between fragmentation and depoliticization in four particular cases in terms of the crowds the left is trying to interpellate, particularly in the context of June 2013 and the crisis of representation: the crowds inclined towards left politics, the crowds inclined towards left politics but plagued with anti-petismo, the postpolitical and rejectionist crowds, the crowds interpellated by the right. In the first case, the current state of fragmentation of the left operated as an obstacle to conveying a cohesive alternative project to these crowds. This is the case, for example, of the electorate base that left the PT (because of betrayal and/or perception of corruption) but could not see themselves voting or aligning with the PSOL, the PSTU, or the PCB. In the case of the PSOL, the perspective of the party as small, with weak political strength, as a party of the middleclasses/universities (versus the PT's association with the industrial working class and campesinos), or as too radical of an alternative, created obstacles to its projection to represent this segment. To change this perspective, the party would have had to address these issues beginning before June 2013, since it is difficult to reveal oneself to the crowds during periods of turmoil and direct dispute without prior contact and (perceived) as relative newcomers to the spectrum of left politics at the mass level. This difficulty in connecting with the crowds before they are mobilized is one of the reasons why June 2013 was an episode in the history of demonstrations in Brazil that was not organized by the left, whereas the prior work through campaigns, demands, occupations and more united leftist articulation in Belo Horizonte led to a more hospitable environment for the left to guide some of the activity of the period. In Rio de Janeiro, São Paulo, and Brasília, the low level of articulation in the radical left and the 
permanence of vanguardist and/or tactical disputes during June hurt the possibilities, together with the lack of knowledge of the organizations by the crowds, for the radical left to be perceive as a political camp of their own. The result was that only a portion of the crowds inclined towards the left was able to relate to the radical left at such a profound level as to organize themselves and join the militancy. Caio Dezorzi (Esquerda Marxista) refers to this portion as a vanguard of this same crowd, since, in his view, the majority of the youth, for example, that made up the crowds in June 2013 was modified by that experience, but ended up returning to their normal lives anyway (Dezorzi, 2015). This corresponds as growth for the left related to June 2013, but it is still growth that qualitatively corresponds more or less to the same niche where the radical left and its debates have found success and a captive audience: youth connected to the student movement, university graduates, organized labour, and intellectuals. This is observed in the debates that were intensified post-June around social and democratic reforms, which failed to reach the working class at large beyond rhetoric, populism, and mediacontrolled messages around anti-corruption and austerity (Demier, 2016b, p. 10). For Givanildo Giva, the fact that the radical left continues to revolve around the same niches, with only marginal work in the poor communities and favelas, for instance, the link between fragmentation and depoliticization will continue for lack of intensive base-building work (Giva, 2015). Talking about the experiences of 2013 and 2014 in São Paulo, he says:

It was very different in Belo Horizonte. [Here] we didn't manage well, and I think that there's a deterioration of the party practices, of the practices out there, and no one managed to legitimize themselves. There wasn't a group that managed to aggregate [in the demonstrations] (Giva, 2015).

Giva's insight connects the problem of fragmentation, and the little reference the radical left was able to input in the crowds (thus even failing to interpellate successfully thw crowds inclined towards the left), to the problem of insufficient or inadequate base-building. 
As brought forward in previous chapters, the radical left associates the success of the PT with the early years of base-building by the party and its militancy, and recognizes as a whole that it must dedicate more resources and time to base-building of their own. Yet, even after 2013, base-building remains relatively low if compared to the PT years. Part of this is related to the depoliticization encountered in the working class, coupled with anti-petismo turned antileftism, but it is also a problem in terms of how to do base-building on a constant basis when there are various radical left organizations "competing" for the same base despite relaying, in general, a common anti-capitalist project to these crowds. Leftist fragmentation hurts basebuilding prospects because it creates the need to prioritize the survival of the organization, changing tactics and how resources are allocated away from base-building efforts, while sending multiple fragmented messages to the prospective base in a series of attempts of building relationships in niches that oftern wear out the militancy due to frustration and to encountering the internal disputes of the radical left also in the field.

The case where anti-petismo is present is worsened when considering the crowds that have affinity with leftist issues, be it right to housing or investment in public services, but whose anti-petismo prevents it from recognizing any of the radical left organizations as legitimate channels for their indignation and struggle. With the amplification of the PT betrayal after the 2014 elections, when Dilma Rousseff began implementing a series of attacks on the working class through a neoliberal austerity programme, the challenge of the fragmented radical left to politicize grew in size and difficulty. It was not a matter of simply detaching oneself from anti-petismo to the general crowds, but also considering the damage of antipetismo during base-building work in areas where leftist ideology was now associated with 
lies, negligence, and corruption. The growth in anti-petismo between June 2013 and 2015 is also a growth in the delegitimization of leftist demands and proposals (Mattos, 2016, p. 106).

To counter the growth in anti-leftism is not an easy task. Although there is a very depoliticized anti-petismo that has been instrumentalized by right-wing forces to change government in Brazil, the reason why anti-petismo has grown so rapidly is because it has also reached areas where the PT was once hegemonic and was present through base-building from the beginning. In these areas, anti-petismo is a symptom of a legitimate frustration and disgust with the PT project. It gets complicated because this sentiment is part of a mix of depoliticized and demobilized readings of the conjuncture that was brought forward by the PT's way of governing but also by how the mainstream media has been able to manipulate information ideologically to heighten the contradiction between the theoretical and practical consciousness of the working class. The prevalent common sense is one that works against the best interests of the class, but since its interests become either associated with co-optation or corruption in the PT camp, the common sense is also fatalist and contributes to the elements of the crisis of representativity that benefit the right. The issue is that the radical left needs to reclaim the past experiences of base-building that belong to the PT and renew them as mobilizing factors (Giva, 2015). This is almost impossible under the current state of fragmentation, since the delegitimizing efforts thrown at the radical left through anti-leftism tend to be enhanced by the internal disputes and the insistence of identifying every other radical left organization as a competitor "on the path of the PT" (see Chapter 6). As much as this is could be just easy rhetoric on behalf of one organization in reference to the other, this kind of speech appeals to something like an everlasting "contamination" of the PT in the radical left and spoils the 
process of disassociating the camp as a whole, not only single organizations, from the bad experiences of the PT.

This leads us to the problem of how the fragmentation of the left interacts with the postpolitical, almost rejectionist, crowds, as well as those that have been interpellated by the right with ultra-politics (and/or hypocritical instrumental engagement with post-politics) or have been in the right-wing spectrum all along. The first are crowds who do not identify with the left but would side with it if led to believe that the radical left presents an alternative to the PT governments and the corruption associated with it and generalized in the right that is also efficient with public resources. These crowds are caught into a particular depoliticized sphere of the crisis of representation: they want better but its definition of better is still determined according to common sense. The challenge to politicize them is very intense because rejection is everywhere: anti-petismo, moral panic around corruption, contradictory approaches to the importance of public resources versus economic liberalism, frustrations with the electoral system that ambiguously fuelled Eduardo Cunha's counter-political reform, and a flirtation with the right-wing proposed alternative of order, punishment, and a neoliberal reduction of the state. Because of these contradictions, this crowd sometimes works against the left and leftist demands, also dabbling with anti-leftism in these actions ("the radical left is ok as long as it isn't the PT kind of left, and as long as being a different kind of left isn't too radical). This does not mean that this post-political crowd should be rejected, since it is also composed of working class segments from the lower to the middle-classes that ought to be represented by the radical left and must be reached in a struggle for hegemony.

The fragmentation of the radical left looks odd to this crowd because it cannot show unity during important periods of struggle (e.g.: electoral fronts), let alone promote a cohesive 
alternative project, and ends up reflecting the fragmentation of the political-electoral system most associated with the idea of political organizing to post-political/mainstream crowds. The infighting and attacks that promote each other's demoralization weakens the perspective of the radical left when it meets at protests and makes opposition to the government. This is further complicated by the engagement of radical left organizations with post-politics in order to reach this crowd, which was explored in Chapter 4. The depoliticization of post-politics can actually be damaging to the prospects of presenting a radical left that can adequately address the problems faced by the working class (going as far as promoting distrust in the previous two crowds examined) and may even contribute to the overall feeling of rejection, whose expression has been noted particularly with the growth of blank and spoiled ballots at the Brazilian elections over the past few years.

As per the crowds captured and mobilized by the right, they represent and mobilize towards the interests of the elite (whether they belong in the elite or not). The challenge for the radical left is to politicize the other crowds against the right-wing project and present an alternative project that can seize expectations and needs and shape them as leftist demands; that is, take a situation where the lower and middle classes are said to hate taxes because of their unfair tax burden to argue for a tributary reform that more justly taxes the rich while shielding these crowds from the neoliberal vilification of taxes, the public, and the common in general. Since the Brazilian right is generally more organized and united than the Brazilian left, this process of counter-politicization so that collective indignation can be transformed into progressive collective demands is constantly under attack. While not a new phenomenon, it has gained strength through the visibility given to the political arena since 2013 , and enabled new forms of right-wing organizations engaged in a promotion of neoliberal policies and an 
attack on anti-oppression struggles. The election of 2014, for example, already showed a right that was intent and organized to attack the parties and movements to the left of the PT, and the criminalization of the MTST in 2015 is also evidence of the fact that the radical left cannot hide under its own fragmentation and that it will be attacked whether it is united or fragmented. The difference is that possibilities for counter-attack are diminished under fragmentation, especially if matters of divergence in the radical left can be manipulated and used in the favour of the right (e.g.: past disagreements over business financing of radical left campaigns that could be used by the right to imply "broken principles" and untrustworthiness).

The fragmentation of the radical left has a direct impact on the politicization and depoliticization of the working class, thus influencing its ability to interpellate the crowds towards becoming a political subject (the class mobilized and organized in the formation of a collective will). This interpellation involves transforming current criticism into a more permanent movement of "socio-historical criticism, whose subject is wider social groupings beyond the people with immediate responsibilities and beyond the ruling personnel" (Gramsci, 2000 , p. 201). Since the crowds of June 2013 bore the characteristics of both organic and conjunctural movements, the challenge involves changing the nature of depoliticized criticism that favoured the conjunctural movements and their focus on criticism of a day-to-day and personalist quality into criticism born out of a resolution between the double consciousness of the class. In a Gramscian perspective, politicization will involve the formation of good sense and its implementation in the place of common sense. The radical left, while aware of this challenge, has either found many obstacles to it or given it low priority in relation to the other several challenges posed by the fragmented conjuncture. 
This fragmentation prevents the radical left from rising to the tasks Gramsci identifies as the core tenets of the organization of the class. This is applicable, though in varying degrees, to three particular forms of organization of the radical left examined in this dissertation: political parties and strategic organizing for the horizon, social movements as channels for immediate demands into a politicized view of the struggle, and labour unions as organizing outlets of the class in its most evident spaces of contradiction in relation to capital. When these units of the radical left are in crisis internally and among themselves, they fall behind on their ability to represent the working class, so that the radical left finds itself unable to successfully fill the empty signifiers of representation during crucial moments in between the contradictions of the status quo (i.e.: political and economic crisis). Gramsci writes:

All problems of organization are political problems. Their solution must enable the party to carry out its fundamental task of ensuring that the proletariat acquires complete political independence; giving it a physiognomy, a personality and a precise revolutionary consciousness; and preventing any infiltration or disintegrative influence from classes and elements which, even if they have interests contrary to capitalism, are not willing to take the struggle against the latter to its ultimate consequences (Gramsci, 2000, p. 157).

The political problems that lead to inability, inefficacy, and loss of representation in the left are examined in the following section in terms of the divisions at the root of leftist fragmentation.

\section{$\underline{\text { A divided left }}$}

The divisions in the radical left vary in nature, but can be categorized as divisions of a theoretical kind (e.g.: Marxist-Leninists versus Trotskyists), of a tactical kind (e.g: level of engagement with PT governismo), and those pertaining to fractionary practices in the radical left that are most often associated with sectarianism, vanguardism, and economism. Some of these divisions correspond to the plurality in thought and strategy in the radical left, while 
others have a direct impact on the state of fragmentation. The more heightened the state it, the more the "healthy" divisions can be used to fuel sectarianism and prevent collaboration. This section presents some of the divides related to me during fieldwork through interviews as well as based on my own experience as a participant-observer in events and activities geared towards united action. It concerns primarily ongoing schisms and conflicts, especially since June 2013, rather than a schematic approach to the recent history of divisions in the Brazilian left.

\section{Theoretical divides}

When asked about their organizations, most of the militants I spoke to would make reference, at some point, to the theoretical roots and guides of that organization. This is more common to political parties and organizations of the kind, although collectives and social movements would also make reference to it, at least in terms of being Marxist or internationalist, occasionally. The PSTU, for example, follows a Trotskyist approach guided by Nahuel Moreno's Trotskyism, whereas the Insurgência is also Trotskyist but more connected to Ernest Mandel's tradition despite having morenista roots. This kind of distinction has strong ties to what communist international organization a group is affiliated with, although there are exceptions to this, such as the MES, which has a strong morenista tradition but is closer to Mandel's Fourth International than Moreno's ITWLfi. For João Machado (PSOL Insurgência), such differences are not determining of the lack of dialogue between such organizations and the different views inside of the PSOL are evidence of this. His opinion is that the biggest difficulty so far is less in terms of finding programmatic agreement and more over organizations not making the effort or deeming the effort worth it (Machado, 2015). While the will of the organizations is certainly a factor, I argue that their prior theoretical and 
programmatic divides are often used as justification for the lack of will. By appealing to an external resolution or past grievances between internationals, certain organizations are able to find a convenient reasoning for their own self-reproduction in times of fragmentation. Given this, there are, clearly, matters of international and programmatic relevance that differ across the radical left that should not be taken lightly and will inform strategies on the ground directly. One example pertains to international interpretations of the Spanish and Greek scenarios or approaches to Palestinian solidarity. These divisions fall into what I see as healthy divides, as they contribute to the diversity of thought in the left and the schisms considered to be progressive (as breaking away from predatory or ossified organizations). The problem lies in using diversity as a distancing factor rather than establishing spaces of dialogue where conjunctural readings and strategic perspectives can be exchanged and synthesized collectively. Israel Dutra (PSOL - MES) finds that when there is no synthesis over these thematic issues, when each interpretation is treated "vulgarly" to delineate differences, the divides certainly get in the way of collaboration (Dutra, 2015).

These theoretical differences and how they are interpreted also influence organizational models in the left, how new voices are heard and incorporated, as well as immediate approaches to mass uprisings such as June 2013. Cyro Garcia (PSTU) describes how the Marxist-Leninist position of the PSTU influences not only their perception of how the party should be, but also its overall programme:

In the PSTU we defend a Leninist concept of the party. It's Marxist-Leninism from the theoretical-programmatic point of view: a programme with class independence, a programme that places the question of socialism and the destruction of capitalism and the construction of a new society from a process of rupture with the bourgeois order [...] We defend total freedom of discussion but total unity in action. There's an ample debate, but from the moment that the position is voted on, that position will be defended by everyone (Garcia, 2015). 
Zé Maria (PSTU) supports this statement in his interview (J. M. de Almeida, 2015). The schism that led to the creation of the organization MAIS in mid-2016, however, was motivated by internal conflicts over the interpretation of the PSTU's concept of party and how free the debates really were during and in-between congress periods (Carneiro, 2015). ${ }^{48}$ In their departure manifesto, the militants that would proceed to form the MAIS, refer to the deterioration of opportunities for synthesis inside of the party and the dragging out of unproductive debates (É preciso arrancar alegria ao futuro, 2016). This interpretation led them to believe it was better to leave the party in an organized manner, given that there were already a series of militants leaving on their own. The benefit of organized schisms such as this is that they lead to internal and public evaluations of the reasons behind a schism involving large amounts of militants, but it is not the rule for all splits within leftist organizations, especially when dissidence and schisms absorb the heat of broken discussions and personal conflicts. The case of the conflict with the militants of MAIS is an example of how initially healthy theoretical divides become reified in terms of organizational and debate format as to prevent the dialogue and synthesis that benefit the advancement of political programmes. A schism, in such situations, is almost inevitable.

Another kind of divide related to political/theoretical tradition that tends to become ossified and instrumentalized in times of fragmentation is the common diagnostics inside of the radical left of who is reformist and who is revolutionary. This diagnostic is often employed to justify broken alliances, refusal to set common goals, and collaboration in both expedient

${ }^{48}$ When the PSTU makes reference to Leninist party, one important characteristic is the defense of a party without factions during normal (non-congress periods). The controversy surrounding the MAIS split from the PSTU and previous dissidences in 2014-2016 pertains to the difference between factions and groups engaged in debates distinct or contrary to the debates defended by the direction of the party (Fernandes, 2016). 
and permanent arrangements. The reformist versus revolutionary debate ${ }^{49}$ is an important one in the history of the global left and it helps to set priorities and define leadership - the latter especially concerning the identification of the leadership with the class. It is also an important one in the context of a moderate $\mathrm{x}$ radical left, such as by arguing that the reformism of the PT, for example, is sustained by the absence of a close trusting relationship with the base, which stops pressuring the organization (Miranda, 2015). This should not be translated directly, however, into an interpretation of the radical left as wholly revolutionary. In fact, the reformist deviations that often occur in the radical left, as it is subject to tactical error especially in times of right-wing offense such as these, are used to foment the ossified view that an organization exposed to reformist practices is reformist, as if an organization that weighs every single tactic to an absolute revolutionary measure is, by default, the vanguard of the revolutionary vanguard.

This is very common in the debates between the political parties more than regarding social movements or unions. It was common to hear references of one party being a "revolutionary party" whereas the other is not or is reformist for reasons such as speech void of traditional socialist expressions such as "proletariat" and "bourgeoisie", or an embracing of other anti-oppression causes as priority, in lieu of a primary focus on the organization of the working class in their workplaces (Fernandes, 2015).

Finally, theoretical divides also influence how each actor or faction of the radical left approaches the interaction of the base, the meaning of politicization, and the perspectives of

\footnotetext{
${ }^{49}$ Rosa Luxemburg is one of the most well-known reference in this debate together with Lenin. More recently, authors such as André Gorz and Carlos Nelson Coutinho have been both praised and criticized in the left for contributions on the notion of "revolutionary reforms." In Brazil, André Singer has spoken of weak reformism to refer to the PT's lulista strategy.
} 
organization. There are organizations that aim at "directing" the class from a position of vanguard, others that aim at directing the struggles but not the class itself, others more focuses on pedagogy and místicas to break down hierarchies, and others flirting with the horizontalist format that was praised in 2013 amid rejection of leaderships and the presence of autonomist political references. The PSTU, for example, is focused on the idea of "directing the masses" and their struggles rather than just influencing it, as Mácia Teixeira (former PSTU) puts it, which is aligned with the party's reading of Bolshevism and Nahuel Moreno's positions (J. M. de Almeida, 2015; Moreno, 2003, p. 167 [1989]; Teixeira, 2015). The views inside of the PSOL vary according to tendency, with the organizations following the popular-democratic programme focused on leadership through apparatus (primarily electoral) and other Trotskyist organizations seeing their roles as vanguard but currently re-evaluating leadership, debate, and decision-making structures according to some of the crowd impulses of June that questioned vertical leadership (Fernandes, 2015; Madeira, 2015).

These different approaches will, clearly, lead to conflicts when it comes to collective action. If the view of the revolutionary entity is of one party versus the other, rather than the whole of the radical left as a Modern Prince (Gramsci, 2007a), the points of convergence in the radical left may deteriorate into points of divergence. Sometimes, this is expressed in petty daily actions: which organization speakers longer on the microphone or on top of the sound truck, which organization is more "liked" on social media, which organization gets to go first in the demonstrations and whose banners, flags, and posters are bigger and more portrayed in the media. On other occasions, this kind of conflict over how to politicize, how to approach the base, and how to make decisions will lead to an enhancement of internal conflicts (and subsequent schisms), the breakdown of party congresses, and the inability to create fronts on 
equal footing because of the desire to direct (even though other organizations may bring forward a stronger and larger base). Rafael Madeira (PSOL - Insurgência) is critical of how theoretical divergences become ossified as to prevent collaboration "on principle." When speaking of democratic centralism, for example, he makes reference to creating spaces for synthesis instead of more reasons that could create further fragmentation:

"You can't be a militant that is always criticizing political definitions but doesn't take part in base organisms and doesn't build the mass movement $[\ldots]$ If we manage to define the rules $[\ldots]$ to manage to incorporate minority positions, including divergences in the majority and be able to open up to tendencies to discuss the non-consensual questions, I think that this will create the mechanisms for a democratic centralism [...]" (Madeira, 2015)

\section{$\underline{\text { Tactical divides }}$}

Tactical divides are common and expected in the left at any moment, fragmented or not. They concern conjunctural interpretations and manoeuvring and adaptation according to an organization's strategic horizon. When the left is fragmented, however, tactical divides tend to become rigid due to lack of dialogue and suspicion over each other's tactics and may prevent opportunities to foster dialogue. Briefly, I outline a few examples of tactical divides in the radical left I observed during fieldwork. They are, primarily, related to an organization's approach/engagement with the PT and governismo, how elections are treated/prioritized, how particular places of struggle figure in the priority of the organizations (e.g.: unions, student movements, and the overall relationship to an organization operating from a different political category - how social movements interact with parties, how parties interact with labour unions, etc). 
The tactical engagement with governismo is the most prominent divide of its kind in the radical left, with the PT in power. This is evident during June 2013, when there was ricochet of anti-petismo on the radical left, and in particular during the impeachment crisis, when the moderate left's sequestering of demands towards a defence of the Rousseff government was loud and clear (e.g.: the FRP talks and the organization of demonstrations). These two moments are, of course, connected to a broader fear of co-optation and manipulation of struggles by the PT and allies throughout the PT governments and have caused worried in the radical left pertaining to how an organization's engagement with the PT, in all its ambiguity around a party of order with leftist base and appearance, could affect not only the image of autonomy in the radical left but its actual autonomy as well.

Second to the concerns around governismo, which is particular, in this case, to when the PT is in power, there are matters around electoral engagement, which is a dilemma faced by the socialist left beyond Brazil. This is most evident when it comes to considering electoral fronts in the radical left, when the perspectives of the PSOL, PSTU, and PCB differ (partly due to apprehension around institutional power, partly due to strategic perspectives on liberal representative democracy), but can also be observed in terms of the tactics employed before and during elections by distinct tendencies inside of the PSOL, for example. The APS is one of the tendencies that prioritize electoral victories inside of the PSOL, although almost every other tendency also dedicates effort and resources to trying to get their own candidates elected. Matters concerning the programme presented during the election also create divides, as evidenced by interviews that highlighted dilemmas in terms of making broader agitative statements about socialism and revolution or speaking directly to themes and demands of the people at the time (J. M. de Almeida, 2015; Genro, 2015). This kind of dilemma is related to 
the tactical approach to elections and why the party/organization gets involved in them in the first place: competing to win parliamentary or executive spaces or competing to take advantage of the period of political dispute and debate (more limited now with Cunha's political reform) to get the organization's message to the people. This is examined again when I consider elections in terms of expedient arrangements of collaboration in the radical left.

In terms of the places of struggle that are prioritized by an organization, they affect primarily their scope of influence, which discourse is employed to appeal to a particular base, and whether these spaces are capable of promoting encounters between radical left organizations and the quality of these encounters. One example is the student movement, in which there are expressions of all organizations of the radical left, although some more than others. Even the National Union of Students (UNE), which is heavily led by the moderate left, has operated as a place of encounters and dialogue for the radical left. Because of the heavy weight of the moderate left in this space, the radical left has to find creative ways to coordinate, collaborate, and create common goals in order to gain space in the organized student movement. The different tactical approach to the movement by the PSTU, however, contributed to a divide between the party's youth and students and those of the rest of the radical left. This concerns the PSTU's idealization and creation of a separate national student union/assembly in the shape of the ANEL. Although the ANEL welcomed student organizations from the radical left in general (Tavares, 2015), the UNE remained the priority for intervention by these organizations because of their growing strength as a Leftist Opposition bloc (Drummond, 2015; Nascimento et al., 2015). The same can be argued about labour unions and the spaces of intervention. The PSTU and the MES, for example, intervene in the labour movement through CSP-Conlutas, whereas the Brigadas Populares is close to the 
Intersindical-Central. The PCR/UP is still tied to the CUT, as is Esquerda Marxista. This fragmentation in the labour union movement affects the spaces of collaboration as well as the tactical priorities of each organization. The PSTU, for instance, puts a heavy deal of resources into intervening through organized labour, whereas, from my observations, the tendency Insurgência is more inclined towards building a relationship with fellow unions than specifically directing them (although the recent creation of their organized labour collective Braços Dados may eventually change this) (Fernandes, 2015).

Finally, another tactical divide concerns how organizations relate to each other and the temptation to try to direct the fate of a social movement or union, for example. The type of alliance the PT and the MST have illustrates this in the moderate left, especially regarding the loss of autonomy of the MST in terms of its partisanship and leniency in the fact of setbacks during the PT governments (Barone, 2011). Since the MTST has become a leading social movement in the radical left, other organizations have looked to influencing and possibly directing the movement. The latter led to tension between the MTST and the PSTU in the past and contributed to the MTST leaving the CSP-Conlutas (former Conlutas) as a member organization (Machado, 2015; Simões, 2015). For Guilherme Boulos, the fate of the MTST is definitely in dispute and this is expected if the radical left hopes to influence more people, especially in the peripherical and poor areas. The problem occurs when the dispute is disloyal and self-serving, appealing to the tactics of co-optation and manipulation employed by the PT regarding social movements in the past and present. The different approaches to fighting over the fate of another organization are also tactical divides, since they come from particular readings of collaboration and hegemony and affect the relationships of the radical left according to experiences of trust, distrust, attempts at disruption and attempts at dialogue. 
Everyone is fighting over [the MTST]. The PT is, the PSOL is, the PSTU is often in very disloyal ways. The MTST is! [...] There different ways of making a dispute. You have loyal and disloyal disputes. You have respectful and disrespectful disputes. Political dispute and disputes aimed at organizational hegemony, taking over, co-opting an organization. But what I think is important to highlight in all of this is that we shouldn't be afraid of dispute and conflict; politics is dispute, politics is conflict (Boulos, 2015b).

\section{$\underline{\text { Sectarianism }}$}

The level of dispute and the way it is practiced can therefore be productive or destructive in a setting of fragmentation such as the one experienced today. This is well noted in terms of sectarian practices and perspectives of "organizational hegemony" as pointed out by Boulos above. Martin Jay is critical of the kind of sectarianism that goes unnoticed or protected by theory; for him, this is the "sectarianism of those who jealously guard the purity of their version of the tradition against all the rest" (Jay, 1984, p. 4). This is the most common form of sectarianism plaguing the Brazilian radical left and the one most referred to by interviewees, although there are other kinds related to day-to-day petty disagreements, personal feuds, and general distrust that also affect the possibilities of the radical left to not only work together but also begin building a collective programme that transcends the boundaries of each organizations. For Gramsci, the damage of sectarianism relates to the political content of struggles: "Sectarianism is "apoliticism", and, if you look into it, sectarianism is a form of personal "patronage", whereas it lacks the party spirit which is the fundamental element of “public spirit” (Gramsci, 2007a, p. 145).

Sectarianism leads to an environment of growing distrust amidst fragmentation, which puts organizations in a defensive position, be it towards self-reproduction be it towards a rejection, on principle, of efforts and opportunities offered by others. It reinforces the logic of schism, but it is not the sole cause of it. Sectarianism better translates a political purism of an 
isolated kind, and this isolation may be manifested as vanguardism or as political work on the sidelines that is disconnected from the general orientation of the radical left. Wagner Farias (PCB) sees this as one of the principal elements in the difficulty to have a coordinated and collaborative radical left:

A good deal of the struggles with have big difficulties to become one (fusionar), because in period of betrayal or when you see the synthesis in the shape of betrayal, the relations of distrust increase. So the organizations end up without the minimum link of trust among them (Farias, 2015).

Distrust can come from betrayal, as Farias points out. It may also be the result of a long cycle of refusing to trust, of being a part of a fragmented left that is also a defensive one. This element is connected to leftist melancholia, as can be seen according to the scenario presented in the previous chapter, but over and excessive defensiveness is an element of sectarianism that blinds organizations from experiencing the self-critique and changes in the rest of the left. Calling each other wrong by principle and by believing that one is right from the beginning is not simple stubbornness, it must also be called out for the damage it does to leftist possibilities and the class they aim to represent.

When militants see themselves as winners or losers, prospects around unity fall apart by being lowered into the laps of leaders and directors of each organization and result in weak agreements and only temporary partnerships (Giva, 2015; Madeira, 2015). Without trust, the likelihood of left re-composition is diminished, especially distrust escalates into offenses and the impossibility to work alongside one another under repression (Farias, 2015). Whenever I asked militants from the PSOL at different gatherings why they thought there was so much internal conflict inside of the party, anecdotes would come out of electoral fraud during the party's congress and even the occasional fist fights. Physical aggression is of course not new to the ranks of political in-fighting in the left, especially when it concerns the desire to control 
an apparatus. Gangsterism in the left is usually a practice within syndicalism precisely due to the power of the union apparatus (Braga, 2015), but it was common inside the PT tendencies (Dezorzi, 2015; Miranda, 2015) and continues to be replicated in the PSOL, especially during congressional periods, when schisms may happen through lockouts and barring entry to common spaces, as was the case of the APS split a few years back (Varela, 2015). Conflicts across the organized left and other organizations have also intensified since 2013, such as the fights between the PSTU and the Independent Popular Front (FIP) or the Popular Revolutionary Student Movement (MEPR) or between the PSTU and those engaged in Black Bloc tactics (Carneiro, 2015; Farias, 2015; Prazeres, 2015), and the reduction of tactical disagreements and the fight over organizational space to aggression in the hallways and behind closed doors. Ruy Braga characterizes the escalation of political divergences into physical conflicts and rows as the eruption of tension in the left, which derails dialogue into the logic of competition, wherein one has to show up and show off more than the other much like "student gymkhanas" without the benefit of intense programmatic debate (Braga, 2015). I was able to attest to this during participant-observation, by noticing how the tension between the various organizations of the radical left creates a need to validate one's organization by invalidating the other's, often through harsh language and ad hominem statements that do not make room for critical qualification. In addition, the practice of poaching each other's militants is still common. It adds to hostility and resentment in shared militant environments. Resentment produces negative affects and creates the necessity of a culprit to blame (Brown, 1995, p. 68). According to Mácia Teixeira, this dynamic also distracts from efforts to expand the base instead promoting fighting over the small base that already belongs to the radical left (Teixeira, 2015). While these factors do not prevent the appointed representatives of each 
organization from meeting occasionally and even collaborating topically through front-based action, the tension and competition prevents permanent and earnest joint action to build the base and politicize broadly. In fact, if the visible fragmentation of the left is already confusing to the masses, visible fights tempered by gangsterism or disrespect also affect the ability of the radical left to bring a coherent message and appear trustworthy.

Mácia Teixeira (former PSTU) recognizes the problem that stubbornness and believing in one's righteousness by principle can be in times of fragmentation: "We believe that it must be directed in a certain way, so at some moment there will be dispute $[\ldots]$ But now that we are in a process of accumulating forces I think that to be the least sectarian possible is not just a matter of party construction, it is a matter of the material possibility of mobilizations happening" (Teixeira, 2015). Her critique is in line with the approach promoted by MAIS in their manifesto after leaving the PSTU, which is one example of a schism happening not because of sectarianism by the fraction that left, but of critique of the sectarianism of the larger party entity and its direction.

This has been a particular problem in the radical left in terms of the positioning of multiple vanguards. At times of intense depoliticization and mobilization that barely breaks through the margins of society, the radical left, as a politicized institution, is in itself the whole of the vanguard. The problem is that if it only sees itself as a vanguard, or if it expends energy and time fighting to be the "vanguard of the vanguard," real efforts at politicization, connected to base-building and organic action in the working class, will be lost or diverted. Érica Ramos (PCB), whose party views the need for a leading vanguard, agrees with this: "I think that there's a lot of critique in relation to other organizations but little organic action, sometimes, by the parties [...] always trying to put themselves as a vanguard but not building themselves as the 
vanguard" (Ramos, 2015). Givanildo Giva (PSOL / Terra Livre) is even more critical of this vanguardism:

No one is going to organize and direct this thing. There's no possibility for that. This is going to be a process very diverse, very chaotic, and this thing of thinking about being the vanguard of the revolution, whoever thinks that [should know] that it's an enormous stupidity (Giva, 2015)

Although Gramsci makes a critique of this in terms of party fractions, it can be considered in this context as a critique of overall leftist fractions: "Every party fraction believes it has the infallible recipe for arresting the weakening of the party as a whole, and it uses every means to take over the leadership, or at least take part in it" (Gramsci, 2000, p. 262). This critique provides an interesting insight into why, perhaps, fragmentation is such a widely recognized problem in the radical left but it is never really approached with the necessary tools to solve it. Based on my observations, it is my suggestion that there is a general sentiment in the radical left that through self-construction and hegemonic dispute, one organization or a select group of organizations will grow to such hegemony as to take over the leadership of the left, making it strong by default. It is almost as if unity can be built by phagocytosis.

This also alludes to a certain detachment from daily action and the consciousness of the working class that ends up prioritizing leadership over building the base for leadership. Sometimes this is done out of pure belief that one's organization has the path to revolution and rather than collectively building this path, all other should just join along. The error lies in the fact that building a vanguard without building a base is trying to take shortcuts that will eventually display their weakness because, as Edson Índio (Intersindical-Central) points out, the real issue in this conjuncture is not a crisis of direction, but a crisis of the base to which the direction is nothing but minor (Índio, 2015). This is echoed by Rafael Madeira (PSOL Insurgência), who criticizes the tendency to try to convince the class of whoever is more 
revolutionary without the connection that would interpellate crowds into a class with consciousness and care for revolution (Madeira, 2015). This line of thought is also corroborated by Guilherme Simões (MTST) through his argument that although building fronts and alliances is important, they will matter little if the organizations in this joint effort have not a real influence and connection to the base: "As long as we prioritize programmes, sentences, “meaningful statements" we won’t go very far prioritizing disputes of positions like “ no, your programme is reformist, yours is revisionist, yours is Stalinist...” (Simões, 2015).

Guilherme Boulos (MTST) sees an infatile need for self-affirmation in some sectors of the left that is related to this desire to appear the most revolutionary, the different one, so that the more one organization tries to appear different, rather than procuring collective synthesis, the more division there will be (Boulos, 2015b). This is enhanced by distrust that the other may also have principles that will safeguard their loyalty to the class when pursuing alliances and syntheses beyond their own inner circles. This concern is strong in the MTST because, as a social movement, it has had to negotiate and enter into dialogue with the PT governments. It has also been a leader in the formation of fronts and joint demonstrations because of its strong base when compared to other organizations in the radical left. Boulos sets this context by saying:

There's a sector in the left that believes that if you relate with someone who thinks differently, then you risk thinking like that person, that this is contamination [...] "Well, if you relate with someone who is governista, this is transmitted in the air and you'll be come governista. It's sectarianism [...] We are secure, we have some principles that safeguard this unity. The moment that these principles can no longer be supported by [other] sectors, well then, the front won't be able to go ahead (Boulos, 2015b).

This sectarianism, which in this particular context can be related back to melancholia and fear of the path of the PT, is predominant in all kinds of attempts at creating fronts and alliances in the fragmented radical left. Although much of this relates to the front attempts 
during the impeachment crisis, when the governista sector was heavily trying to influence all processes, it is very clear also during electoral periods. The impediments to having a coherent socialist left front in 2014 form an example of this. While the PSTU and the PCB stepped aside and favoured their own candidates, the PSOL also refused in some degree by hegemonizing the electoral alliances in a way that PSOL candidates would benefit from the votes in PSTU and PCB candidates, but PSTU and PCB candidates would benefit in a lesser degree. This was also a concern because the PSOL proposals would take priority, and attempts at creating a programme of minimum accord among these parties so that the front would simply be a platform for the PSOL programme were hurt by distrust, sectarianism, vanguardism, and prioritization of one's self-construction, all of which I suggest were displayed in higher or lower degrees by all three parties (Fernandes, 2014).

In terms of sectarianism, the problem is extended to the still confusing state of the left, which is not exclusive to Brazil, when it comes to disputing elections. If a party devotes large resources to elections, then it must be reformist. If another party does not devote resources to election, then it must also be, by default, sectarian. In the current state of fragmentation, electoral prospects are hurt because the beliefs prevail through purism and are hardly challenged by real attempts at dialogue. Rafael Madeira (PSOL - Insurgência) is critical of this purism because it often bets on sabotaging the opportunity of the other organization to also make its appeal (Madeira, 2015). In general, purism appeals to a political superiority of an almost religious order, shunning the other and the possibilities of working with the other because their politics are different and may taint the "revolutionary" characteristics of the pure politics of one's organization. 
João Telésforo (Brigadas Populares - former PSOL) worries that this affects the growth of the left in general, which is in line with the suggestions in this dissertation. He argues that:

One of the reasons us because [the left] comes from a discourse of radical democracy from the inside out, political participation and so no, but on the inside... [...] The problem is always thinking that the growth of your organization is more important than the political growth [in general] [...] Any organization, it doesn't even have to be political $[\ldots]$ it always has a large preoccupation with itself, survival, growth, etc (Telésforo, 2015)

For JC Miranda (Esquerda Marxista) sectarianism and self-proclamation closes doors to important opportunities in the left (Miranda, 2015). During debates, I witnessed several members of the PSOL argue that, for instance, if the PSOL, PSTU, and PCB had been together in the elections of 2014, the PSTU would have had strong chances of electing a candidate to the federal congress. ${ }^{50}$ Although sectarianism can be identified everywhere else in the radical left, this adds to the general view of the PSTU as sectarian. Pablo Iglesias, from Podemos in Spain, sees fragmentation as a matter that costs the left dearly at moments such as the election, when the right-wing is very united and cohesive and stands to take the most advantage of voting systems that favour coalitional politics (Iglesias, 2015). Sectarianism and high fragmentation cause the radical left parties to have limited opportunities of direct exposure to the population under the current electoral rules, and since this is a moment to present not simply an electoral project but also a political project, the very few opportunities at politicization beyond elections during electoral periods come out fragmented and even weak. Not to mention the tendency for the three parties (PSOL, PSTU, and PCB) to come at each other in order to

\footnotetext{
${ }^{50}$ Although outside of the methodological scope of this dissertation, which goes until August $31^{\text {st }}, 2016$, this same argument can be extended to the 2016 municipal elections when, for instance, the PSTU failed to elect Amanda Gurgel (PSTU / MAIS) as a city councilor because without an electoral coalition, Gurgel's place as the second most voted candidate was not enough to have her surpass the necessary electoral coefficient for election.
} 
defend their own programmes and particular differences. This makes it hard to reach out to the masses cohesively, especially when the moderate left still manages to maintain some electoral discourse cohesion (even though they do not follow through with it necessarily).

In the case of the PSTU's principled isolation during elections, Israel Dutra (PSOL MES) traces this to the PSTU being known for "excessive vanguardism" and of "trying to always direct and a way that is little dialogical" (Dutra, 2015). This makes reference to what Henrique Carneiro (professor at USP - former PSTU) calls a "vanguard fetish," which relates not to a vanguard based on concrete struggles, but one ossified through corporativist struggles in the labour union sector and that does not really translate into political influence (Carneiro, 2015). This excessive and/or fetichistic vanguardism relates to an interpretation of what it means to lead the class that is overtly criticized by Gramsci in the Italian context and that may be applied directly to the current situation in Brazil:

The principle that the party leads the working class must not be interpreted in a mechanical manner. It is not necessary to believe that the party can lead the working class through an external imposition of authority. This is not true, either with respect to the period which precedes the winning of power, or with respect to the period which follows it. The error of a mechanical interpretation of this principle must be combated in the Italian party, as a possible consequence of the ideological deviations of the far left. For these deviations lead to an arbitrary, formal over-estimation of the party, so far as its function as leader of the class is concerned. We assert that the capacity to lead the class is related, not to the fact that the party 'proclaims' itself its revolutionary organ, but to the fact that it 'really' succeeds, as a part of the working class, in linking itself with all the sections of that class and impressing upon the masses a movement in the direction desired and favoured by objective conditions. (Gramsci, 2000, p. 159)

Self-proclamation of one organization is a weak tool for interpellating the crowds into an actual political subject and an ineffective tool for maintaining high class consciousness and mobilization in the base. This is so because leadership relies on concrete, material, matters to survive beyond corporativist demands and personal loyalty. It ends up detaching that group or organization from the present dynamics of the political conjuncture, further isolating it and 
almost worsening the desire for self-proclamation to get out of isolation. Ruy Braga (professor at USP - former PSTU), concerned with a sectarianism that focuses on self-growth rather than the growth of the left in general, argues:

Sectarianism is a demonstration of weakness either ideological or programmatic or political $[\ldots]$ The sectarian is a group or individual or grouping that lives off ready made formulas, it doesn't do rigorous politics, because it always applies the same model [...] Today, in my opinion, sectarianism is more damaging, especially the sectarianism of the directions, it's more damaging because it prevents this proximity with this mass, the bases of the CUT and the PT (Braga, 2015).

Sectarianism in the fragmented left leads to predatory practices that threaten the role of the radical left to politicize and mobilize before setbacks run by the PT governments or any other government. It prevents not only real dialogue and the intention to re-unify leftist forces towards a joint programme, which require building a strong base and re-evaluating a whole set of practices outlined in the previous chapters. Sectarianism also prevents the simplest of alliances and agreements that could be set at the level of the direction of organizations, giving the appearance of a weak left that cannot even agree among themselves, let alone lead depoliticized crowds into political agreement.

\section{Fronts and alliances}

Fronts and alliances are the names of the most common ways thought up by the left to collaborate, especially at times when those in power are promoting direct attacks on the working class and the oppressed. From my perspective, there is a definite difference between a front and an alliance: fronts are used to denote more specific spaces of collaboration and alliances for broader and more permanent spaces, though the terms may end up being used interchangeably out of convenience or taste. This brief section refers to expedient or permanent arrangements in the left, mostly around fronts, and points out the absence of real alliances in 
the horizon. It also hashes out a few more obstacles outlined in the interviews when it comes to collaborating under fragmentation (and beyond fragmentation).

These arrangements rely on one basic principle to be able to happen: the ability to make compromises towards creating minimum agreements that will set the direction of the arrangement. I often heard that this is at the core of the problem of radical left, which I associate with the logic of schism: the leadership of groups sit down together in environments designed to foster collaboration and maybe formalize a front of action, but instead, they process to impose their own projects rather than creating a common one. This contributes to an intransigent, stubborn environment that is self-serving and neglectful of the collective demands at hand. Sectarianism plays as an element in these situation, but also does a kind of intransigence that is less related to purism and more to difficulties to establish real dialogue (instead of just talking past each other). This kind of internal intransigence is considered detrimental by Antonio Gramsci and in fact relies on what he calls a "fear of dangers." Because compromise involves trust, not compromising involves distrust and fear of what the other may do. Thus, it is a fear that creates more isolation in the left and leads to the breakdown of dialogue before it even happens. Gramsci writes:

An element to be added as exemplifying theories of so-called intransigence is that of rigid aversion on principle to so-called compromises, which has as a subordinate manifestation what can be called the "fear of dangers". It is apparent that the aversion on principle to compromises is closely tied to economism, in that the conception on which this aversion is based cannot be other than the iron conviction that there exist objective laws for historical development of the same character as natural laws, with, in addition, the belief in a fatalistic finalism of a similar character to religious belief: since the favourable conditions are predestined to come into existence and from these will be determined, in a somewhat mysterious way, regenerative events. The result is not only uselessness but the loss of all voluntary initiative aiming to predispose this situation according to a plan. (Gramsci, 2007a, p. 160) 
There is a general appeal in the radical left that it must, as the left beyond the PT (antigovernista), finally agree to something and heed to it (Braga, 2015). This would imply fostering intransigence as an antagonistic value towards the right, but not one present inside the radical left. This has not been the case given how hard it was to reach minimum agreements over matters that seemed to have an apparent resolution from a socialist standpoint: uniting against the austerity measures of the PT, then uniting against the austerity measures of the Temer government, uniting against the closure of public schools, calling a unified general strike against cuts to workers' rights, and so on. Instead, agreements were often harmed by intransigence on other matters that did not necessarily affect collaboration on these particular issues, such as lack of unity against austerity because one would not work alongside governistas or disorganized support for student-led occupations of public schools because of their more autonomist tendencies that would affect a party's ability to direct the occupations and created a certain level of dismissal over their political potential. ${ }^{51}$

Clearly, even if there were perfect minimum agreement among most of the leftist forces inside of the radical left, this alone would not guarantee the success of any front or mobilization without actually influencing the crowds and the base. E.P. Thompson argues that any discussion of socialism, the more eloquent and critical it may be, "cannot be promoted by a comfortable meeting of the cosily committed, nor by an uncomfortable meeting of antagonistic sectarians" (Thompson, 1978). That is, fronts need to become spaces connected to the base

\footnotetext{
${ }^{51}$ The position of the radical left improved between 2015 and 2016 over student occupations, in my opinion, especially because these occupations became very politicized against the Temer government in the 2016 period. They have, indeed, contributed to spaces of dialogue between students and the radical left and sparked a wave of resistance to the austerity measures of this government. Conflicts remains, however, related to the now former PT governista sector, especially regarding the low or lack of action by organizations of the moderate left that should be demonstrating their mobilizing power at this point such as the CUT and the UNE.
} 
first if there is to be any hope of permanent alliances in the horizon. The fact that they have not been effective or well-coordinated, not even among the leftist leadership, is evidence of how fragmentation is preventing leftist growth and neglecting the depoliticization that remains despite new mobilizations in the last period.

In terms of expedient arrangements, primarily in the shape of fronts (Frente de Esquerda, Frente Ampla, Frente Socialista, etc), the radical left organizations agree in principle that they are necessary if the radical left is to overcome fragmentation, influence its base politically, and interpellate the crowds away from the right and into a leftist political subject. They cannot, however, agree in general on the shape of the front, the influential channels inside of it, the leadership, and who should and who should not take part in it. JC Miranda (Esquerda Marxista) explain that what matters if that the front must be truly leftist, not self-proclamatory, and not adapted to the order as the PT has done (Miranda, 2015). This changes in the perspective of the PSTU, for example, which argues for some "truly leftist" fronts that would exclude those involved with the moderate left and reformist proposals, for instance, and others against austerity that could include unions and other organizations from the centre-right that claim to uphold an anti-austerity position (J. M. de Almeida, 2015; Farias, 2015; Prazeres, 2015). The contradiction lies when this level of flexibility is allowed for expedient fronts on matters such as labour rights but rejected when it comes, for example, to the MTST that as a social movement must have flexibility of its own to deal with the government and the moderate left. ${ }^{52}$ As damages caused by fragmentation become more

\footnotetext{
${ }^{52}$ In general, the MTST has demonstrated a position coherent with its principles when dealing with the PT governments. It has, however, hurt its own image as a coherent social movement when it allows space for Lula to make speeches to the crowd with moderate left, class conciliation content.
} 
evident and attacks on the working class increase, these principled rejections tend to be replaced by more general flexibility when it comes to fronts. The PCB, which was very critical of the MTST's flexibility with governismo during the interviews, began collaborating with the Frente Povo Sem Medo by the end of 2015 and into 2016, especially as the worsening of the impeachment crisis signalled major attacks by the Temer government (Fernandes, 2016).

This kind of conflict inside of the radical left around expendient fronts indicates how much hard work at dialogue, synthesis formation, and sense of collective as the left (rather than as individual organizations) is necessary if the radical left is to overcome fragmentation through more permanent spaces of collaboration. The more permanent space in the radical left today is certainly the PSOL, since it is a party of tendencies that negotiate between their own autonomy and a cohesive direction of the party (sometimes through dialogue, sometimes through fierce disputes when internal democracy fails). This is, however, just one model of collaboration towards a joint project, and it must not be assumed that a broad party/party of tendencies is the sole answer during fragmentation. In fact, fragmentation extends to the inside of the PSOL and causes several fights, predatory disputes, and damages to the party's principles of internal democracy.

An interesting proposal was made by the Brigadas Populares for more permanent collaboration in the shape of "Open unity for a new political and social majority in Brazil" (Brigadas Populares, 2011). The proposal states the following:

The overcoming of the fragmentation of the popular and leftist camp in our country, resulting from a theoretical, political and organizational crisis that affects the revolutionaries in the last decades is urgent. This perspective urges the recomposition of the perspective of open unity, that is, the constant convergence and in different levels around platforms that accumulate strength towards socialism (Brigadas Populares, 2011). 
This proposal entails the formation of coherent socialist organizations, in the view of each group, that must aim to constitute, collectively, a political front that will express unity through minimum agreements and direct attention to the material demands of the class. At first, it seems similar to the proposal for any front, but it actually entails a front at the level of minimum agreement but collaboration as a principal objective of these coherent socialist organizations, which must understand that their existence is tied to creating this new political majority. The Brigadas Populares is a small and relatively new organization, but it has grown in the recent past and its openness to collaboration has allowed it bring forth this proposal. Unity, in their view, is similar to how the MES sees unity, as an aggregator of multiple identities with enough political maturity to advance a cohesive programme (Brigadas Populares, 2011; Dutra, 2015).

\section{The mosaic left}

Although the proposal by the Brigadas Populares remains on paper, it is not isolated. It actually resonates with the idea that a dynamic left capable of dealing with the challenges posed by the various systems of exploitation and oppression today must resemble a mosaic left, especially after so much fragmentation. Mario Candeias argues that part of the current problem of perspectives on left unity is that it attempts to impose unity as one flag so homogeneous that it negates the various differences inside of the left that actually tend towards a productive and critical environment (Candeias, 2010, p. 8). This unity project mistakes the interesting diversity that can make the left creative and encourages new syntheses to deal with the continuous evolvement of the problems set by capitalism and all systems of oppression for sectarianism, the logic of schism, predatory practices and irreconcilable divides. 
Speaking of the political party, Gramsci asserts that "a party is never completely formed, in the sense that every development creates new tasks and functions, and in the sense that for certain parties the paradox is true that they are completed and formed only when they no longer exist" (Gramsci, 2007a, p. 149). Based on this, the understanding of how the left should unite as a mosaic calls into relevance the discussion of a historical bloc, especially in terms of how syntheses and agreements ought to be set in its formation.

An appropriate political initiative is always necessary to [...] change, that is, the political direction of certain forces which must be absorbed in order to realise a new, homogeneous, economico-political historical bloc, without internal contradictions; and since two "similar" forces can only be fused in the new organism through a series of compromises or by force of arms, coming together on a plan of alliance or by subordinating on to the other with coercion, the question is whether one has this force and whether it is "productive" to employ it. If the union of two forces is necessary in order to conquer a third, [...] the only concrete possibility is compromise, since force can be employed against enemies, not against a part of oneself which one wants to assimilate rapidly, for which "good will" and enthusiasm are necessary (Gramsci, 2007a, p. 161).

The fragmented radical left first must acknowledge its parts as belonging to one left rather than many parts as several, opposing, contradictory lefts. This recognition prioritizes the minimum agreements that can eventually lead to more homogeneity, as a fusion of fragments, though it does not require in essence a single party or organization. Assimilation, in this case, must be read as the making of synthesis among similar parts so that the result can be a historical bloc rather than an organization hegemonizing over similar others through different displays of force. The key to interpreting Gramsci's proposition, then, is to consider what it is to be similar and how finding common ground requires constructive good will instead of a destructive and predatory desire to direct others as an organization from above. To be similar is to see leftist actors as parts, rather than isolated fragments, of the mosaic proposed by Candeias. The final section of this dissertation will reconsider the matters of fragmentation and 
depolicitization under a crisis of praxis to argue for a mosaic left as a historical bloc, although more research beyond the scope of this work is needed on the propositional aspect of what a defragmented/united left would look like and how it would operate, especially in the Brazilian circumstances. 


\section{Conclusion}

This dissertation examined fragmentation and depoliticization in light of the most recent socio-political arrangement in Brazil. It is a conjuncture that began in June 2013, with elements given from the beginning of that year, and that it is by no means complete. It looked at June as a historical marker that, in all its hetereogeneity, brings forward a complex scenario for the left as a revolutionary agent. June 2013 was not a revolution in itself. It did not change the regime, it did not drastically affect the economic system, it did not, at that moment, remove tyranny from power nor did it install popular power at large. For such reasons, Paulo Gajanigo sees June as an enigma: it was too rich of a mark to be interpreted according to the standard labels of revolutionary, reformist, or reactionary (Gajanigo, 2016). It was all of it and none of it at the same time; hence, the need to continue to explore the meaning(s) of June 2013 in search not of a consensual reading of the event but of interpretations that, when put in dialogue with each other, are capable of producing as much richness as those days with millions in the streets did.

Part of this challenge consists of seriously analysing the implications of this new conjuncture for the left, especially since obstacles the left encountered to interpret June and the quality of social movement of the time, together with its consequences until today, relate to various issues, setbacks and advancements in the most recent history of the Brazilian left: from the PT as an aggregator to heightened fragmentation in the interregnum. This dissertation was written with this challenge in mind, and I found that to systematically analyse depoliticization, which I believe to be what threw many on the left into confusion with respect to June, would be of great help. To do so, I employed the concepts of post-politics and ultra-politics to explain 
how depoliticization occurs in different ways and is even employed by the radical left, and not simply the moderate left through the PT as would be originally assumed whenever the setbacks of the conjuncture were seen, by radical left militants, as almost wholly the fault of the PT. The chapter on melancholia helped to hash out the complicated relationship between the radical left and the PT, especially because of different elements of melancholia that were paralysing politically and strategically on both sides. This paralysis operates through the PT in terms of demobilization connected to the party's trasformismo, whereas the paralysis of the radical left follows a long process of conflicts with the PT and the symbols it evokes, as well as strategic difficulties concerning the political base of the PT and to where it has migrated according to depoliticization and politicization patterns.

\section{Crisis of praxis}

In a way, a crisis of praxis is a multiplicity of crises that relate to the isolation of practice from theory in the left, especially revolutionary theory. Stédile argues that in Brazil there are three interrelated crises: a crisis of party political practices, a crisis of the political class in general, and an ideological crisis of Brazilian society, which I identify as symptomatic of massive depoliticization, especially evidenced in the replacement of class, political, and social consciousness by individual interests promoted by neoliberalism (Stedile in Chauí, Boff, Stedile, Santos, \& Guimarães, 2006, p. 151).

The protests of 2013 had ambiguous results for Brazilian society, as is expected of popular outcry in the face of hegemonic renewal during a crisis of praxis. The small victories pertaining to the repeal of transport fare hikes after the June 2013 demonstrations were retracted less than a year later. The alternative media expanded and gained new audiences, 
although it sometimes operates aimlessly while the mainstream corporate media continues to operate and promote dubious discourses that criminalize the activities of social movements and popular mobilizations and attack progressive ideas and projects for social justice. The five pacts proposed by president Rousseff to appease the protesters were of minimal impact, and the use of coercion and tactics of legitimization by the government has eclipsed its own proposal for a plebiscite for political reform. Meanwhile, the right's territory remains mostly unscathed. With so many drawbacks, what positive changes really emerged from the resurgence of popular demonstrations?

In simple terms, the protests "have been a political school for a new generation of workers, with potentially far reaching consequences" (Saad-Filho \& Morais, 2014, p. 242). There is potential for dialogue in the radical left, though there is also potential for miscommunication and defensive politics if this dialogue is limited to electoral interests, selfconstruction and vanguardist positions. The crisis of representation of the political parties reflects the difference between coalitions and alliances; the latter refers to long-term political alliances that are formed out of collective interests and goals, while the former consists of temporary groupings of political actors pursuing specific agendas. When coalitions/fronts take precedence over alliances, left politics becomes more fragmented and stuck on short-term disputes over short-term gains.

With the help of the interviews, I was able to assert a connection between this lost praxis and a melancholia in the radical left. This melancholia is paralysing in various ways. It creates expectations that the ruin of the PT will lead to a rise of the masses and a new politicizing cycle towards the radical left. It also fuels vanguardism connected to past victories and the idealization of political models. More than anything, it traps the radical left into an 
internal cycle of self-affirmation and construction that is detrimental to its positioning as an alternative to the base leaving the PT and the crowds as they mobilize and demobilize.

The result is the validation of a long history of schisms, fractions, permanent conflicts and disagreements, and predatory disputes in the left. This history belongs to the international left, which is also plagued by the elements brought forth in this dissertation in lesser or higher degrees, depending on the place. The particular conjuncture at hand here, however, brings in a combination of depoliticization, melancholia, and fragmentation that is dangerous to the prospects of harnessing the energy of the new mobilizations of June and onwards and of channeling it towards an organized progressive political outcome.

\section{The mosaic and collective will}

Despite different interpretations for fragmentation and depoliticization, one thing was certain in all interviews: the left must fight fragmentation in order to face off the challenges put forward by this conjuncture, especially in light of the impeachment crisis and the new Michel Temer government. It must do so by uniting struggles on the ground, moving away from simple agreements determined at leadership meetings. This is what Andrew Feenberg refers to as "establishing a framework of meaning;" that is, fighting depoliticization is not a top-down approach and it will require continuous base-building work from a non-corporatist perspective of the base:

Can the fragmented struggles of this historical period fulfill the program of philosophy of praxis? The answer to this question depends on the type of practice that is supposed to resolve the antinomies. If that practice is conceived as revolution in the traditional sense, then clearly no resolution is likely in the foreseeable future. On the other hand, a fuller account of practice reveals a hidden dimension overlooked in the exclusive focus on revolutionary activity. That dimension is the horizonal work of establishing the framework of meaning within which activity goes on. Reification is such a horizon and so is the dereifying challenge to it. If changes in that hidden dimension are understood 
as essentially transformative, then the philosophy of praxis survives the loss of its revolutionary guarantee (Feenberg, 2014).

In the words of Mácia Teixeira (MAIS - former PSTU), the challenge lies in building a left that is less concerned with the spotlights and more concerned with the base, even if this base does not listen to the left just yet (Teixeira, 2015).

The municipal elections of 2016 and the debates that ensued in society showed that the radical left understands the need to introduce a project of politicization in society. The content of this project and the capacity to undertake it, however, are still topics to be discussed seriously beyond the limits of each organization towards a historic bloc way of thinking. Based on important learning experiences for the radical left in the last years, with the impactful occupation of public schools by relatively autonomous and spontaneous high schools students as a highlight, the radical left will likely frame this project through the strengthening of alliances and promoting dialogue, fighting the neoliberal assault on Brazilian politics (among other aspects), educating the masses and each other on theory in relation to collective practical activity, and increasing the use of public space (framed as commons) to contest capitalism and the capitalist State. The radical left parties seem interested in expanding their support base through political pedagogical tools, although the PSTU and the PCB are more likely to target "class formation," specifically, given their direct approach to class, than the PSOL. The connections between these parties and organized social movements and labour movements have advanced since June, but there is still suspicion and fear of vanguardism permeating their relations. The analysis on post-politics indicates that the expansion of dialogue with the intent of further connecting with the base (and growing it by interpellating the crowds) involves instigating political consciousness that is also class-consciousness. This way, the left may have a unified political subject in its hands that is also aware of the social and political antagonisms 
that surround it. Contra the multitude ideal of post-politics and pluralist democracy, left praxis depends on emphasizing some divisions because exploitation, oppression, and dispossessions are at the core of the dynamics targeted by a left politics against the status quo. Unity helps with the formulation of a collectivity, but this collectivity needs a purposeful end in order to advance. This purposeful end is given by the power of class antagonism, which is static in the democratic status quo, but a fuel for common struggle in radical, and ultimately, revolutionary politics. In the words of Petras and Veltmeyer, "what is clearly lacking [...] is a unified political organization (party, movement, or combination of the two) with roots in the popular neighbourhoods, capable of creating representative organs that promote class consciousness and point toward taking state power" (Petras \& Veltmeyer, 2005, p. 235).

Based on the experiences highlighted during fieldwork, I am more favourable towards the idea of a unified political organization that is heterogeneous, preserves political identities and fosters dialogue at several different levels through democratic, if possible, diagonal mechanisms that answer to the base rather than to the direction of the organization (Dean, 2012, p. 211). This means envisioning unification less like a simple party of tendencies like the PSOL, or a "party-movement" as Podemos is described, given the limitations these models present in periods marked by a rise in reactionary politics and general distrust of the political space by the people. Although the research involved in this dissertation is insufficient to suggest what the unification of the radical left (considering a politicization towards the left of moderate left actors too) should look and be like instead, the understanding of fragmentation presented here points to the notion of a mosaic left presented in the previous chapter.

As the left becomes fragmented, different worldviews, theoretical interpretations, organizational models, relationships and targets are presented, and a unification through a 
blanket organization would wipe out disputes but also wipe out productive differences that can fuel the creativity the left needs to overcome present and future challenges. The complexity of the systems of exploitation and oppression today, exacerbated by $21^{\text {st }}$ Century obstacles such as climate change, technological control, and the refugee crises, require ever evolving diagnostics and strategies on behalf of the left. Those who believe that to replicate the Bolshevik party, or to be faithful to the literal words of Lenin is enough will fall behind and risk wasting their revolutionary energy away.

This is why I conclude this dissertation by urging the left to rescue the notions of historic bloc, collective will, and the Modern Prince presented by Antonio Gramsci. Rescuing does not mean reproduction, but close attention that will lead to a re-examination of the conjuncture and what is meant by a united left through these concepts and suggestions. Historical notions around party organization have contributed to the ossification of the Modern Prince as a centralized, hierarchical, enlightened organization. They have also imbued the left with light readings of what a historic bloc ought to be like, mostly by undermining it as expedient experiments or blanket definitions that do not require real connection to exist (i.e.: just thinking similarly is enough, such as being anti-capitalist, socialist, and so on). Collective will, on the other hand, has barely been remembered as the name of what the left should be building if it is to overcome the instrumental relation between the vanguard and the base. As expressed in Chapter 1, a revolutionary collective will may exist in society in a somewhat primitive stage, but will only be effective if "directed towards a given political objective" (Coutinho, 2009, p. 35; Gramsci, 2000, p. 239).

Indignation, during June 2013, had the potential of being directed towards a given political objective, but the fragmentation of the left, coupled with sentiment that translated as 
melancholia in the left and anti-leftism in the right, harmed the possibilities for channelling this potential into organized and consistent action. It is true that since June 2013, the radical left has been in a more productive, welcoming, and strategically beneficial position than before 2013. One of the strongest pieces of evidence regarding this is how the radical left is no longer invisible in the eyes of the masses, the media, and even the right. Social movements such as the MTST and parties such as the PSOL have gained supporters in the past years and managed to lead action that caused even the most reactionary newspapers to draw a line between petista leftism and this other kind of leftism that, in their view, was more radical and dangerous. Although the radical left was not able to interpellate the crowds of June en masse, it has grown in appeal to part of the base migrating from the PT towards a more radical left stance and has demonstrated a strong connection to youth, women, and peripherical communities through educational, feminist, right to the city and other emancipatory struggles. The World Cup, despite the low wave of protests and difficulties to mobilize in major cities such as São Paulo and Brasília, is an example of how a concept and/or event can be changed in the minds of people, altering hegemonic consent, through counter-knowledge and some thousands in the streets (see Chapter 3). The World Cup happened, but it did not happen without struggle - even if less intense than expected by the radical left - and it did not happen with the popular support and passion the government and the elites had hoped to instigate. At the same time that the crisis of representation means the loss of popular faith in the state, leftist critique of the state and neoliberal governments has been taken into account by youth mobilizing around their schools and education policy and by enthusiastic crowds around electoral campaigns such as Luciana Genro's (2014) and Marcelo Freixo's (2016). The PT has found it hard to co-opt such 
experiences, and the rise in right-wing voices has not been enough to muffle the creative and diverse ways those politicized towards the left and/or leftist demands have found to mobilize.

It may be hard to reconcile the fact that the radical left has grown since June 2013 but rejection to it, based on an extrapolation of anti-leftism and ultra-politics, has grown also. At first glance, it seems contradictory to propose such a parallel of phenomena, but the content and arguments presented in this dissertation point to how it is possible to see indignation as a motor for politicization at the same time that indignation is also instrumentalized by the right, especially in the midst of an economic crisis. These counter-movements tend to cancel each other out, though leftist fragmentation and melancholia surrounding the PT make the playing field more advantageous to reactionary sectors. Depoliticization is still rampant, despite new opportunities in this conjuncture, because depoliticization through ultra-politics is being aggressively played to contain the more revolutionary excesses of energy of June 2013.

In revolutionary upheavals some energy - or rather some utopian dreams take place, they explode - and even if the actual result of a social upheaval is just a - commercialised every day life, this excess of energy, - what gets lost in the result, persists not in reality, but - as a dream haunting us waiting to be redeemed (Slavoj Žižek 2012).

In the meantime, the horizon for the radical left remains one of fragmentation: organizational fragmentation and fragmentation of consciousness. I anticipate that the elements analysed in this project may help the radical left to confront its own fragmentation more directly and that the call, made by the militants themselves, to return to base-building and careful approaches to politicization beyond the moderate $\mathrm{x}$ radical left split will be tended to with the gravity it requires. 


\section{Appendices}

\section{Appendix A: Political Organizations}

\begin{tabular}{|c|c|c|}
\hline Acronym & Portuguese & English (official or loose translation) \\
\hline APS & Ação Popular Socialista & Socialist Popular Action \\
\hline CLV & Coletivo Luta Vermelha & Red Struggle Collective \\
\hline CMI & Conselho Missionário Indigenista & Indigenous Missionary Council \\
\hline CMI & Corrente Marxista Internacional & International Marxist Tendency \\
\hline CPT & Comissão Pastoral da Terra & Pastoral Commission of the Land \\
\hline CS & Convergência Socialista & Socialist Convergence \\
\hline CSOL & Coletivo Socialismo e Liberdade & Socialism and Freedom Colletive \\
\hline $\begin{array}{l}\text { CSP- } \\
\text { Conlutas }\end{array}$ & Central Sindical e Popular Conlutas & $\begin{array}{l}\text { (Labour and Popular Central Union } \\
\text { Conlutas) }\end{array}$ \\
\hline CST & $\begin{array}{l}\text { Corrente Socialista dos } \\
\text { Trabalhadores }\end{array}$ & Socialist Workers' Current \\
\hline CTB & $\begin{array}{l}\text { Central dos Trabalhadores e } \\
\text { Trabalhadoras do Brasil }\end{array}$ & $\begin{array}{l}\text { Central of Male and Female Workers of } \\
\text { Brazil }\end{array}$ \\
\hline CUT & $\begin{array}{l}\text { Central Unificada dos } \\
\text { Trabalhadores }\end{array}$ & Unified Workers' Central \\
\hline DEM & Democratas & Democrats \\
\hline DS & Democracia Socialista & Socialist Democracy \\
\hline FBP & Frente Brasil Popular & Popular Brazil Front \\
\hline FIP & Frente Independente Popular & Independent Popular Front \\
\hline LITqi & $\begin{array}{l}\text { Liga Internacional dos } \\
\text { Trabalhadores - Quarta } \\
\text { Internacional }\end{array}$ & International Workers' League (IWLfi) \\
\hline LSR & Liberdade, Socialismo e Revolução & Freedom, Socialism and Revolution \\
\hline МAB & $\begin{array}{l}\text { Movimento dos Atingidos por } \\
\text { Barragens }\end{array}$ & Movement of People Affected by Dams \\
\hline MAIS & $\begin{array}{l}\text { Movimento por uma Alternativa } \\
\text { Independente Socialista }\end{array}$ & $\begin{array}{l}\text { Movement for an Independent Socialist } \\
\text { Alternative }\end{array}$ \\
\hline MBL & Movimento Brasil Livre & Free Brazil Movement \\
\hline MEPR & $\begin{array}{l}\text { Movimento Estudantil Popular } \\
\text { Revolucionário }\end{array}$ & $\begin{array}{l}\text { Popular Revolutionary Student } \\
\text { Movement }\end{array}$ \\
\hline MES & Movimento Esquerda Socialista & Socialist Left Movement \\
\hline MLB & $\begin{array}{l}\text { Movimento de Luta nos Bairros, } \\
\text { Vilas e Favelas }\end{array}$ & $\begin{array}{l}\text { Movement for the Struggle in the } \\
\text { Neighbourhoods, Villages and Slums }\end{array}$ \\
\hline MLP & Movimento Luta Popular & Popular Struggle Movement \\
\hline MML & Movimento Mulheres em Luta & Movement Women in Struggle \\
\hline MPL & Movimento Passe Livre & Free Pass Movement \\
\hline МPM & Movimento Popular por Moradia & Popular Movement for Housing \\
\hline MRP & Movimento Resistência Popular & Popular Resistance Movement \\
\hline
\end{tabular}




\begin{tabular}{|c|c|c|}
\hline MST & $\begin{array}{l}\text { Movimento dos Trabalhadores } \\
\text { Rurais Sem Terra }\end{array}$ & Landless Workers' Movement \\
\hline MTST & $\begin{array}{l}\text { Movimento dos Trabalhadores Sem } \\
\text { Teto }\end{array}$ & Homeless Workers' Movement \\
\hline PCB & Partido Comunista Brasileiro & Brazilian Communist Party \\
\hline PCdoB & Partido Comunista do Brasil & Communist Party of Brazil \\
\hline PCR & Partido Comunista Revolucionário & Revolutionary Communist Party \\
\hline PMDB & $\begin{array}{l}\text { Partido do Movimento } \\
\text { Democrático Brasileiro }\end{array}$ & Brazilian Democratic Movement Party \\
\hline PSB & Partido Socialista Brasileiro & Brazilian Socialist Party \\
\hline PSC & Partido Social Cristão & Social Christian Party \\
\hline PSDB & $\begin{array}{l}\text { Partido da Social Democracia } \\
\text { Brasileira }\end{array}$ & Brazilian Social Democracy Party \\
\hline PSM & Frente Povo Sem Medo & People without fear Front \\
\hline PSOL & Partido Socialismo e Liberdade & Party of Socialism and Freedom \\
\hline PSTU & $\begin{array}{l}\text { Partido Socialista dos } \\
\text { Trabalhadores Unificados }\end{array}$ & Unified Socialist Workers' Party \\
\hline & Partido dos Trabalhadores & Workers' Party \\
\hline PV & Partido Verde & Green Party \\
\hline RAIZ & RAiZ Movimento Cidadanista & (“Root” Citizenry Movement) \\
\hline REDE & Rede Sustentabilidade & (Sustainability Network) \\
\hline UGT & União Geral dos Trabalhadores & General Workers' Union \\
\hline UJC & União da Juventude Comunista & Communist Youth Union \\
\hline UJS & União da Juventude Socialista & Socialist Youth Union \\
\hline UNE & União Nacional dos Estudantes & National Student Union \\
\hline UP & Unidade Popular pelo Socialismo & Popular Unity for Socialism \\
\hline \multirow[t]{15}{*}{ US } & Unidade Socialista & Socialist Unity \\
\hline & Insurgência & Insurgency \\
\hline & Brigadas Populares & Popular Brigades \\
\hline & Consulta Popular & (Popular Consultation) \\
\hline & Enlace & (Link or Bond) \\
\hline & Esquerda Marxista & Marxist Left \\
\hline & Força Sindical & Syndical Strength \\
\hline & Intersindical & (Interunion) \\
\hline & Juntos & (Together) \\
\hline & Levante Popular da Juventude & Popular Youth Upsurge \\
\hline & O Trabalho & (The Labour) \\
\hline & Quarta Internacional & Fourth International \\
\hline & Rua Juventude Anticapitalista & ("Street” Anti-capitalist Youth) \\
\hline & Terra Livre & (Free Land) \\
\hline & Vem pra Rua & (Come to the streets) \\
\hline
\end{tabular}




\section{Appendix B: Other acronyms}

Acronym Portuguese

\begin{tabular}{l|l}
\hline APH & Assembleia Popular Horizontal \\
MCMV & Minha Casa Minha Vida \\
PAC & Programa de Aceleração do Crescimento \\
PROUNI & $\begin{array}{l}\text { Programa Universidade para Todos } \\
\text { Programa de Apoio a Planos de Expansão } \\
\text { e Reestruturação das Universidades } \\
\text { Federais } \\
\text { Sistema Único de Saúde }\end{array}$ \\
SUS & $\begin{array}{l}\text { Sista } \\
\text { REI }\end{array}$
\end{tabular}

English (Official or loose translation)

Horizontal Popular Assembly

My House My Life

Growth Acceleration Programme

University for All Programme

Programme for Restructuration and

Expansion of Federal University

Unified Health System 


\section{Appendix C: Chart of leftist organizations}

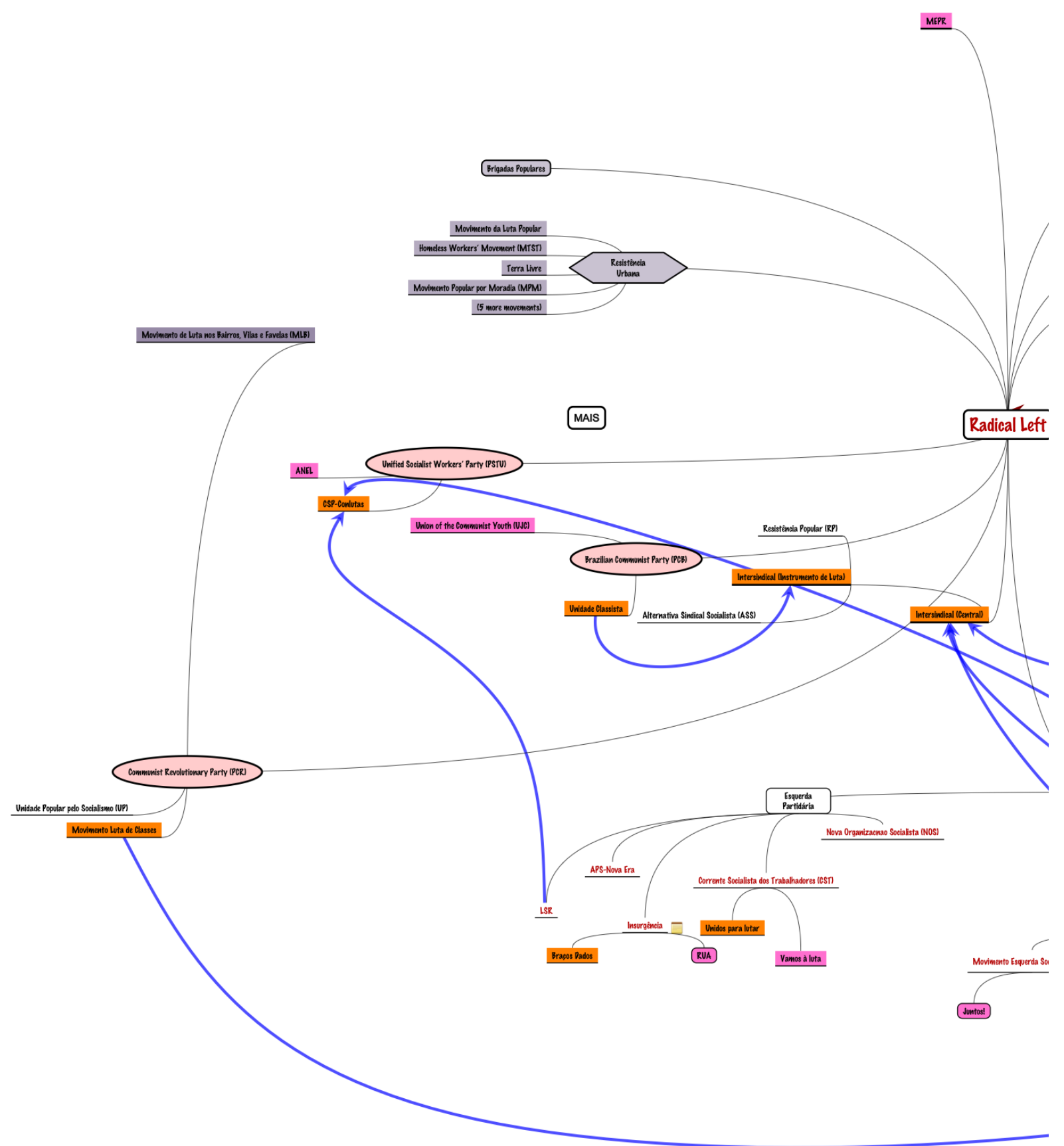




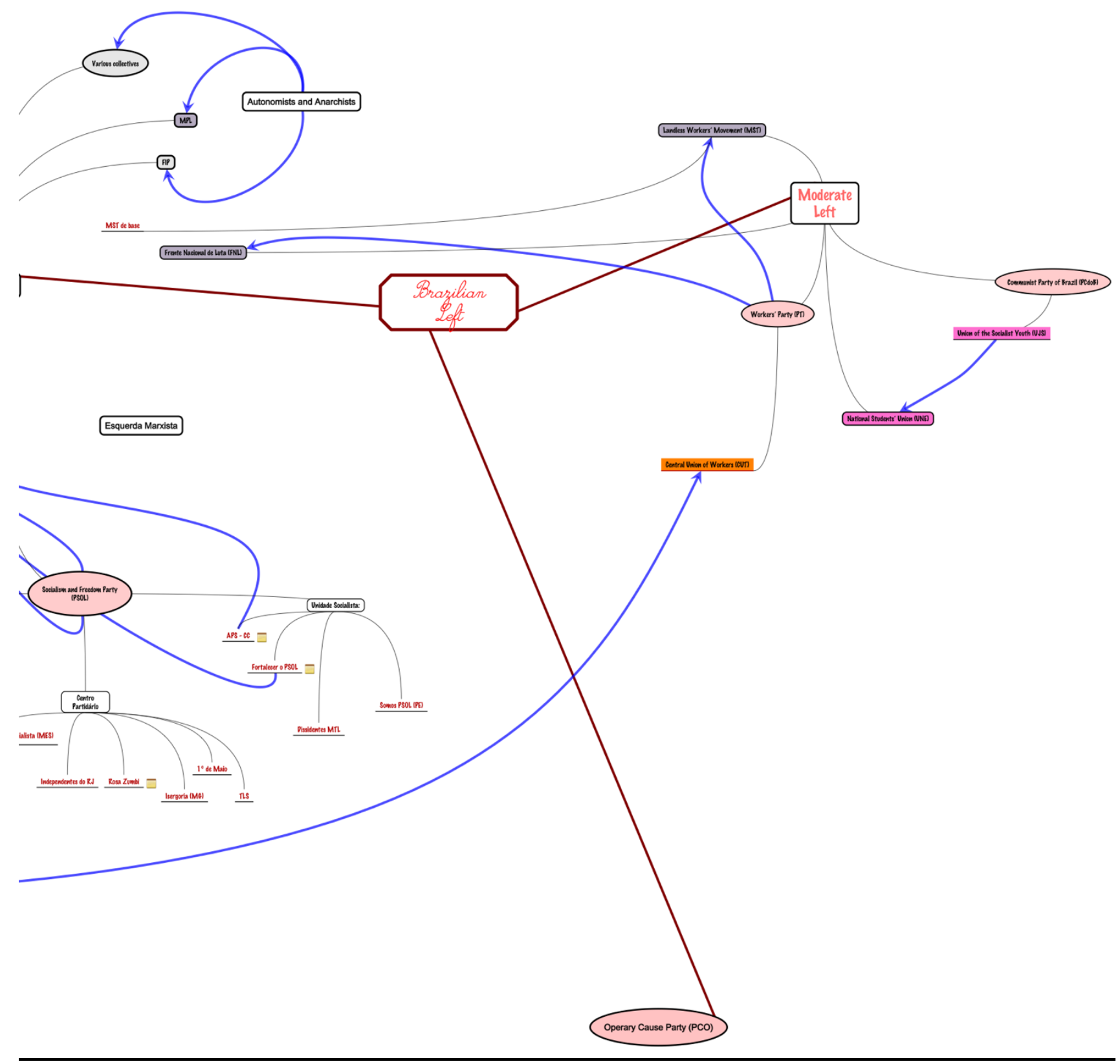




\section{Appendix D: Methodological considerations}

\section{Methodology and research design}

The participant observation method was ideal for this project because it blurred the line between researcher and research participant, which was necessary to get insights into the daily activities and strategic constructions of the Brazilian left. As a participant observer, I was in the privileged position of absorbing and analysing my surroundings and the individuals who inhabit these surroundings in the field, while becoming one of these individuals and actively interacting with the space and other actors. I was not a lead actor in the field, but I was given the opportunities to connect with those who are in more than a passive manner. These interactions were more horizontal in character and allowed me to perceive matters closer to the perspective of the research participant; directly and rapidly informing my inquiries in the field in a very reflexive way. While this research was conducted through ethnographic methods, I chose not to write an ethnography of the radical left. I opted instead to use the rich material gathered over two years to cross-examine other observations and published material of the left and analyse it theoretically according to insights gathered during the interviews.

In the 2014 portion of fieldwork, I used visual ethnography as a direct source of information through a theoretical analysis of the ethnographic material produced by myself during the fieldwork. It helped me to network and make important contacts for the 2015-2016 ethnographic portions of the fieldwork. My experience as a participant observer was recorded through notes, audio notes, and the production of photographs during the research experience. These photographs were of primary interest during activities of political contestation such as protests, and active organizational activities such as popular assemblies and general meetings. 
The importance of the photographs was also to provide a cohesive view of what activities were easily visible to the society in general (and the State), and what activities were constitutive of continuous organizing and pedagogical work by groups and individuals - revealing specific elements of political drive and praxis.

The principle of collaboration is dependent on a respectful relationship between the parties involved and the sharing of authority and input. The space of contestation that the case study of this dissertation explored required a thoughtful and trusting relationship between myself and the groups and actors identified as key to this study and in the Brazilian left. The ethnographic method was chosen to foster this trust in ways that simply pursuing interviews would not accomplish. The in-depth interviews followed the general interview guided approach, where a checklist is used to ensure relevant topics are covered even though the interviewer and interviewee will converse more informally (Berry, 1999). This informality was important to foster a levelled dialogue, where I could be perceived as a researcher with an academic goal but also as an active participant in society who shares many of the preoccupations voiced by the interviewed actors. The objective of these interviews was to elicit information on the importance placed on developing dialogue side-by-side with the accomplishment of particular demands, ideology and practices, and identify in what ways solidarity can be and has been a motivator in undertaking action (including whether it is ever considered in the context of reaching out to the middle class and the elites). The questions were presented in a way conducive to a reflexive environment, aiming to have the interviewees not only relate facts and experiences but also reflect critically upon them as we speak. As a result, my own reflexive position influenced the direction of the dialogue during the interviews. 


\section{The militant-researcher}

My challenge writing this dissertation in 2016 was to ensure that my initial optimism regarding the experiments in dialogue and joint action observed in many cities through strikes, occupations and collective resistance would not turn into resentment against those organizations that I followed closely and that insisted that the war was half-won, the Other is to blame for the crisis, and that the dialogue was a one-way road better understood as imposed vanguardist representation and dirigismo. I realized that the idea that our once shared optimism would lead the way as long as we framed events and political action as revolutionary enough was fine for agitation and propaganda, but was distant from a restored radical praxis that could penetrate the depoliticized minds and the low-level of societal class consciousness because it was still concentrated on a vanguard that represented only a fraction of its base and bore a consciousness drastically different from the depoliticized mass (including large portions of the disorganized working class). The forces that led to unity in the last 1970s towards the creation of the Workers' Party and managed to effectively represent and mobilize millions of people in a politicized way were not present this time and any idea of left re-composition depended on figuring out the extent of fragmentation and depoliticization in the way they interacted and reproduced a crisis of praxis in Brazil. I wanted to see change and speak of June 2013 with the same spark in my eyes and my research participants, but the more fragmentation I observed and the fewer commitments I saw to building real alliances beyond the idealistic view of leftist and socialist fronts promoted by every single organization, the more conscious I became that the optimism was acceptable in the space of political action and will, while it was fine for this dissertation to add the pessimism necessary to encourage thought towards self-critique and strategic renewal. This is the challenge of being an academic researcher, but also primarily, a 
militant activist in that same field of research. Doing so, I could work towards seeing both the good and the bad in June 2013 and look for ways to transcend it (not melancholically repeat it) in a renewed left praxis that tackled fragmentation and depoliticization seriously, in all their complexity.

When designing the methodology for this study, I was constantly worried about this double nature of being a militant-researcher. I took all precautions to ensure that previous affective ties to organizations and their militants would not cloud the development of the research nor shape the direction of interviews. Together with my committee, I determined that the relevance and performance of an organization in this difficult political conjuncture would be the primary guide for where I should focus my attention and energy. First, the choice of ethnography as a methodology allowed me this flexibility, but also required full reflexivity on my behalf. I was to exercise in self-criticism as much as I demanded the same from the left organizations with which I engaged. Interestingly, on the personal side, this academic selfcriticism led me to eventually sever ties or distance myself from organizations that I previously admired in some degree, and my own affinity became influenced by the methods of relevance and performance I had set previously. This is partly due to my growing practice alongside the organizations I deemed most coherent during this ultra-political, post-political conjuncture. While it meant more ethnographic material on these organizations, it also meant more scrutiny on them and the need to hold them to the high standards of the theory I was employing. Second, the ethnographic pursuit opened the doors to fact-checking and witness-bearing that was fundamental for filtering the content of interviews, public statements, and other positioning by each organization. This is important because whenever one is dealing with activism, one is also dealing with people's passions, convictions, and their own personal agitation and 
propaganda that could cloud self-critique and promote a defensive view of the organizations involved.

This led me to my second challenge as a militant-researcher, which relates to the ability to critique organizations I have come to know well while maintaining an amiable relationship with their militants. In a way, this was in itself an exercise in building dialogue in places where dialogue with outside views has not been the norm for a while. Apart from cases of clear sectarianism, leftist organizations respected outside views but engagement with them was normally done on a topical need-based basis. This is actually a common expression of fragmentation, since the survival of each organization in these circumstances depends on their own ability to formulate reality. On the other side, the Workers' Party had established the practice of dealing with internal dissidence with threats of expulsion and personal alienation, while other groups interpreted democratic centralism in ways that curtailed open debate in one aspect or another and made it difficult to connect to the new levels of spontaneity in politics expressed since June 2013. Too much theoretical intransigence and practical stubbornness got the remaining radical Left accustomed to schisms and fractions. It is always easy to set one apart and establish one's differences than to spend the time and effort in finding paths for new synthesis. This is not simply a personality or social matter, but also an issue of incoherent praxis, as most Marxist organizations should have been adopters of internal dialectics too whenever it came to disagreements over the conjuncture or even organizational events. The habit of schisms and fractions will be explored in-depth when I look at how such divides are present both among the various organizations in the left and inside them (e.g.: the degeneration of the right to tendency into a practice of internal fractions). 
While I am confident in my methodology inasmuch as it pertains to the researcher aspect of my militant-researcher praxis, and as to the product of research presented in this dissertation, it is harder to negotiate the impact of my critiques, observations, and analyses on my militant self and its relationship to other militants. I have been able, for example, to keep a critical stance of the organizations built by friends and family, with or without affinity ties, but my need for conveying these critiques, always with a constructive intent, has not always come without personal strain. If one thing is certain in a fragmented Left, it is that critiques are often read very defensively, since these organizations are used to criticizing each other in a predatory way designed to reassert their own positions and differences.

During the interviews, I identified as a militant-researcher, although I could tell that some interviewees saw me as either one or the other when we discussed the issues at hand. I made it clear that I was an independent researcher as well as an independent militant, which meant that I was not attached to any particular political organization in Brazil. This information was important to prevent distrust and defensiveness and encourage the participants to be open and receptive to the questions. In most of the occasions, the interview environment was amiable, led to fruitful conversations and produced what I consider to be answers as honest as the organizations' own confident matters allow. This honesty was more prominent in cases where I knew the interviewee from beforehand or engaged in activism alongside them. In other cases, there was still some distance and I witnessed arguments that would eventually be refuted by my own ethnographic research with/on the organization. All in all, I finished the cycle of interviews feeling indebtedness to the commitment of the participants, which I valued highly considering the pervasiveness of distrust in the Brazilian left for the past years. It is not uncommon for organizations to share information or organize together (for protests, 
occupations, topical alliances, etc) with some degree of bad faith (as survivalism can also turn predatory), which was not the case during this study.

This indebtedness and my own commitment to the formation of syntheses in the radical left, for the continuous development of this Left in relation to building a communist horizon in Brazil, demands this disclosure and reaffirmation that all critiques provided in this study were put forward thoughtfully and in no way convey direct criticism of the participants and their own activism (which I personally hold in high regard for all of them). To this matter, the analyses presented on depoliticization and fragmentation were born out of the desire to expose problems so they can be solved by the formation of syntheses, for the good of the revolutionary prospects in Brazil, and in hopes that our activism will merge more permanently in the future through fruitful dialogical alliances and left re-composition. 


\section{Bibliography}

Acioli, Patrícia. (2008). Aldo quer PMDB para formar '3a via"na capital. Diário Comércio Indústria e Serviços.

Almeida, Eduardo. (2014, January 2). As polêmicas surgidas em 2013 | PSTU. PSTU. Retrieved from http://www.pstu.org.br/node/20231

Almeida, Gelsom Rozentino De. (2007). O governo Lula, o Fórum Nacional do Trabalho e a reforma sindical. Revista Katálysis, 10(1), 54-64. doi:10.1590/S141449802007000100007

Almeida, José Maria de. (2015, April 27). Interview by Sabrina Fernandes. São Paulo.

Anderson, Kevin. (1986). Sources of Marxist Humanism: Fanon, Kosik, Dunayevskaya. Quarterly Journal of Ideology, 10(4), 15-29.

Anderson, Kevin B., \& Rockwell, Russell (Eds.). (2012). The Dunayevskaya-Marcuse-Fromm Correspondence, 1954-1978: Dialogues on Hegel, Marx, and Critical Theory. Lexington Books.

Anselmo, Júlio. (2016, January 15). Sobre as lições de junho de 2013 e as lutas em 2016 | PSTU. PSTU. Rio de Janeiro. Retrieved from http://www.pstu.org.br/node/21891

Antunes, Ricardo. (2006). Uma esquerda fora do lugar: o governo Lula e os descaminhos do PT. Campinas: Autores Associados.

Antunes, Ricardo. (2013). Trade Unions, Social Conflict, and the Political Left in Present-Day Brazil. In J. R. Webber \& B. Carr (Eds.), The New Latin American Left: cracks in the 
empire. Lanham: Rowman \& Littlefield Publishers.

APS. (2004). Manifesto de Fundação da Ação Popular Socialista. In $1^{\circ}$ Encontro Nacional. Brasília.

APS. (2012). Comunicado Do V Enaps Aos Militantes Da Aps, Sobre O Processo De Ruptura Da Nossa Corrente. V Encontro Nacional Da Ação Popualr Socialista.

Arcary, Valerio. (2016). “Acabou o amor”: a ruína do lulismo e os dilemas da oposição de esquerda. In F. Demier \& R. Hoeveler (Eds.), A Onda Conservadora. Rio de Janeiro: Mauad.

Badiou, Alain. (2010). The Communist Hypothesis. London: Verso.

Balaban, Oded. (1990). Praxis and Poesis in Aristotle's practical philosophy. The Journal of Value Inquiry, 24(3), 185-198. doi:10.1007/BF00149432

Baldini, Leandro. (2016, July 4). Dilma foi a pior em reforma agrária, diz Stédile. Diário do Grande $A B C$.

Barone, Luís Antonio. (2011). O MST frente ao campo político institucional do início do século XXI. REDD - Revista Espaço de Diálogo e Desconexão, 3(2).

Basso, Jussara. (2015, April 18). Interview by Sabrina Fernandes. São Paulo.

Batista, Vera. (2016). Aferição das centrais sindicais. Correio Braziliense, 28, 15-16. Retrieved from http://blogs.correiobraziliense.com.br/servidor/afericao-das-centraissindicais/

Belchior, Douglas. (2015, April 15). Interview by Sabrina Fernandes. São Paulo. 
Benjamin, Walter. (1974). Left-Wing Melancholy. Screen, 15(2).

Bensaïd, Daniel. (2004). Alain Badiou and the Miracle of the Event. In P. Hallward (Ed.), Think Again, Alain Badiou and the Future of Philosophy. London: Continuum.

Bensaïd, Daniel. (2005). On a Recent Book by John Holloway. Historical Materialism, 13(4), $169-192$.

Berry, Rita S. Y. (1999). Collecting data by in-depth interviewing. In British Educational Research Association Annual Conference (pp. 1-12). Conference paper, Brighton.

Bianchi, Alvaro. (2016). A guerra que estamos perdendo. In F. Demier \& R. Hoeveler (Eds.), A Onda Conservadora. Rio de Janeiro: Mauad.

Bloch, Ernst. (2000). The spirit of Utopia. Stanford: Stanford University Press.

Boito, Armando, \& Marcelino, Paula. (2011). Decline in Unionism?: An Analysis of the New Wave of Strikes in Brazil. Latin American Perspectives, 38(5), 62-73. doi:10.1177/0094582X11408560

Bosteels, Bruno. (2005). The Speculative Left. The South Atlantic Quaterly, 104(4), 751-767.

Boulos, Guilherme. (2015a). De que lado você está? São Paulo: Boitempo Editorial.

Boulos, Guilherme. (2015b, April 19). Interview by Sabrina Fernandes. São Paulo.

Braga, Ruy. (2015, April 6). Interview by Sabrina Fernandes. São Paulo.

Braga, Ruy. (2016). A era da pilhagem. In F. Demier \& R. Hoeveler (Eds.), A Onda Conservadora. Rio de Janeiro: Mauad. 
Branford, Sue, \& Rocha, Jan. (2001). Cutting the Wire : the landless movement of Brazil. In Notes from Nowhere (Ed.), We are everywhere: the irresistible rise of global anticapitalism.

Brasil 24/7. (2014, March 24). CUT sai às ruas para defender a Copa no Brasil. Brasil 24/7. Retrieved from http:/www.brasil247.com/pt/247/brasil/134194/CUT-sai-às-ruas-paradefender-a-Copa-no-Brasil.htm

Brigadas Populares. (2011). Manifesto das novas Brigadas Populares, 14-16. Retrieved from http://brigadaspopulares.org.br/?page_id=16

Brigadas Populares. (2015). Por uma nova maioria política para o Brasil e a frente necessária. Retrieved July 3, 2016, from http://brigadaspopulares.org.br/?p=1650

Brown, Wendy. (1995). States of Injury: Power and Freedom in Late Modernity. Princeton: Princeton University Press.

Brown, Wendy. (1999). Resisting Left Melancholy. boundary 2, 26(3), 19-27.

Brysk, Alison. (2013). Speaking Rights to Power: Constructing Political Will. New York: Oxford University Press. Retrieved from http://books.google.com/books?hl=pt$\mathrm{BR} \& 1 \mathrm{r}=\& \mathrm{id}=4 \mathrm{Hdj} 7 \mathrm{YVYZC0C} \&$ pgis $=1$

Caldeira, Rute. (2008). "My land, your social transformation": Conflicts within the landless people movement (MST), Rio de Janeiro, Brazil. Journal of Rural Studies, 24(2), 150160. doi:10.1016/j.jrurstud.2007.12.001

Campos, Carlos Roberto. (2015, June 13). Interview by Sabrina Fernandes. Belo Horizonte. 
Candeias, Mario. (2010). From a fragmented left to mosaic. Luxemburg, 3(1), 2-15.

Capital, Carta. (2015, June). Publicidade federal: Globo recebeu R \$ 6,2 bilhões dos governos Lula D Dilma. Carta Capital. Retrieved from http://www.cartacapital.com.br/blogs/midiatico/emissoras-de-tv-receberam-mais-de-r10-8-bilhoes-publicidade-federal-7609.html

Carneiro, Henrique. (2015, April 20). Interview by Sabrina Fernandes. São Paulo.

Carvalho, Guilherme. (2014). Labor transformation in Brazil and in CWU leaders 'profile *. Revista Ciências do Trabalho, 2, 41-59.

Chambers, S. a. (2011). Jacques Ranciere and the problem of pure politics. European Journal of Political Theory, 10(3), 303-326. doi:10.1177/1474885111406386

Chaú, Marilena, Boff, Leonardo, Stedile, João Pedro, Santos, Wanderley Guilherme dos, \& Guimarães, Juarez. (2006). Leituras da Crise: diálogos sobre o PT, a democracia brasileira e o socialismo. São Paulo: Editora Fundação Perseu Abramo.

Chaú, Marilena, \& Nogueira, Marco Aurélio. (2007). O pensamento político e a redemocratização do Brasil. Lua Nova, 71, 173-228.

Claessens, Stijn, Feijen, Erik, \& Laeven, Luc. (2008). Political connections and preferential access to finance: The role of campaign contributions. Journal of Financial Economics, 88(3), 554-580. doi:10.1016/j.jfineco.2006.11.003

Consolação, Maria da. (2015, June 13). Interview by Sabrina Fernandes. Belo Horizonte.

Consulta Popular. (2004). Refundar a esquerda para refundar o Brasil. São Paulo. Retrieved 
from http://www.consultapopular.org.br/sites/default/files/Refundar a esquerda para refundar o Brasil.doc

Correio do Povo. (2015, March 27). Cpers aprova desfiliação da CUT e garante greve se salários forem parcelados. Correio do Povo. Retrieved from http://www.correiodopovo.com.br/Noticias/Geral/2015/3/552452/Cpers-aprovadesfiliacao-da-CUT-e-garante-greve-se-salarios-forem-parcelados

Coutinho, Carlos Nelson. (2009). O conceito de vontade coletiva em Gramsci. Revista Katálysis, 12(1), 32-40.

Coutinho, Carlos Nelson. (2012). Gramsci’s Political Thought. Leiden: Brill.

CPT. (2009). Tabela 13 - Violência contra a pessoa - 2008/2009, 277. Retrieved from http://www.cptnacional.org.br/index.php?option=com_jdownloads\&Itemid=23\&view=f inish $\&$ cid $=146 \&$ catid $=16$

CPT. (2015). Conflitos no Campo Brasil 2015. (A. Canuto, C. R. da S. Luz, \& I. Wichinieski, Eds.). São Paulo: CPT Nacional. doi:10.1017/CBO9781107415324.004

CUT. (2015, November 20). Sindicato e Ministério ampliam divulgação do Programa de Proteção ao Emprego - CUT - Central Única dos Trabalhadores. Retrieved from http://www.cut.org.br/noticias/sindicato-e-ministerio-ampliam-divulgacao-doprograma-de-protecao-ao-emprego-e 57a/

Dean, Jodi. (2005). Žižek against Democracy. Law, Culture and the Humanities, 1(2), 154177. doi:10.1191/1743872105lw012oa

Dean, Jodi. (2009a). Politics without Politics. Parallax, 15(3), 20-36. 
doi:10.1080/13534640902982579

Dean, Jodi. (2009b). Democracy and Other Neoliberal Fantasies: communicative capitalism and Left politics. Durham: Duke University Press.

Dean, Jodi. (2012). The Communist Horizon. London: Verso.

Demier, Felipe. (2016a). A revolta a favor da ordem: a ofensiva da oposição de direita. In F. Demier \& R. Hoeveler (Eds.), A Onda Conservadora. Rio de Janeiro: Mauad.

Demier, Felipe. (2016b). Introdução: O barulho dos inocentes: a revolta dos "homens de bem." In F. Demier \& R. Hoeveler (Eds.), A Onda Conservadora. Rio de Janeiro: Mauad.

Dezorzi, Caio. (2015, April 24). Interview by Sabrina Fernandes. São Paulo.

Drummond, Nathalie. (2015, May 26). Interview by Sabrina Fernandes. Rio de Janeiro.

Dunayevskaya, Raya. (2000). Marxism and freedom: from 1776 until today. Amherst: Humanity Books.

Dunne, Joseph. (1993). Theory, Techne, and Phronesis: distinctions and relations. In Back to the Rough Ground: "Phronesis" and "Techne" in Modern Philosophy and in Aristotle. Notre Dame and London: University of Notre Dame Press.

Duquette, Michel, Galdino, Maurilio, Levy, Charmain, Marques-Pereira, Bérengère, \& Raes, Florence. (2005). Collective Action at the Crossroads: The Empowerment of the Left. In M. Duquette, M. Galdino, C. Levy, B. Marques-Pereira, \& F. Raes (Eds.), Collective Action and Radicalism in Brazil (pp. 156-205). Toronto: University of Toronto Press.

Dutra, Israel. (2015, April 11). Interview by Sabrina Fernandes. São Paulo. 
É preciso arrancar alegria ao futuro. (2016). É preciso arrancar alegria ao futuro Manifesto. Retrieved from http://alegriaaofuturo.com.br/wp-content/uploads/2016/07/manifestoA3b.pdf

Epstein, Barbara. (1997). Postmodernism and the Left. New Politics, 6(2).

Epstein, Barbara. (2013). The Rise, Decline and Possible Revival of Socialist Humanism. In 10th Annual Historical Materialism Conference. DRAFT (cited with author's permission), London.

Esquerda Diário. (2015, July 20). Congresso do MRT aprova proposta de entrada no PSOL. Esquerda Diário. Retrieved from http://www.esquerdadiario.com.br/Congresso-doMRT-aprova-proposta-de-entrada-no-PSOL

Fanon, Frantz. (2004). The Wretched of the Earth. New York: Grove Press.

Farias, Wagner. (2015, April 8). Interview by Sabrina Fernandes. São Paulo.

Feenberg, Andrew. (2014). The Philosophy of Praxis: Marx, Lukács, and the Frankfurt School. London: Verso.

Félix Sánchez, Neto, João Machado Borges, \& Marques, Rosa Maria. (2008). Brazil. Lula’s government: a critical appraisal. In P. Barrett, D. Chavez, \& C. Rodríguez-Garavito (Eds.), The New Latin American Left: utopia reborn (pp. 42-68). London: Pluto Press.

Fernandes, Sabrina. (2014). Fieldwork sources.

Fernandes, Sabrina. (2015). Fieldwork sources.

Fernandes, Sabrina. (2016). Fieldwork sources. 
Fiennes, Sophie. (2012). The pervert's guide to ideology. United Kingdom: P Guide Productions and Zeitgeist Films.

Freire, Paulo. (1970). Pedagogy of the Oppressed. New York: The Seabury Press.

Freire, Paulo. (2005). Pedagogia do Oprimido (49th print.). Rio de Janeiro: Paz e Terra.

Freire, Paulo. (2010). Educação como prática da liberdade. São Paulo: Paz e Terra.

Fromm, Erich (Ed.). (1966a). Socialist humanism: an international symposium. Garden City: Anchor Books.

Fromm, Erich. (1966b). Preface. In E. Fromm (Ed.), Socialist humanism: an international symposium (pp. vii-xiii). Garden City: Anchor Books.

Fromm, Erich. (2011). Marx's concept of man. Mansfield Centre: Martino Publishing.

G1. (2013). Veja pesquisa completa do Ibope sobre os manifestantes. G1 Brasil. São Paulo. Retrieved from http://g1.globo.com/brasil/noticia/2013/06/veja-integra-da-pesquisa-doibope-sobre-os-manifestantes.html

Gajanigo, Paulo. (2016). Junho como enigma, ainda | Blog Junho. Blog Junho. Retrieved from http://blogjunho.com.br/junho-como-enigma-ainda/

Garcia, Cyro. (2015, May 28). Interview by Sabrina Fernandes. Rio de Janeiro.

Genro, Luciana. (2015, April 29). Interview by Sabrina Fernandes. São Paulo.

Gibson-Graham, J. K. (2003). An ethics of the local. Rethinking Marxism: A Journal of Economics, Culture \& Society, 15(1), 49-74. doi:10.1080/0893569032000063583 
Gibson-Graham, J. K. (2006). Introduction: a politics of economic possibility. In Postcapitalist Politics (pp. xix-xxxvii). Minneapolis: University of Minessota Press.

Giva, Givanildo. (2015, April 7). Interview by Sabrina Fernandes. São Paulo.

Goulart, Serge. (2012, October 22). PSOL e PSTU, esquerdismo, oportunismo e capitulação à \begin{tabular}{l|lll} 
burguesia & Esquerda & Marxista. & Retrieved
\end{tabular} http://www.marxismo.org.br/content/psol-e-pstu-esquerdismo-oportunismo-ecapitulacao-burguesia

Gramsci, Antonio. (1971). Selections from the Prison Notebooks of Antonio Gramsci. New York: International Publishers. doi:10.1080/10286630902971603

Gramsci, Antonio. (1999). Selections From the Prison Notebooks of Antonio Gramsci. Elec Book, 73(3), 453. doi:10.2307/479844

Gramsci, Antonio. (2000). The Antonio Gramsci reader: selected writings, 1916-1935. (D. Forgacs, Ed.). New York: New York University Press.

Gramsci, Antonio. (2007a). The Modern Prince \& other writings. New York: International Publishers.

Gramsci, Antonio. (2007b). Prison Notebooks: Volume III. (J. A. Buttigieg, Ed. \& Trans.). New York: Columbia University Press.

Gross, Jacob P. K. (2011). Education and hegemony: the influence of Antonio Gramsci. In B. Levinson (Ed.), Beyond critique: exploring critical social theories and education. Boulder: Paradigm Publishers. 
Guimarães, Juarez. (1990). A estratégia da pinça | Teoria e Debate. Teoria e Debate, 12. Retrieved from http://www.teoriaedebate.org.br/materias/politica/estrategia-dapinca?page $=$ full

Harvey, David. (2000). Spaces of Hope. Berkeley: University of California Press.

Harvey, David. (2012). Rebel Cities: From the Right to the City to the Urban Revolution. New York: Verso.

Hesketh, Chris, \& Morton, Adam David. (2014). Spaces of Uneven Development and Class Struggle in Bolivia: Transformation or Trasformismo ? Antipode, 46(1), 149-169. doi:10.1111/anti.12038

Holloway, John. (2002). Change the World Without Taking Power (Vol. 0). London: Pluto Press.

Holst, John D. (2002). Social Movements, Civil Society, and Radical Adult Education (1st ed.). Westport: Bergin \& Garvey.

Iasi, Mauro. (2015, May 25). Interview by Sabrina Fernandes. Rio de Janeiro.

IBGE. (2016, March 3). Em 2015, PIB cai 3,8\% e totaliza R\$ 5,9 trilhões. Sala de Imprensa $\begin{array}{lll}\text { IBGE. } & \text { Retrieved } & \text { from }\end{array}$ http://saladeimprensa.ibge.gov.br/noticias.html?view=noticia\&id=1\&idnoticia=3111\&b usca $=1 \& \mathrm{t}=2015$-pib-cai-3-8-totaliza-r-5-9-trilhoes

Iglesias, Pablo. (2015). Politics in a Time of Crisis: Podemos and the Future of Democracy in Europe. London: Verso. 
Índio, Edson. (2015, April 28). Interview by Sabrina Fernandes. São Paulo.

Jay, Martin. (1984). Marxism and Totality: The Adventures of a Concept from Lukacs to Habermas. Berkeley and Los Angeles: University of California Press.

Karepovs, Daniel, \& Leal, Murilo. (2007). Os trotskismos no Brasil: 1966-2000. In M. Ridenti \& D. A. Reis (Eds.), História do Marxismo no Brasil (v. 6) (pp. 153-237). Campinas: Editora da Unicamp.

Katz, Claudio. (2013). Socialist Strategies in Latin America. In J. R. Webber \& B. Carr (Eds.), The New Latin American Left: cracks in the empire. Lanham: Rowman \& Littlefield Publishers.

Kolakowski, Leszlek. (1968). Toward a Marxist Humanism. New York: Grove Press.

Kosik, Karel. (1976). Dialectics of the concrete: A study on problems of man and world. Boston: D. Reidel Publishing Company.

Laclau, Ernesto, \& Mouffe, Chantal. (2001). Hegemony and Socialist Strategy: Towards a Radical democratic Politics (2nd ed.). New York: Verso.

Ladosky, Mario Henrique. (2014). CUT and Corporatism in Brazi. Revista Ciências do Trabalho, No. 3(december), 109-137.

Ledwith, Margaret. (2001). Community work as critical pedagogy: re-envisioning Freire and Gramsci. Community Development Journal, 36(3), 171-182.

Lukács, Georg. (1971). History and class consciousness: studies in Marxist dialectics. Cambridge, Mass: MIT Press. 
Machado, João. (2015, April 9). Interview by Sabrina Fernandes. São Paulo.

Madeira, Rafael. (2015, March 26). Interview by Sabrina Fernandes. Brasília.

Marcuse, Herbert. (1941). Reason and revolution: Hegel and the rise of social theory. New York: Oxford University Press.

Marcuse, Herbert. (1966). Socialist Humanism? In E. Fromm (Ed.), Socialist humanism: an international symposium (pp. 107-117). Garden City: Anchor Books.

Marcuse, Herbert. (1973a). The foundation of historical materialism. In Studies in Critical Philosophy. Boston: Beacon Press.

Marcuse, Herbert. (1973b). On the philosophical foundation of the concept of labor in Economics. Telos, 16, 9-37.

Marcuse, Herbert. (1991). One-dimensional Man. Boston: Beacon Press.

Martinez, Paulo Henrique. (2007). O Partido dos Trabalhadores ea conquista do Estado: 19802005. In M. Ridenti \& D. A. Reis (Eds.), História do Marxismo no Brasil (v. 6) (pp. 239289). Campinas: Editora da Unicamp.

Marx, Karl. (1973). Grundrisse. Middlesex: Penguin Books.

Marx, Karl. (1981). Capital: Volume III. London: Penguin Books.

Marx, Karl. (1994). Theses on Feuerbach. In Selected writings. Hackett Publishing Company.

Marx, Karl. (2007). Economic and Philosophic Manuscripts of 1844. (T. B. Bottomore, Trans., E. Fromm, Ed.)Marx's concept of man. Mansfield Centre: Martino Publishing. 
Marx, Karl, \& Engels, Friedrich. (1998). The German Ideology. Amherst: Prometheus Books.

Mattos, Marcelo Badaró. (2016). De junho de 2013 a junho de 2015: elementos para uma análise da (crítica) conjuntura brasileira. In F. Demier \& R. Hoeveler (Eds.), A Onda Conservadora. Rio de Janeiro: Mauad.

Mayer, Joviano. (2015, June 15). Interview by Sabrina Fernandes. Belo Horizonte.

Mayo, Peter. (1996). Transformative adult education in an age of globalization: A GramscianFreirean synthesis and beyond. The Alberta Journal of Educational Research, 42, 148160.

Mayo, Peter. (2010). Antonio Gramsci and his Relevance to the Education of Adults. In P. Mayo (Ed.), Gramsci and Educational Thought (pp. 21-37). West Sussex: WileyBlackwell.

Mclaren, Peter, \& Jaramillo, Nathalia E. (2007). Pedagogy and Praxis in the Age of Empire: Towards a New Humanism. Rotterdam: Sense Publishers.

Melito, Leandro. (2016, May 24). Eduardo Bolsonaro apresenta projeto que criminaliza $\begin{array}{llll}\text { comunismo. } & \text { Portal } & \text { EBC } & \text { Retrieved }\end{array}$ http://www.ebc.com.br/noticias/politica/2016/05/eduardo-bolsonaro-apresenta-projetode-lei-que-criminaliza-apologia-ao

Melo, Demian. (2015, October). "Escola sem partido" ou escola com "partido único”? Blog Junho. Retrieved from http://blogjunho.com.br/escola-sem-partido-ou-escola-compartido-unico/

Melo, Demian. (2016a). A direita ganha as ruas: elementos para um estudo das raízes 
ideológicas da direita brasileira. In F. Demier \& R. Hoeveler (Eds.), A Onda Conservadora. Rio de Janeiro: Mauad.

Melo, Demian. (2016b, January). Para além da marolinha: a crise e a onda conservadora no Brasil. Blog Junho. Retrieved from http://blogjunho.com.br/para-alem-da-marolinha-acrise-e-a-onda-conservadora-no-brasil/

MES. (2016). Que o povo decida! Fora Temer e eleições gerais para apontar saídas à crise política! Retrieved from http://esquerdasocialista.com.br/que-o-povo-decida-fora-temere-eleicoes-gerais-para-apontar-saidas-crise-politica/

Meszaros, George. (2000). Taking the Land into Their Hands: The Landless Workers , Movement and the Brazilian State. Journal of Law and Society, 27(4), 517-541.

Miranda, JC. (2015, April 10). Interview by Sabrina Fernandes. São Paulo.

Mohr, Rodolfo. (2015, July 10). Interview by Sabrina Fernandes. Brasília.

Morais, Lecio, \& Saad-Filho, Alfredo. (2005). Lula and the Continuity of Neoliberalism in Brazil: Strategic Choice, Economic Imperative or Political Schizophrenia ? Historical Materialism, 13(1), 3-32.

Morais, Lécio, \& Saad-Filho, Alfredo. (2011). Da economia política à política econômica: o novo-desenvolvimentismo e o governo Lula. Revista de Economia Politica, 4(124), 507527. doi:10.1590/S0101-31572011000400001

Moreno, Nahuel. (2003). El partido y la revolución.

Mouffe, Chantal. (2013). Agonistics: Thinking the world politically. London: Verso. 
Moura, Pablo Thiago Correira de. (2011). As razões da esquerda radical - PCB, PSTU e PSOL: Estrutura organizativa e objetivos políticos. Universidade Federal do Rio Grande do Norte, Natal.

MTST. (2012, July 14). Carta do MTST de saída da CSP-Conlutas «PARTIDO SOCIALISMO E LIBERDADE. Rio de Janeiro. Retrieved from http://psol50sp.org.br/blog/2012/07/15/carta-do-mtst-de-saida-da-csp-conlutas/

Nascimento, Simone, Constantino, Mário, \& Bruner, Felipe. (2015, April 21). Interview by Sabrina Fernandes. São Paulo.

Nuzzi, Vitor. (2014, February 6). Líder do MST considera "erro político" fazer mobilização durante a Copa - Rede Brasil Atual. Rede Brasil Atual. Retrieved from http://www.redebrasilatual.com.br/politica/2014/02/lider-do-mst-considera-erropolitico-fazer-mobilizacao-durante-a-copa-3939.html

Paipais, Vassilios. (2014). Between Politics and the Political: Reading Hans J. Morgenthau's Double Critique of Depoliticisation. Millennium, 42(2), 354-375. doi:10.1177/0305829813515040

Paulson, Justin. (2010). The Uneven Development of Radical Imagination. Affinities: A Journal of Radical Theory, Culture, and Action, 4(2), 33-38.

Paulson, Justin, \& Schein, Rebecca. (2012). Justin Paulson and Rebecca Schein's Response to “The Left After Politics.” Studies in Political Economy, 89, 131-137.

PCB. (n.d.). A Estratégia e a Tática do PCB. Retrieved March 23, 2014, from http://pcb.org.br/portal/docs/estrategia.pdf 
PCB. (2014). Breve histórico do PCB. Retrieved from http://pcb.org.br/portal/docs/historia.pdf

PCR. (2016). História - Partido Comunista Revolucionário - PCR. Retrieved May 9, 2016, from http://pcrbrasil.org/pcr/historia/

Peron, Isadora. (2013). Lula diz que financiamento privado na eleição deveria ser "crime inafiançável” - politica - versaoimpressa - Estadão. Estadão. São Paulo. Retrieved from http://www.estadao.com.br/noticias/impresso,lula-diz-que-financiamento-privado-naeleicao-deveria-ser-crime-inafiancavel,1013706,0.htm

Petras, James. (2005). Brasil e Lula: Ano Zero. (A. Piasecka-Till, Trans.). Blumenau: Edifurb.

Pinto, Rodrigo Sampaio, \& Sales, Jean Rodrigues. (2002). O PCdoB no primeiro Governo Lula: Considerações das lideranças partidárias. In Anais do XV Encontro Regional de História da ANPUH-RIO (pp. 1-18).

Piza, Paulo Toledo, Paulo, Paula Paiva, Araújo, Glauco, \& Domingos, Roney. (2016, March 18). Manifestação de apoio ao governo federal fecha Avenida Paulista, em SP. G1 São Paulo. Retrieved from http:/g1.globo.com/sao-paulo/noticia/2016/03/manifestacao-deapoio-ao-governo-federal-fecha-avenida-paulista-em-sp.html

Prazeres, Altino. (2015, April 13). Interview by Sabrina Fernandes. São Paulo.

Prevost, Gary, Vanden, Harry E., \& Campos, Carlos Oliva. (2012). Social Movements and Leftist Governments in Latin America: Confrontation or Co-option? New York: Zed Books.

PSOL. (n.d.). PSOL 50 | Programa. Retrieved March 23, 2014, from http://www.psol50.org.br/site/paginas/2/programa 
PSTU. (n.d.). Partido | www.pstu.org.br. Retrieved March 23, 2014, from http://www.pstu.org.br/partido

PSTU. (2016, July 6). Declaração da Direção Nacional do PSTU. Facebook. Retrieved from https://www.facebook.com/notes/pstu-nacional/declaração-da-direção-nacional-dopstu/1046762125414417

Publications, Sage. (2010). The MST Challenge to Neoliberalism, 27(5), 33-45.

Rabelo, Renato. (2003, June 5). Previdência: o voto do PCdoB na CCJ. ADITAL. Retrieved from http://www.adital.com.br/site/noticia2.asp?lang=PT\&cod=7384

Ramos, Érica. (2015, April 2). Interview by Sabrina Fernandes. Brasília.

Reis, Daniel Aarão. (2007). Marxismo, sociedade e partidos políticos hoje. In M. Ridenti \& D. A. Reis (Eds.), História do Marxismo no Brasil (v. 6) (pp. 439-461). Campinas: Editora da Unicamp.

Ricci, Rudá. (2006). Lulismo: três discursos e um estilo*. Lutas Sociais, 15/16, 171-183.

Ricci, Rudá. (2013). Lulismo. Brasília: Contraponto.

Ricci, Rudá. (2015, January 5). As origens das tendências do PT. Blog do Rudá. Retrieved from http://www.rudaricci.com.br/origens-das-tendencias-pt/

Ricci, Rudá, \& Arley, Patrick. (2014). Nas Ruas: a outra política que emergiu em junho de 2013. (E. Letramento, Ed.). Belo Horizonte.

Ridenti, Marcelo. (2013). Política pra quê? (1st digita.). São Paulo: Editora Atual. 
Rolnik, Raquel. (2013). Apresentação: As vozes das ruas: as revoltas de junho e suas interpretações. In Boitempo Editorial \& Carta Maior (Eds.), Cidades Rebeldes: Passe Livre e as manifestações que tomaram as ruas do Brasil (p. epub). São Paulo: Boitempo Editorial.

Roseno, Renato. (2016). Iniciativas - Renato Roseno. Retrieved May 2, 2016, from http://www.renatoroseno.com.br/iniciativas

Saad-Filho, Alfredo. (2013). Mass Protests under "Left Neoliberalism": Brazil, June-July 2013. Critical Sociology, 39(5), 657-669. doi:10.1177/0896920513501906

Saad-Filho, Alfredo, \& Boito, Armando. (2015). Brazil: The failure of the PT and the rise of the "new right." Socialist Register, 52(52), 213-230.

Saad-Filho, Alfredo, \& Morais, Lecio. (2014). Mass protests: Brazilian spring or Brazilian malaise? Socialist Register, 50, 227-246.

Saccarelli, Emanuele. (2008). Gramsci and Trotsky in the Shadow of Stalinism. The Political Theory and Practice of Opposition. doi:10.4324/9780203929735

Safatle, Vladimir. (2012). A esquerda que não teme dizer seu nome. São Paulo: Três Estrelas.

Safatle, Vladimir. (2015, December 25). A falsa onda conservadora. Folha de São Paulo. Retrieved from http://www1.folha.uol.com.br/colunas/vladimirsafatle/2015/12/1722920a-falsa-onda-conservadora.shtml

Sakamoto, Leonardo. (2013). Em São Paulo, o Facebook e o Twitter foram às ruas. In Boitempo Editorial \& Carta Maior (Eds.), Cidades rebeldes: Passe livre e as manifestações que tomaram as ruas do Brasil (p. epub). São Paulo: Boitempo Editorial. 
Samuels, David. (2001). Money, Elections, and Democracy in Brazil. Latin American Politics and Society, 43(2), 27-48.

Sánchez, Félix, Neto, João Machado Borges, \& Marques, Rosa Maria. (2008). Brazil. Lula’s Government: A Critical Appraisal. In The New Latin American Left: utopia reborn (pp. 42-68). London: Pluto Press.

Santana, Marco Aurélio. (2012). Partidos e Trabalhadores na Transição Democrática: A Luta pela Hegemonia na Esquerda Brasileira. Dados - Revista de Ciências Sociais, 55(3), 787826.

Santana, Marco Aurélio, \& Antunes, Ricardo. (2007). O PCB, os trabalhadores e o sindicalismo na história recente do Brasil. In M. Ridenti \& D. A. Reis (Eds.), História do Marxismo no Brasil (v. 6) (pp. 375-410). Campinas: Editora da Unicamp.

Semeraro, Giovanni. (2007). Da libertação à hegemonia: Freire e Gramsci no processo de democratização do Brasil. Revista de Sociologia e Política, 29, 95-104.

Silva, Fernando. (2015, April 16). Interview by Sabrina Fernandes. São Paulo.

Simões, Guilherme. (2015, May 25). Interview by Sabrina Fernandes. Rio de Janeiro.

Singer, André. (2010). A segunda alma do Partido dos Trabalhadores. Novos Estudos, 88, 89111.

Singer, André. (2012). Os Sentidos do Lulismo: reforma gradual e pacto conservador. São Paulo: Companhia das Letras.

Singer, André. (2014). Rebellion in Brazil: Social and Political Complexion of the June Events. 
New Left Review, 85, 18-37.

Sluyter-Beltrão, J. (2010). Rise and Decline of Brazil's New Unionism: The Politics of the Central \{Ú\}nica Dos Trabalhadores. book, Bern: Peter Lang. Retrieved from http://books.google.ca/books?id=kbzXJICgcdMC

Smith, Murray E. G. (2014). Marxist Phoenix: Studies in Historical Materialism and Marxist Socialism. book, Toronto: Canadian Scholars' Press, Incorporated. Retrieved from https://books.google.com.br/books?id=m5KDAwAAQBAJ

Soto, Emiliano. (2007, November 7). Aqui jaz a União Nacional dos Estudantes | PSTU. PSTU. Retrieved from http://www.pstu.org.br/node/7246

Spronk, Susan. (2013). Neoliberal Class Formation(s): The Informal Proletariat and "New" Workers' Organizations in Latin America. In J. R. Webber \& B. Carr (Eds.), The New Latin American Left: cracks in the empire. Lanham: Rowman \& Littlefield Publishers.

Sul 21. (2012, October 8). Balanço dos vereadores eleitos aponta crescimento da esquerda no país «Sul21. Jornal Sul 21. Porto Alegre: jornalsul21. Retrieved from http://www.sul21.com.br/jornal/balanco-dos-vereadores-eleitos-aponta-crescimento-daesquerda-no-pais/

Swyngedouw, Erik. (2009). The antinomies of the postpolitical city: In search of a democratic politics of environmental production. International Journal of Urban and Regional Research, 33(3), 601-620. doi:10.1111/j.1468-2427.2009.00859.x

Swyngedouw, Erik. (2010). Apocalypse Forever? Post-political Populism and the Spectre of Climate Change. Theory, Culture \& Society, 27(2-3), 213-232. 
doi:10.1177/0263276409358728

Tavares, Arielli. (2015, April 24). Interview by Sabrina Fernandes. São Paulo.

Teixeira, Mácia. (2015, March 22). Interview by Sabrina Fernandes. Brasília.

Telésforo, João. (2015, March 17). Interview by Sabrina Fernandes. Brasília.

Thompson, Edward Palmer. (1978). An open letter to Leszek Kolakowski. In The poverty of theory \& other essays (pp. 303-402). New York: Monthly Review Press.

Thompson, Edward Palmer. (1991). The making of the English working class. London: Penguin Books.

Tiburi, Marcia. (2016). Como conversar com um fascista. Rio de Janeiro: Record.

Varela, Alexandre. (2015, July 9). Interview by Sabrina Fernandes. Brasília.

Vázquez, Adolfo Sánchez. (2011). Filosofia da práxis. São Paulo: Expressão Popular.

Vianna, Alexander Martins. (2013). As multidões de junho de 2013 no Brasil: o desafio de explicar e compreender. Revista Espaço Acadêmico, (146), 36-48.

Webber, Jeffery R., \& Carr, Barry. (2013). Introduction: The Latin American Left in Theory and in Practice. In J. R. Webber \& B. Carr (Eds.), The New Latin American Left: cracks in the empire (pp. 1-27). Lanham: Rowman \& Littlefield Publishers.

Wills, Jane. (2006). The Left, its Crisis and Rehabilitation. Antipode, 38(5), 907-915. doi:10.1111/j.1467-8330.2006.00485.x

Wilson, Japhy, \& Swyngedouw, Erik. (2015). Seeds of Dystopia. In The post-political and its 
discontents. Edinburgh: Edinburgh University Press.

Wright, Erik Olin. (2015). Understanding class. London: Verso.

Žižek, Slavoj. (1998). For a leftist appropriation of the European legacy. Journal of Political Ideologies, 3(June), 63-78. doi:10.1080/13569319808420769

Žižek, Slavoj. (1999). The Ticklish Subject. London: Verso.

Žižek, Slavoj. (2002). Welcome to the desert of the real. London: Verso.

Žižek, Slavoj. (2009). First As Tragedy, Then As Farce. London: Verso.

Žižek, Slavoj. (2012). The year of dreaming dangerously. London: Verso.

Žižek, Slavoj. (2014). Event: Philosophy in Transit. London: Penguin Books. 